\title{
Ice Growth and Platelet Crystals in Antarctica
}

by

Jonathan Crook

A thesis

submitted to the Victoria University of Wellington

in fulfilment of the

requirements for the degree of

Doctor of Philosophy

in Mathematics.

Victoria University of Wellington

2010 


\begin{abstract}
First-year land-fast sea ice growth in both the Arctic and the Antarctic is characterised by the formation of an initial ice cover, followed by the direct freezing of seawater at the ice-water interface. Such growth usually results, through geometric selection, in congelation ice. This is, in general, the typical crystal structure observed in first-year ice growth in the Arctic. However, in certain regions of the Antarctic, platelet crystals are observed to contribute significantly to the ice growth, beyond a depth of $1 \mathrm{~m}$.

This thesis will investigate a number of ideas as to why the platelet crystals only appear in the ice after a significant amount of congelation growth has occurred. One of the key premises will be that platelet ice forms when smaller frazil crystals, beneath the ice, rise up and attach to the interface. They are then incorporated into the ice cover and become the platelets seen in ice cores.

The Shields criterion is used to find the strength of turbulence, associated with tidal flow, required to keep a frazil crystal from adhering to the interface. It is shown that the sub-ice flow is sufficient to keep most crystals in motion. However, this turbulence may weaken or dissipate completely as the tide turns. The velocity associated with brine rejection is suggested as an alternative to keep the crystals in suspension during these periods of low shear turbulence. Brine rejection occurs as the sea ice grows, rejecting salt into the seawater below. By comparing this velocity with a model for the frazil rise velocity it is shown that brine rejection has sufficient strength to keep crystals in suspension. This effect weakens as the ice gets thicker, allowing larger frazil crystals to rise to the interface.

The early work in this thesis shows that a flow can keep a single crystal from adhering to the interface. This can be regarded as the competence of
\end{abstract}


a flow to keep a crystal in suspension. However, of equal importance is the capacity of a flow to keep a mass of crystals in suspension. It is shown that, given a sufficiently large mass of crystals beneath the ice, the same flow that can hold a single crystal in suspension will not be able to keep all the crystals in motion. The deposition of crystals is predicted to occur in a gradual manner if there is a steady build-up of crystals beneath the ice. The largest crystals, close to the interface, will settle against the ice as the flow is unable to support the entire mass of crystals

Also considered is whether frazil crystals may be similar to cohesive sediments. If this is the case, a sudden influx of crystals from outside of the system may lead to the formation of a layer of unattached crystals beside the ice-water interface. This can cause a critical collapse of the turbulent field, resulting in the settling of a large quantity of frazil crystals.

Though the emphasis of much of this thesis is on the effect of the flow on the crystals, it is also found that a mass of crystals can have a stabilising effect on the flow. The change in the density profile induced by an increase in the frazil concentration towards the ice-water interface (and hence a decrease in the density of the ice-water mixture) damps the turbulence produced by shear. The mass and size of crystals in suspension play major roles in the strength of stabilisation.

Measurements of turbulence and the suspension of frazil crystals beneath sea ice are difficult to make. This thesis aims to present and analyse a number of models which may explain the platelet puzzle - the delayed appearance of the platelet crystals in ice cores. These are compared with the observations which are available, and conclusions made on the validity of the theories presented. 


\section{Acknowledgments}

First and foremost I must thank Mark $\mathrm{M}^{c}$ Guinness, my supervisor, who has guided and mentored me through this process of producing my thesis. He has always retained a positive attitude to the work, never failing in making time for me whenever I needed it. Similarly, I know that there was always an open door and a friendly ear in the office of my co-supervisor, Matt Visser.

Also of great importance are the significant financial contributions which various groups have made to support me in my work, and in allowing me to present it, both within New Zealand and overseas. Many thanks go to the New Zealand Institute of Mathematics and its Applications (NZIMA) who have funded the final two years of my thesis. I also appreciate the important grants awarded to me by the Johnsonville Rotary Club and the New Zealand Mathematical Society.

I must thank Victoria University here in Wellington, especially the Maths department: not just for the standard support that one often takes for granted, but also for financial support, especially in allowing me to gain experience through travel. I was also fortunate to be invited to spend time at the Mathematics Applications Consortium for Science and Industry (MACSI) at the University of Limerick in Ireland. They also helped me with my travel there and were quick to welcome and involve me in the work (and Guinness - which is part of the work!) there.

Writing a thesis is often a lonely process and so family and friends are invaluable. Special thanks to mum, for giving me a house to live in and 
allowing me to focus solely on the work. And also for proofreading what I'm sure wasn't the lightest reading before bed!

Last, but not least, all those people at Uni who know exactly what you are going through; those that I have shared a room with, both physically (Sione and Nicole, cheers) and virtually (Ros, gidday); and those that I have just been able to share a laugh or a kick-around with when things seemed tough - the whole Physics group.

I could probably write another thesis listing all the people who deserve thanks, so I will stop here, but to those who have helped me along my way, know that you have my deepest and sincerest gratitude. 


\section{Contents}

List of Figures vi vi v v v

List of Tables $\quad x$

$\begin{array}{lll}1 & \text { Introduction } & 1\end{array}$

2 Background 4

2.1 Initial Formation $\ldots \ldots \ldots . \ldots . \ldots 5$

2.2 Sea Ice Growth . . . . . . . . . . . . . . . . . . . . 9

2.2 .1 Congelation Growth . . . . . . . . . . . . . . . . 10

2.2 .2 Analytic Modelling . . . . . . . . . . . . . . . 11

2.2 .3 Numerical Modelling . . . . . . . . . . . . . . . . . . . . . . . . . . . . . . 14

$2.2 .4 \quad$ Mushy Zones . . . . . . . . . . . . . . . 16

2.2 .5 Frazil and Platelet Ice . . . . . . . . . . . . . . 19

2.3 Salinity . . . . . . . . . . . . . . . . 22

2.4 Turbulence . . . . . . . . . . . . . . . . . . . . 26

2.4 .1 Turbulence and frazil suspension . . . . . . . . . 27

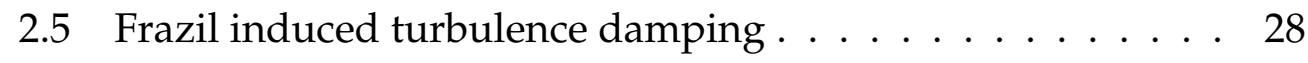

2.6 Summary . . . . . . . . . . . . . . . . . . . . . 29

3 Shear flow, frazil and platelet ice 31

3.1 Frazil ice or platelet ice? . . . . . . . . . . . . . . . . . . 31

3.2 Mechanisms for growth . . . . . . . . . . . . . 33

3.3 Quantity of growth . . . . . . . . . . . . . 36 
3.4 Platelet inclusion in sea ice. . . . . . . . . . . . . . . . . . . . 39

3.5 The Shields Criterion . . . . . . . . . . . . . . . . . . . . . 41

3.6 Shear results . . . . . . . . . . . . . . . . . . . . 46

3.6 .1 Tidal and friction velocity $\ldots \ldots \ldots$. . . . . . . 46

3.6 .2 Frazil in suspense? . . . . . . . . . . . . . . . . . . 49

3.7 Summary . . . . . . . . . . . . . . . . 50

$4 \quad$ Stirring due to brine rejection 52

4.1 Brine Rejection . . . . . . . . . . . . . . . . . . . . . 53

4.2 Stokes' flow . . . . . . . . . . . . . . . . . . 55

4.2 .1 Crystal buoyancy . . . . . . . . . . . . . . . 56

4.2 .2 Rise velocities . . . . . . . . . . . . . . . . . . . . . . . . . . . 59

4.3 Brine rejection velocity $\ldots \ldots \ldots \ldots$. . . . . . . . 60

4.3 .1 Density of seawater. . . . . . . . . . . . . . . 62

4.4 Ice growth data $\ldots \ldots \ldots \ldots \ldots$. . . . . . . . . . . . 64

4.5 Brine plumes and frazil . . . . . . . . . . . . . . . . . 66

$4.5 .1 \quad$ Air temperature and seawater salinity . . . . . . . . 70

$4.5 .2 \quad$ Varying mixed layer depth $\ldots \ldots \ldots \ldots$. . . . . . 72

4.6 Brine rejection in a turbulent environment . . . . . . . . . . 74

$4.7 \quad$ Torque on a frazil crystal $\ldots \ldots \ldots \ldots \ldots$

4.8 Summary . . . . . . . . . . . . . . . . . . . 81

5 A two-phase sea ice model $\quad 83$

5.1 Stefan solution. . . . . . . . . . . . . . . . . . . . . 84

5.2 Model regions . . . . . . . . . . . . . . . . . . . . 87

5.2 .1 In the ice . . . . . . . . . . . . . . . . . . . . . 87

5.2 .2 The intermediate zone . . . . . . . . . . . . . . . 91

5.2 .3 Below the ice . . . . . . . . . . . . . . . . . . 92

5.3 The two-phase model . . . . . . . . . . . . . . . . . . . 94

$5.3 .1 \quad$ Ice growth in the presence of shear flow . . . . . . . . 95

5.3 .2 Results . . . . . . . . . . . . . . . . . 96

5.3 .3 Role of salt . . . . . . . . . . . . . . . . . . . . . . . . . 98 
$5.3 .4 \quad$ Model Sensitivity . . . . . . . . . . . . . . . . . . . . . 99

5.4 The effects of brine rejection on ice growth $\ldots . . \ldots . .107$

5.5 Heat flux . . . . . . . . . . . . . . . . . . . . . . . . . 109

5.5 .1 Frazil production . . . . . . . . . . . . . . . . 113

5.6 Summary . . . . . . . . . . . . . . . . . . . . . . . 115

\begin{tabular}{|lll}
6 & Shear stabilisation of platelet ice & 117
\end{tabular}

6.1 Bedload or suspended load . . . . . . . . . . . . . . 117

6.1 .1 Suspended load criteria . . . . . . . . . . . . . . . 118

6.1 .2 Suspension criterion . . . . . . . . . . . . . . . . . 124

6.2 The effect of frazil on the flow . . . . . . . . . . . . . 130

6.2 .1 The flux Richardson number . . . . . . . . . . . . . 132

6.2 .2 Reduction in $\mathrm{u}_{*} \ldots \ldots \ldots \ldots$

6.3 Collapse of turbulence . . . . . . . . . . . . . . . . . . . 142

6.3 .1 Cohesive or non-cohesive? . . . . . . . . . . . . 143

6.3 .2 Criterion for collapse . . . . . . . . . . . . . . . . 144

6.4 Critical flux Richardson number . . . . . . . . . . . . . . . . 149

6.5 Summary . . . . . . . . . . . . . . . . . . . . . . . . 154

$\begin{array}{lll}7 \text { Conclusions } & 157\end{array}$

7.1 Shear flow . . . . . . . . . . . . . . . . . . . . 157

7.2 Rise velocity . . . . . . . . . . . . . . . . . . . . . 158

7.3 Brine rejection . . . . . . . . . . . . . . . . . . . . . . . . . . 159

7.4 Ice growth $\ldots \ldots \ldots \ldots \ldots$

7.5 Shear stabilisation . . . . . . . . . . . . . . . . . . . . 162

$\begin{array}{ll}\text { Glossary } & 164\end{array}$

\begin{tabular}{|l|l|}
\hline A Conservation equations & 168
\end{tabular}

A.1 Conservation of salt . . . . . . . . . . . . . . . . . . 168

A.2 Conservation of energy . . . . . . . . . . . . . . . 170 
\begin{tabular}{lll}
\hline B & Matlab M-files & 171
\end{tabular}

B.1 M-file ${ }^{\prime}$ RungeKuttarealTa' . . . . . . . . . . . . . . . . 171

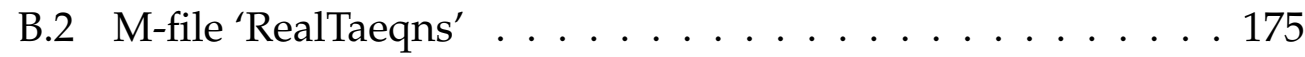

\begin{tabular}{|ll}
\hline C Stress Due to a Suspended Load & 180
\end{tabular}

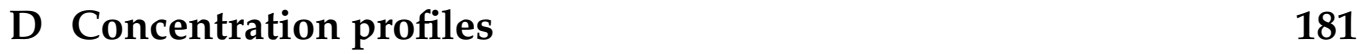

D.1 Linear eddy viscosity . . . . . . . . . . . . . . . . . . . . . 181

D.2 Parabolic eddy viscosity . . . . . . . . . . . . . . . . 183

D.3 Eddy viscosity varying with $\mathrm{Ri}_{f} \ldots \ldots$. . . . . . . . . . 183

\begin{tabular}{ll}
\hline Bibliography & 186
\end{tabular} 


\section{List of Figures}

1.1 The Antarctic continent. . . . . . . . . . . . . . . . . . 2

2.1 Map of Antarctica detailing sea ice extent . . . . . . . . . 5

2.2 Freezing point temperature and temperature of maximum density of water . . . . . . . . . . . . . . . . . 7

2.3 Pancake ice. . . . . . . . . . . . . . . . . . . . . . . 9

2.4 Preferential crystal growth $\ldots \ldots \ldots \ldots \ldots$

2.5 Vertical thin section showing congelation ice . . . . . . . . 11

2.6 Supercooling at a flat interface during sea ice growth . . . . 17

2.7 Vertical thin section showing platelet ice . . . . . . . . . . 21

2.8 Salinity profile of Antarctic first-year sea ice in $\mathrm{M}^{c}$ Murdo

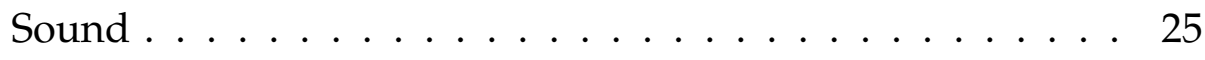

2.9 Salinity profile in Alaskan first-year sea ice . . . . . . . . 25

3.1 The four mechanisms of multi-year frazil growth. . . . . . . 34

3.2 The movement of platelet and frazil crystals from underneath an ice shelf to below sea ice . . . . . . . . . . . . . . 35

3.3 Locations of referenced sea ice surveys in Antarctica. . . . . 38

3.4 Ice core image showing the late appearance of platelet ice. . . 40

3.5 Threshold curve for the Shields parameter. . . . . . . . . . 43

3.6 Critical friction velocity predicted by the Shields criterion, varying the critical Shields parameter $\ldots \ldots \ldots$. . . . 45 
3.7 Critical friction velocity for the Shields criterion, varying the aspect ratio ................. 46

3.8 Near-surface tidal velocities in $\mathrm{M}^{c}$ Murdo Sound . . . . . . . 48

3.9 Comparing tidal-induced friction velocities with the critical frazil friction velocity . . . . . . . . . . . . 50

4.1 Turbulence induced by brine rejection . . . . . . . . . . . 53

4.2 Vertical sea ice thin section showing brine channel and tubes 55

4.3 Frazil rising in still water . . . . . . . . . . . . . 57

4.4 Trajectories of a descending disc . . . . . . . . . . . 58

4.5 Stokes' law rise velocity for a crystal rising with its face perpendicular to its motion . . . . . . . . . . . . . 60

4.6 Variation in the density of seawater with salinity . . . . . . . 62

4.7 Ice growth data in days and degree-days $\ldots . . . . . . .665$

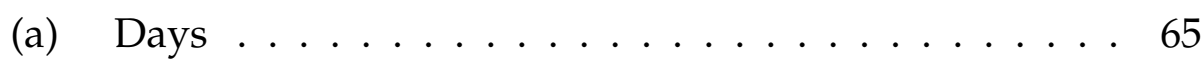

(b) Degree-days . . . . . . . . . . . . . . 65

4.8 Ice growth rates . . . . . . . . . . . . . . . . . . . 67

4.9 Average brine plume velocity . . . . . . . . . . . . . . 68

4.10 Frazil sizes kept in suspension due to brine rejection . . . . . 70

4.11 The effect of altering the air temperature on frazil sizes kept in suspension ..................... 71

4.12 The effect of altering the mixed layer salinity on frazil sizes kept in suspension . . . . . . . . . . . . . . . 72

4.13 The effect of altering the mixed layer depth on frazil sizes kept in suspension . . . . . . . . . . . . 73

4.14 Frazil rise velocity in a turbulent environment . . . . . . . . 75

4.15 A sudden drop in the radius of frazil crystals held in sus-

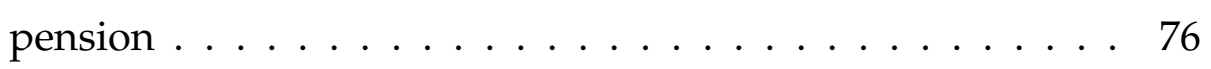

4.16 Forces on a settling frazil crystal . . . . . . . . . . . 78

4.17 Ratio of torques on a settling frazil crystal . . . . . . . . . . 80 
5.1 Ice growth model compared with various data-based empirical equations. . . . . . . . . . . . 86

5.2 Description of the two-phase sea ice growth model . . . . . . 88

5.3 Antarctic air temperature field data . . . . . . . . . . . . 100

5.4 Ice growth using Antarctic temperature data . . . . . . . . . 101

5.5 Ice growth for different air temperatures . . . . . . . . . . . . 102

5.6 Effect on the ice growth of changing the mixed layer temperature . . . . . . . . . . . . . . . . . . 104

5.7 Effect on the ice growth of supercooling the mixed layer . . 105

5.8 Effect on the ice growth of varying the friction velocity . . . 106

5.9 Ice growth in a combined shear and brine rejection friction velocity model . . . . . . . . . . . . . . . . . 109

5.10 Atmospheric and oceanic heat fluxes during ice growth . . . 110

5.11 Comparing the oceanic heat flux for the model using real or average air temperature values . . . . . . . . . . 113

6.1 Modified Shields diagram . . . . . . . . . . . . . . . . . 121

6.2 Critical Shields parameter value for suspension. . . . . . . . 123

6.3 Average mass of frazil crystals kept in suspension per unit volume . . . . . . . . . . . . . . . . . . . . . 128

6.4 Number concentration of frazil crystals kept in suspension . 129

6.5 Effect of the eddy viscosity on the flux Richardson number . 137

6.6 Contours of the flux Richardson number . . . . . . . . . . . . 138

6.7 Decrease in the friction velocity, depending on the shear strength . . . . . . . . . . . . . . . . 140

(a) Reduction in $\mathrm{u}_{*} \ldots$. . . . . . . . . . . . . . . 140

(b) Ratio of reduced $\mathrm{u}_{*}$ to sediment-free $\mathrm{u}_{*} \ldots \ldots$. . . . 140

6.8 Variation of the decrease in the friction velocity with depth caused by a suspended load . . . . . . . . . . . . . . . . . . 141

(a) Reduction in $\mathrm{u}_{*} \ldots \ldots$. . . . . . . . . . . . . 141

(b) Ratio of reduced $\mathrm{u}_{*}$ to sediment-free $\mathrm{u}_{*} \ldots \ldots \ldots 141$

6.9 Critical concentration profiles . . . . . . . . . . . . . 147 
6.10 Depth at which certain values of the flux Richardson number occur . . . . . . . . . . . . . . . . . . . . 152

6.11 Depth at which certain values of the flux Richardson number occur, assuming there is a maximum mass allowed in suspension . . . . . . . . . . . . . . 153

A.1 Salt flux diagram . . . . . . . . . . . . . . . . . 169 


\section{List of Tables}

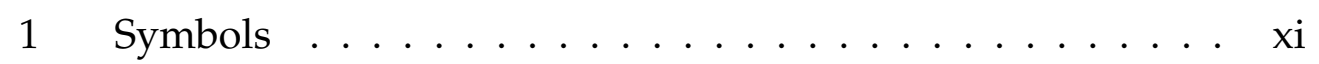

2 Constants . . . . . . . . . . . . . . . . . . xiv

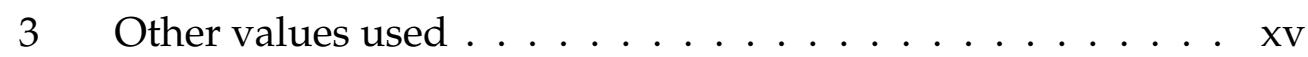

3.1 Quantity and position of platelets in sea ice . . . . . . . . 39

6.1 Critical depth-averaged sediment concentration . . . . . . 148 
Table 1: Symbols

\begin{tabular}{|c|c|c|}
\hline symbol & name & unit \\
\hline$A_{b p}$ & (cross-sectional) area of the brine plume & $\mathrm{m}^{2}$ \\
\hline$A_{z}$ & vertical component of mean turbulent flow acceleration & $\mathrm{m} . \mathrm{s}^{-2}$ \\
\hline$b$ & Rouse number & - \\
\hline$B=\left\langle w^{\prime} b^{\prime}\right\rangle$ & buoyancy flux & $\mathrm{m}^{2} \cdot \mathrm{s}^{-1}$ \\
\hline$c$ & frazil concentration & kg. $\mathrm{m}^{-3}$ \\
\hline$C_{a}$ & reference concentration & kg. $\mathrm{m}^{-3}$ \\
\hline$d$ & disc diameter & $\mathrm{m}$ \\
\hline$d_{e}$ & effective diameter & $\mathrm{m}$ \\
\hline$\dot{d}$ & ice growth rate due to ice expansion & $\mathrm{m} \cdot \mathrm{s}^{-1}$ \\
\hline$F_{b}$ & force due to buoyancy & $\mathrm{N}$ \\
\hline$F_{b p}$ & force due to a brine plume & $\mathrm{N}$ \\
\hline$F_{\text {net }}$ & net force due to a suspended load & $\mathrm{N}$ \\
\hline$h$ & position of the ice-water interface & $\mathrm{m}$ \\
\hline$h_{0}$ & position of the ice-water interface at time $=0$ & $\mathrm{~m}$ \\
\hline$h_{\max }$ & location of maximum viscosity & $\mathrm{m}$ \\
\hline$h_{s}$ & snow layer thickness & $\mathrm{m}$ \\
\hline$\dot{h}$ & velocity of ice-water interface & $\mathrm{m} . \mathrm{s}^{-1}$ \\
\hline$H_{i}$ & specific enthalpy of ice & $\mathrm{J}$ \\
\hline$H_{w}$ & specific enthalpy of water & $\mathrm{J}$ \\
\hline$I$ & dimensionless moment of inertia & - \\
\hline$I_{d i s c}$ & moment of inertia of a disc & $\mathrm{kg} \cdot \mathrm{m}^{2}$ \\
\hline$m$ & mass of a frazil crystal & $\mathrm{kg}$ \\
\hline$m_{f}$ & mass of frazil produced per unit area & $\mathrm{kg} \cdot \mathrm{m}^{-2}$ \\
\hline$m_{i}$ & dry mass of ice & $\mathrm{kg}$ \\
\hline$\dot{m}$ & mass flow rate & $\mathrm{kg} \cdot \mathrm{s}^{-1}$ \\
\hline$q$ & internal heat source & $\mathrm{W} \cdot \mathrm{m}^{-2}$ \\
\hline$Q$ & volume flow rate & $\mathrm{m}^{3} \cdot \mathrm{s}^{-1}$ \\
\hline$Q_{A}$ & heat flux (ice-atmosphere interface) & W.m $\mathrm{m}^{-2}$ \\
\hline
\end{tabular}


Symbols

\begin{tabular}{|c|c|c|}
\hline symbol & name & unit \\
\hline$Q_{S}$ & turbulent flux of salt (ice-water interface) & $\mathrm{kg} \cdot \mathrm{m}^{-2} \cdot \mathrm{s}^{-1}$ \\
\hline$Q_{T}$ & turbulent flux of heat (ice-water interface) & W.m $\mathrm{m}^{-2}$ \\
\hline$r_{d}$ & frazil disc radius & $\mathrm{m}$ \\
\hline$r_{e}$ & effective radius (equivalent sphere) & $\mathrm{m}$ \\
\hline$R$ & effective radius & $\mathrm{m}$ \\
\hline$R e$ & Reynolds number & - \\
\hline$R e_{d}$ & disc Reynolds number & - \\
\hline$R e_{g}$ & grain Reynolds number & - \\
\hline$R i_{f}$ & flux Richardson number & - \\
\hline$R i_{f, c r}$ & critical flux Richardson number & - \\
\hline$S_{w}$ & interfacial salinity & psu \\
\hline$t$ & time & $\mathrm{s}$ \\
\hline$t_{d}$ & thickness of a frazil crystal & $\mathrm{m}$ \\
\hline$T$ & temperature & ${ }^{\circ} \mathrm{C}$ \\
\hline$T_{a}$ & air temperature & ${ }^{\circ} \mathrm{C}$ \\
\hline$T_{f}$ & freezing point temperature & ${ }^{\circ} \mathrm{C}$ \\
\hline$u$ & rise velocity of a crystal & $\mathrm{m} . \mathrm{s}^{-1}$ \\
\hline$u_{S t}$ & Stokes' (rise) velocity & $\mathrm{m} \cdot \mathrm{s}^{-1}$ \\
\hline$u_{\text {total }}$ & combined turbulent velocity (brine and shear) & $\mathrm{m} \cdot \mathrm{s}^{-1}$ \\
\hline$u_{*}$ & friction velocity & $\mathrm{m} . \mathrm{s}^{-1}$ \\
\hline$u_{*, c r}$ & critical friction velocity & $\mathrm{m} . \mathrm{s}^{-1}$ \\
\hline$U$ & shear flow strength & $\mathrm{m} \cdot \mathrm{s}^{-1}$ \\
\hline$v_{\max }^{\prime}$ & maximum vertical turbulence velocity fluctuations & $\mathrm{m} \cdot \mathrm{s}^{-1}$ \\
\hline$v_{u p}^{\prime}$ & upward fluctuations of velocity components & $\mathrm{m} \cdot \mathrm{s}^{-1}$ \\
\hline$V$ & volume of a disc & $\mathrm{m}^{3}$ \\
\hline$V_{i}$ & total volume of frazil ice in a suspension & $\mathrm{m}^{3}$ \\
\hline$V_{s}$ & volume of a sphere & $\mathrm{m}^{3}$ \\
\hline$V_{w}$ & volume of water (displaced by frazil) & $\mathrm{m}^{3}$ \\
\hline
\end{tabular}


Symbols

\begin{tabular}{|c|c|c|}
\hline symbol & name & unit \\
\hline$w_{s}$ & rise (settling) velocity & $\mathrm{m} \cdot \mathrm{s}^{-1}$ \\
\hline$W_{s}$ & effective rise (settling) velocity & $\mathrm{m} \cdot \mathrm{s}^{-1}$ \\
\hline$w_{*}$ & brine plume (convective scale) velocity & $\mathrm{m} \cdot \mathrm{s}^{-1}$ \\
\hline$z$ & vertical direction (depth) & $\mathrm{m}$ \\
\hline$z_{a}$ & reference depth & $\mathrm{m}$ \\
\hline$z_{m l}$ & mixed layer depth & $\mathrm{m}$ \\
\hline$z_{0}$ & interfacial roughness length & $\mathrm{m}$ \\
\hline$\epsilon$ & aspect ratio & - \\
\hline$\theta$ & degree-days of freezing & degree-day \\
\hline$\theta_{s}$ & the Shields parameter & - \\
\hline$\theta_{s c}$ & critical Shields parameter for motion & - \\
\hline$\theta_{s s}$ & critical Shields parameter for suspension & - \\
\hline$\kappa^{\prime}$ & modified von Kármán constant & - \\
\hline$\Lambda$ & Leeder's suspended load criterion & - \\
\hline$\nu_{T}$ & eddy viscosity profile & $\mathrm{m}^{2} \cdot \mathrm{s}^{-1}$ \\
\hline$\lambda$ & length scale of dominant eddies & $\mathrm{m}$ \\
\hline$\rho_{m}$ & density of the ice-water mixture & $\mathrm{kg} \cdot \mathrm{m}^{-3}$ \\
\hline$\rho_{\text {sed }}$ & sediment density & $\mathrm{kg} \cdot \mathrm{m}^{-3}$ \\
\hline$\rho_{w}$ & seawater salinity & $\mathrm{kg} \cdot \mathrm{m}^{-3}$ \\
\hline$\tau$ & wall shear stress & $\mathrm{Pa}$ \\
\hline$\tau_{b}$ & torque due to buoyancy & N.m \\
\hline$\tau_{b p}$ & torque due to brine plumes & N.m \\
\hline$\tau_{\text {crys }}$ & stress due to immersed crystals & $\mathrm{Pa}$ \\
\hline$\tau_{z z}$ & vertical stress component & $\mathrm{Pa}$ \\
\hline
\end{tabular}


Table 2: Constants

\begin{tabular}{|c|c|c|c|}
\hline symbol & definition & value & unit \\
\hline$a$ & & $54.11 \times 10^{-3}$ & ${ }^{\circ} \mathrm{C}$ \\
\hline$c_{i}$ & specific heat capacity of ice & $\sim 2050$ & $\mathrm{~J} . \mathrm{kg}^{-1} \cdot{ }^{\circ} \mathrm{C}^{-1}$ \\
\hline$c_{p}$ & specific heat capacity of water & $\sim 3974$ & $\mathrm{~J} \cdot \mathrm{kg}^{-1} \cdot{ }^{\circ} \mathrm{C}^{-1}$ \\
\hline$c_{t}$ & average heat transfer coeffecient & 24 & $\mathrm{~J} \cdot \mathrm{m}^{-2} \cdot \mathrm{s}^{-1} \cdot{ }^{\circ} \mathrm{C}^{-1}$ \\
\hline$C_{S}$ & turbulent salt transfer coefficient & $C_{T}\left(\frac{P r}{S c}\right)^{\frac{2}{3}}$ & - \\
\hline$C_{T}$ & turbulent Stanton number & 0.0056 & - \\
\hline$f$ & seawater to sea ice salinity ratio & 0.14 & - \\
\hline$g$ & gravity & 9.81 & $\mathrm{~m} \cdot \mathrm{s}^{-2}$ \\
\hline$H_{0}$ & length scale & 0.12 & $\mathrm{~m}$ \\
\hline$k_{i}$ & thermal conductivity of sea ice & 2.1 & $\mathrm{~W} \cdot \mathrm{m}^{-1} \cdot{ }^{\circ} \mathrm{C}^{-1}$ \\
\hline$k_{s}$ & thermal conductivity of snow & $\sim 0.25$ & $\mathrm{~W} \cdot \mathrm{m}^{-1} \cdot{ }^{\circ} \mathrm{C}^{-1}$ \\
\hline$K$ & drag co-effecient & $1.5-5.4 \times 10^{-3}$ & - \\
\hline$L$ & latent heat of freezing of sea ice & $\sim 289,000$ & $\mathrm{~J} . \mathrm{kg}^{-1}$ \\
\hline$L_{i}$ & latent heat of freezing of pure ice & 334,000 & $\mathrm{~J} \mathrm{~kg}^{-1}$ \\
\hline $\operatorname{Pr}$ & Prandtl number & 13.8 & - \\
\hline$S c$ & Schmidt number & 2438 & - \\
\hline$S_{i}$ & salinity of the ice & $f S_{w}$ & psu \\
\hline$S_{m l}$ & salinity of the mixed layer & 35 & psu \\
\hline$S_{0}$ & salinity scale & 35 & psu \\
\hline$t_{0}$ & time scale & 0.57 & days \\
\hline$T_{m l}$ & mixed layer temperature & -1.89 & ${ }^{\circ} \mathrm{C}$ \\
\hline$T_{0}$ & temperature scale & 35 & ${ }^{\circ} \mathrm{C}$ \\
\hline$\alpha_{S}$ & mass diffusivity of salt & $1.3 \times 10^{-7}$ & $\mathrm{~m}^{2} \cdot \mathrm{s}^{-1}$ \\
\hline$\alpha_{T}$ & thermal diffusivity & $7.4 \times 10^{-10}$ & $\mathrm{~m}^{2} \cdot \mathrm{s}^{-1}$ \\
\hline$\kappa$ & von Kármán constant & 0.4 & - \\
\hline$\mu$ & dynamic viscosity of seawater & $1.88 \times 10^{-3}$ & $\mathrm{~kg} \cdot \mathrm{m}^{-1} \cdot \mathrm{s}^{-1}$ \\
\hline$\nu$ & kinematic viscosity of seawater & $1.83 \times 10^{-6}$ & $\mathrm{~m}^{2} \cdot \mathrm{s}^{-1}$ \\
\hline$\rho_{i}$ & density of sea ice & 910 & $\mathrm{~kg} \cdot \mathrm{m}^{-3}$ \\
\hline
\end{tabular}


Constants

\begin{tabular}{llll}
\hline symbol & definition & value & unit \\
\hline$\rho_{m l}$ & density of the mixed layer & 1030 & kg.m ${ }^{-3}$ \\
\hline
\end{tabular}

Table 3: Other values used

\begin{tabular}{|c|c|c|}
\hline symbol & definition & value \\
\hline$A$ & $a \frac{S_{0}}{T_{0}}$ & 0.054 \\
\hline$A_{1}$ & $\frac{S_{0}}{\rho_{0}} \frac{d \rho_{w}}{d S}$ & 0.028 \\
\hline$c_{1}$ & - & 1 \\
\hline$c_{2}$ & - & 1.12 \\
\hline$T_{s}$ & $\frac{u_{*}^{2}-u_{*, c r}^{2}}{u_{*, c r}^{2}}$ & - \\
\hline$\alpha$ & - & 4.7 \\
\hline$\beta$ & $\frac{(1-f) c_{p} C_{T} T_{0} \rho_{0}}{C_{S} L \rho_{m l}}$ & 12.5 \\
\hline$\beta_{1}$ & - & 1 \\
\hline$\beta_{2}$ & $\kappa z_{m l} g \frac{\rho_{m l} l}{\rho_{w}^{2}} C_{S} \frac{d \rho_{w}}{d S}$ & - \\
\hline$\gamma_{1}$ & $\frac{1.7 k_{i}\left|T_{a}\right|}{u_{*} C_{S} \rho_{m l} \mathcal{L}}$ & - \\
\hline$\zeta$ & $\frac{\alpha \kappa g w_{s}\left(\rho_{i}-\rho_{w}\right) z_{a} C_{a}}{\rho_{i} \rho_{w} u_{*}^{3}}$ & - \\
\hline $\bar{\zeta}$ & $\frac{\alpha \kappa g w_{s}\left(\rho_{i}-\rho_{w}\right)}{\rho_{i} \rho_{w} u_{*}^{3}}$ & - \\
\hline$\zeta_{1}$ & $\frac{\kappa g w_{s}\left(\rho_{i}-\rho_{w}\right) z_{a} C_{a}\left(1+\alpha R i_{f, c r}\right)}{\rho_{i} \rho_{w} u_{*}^{3} R i_{f, c r}}$ & - \\
\hline$\eta$ & $\sqrt{\left(\frac{3}{2}\right)^{\overline{3}} \frac{\left(\rho_{w}-\rho_{i}\right) g}{\rho_{w}}}$ & 1.14 \\
\hline$\xi_{1}$ & - & 0.00156 \\
\hline$\xi_{2}$ & - & 0.0024 \\
\hline$\xi_{3}$ & - & 26.3 \\
\hline $\mathcal{L}$ & $L-\frac{(1-f) C_{T} \rho_{w} c_{p} T_{m l}}{C_{S} \rho_{m l}}$ & - \\
\hline
\end{tabular}




\section{Chapter 1}

\section{Introduction}

In 1773, Captain James Cook became the first man to cross the Antarctic Circle and circumnavigate the southern continent. Though he did not see land, observations of rocks in the icebergs led him to surmise that an undiscovered land must be nearby. He did not believe it to be worth investigating, however, and notably said "I make bold to declare that the world will derive no benefit from it" (Owen, 2007).

In spite of Cook's prediction, explorers and researchers have been drawn by the allure of the southern continent. The first sighting of the Antarctic continent occurred in 1820 and was soon followed by the first landing in 1821. The first completed trek to the South Pole was achieved in 1911 by Norwegian Roald Amundsen. Antarctica's usefulness to research, with its pristine and virtually untouched environment, soon became apparent. The International Geophysics Year in 1957-1958 paved the way for the non-nationalisation of Antarctica. More recently, the International Polar Year (2007-2009) has brought researchers together from around the world, sparking new ideas and initiatives.

The aim of this thesis is to contribute to the continuing research of the Antarctic continent. Of particular interest will be the growth of land-fast sea ice and the presence and interaction of the ice crystals which exist underneath the ice. Chapter 2 will briefly describe some of the processes 


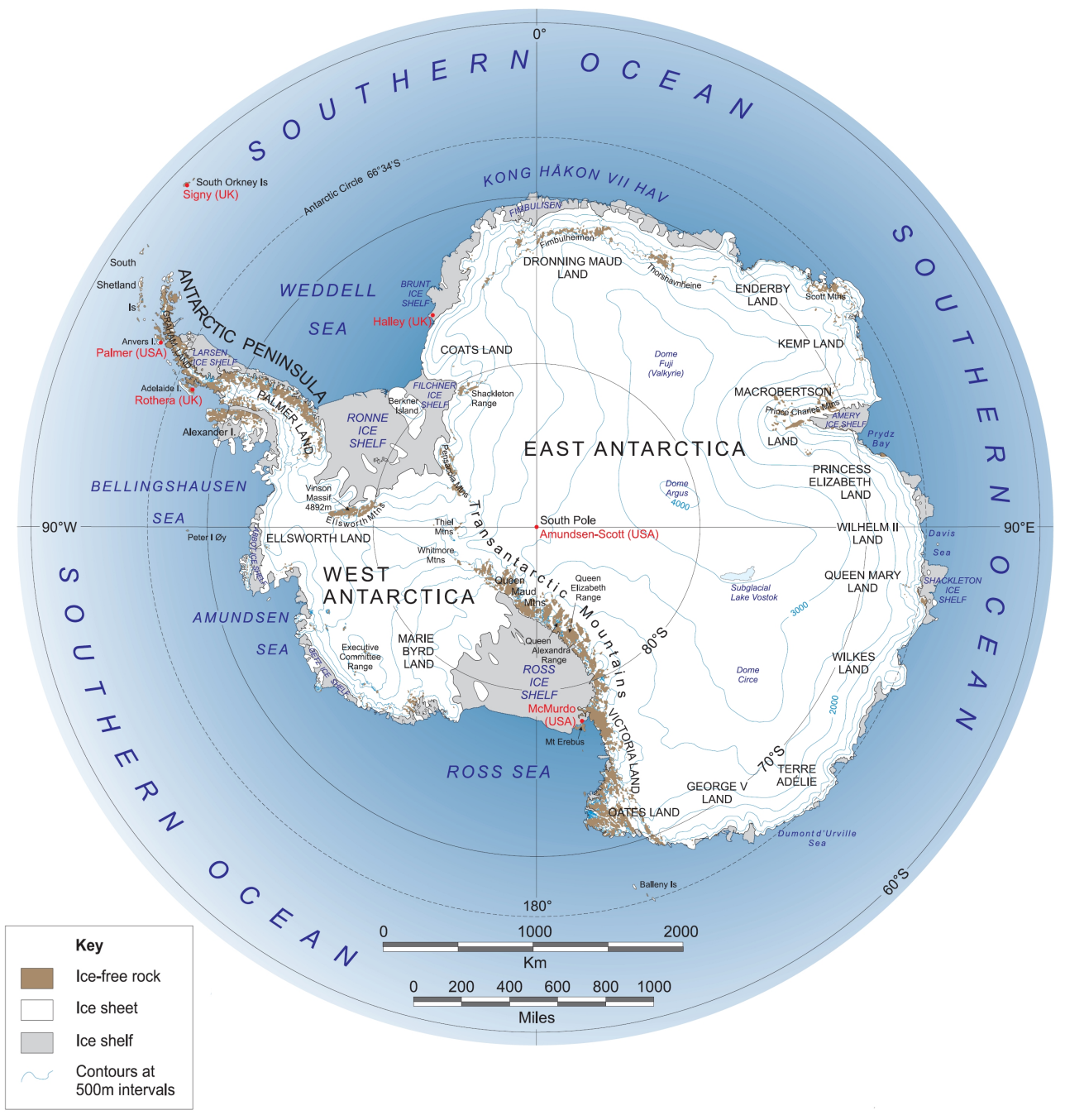

Figure 1.1: The Antarctic continent and its year-round ice presence. Some of the scientific bases are shown. A large number can be found on the Antarctic peninsula due to its more "tropical" climate. The peninsula points towards South America. The American $\mathrm{M}^{c}$ Murdo Base is situated beside the Ross Ice Shelf. New Zealand's Scott Base is nearby, on Ross Island. New Zealand is the nearest major land mass from this location. Image from the U.S. Geological Survey, Department of the Interior/USGS. 
involved in Antarctic ice formation and growth and also present a short investigation highlighting the relevant work which has already been done in this field.

Chapter 3 will introduce the platelet puzzle in Antarctica. The key question is why, though platelet crystals are known to be a significant source of ice growth in certain Antarctic regions, do they only appear in ice cores after a significant amount of growth has occurred? It will be asked whether a sub-ice shear flow is strong enough to keep frazil ice crystals (which may lead to the platelet growth) in motion, preventing them from attaching to the interface.

Another possible solution to the platelet puzzle will be suggested in Chapter 4 . As it freezes, ice rejects salt in plumes of highly saline water. These plumes create turbulence which weakens as the ice growth slows. It will be asked whether these weakening plumes may prevent the frazil from rising to the ice-water interface. A brief discussion will also be had on whether a crystal which reaches the interface will turn to sit flat against the underside of the ice.

In Chapter 5 an ice growth model is developed and solved numerically, with results compared to field results and other models. Chapter 6 will return to the platelet puzzle to investigate the effect a turbulent flow may have on a mass of frazil, as opposed to a single crystal. It will also look at the simultaneous effect that the frazil concentration may have on the flow.

Finally, Chapter 7 will conclude the work in this thesis, outlining the key results of the research and making some recommendations for future investigations. 


\section{Chapter 2}

\section{Background}

Antarctica is the fifth largest continent in the world with an area of nearly 14 million $\mathrm{km}^{2}$, and just $2 \%$ lacks an ice cover. During the summer there is a further 2.5 million $\mathrm{km}^{2}$ of land-fast sea ice attached to the continent, most of which is found in the Weddell Sea and the Ross Sea regions (whose locations can be seen in Figure 1.1p. During winter the amount of sea ice grows to 19 million $\mathrm{km}^{2}$, more than doubling the size of Antarctica (King. 1969) (Figure 2.1).

First-year sea ice, which grows and melts around Antarctica each year, has a key role in the global climate and ocean systems. Its high albedo means it reflects a large portion of the incoming solar radiation. Sea ice also insulates the water below by limiting the heat exchange between the atmosphere and the ocean. Both of these help regulate the ocean temperature (Comiso, 2003).

Sea ice provides a habitat for a variety of wildlife, including the Emperor and Adélie penguins, seals and birds (Ainley et al., 2003). Underneath the ice, phytoplankton and algae, which are at the bottom of the food chain, can thrive. A safe location is provided by the sea ice, aided by the stabilising effect of the platelet layer (explained further in section 2.2.1) on the water. They provide sustenance for the krill, who in turn are a major ingredient in the diet of the local whales, seals, penguins and fish 


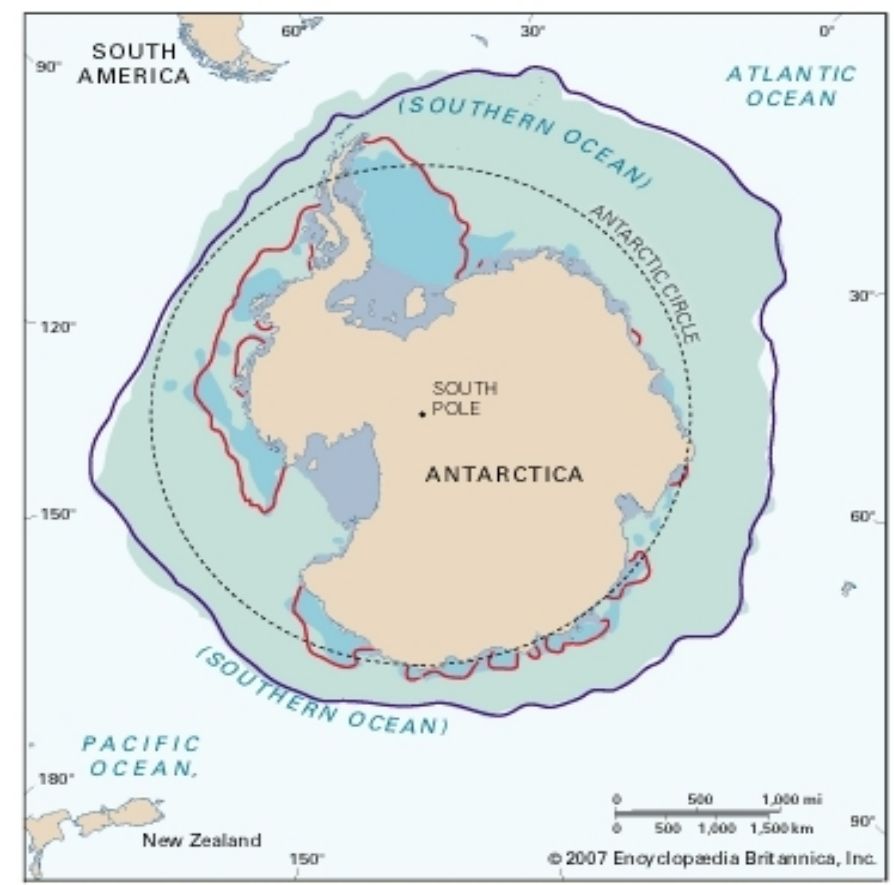

Figure 2.1: Antarctic maximum (September, shaded in light blue) and minimum (February, shaded in dark blue) sea ice extent. Also shaded are the ice shelves in the Weddell and Ross Sea regions. The red and blue lines are the average February and September sea ice extents, respectively, from 1979-2006. Encyclopædia Britannica Online 2008.

(Schnack-Schiel, 2003; Arrigo, 2003). Of no less importance is the release of brine (seawater with a high concentration of salt) during the annual growth of first-year sea ice, as it plays a major role in driving global currents (Shcherbina et al. 2003).

\subsection{Initial Formation}

Ice, when formed from a fresh water source, is relatively free from impurities. Sea ice, on the other hand, forms from water containing a significant concentration of salt. Even though much of this salt is removed from the ice through the loss of briny water, a certain amount of brine and solid salt 
crystals remain. These can have important effects on the properties of sea ice.

In fresh water, the temperature at which maximum density occurs is greater than the temperature at which the water freezes (its freezing point temperature). This means that, as the water is cooled from above (as may occur in a lake during winter), the warmer water sinks to the bottom while the cooled water remains at the surface, creating a stable stratification of the lake water and allowing the top layer to freeze. However, in water which contains salt with a concentration greater than around $24.7 \mathrm{psu}$ (practical salinity units) ${ }^{1}$, the temperature of maximum density drops below the freezing point temperature (as shown in Figure 2.2). The average salinity in Antarctic waters is generally between 34 and $35 \mathrm{psu}$ (Toggweiler and Samuels, 1995; Leonard et al. 2006), and therefore over the $24.7 \mathrm{psu}$ threshold. Thus, the water which is cooled at the surface becomes denser than the water below, leading to instability which can cause mixing in the water column.

Due to the overturning in the upper regions of the ocean, a vertical region of water underneath the sea ice, commonly referred to as a mixed layer, is formed. A mixed layer is created during the initial growth of sea ice and is characterised by having a nearly constant salinity and temperature throughout. Leonard et al. (2006) observed a mixed layer region with a depth of between $20 \mathrm{~m}$ and $50 \mathrm{~m}$ early in the growth season, increasing to be over 50m after 2 months of ice growth. The growth in the mixed layer can potentially slow the rate of ice growth due to the extra quantity of water which must be cooled to the mixed layer temperature.

The growth of the mixed layer is kept in check by a halocline- a strong, vertical salinity gradient which is present in the Southern Ocean (as well

\footnotetext{
${ }^{1} \mathrm{Psu}$, or practical salinity units, are based on a conductivity ratio and have been widely used since 1978. Before this, ppt - $\mathrm{kg}$ of salt per $\mathrm{kg}$ of water in parts per thousand - was the common measure. For the accuracy required in this work, measurements in psu and ppt can be considered equal. See also UNESCO (1978).
} 


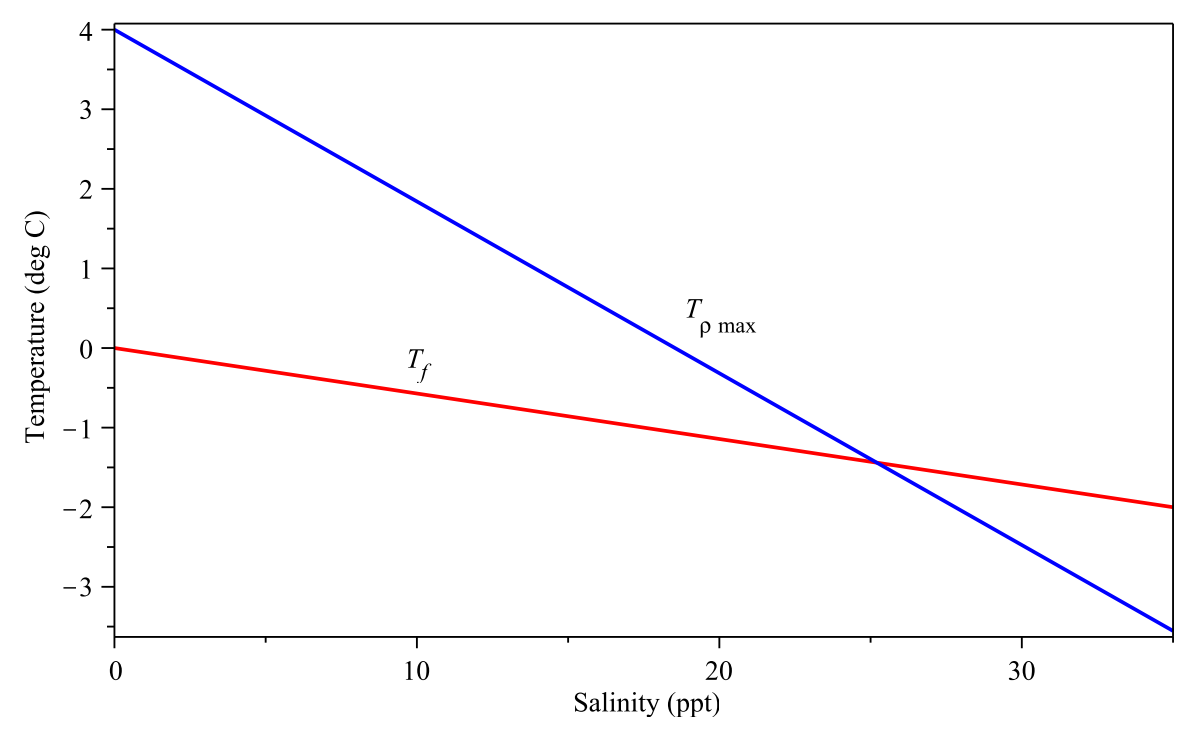

Figure 2.2: The freezing point temperature $T_{f}$ and the temperature of maximum density, $T_{\rho, \max }$, for water of different salinities. The intercept occurs at a salinity of around $25 \mathrm{psu}$ and a temperature of $-1.3^{\circ} \mathrm{C}$. Modified from Weeks and Ackley (1986).

as in Arctic waters) (Notz, 2005). With the water in the halocline having a greater salinity, and thus a greater density, than the water above, a stratified ocean forms in which the mixed layer is unable to mix further with the water deeper down the halocline.

As the mixed layer continues to cool, it eventually reaches its freezing temperature. At this stage, any further heat loss either leads to ice growth or supercooling of the mixed layer. Supercooled water occurs when the water temperature drops below the regular freezing temperature. It is caused by factors such as cooling from wind on open water or movement of water pockets beneath the surface (Martin, 1981).

Supercooled water is conducive to the formation of frazil crystals small, disc-shaped ice crystals. While frazil can potentially nucleate in water with a large amount of supercooling, at naturally occurring temperatures frazil requires foreign particles, such as frozen water droplets from 
the air, to act as nucleation points (Svensson and Omstedt, 1994). After its initial formation, frazil ice grows into a flat, plate-like shape with growth favoured in the basal plane. ${ }^{2}$ Frazil radii can vary from $0.01 \mathrm{~mm}$ up to 10mm (Jenkins and Bombosch, 1995: Svensson and Omstedt, 1998; Smedsrud and Jenkins, 2004), though the diameter of most naturally occurring frazil is less than $5 \mathrm{~mm}$. The thickness of a frazil crystal can be 5 to 100 times smaller than its diameter (Daly, 1984; Lock, 1990). Frazil concentration increases either through further seeding from the atmosphere or by secondary nucleation - new crystals appearing as they are broken off from larger crystals (Daly, 1984; Smedsrud and Jenkins, 2004), until the concentration is great enough that it begins to stick together. Larger frazil crystals are often referred to as platelet $\beta$; a more detailed review of terminology is presented in Chapter 3.

The frazil accretion process leads to the formation of pancake ice (Figure 2.3), which has distinctive upturned edges caused by wind and turbulent water knocking the frazil clumps against each other. These pancakes normally range in size from a few centimetres up to half a metre, though pancakes of over 5 metres in diameter have been observed (Wadhams et al., 1996; Eicken, 2003). The gaps between the pancakes funnel the wind, causing greater stirring and turbulence in the water, which assists further frazil formation (Weeks and Ackley, 1986). Eventually, enough pancake ice is formed that it is tightly packed, damping the turbulent motion, and allowing the interstitial water between the pancakes to freeze in place, thus creating a continuous ice layer also known as the primary ice cover (Lock, 1990).

\footnotetext{
${ }^{2}$ The basal plane contains the a-axes of the crystal and is perpendicular to the primary crystal axis, or c-axis ( $\mathrm{M}^{c}$ Clung and Schaerer. 2006).
} 


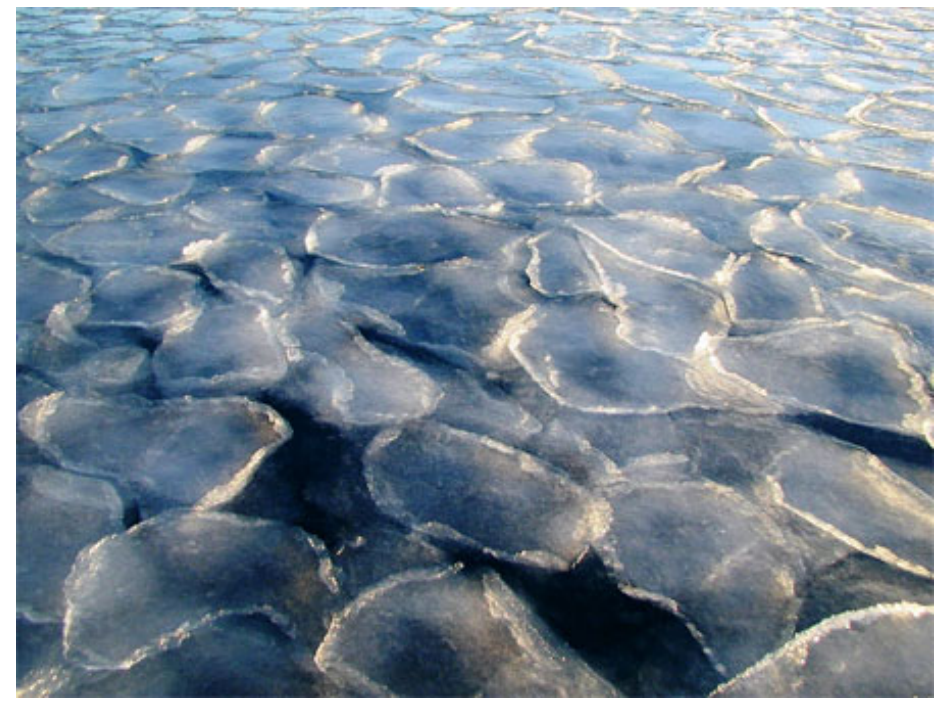

Figure 2.3: Pancake ice: an important step on the way to the formation of a continuous ice sheet; its upturned edges from collisions are a distinguishing feature. Picture by Zee Evans, 2000, available at the National Science Foundation.

\subsection{Sea Ice Growth}

Following the formation of the primary ice cover a transition zone is often observed (Perey and Pounder, 1958), where the c-axes of the crystals change from being randomly orientated to all being close to the horizontal (Langhorne and Robinson, 1983). This transition zone is normally only $10-15 \mathrm{~cm}$ in length, though the depth at which it occurs varies depending on the thickness of the initial frazil layer (Weeks and Gow, 1978).

The move from the random orientation of crystals to a more uniform one occurs through a process of geometric selection, whereby crystals with the basal plane vertically orientated grow into the supercooled region which exists below. This is due to two key reasons: firstly, those crystals with growth axes in the same direction as the heat flow can grow more rapidly; and secondly, with most growth occurring in the basal plane, crystals favourably orientated require less growth to advance downwards than those orientated horizontally (Figure 2.4). 


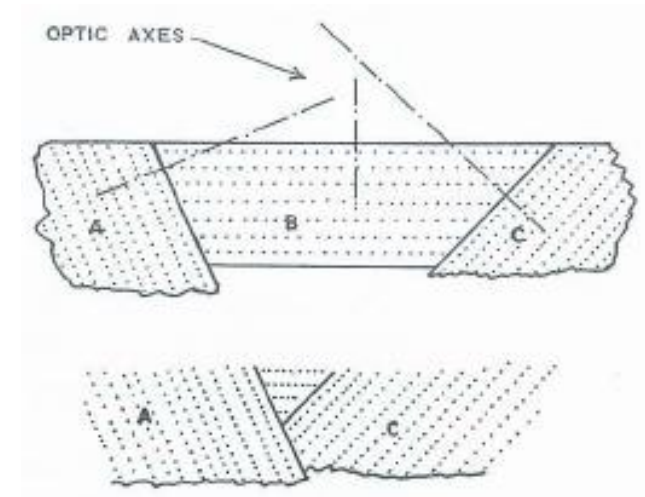

Figure 2.4: Diagram showing the growth of crystals with various c-axis (optic axis) angles. Crystals $\mathrm{A}$ and $\mathrm{C}$ grow preferentially and cut off the crystal with its c-axis vertical. From Perey and Pounder (1958).

Following the transition zone there are two important methods of secondary growth which cause the first-year ice cover to increase in size from below. These are congelation growth - direct freezing of water onto the bottom of the ice-ocean interface - and from platelet ice which may nucleate and grow directly at the base of the ice or form in the ocean and rise to attach to the interface (Lock, 1990).

\subsubsection{Congelation Growth}

The first region of congelation growth which occurs after the transition layer is a columnar zone, named after a similar region found during the solidification of metal ingots. It is characterised by crystals with horizontally orientated c-axes and the major growth axis in the direction of heat flow, as seen in Figure 2.5. This is the most efficient orientation to allow any heat released to conduct vertically upwards though the ice to the atmosphere. The columnar zone can dominate growth, especially in the Arctic. This feature is discussed further in Section 3.3. It is also common for the transition zone above the columnar ice to melt. In regions without any growth added due to frazil or platelet ice, it is reasonable to assume that the entire 


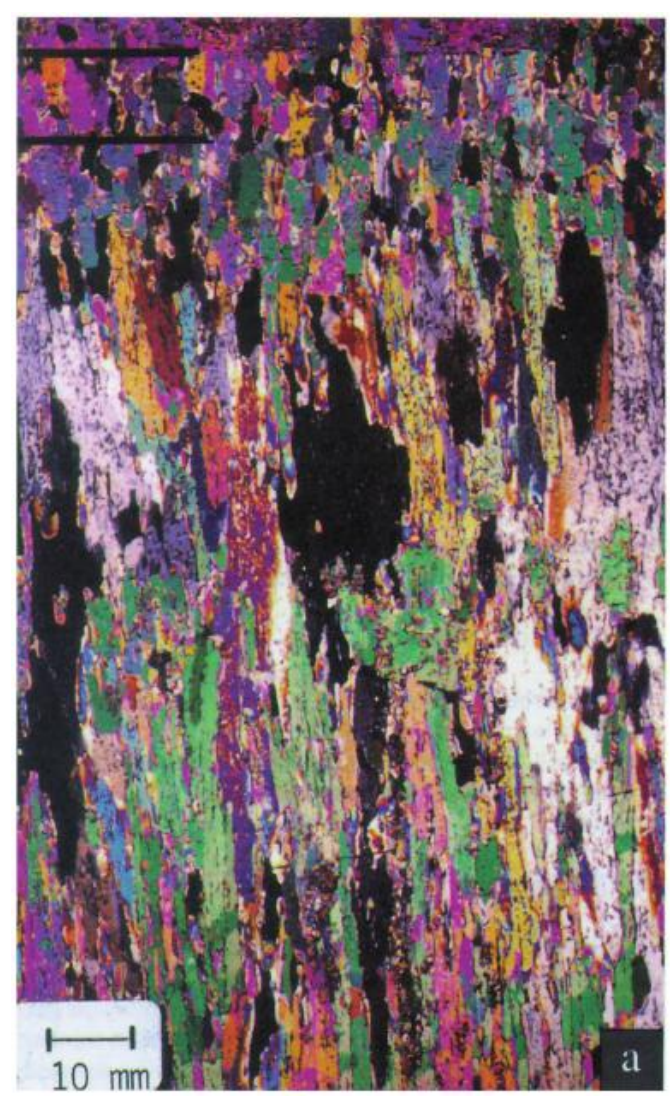

Figure 2.5: The upper $14 \mathrm{~cm}$ of a vertical thin section of first-year sea ice, taken between crossed polarisers. The congelation ice has characteristic long crystals in the vertical direction. The black lines at the top of the image indicate a region of mixed crystals. From Shokr and Sinha (1994), reproduction permission kindly granted by the Arctic Institute of North America.

growth during winter is due to columnar ice (Weeks and Ackley, 1986).

\subsubsection{Analytic Modelling}

Early mathematical modelling of sea ice was based on the theory of vertical heat conduction through the ice. In Leppäranta's (1993) review of analytic sea-ice growth models, the classical heat conduction equation is given as 


$$
\frac{\partial}{\partial t}\left(\rho_{i} c_{i} T\right)=\nabla \cdot\left(k_{i} \nabla T\right)+q
$$

where $t$ is the time, $\rho_{i}$ the density of ice, $c_{i}$ the specific heat of the ice, $T$ is the temperature, $k_{i}$ is the thermal conductivity of the ice and $q$ is an internal heat source (for example solar radiation which has penetrated into the ice (Leppäranta, 1993: Winterton, 1997)). This is also known as Fourier's heat conduction equation with an internal energy source and variable density and specific heat. It is possible to simplify this equation in the case of sea ice growth as the surface area of the ice is, typically, far greater than its thickness. If this is true, the vertical temperature gradients are far greater than the horizontal gradients (Kay, 1963) and Equation 2.1 can be rewritten, taking the $\mathrm{z}$-axis to be in the vertical direction, as

$$
\frac{\partial}{\partial t}\left(\rho_{i} c_{i} T\right)=\frac{\partial}{\partial z}\left(k_{i} \frac{\partial T}{\partial z}\right)+q
$$

The boundary conditions are given at the air-ice interface and the ice-water interface,

$$
\begin{aligned}
& \text { a) } k_{i} \frac{\partial T}{\partial z}=Q_{A} \text { at } z=0 \\
& \text { b) } T=T_{f} \text { at } z=h .
\end{aligned}
$$

These boundary conditions describe the heat flux, $Q_{A}$, at the upper boundary and specify the temperature at the lower boundary to be equal to the freezing point temperature, $T_{f}$, at all times. Finally, as the position of the ice-water interface, $h$, changes as the ice freezes (or melts), it is necessary to consider its movement. It can be given as (e.g. Leppäranta, 1993; $\mathrm{M}^{c}$ Guinness et al. 2009) 


$$
\rho_{i} L \frac{d h}{d t}=\left.k_{i} \frac{\partial T}{\partial z}\right|_{h^{+}}-Q_{T}
$$

where $L$ is the latent heat of freezing and $Q_{T}$ is the heat flux between the ice and the ocean.

One of the difficulties in finding solutions to this model is in calculating the thermodynamic properties of sea ice (for example its density, $\rho_{i}$, and specific heat, $c_{i}$ ) and in finding the heat fluxes of the system. In analytic solutions these properties are often taken to be constant, with varying degrees of accuracy. However, even with a number of the properties of sea ice still being poorly understood (Schwerdtfeger. 1963): Leppäranta, 1993), sea ice models tend to be reasonably accurate. This is partly due a "negative feedback" mechanism, whereby models predicting a smaller amount of ice growth than occurs will have less insulation between the air and the water, thereby growing faster and "catching up" with the actual growth. Models which predict a faster rate of growth have greater insulation and thus the opposite occurs.

An early analytic solution was developed by Jǒsef Stefan and published in 1891. He used Equation 2.2 in the ice, assumed there was no internal source term and that the specific heat, density, thermal conductivity in the ice and the temperature in the water were all constant (Ingersoll et al. 1948). Also key to Stefan's solution is the idea that latent heat, released by freeing at the ice-water interface, is conducted only through the ice (assumed to have a constant temperature gradient) (Leppäranta, 1993). All heat is therefore lost to the atmosphere with none transported, either by convection or conduction, into the water below.

The problem of a moving boundary with a phase change has since been named the Stefan problem, after this work, with the moving boundary condition named the Stefan condition. The solution will be presented and considered in greater detail in Section 5.1 . 


\subsubsection{Numerical Modelling}

Detailed exact models give rise to complex boundary conditions which make analytical solutions impossible. Therefore numerical solutions have become increasingly important in improving sea ice growth models. Computer-driven numerical models are even more vital as sea ice growth models are coupled with atmospheric and ocean circulation models. This allows a more accurate representation of the sea ice and its interactions with its surroundings.

Maykut and Untersteiner (1971) developed a one-dimensional thermodynamic model which was used to investigate the growth of sea ice in the central Arctic. It included the effects of a snow cover, salt content in the ice, internal heating and solar radiation. Four regions were considered:

the atmosphere

any snow cover

the ice

and the ocean

with heat being transferred between the ocean and the atmosphere, through the ice, by conduction. The ablation (loss) and accretion (gain) of ice at both the upper and lower boundaries of the ice layer were calculated to find the change in the depth of the ice.

The model used by Maykut and Untersteiner described the fluxes mathematically at each of the interfaces (air-snow, snow-ice and ice-water) where possible. These were then supplemented with values based on current observational data for terms which could not be found for the model (for example the oceanic heat flux) and for initial conditions. The model was solved using finite-difference techniques and allowed to run until an equilibrium ice thickness was reached.

In an effort to decrease the computing time required to run the numerical model, Semtner (1976) attempted to make a number of simplifications to the system used in Maykut and Untersteiner's model. While 
Semtner retained most of the physical processes and accepted values used by Maykut and Untersteiner, his model focused on decreasing the time taken to reach equilibrium. This was achieved in part by decreasing the number of grid-points used from approximately 40 in the Maykut and Untersteiner model to just 3, one in the snow and two in the ice. Semtner also removed the internal heat source term in the one-dimensional heat conduction equation (Equation 2.2) for ice, and assumed that the specific heat, density and conductivity, which could vary in Maykut and Untersteiner's model, were constant. Even with these changes, Semtner found that his results compared favourably with those of Maykut and Untersteiner. However, as in Maykut and Untersteiner's model, Semtner's work was designed solely for the Arctic region and looked only at areas where an ice cover was present throughout the year.

Semtner's model was adapted by Crocker and Wadhams (1989) for use in $\mathrm{M}^{c}$ Murdo Sound, Antarctica, aiming to be more widely applicable to Antarctic fast-ice growth. An important alteration made for the Antarctic model was the inclusion of frazil and platelets underneath the ice layer. Platelets (frazil crystals which have grown to a certain size) are important as they can attach to the underside of the ice, increasing its size, but at the same time decreasing the rate of heat exchange between the ocean and the atmosphere. Crocker and Wadhams simplified the problem by assuming that when platelet ice "stuck" to the bottom of the ice, it did so at a rate proportional to the percentage of platelet ice found in the platelet layer beneath the ice. The inclusion of this idea resulted in a much better match to icecores taken in $\mathrm{M}^{c}$ Murdo Sound, which had been under-predicted by Semtner's model.

Parkinson and Washington (1979) developed a model which combined a sea ice model with a large-scale atmospheric and oceanic model. Whilst it followed the thermodynamic calculations as described in the previous models discussed, Parkinson and Washington's model also included ice transport. It was applied, in three spatial dimensions, to both the Arctic 
and the Antarctic, with the focus being on the depth and extent of the ice cover throughout the year.

All of these models focused on the thermodynamic processes involved in sea ice growth coupled, to some extent, with atmospheric or oceanic models. However, in all cases, mass transport of salt was neglected. Maykut and Untersteiner (1971) mention that their model lacks a theory of desalination; they only consider the salt's effect on the volumetric heat capacity and the conductivity in the ice. They conclude that for these parameters, the salinity is unimportant at the low temperatures considered. However, salt mass transport has been found to significantly affect the growth rate of sea ice ( $\mathrm{M}^{c} \mathrm{Guinness}$ et al., 2009). It can also, in certain circumstances, lead to the formation of a mushy zone.

\subsubsection{Mushy Zones}

A mushy zone is a region of mixed composition which can occur when a multi-component liquid solidifies (Hills et al., 1983; Fowler, 1985; Huppert and Worster, 1985; Worster, 1986). In sea ice, a mushy zone consists of ice and brine which forms as seawater is frozen. Mushy zones also occur in cooling magma (Fowler, 1989; Hort, 1997) and are commonly found in metallurgy during the solidification of a metal alloy (Wang et al. 2004 ; Vernède et al. 2006).

The first step in the formation of a mushy zone is instability at the icewater interface. Whilst the exact condition for the onset of instability is not precisely defined (Worster, 1986), a commonly used approximation is when the temperature of the mixed layer ahead of the interface drops below the temperature at which freezing begins (also known as the local liquidus temperature). This is generally termed constitutional supercooling and is due to the compositional diffusivity of salt being far less than the thermal diffusivity of heat in the water (e.g. Fowler, 1985: Lock, 1990), see Figure 2.6. Due to the constitutional supercooling, heat diffuses away from 


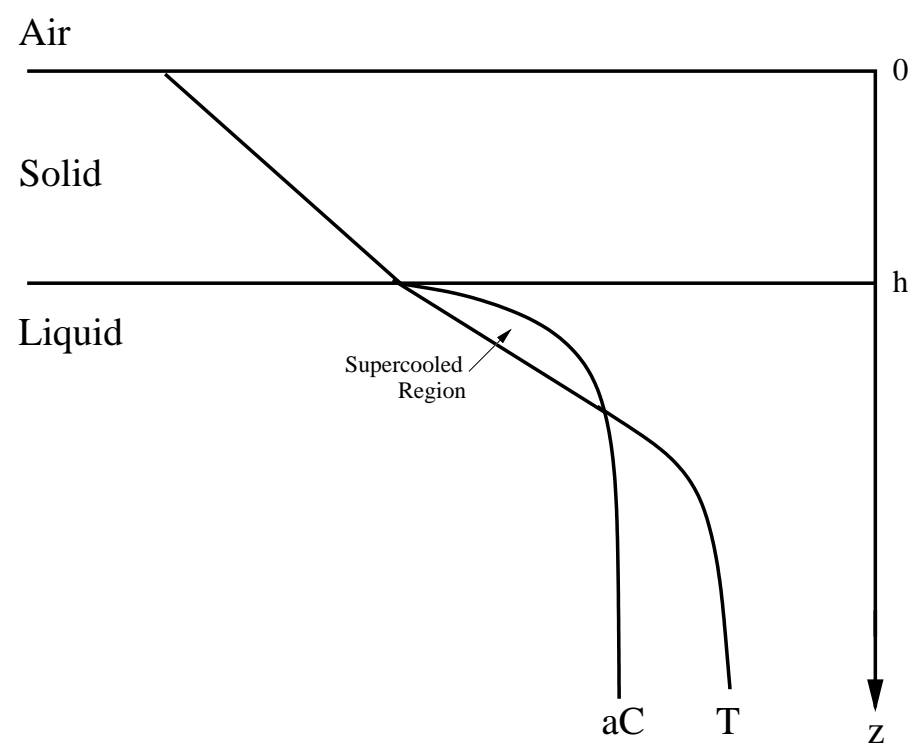

Figure 2.6: Diagram showing the supercooling which can occur during the solidification of a flat interface. ' $\mathrm{a} C$ ' is the freezing point (or local liquidus) temperature and the supercooled region is where the local temperature drops below the liquidus curve. Following Worster (1986).

the ice-ocean interface faster than the salt, leaving a build up of salt at the boundary. As the salt controls the freezing point temperature ahead of the interface, the temperature (with the heat being more uniformly "spread" across the mixed layer) is below the local freezing point and thus supercooled (Fowler, 1985; Worster, 1986).

Hills et al. (1983) defined a theoretical thermodynamic model of solidification of a melt (the ocean) with a mushy zone, and solved the model for specific cases. The model contained two interfaces, melt-mush and mush-solid, with one of the key assumptions being that the system was in local equilibrium. This occurs if the solidification of the liquid is sufficiently slow compared to the actual freezing processes involved. The composition at the mush-liquid boundary then stays close to the liquidus concentration - the concentration at the freezing point - for a given pressure and temperature. 
In Huppert and Worster (1985), a system was investigated in which a melt, when cooled from below, released comparatively heavy fluid back into the melt from the solidifying region. In this set-up, no large-scale convective fluid motion occurs and the movement of heat and solute is caused by molecular diffusion alone. In developing a model to compare with their experiments on various aqueous solutions, they considered the global conservation of mass and solute while assuming that the density of the melt and solid were the same. At the same time, the solid fraction - the portion of the mushy zone which is solid and can be based on the volume or the mass - was taken to be constant throughout the mush. Their experiments showed this last assumption not to be true as the solid fraction varied with height. However, the model still showed a good match with their results for the interface growth rate and temperature profiles in the ice. Using a model that included the possibility for variation of solid fraction with height, Worster (1986) found that his results did not significantly improve on those of Huppert and Worster (1985).

The solid fraction is one of the key features of a mushy zone as it can greatly affect the "thermal, electromagnetic, acoustic and mechanical behaviour of sea ice" (Wettlaufer et al., 1997b). Experimentally, a number of techniques have been used to measure the solid fraction. One of the more common methods used is coring, in which a long tube of ice is removed from the ice layer. Unfortunately, this method can cause brine drainage, which changes the sample as it is removed from the ice. Other methods often involve electrical measurements of capacitance, impedance or resistance (Shirtcliffe et al., 1991; Notz et al., 2005). Shirtcliffe et al. (1991) used a resistance measuring method and found results which differed from their theoretical results by around 10\%, which they partially attributed to errors caused by assuming the density of the solid and ice were the same. (Chiareli and Worster, 1992) found that, while this assumption had some effect (around 5\%), part of the error may have been caused by errors with the experimental method. 
During sea ice growth, after a critical ice thickness has been reached (Wettlaufer et al. 1997a b), brine is released. If the ice is cooled from above the primary mechanism for brine removal during the winter growth period is gravity drainage, as denser brine at the top of the mushy zone is replaced by seawater below (Notz, 2005). This can lead to interfacially driven convection (Wettlaufer et al., 1997a), where convection occurs due to dense, heavy brine being released into the mixed layer causing overturning and further mixing in the water column. This may lead to the formation of freckles or chimneys. These are regions of zero solid fraction which occur through the mushy zone and are a passage for liquid, which has entered the porous mushy zone, to exit (Fowler, 1985; Worster, 1991. 1997). Lake and Lewis (1970) found in their experiments that a large central chimney penetrated high into the ice (on average 1 tube per $180 \mathrm{~cm}^{2}$ ) and was surrounded, nearer the interface, by a number of smaller diameter tubes $\left(42\right.$ tubes $\left./ \mathrm{cm}^{2}\right)$.

\subsubsection{Frazil and Platelet Ice}

One of the difficulties in analysing data on frazil and platelet ice is the variation in their definition. While this is discussed in more detail in Section 3.1. the general difference, as used in this thesis, will be their size. Crystals floating freely some distance from the interface tend to be frail crystals. Those against the interface (loose) or found incorporated into the ice cover (attached) are more likely to be the larger platelet crystals (Smith, 2001).

Frazil ice, as discussed, is an important factor in the initial formation of an ice cover in turbulent waters. In certain regions of Antarctica, it has been found to contribute a significant portion of the growth of both firstyear and multi-year sea ice (Svensson and Omstedt, 1994; Purdie et al. 2006). Weeks and Ackley (1986) calculated, while looking at ice core in the Weddell Sea region, that multi-year ice was comprised of $75 \%$ frazil 
ice on average. In the same study, frazil contributed $46 \%$ of first-year ice growth. Similarly, Jeffries and Weeks (1992) found that, in cores taken in the Ross Sea region, the frazil content varied between $2.3 \%$ and $88.5 \%$, averaging $38.5 \% \pm 27.0 \%$ of the total thickness. The source of this frazil varies depending on the age of the ice.

In first-year ice, the frazil contribution is predominantly from crystals incorporated during the formation of the initial ice layer (the pancake layer). While multi-year ice also retains the frazil from the pancake layer, further frazil can be created through the rafting ${ }^{3}$ of ice floes or due to the rapid creation of frazil in lead: $\left.\right|^{4}$ In this case the frazil is then forced to the bottom of the adjacent ice through ocean turbulence or floe movement (Lange and Eicken, 1991).

More recently, platelet ice has also been found to add significantly to growth of first-year sea ice in Antarctic regions. In $\mathrm{M}^{c}$ Murdo Sound, platelet ice contributions of $28.3 \%$ were found by Jeffries et al. (1993) and of $43 \%$ by Leonard et al. (2006).

As previously mentioned, frazil ice generally forms in turbulent, supercooled water where nucleation points exist (such as impurities in the water or ice crystals broken off from the ice layer itself) (Weeks and Ackley, 1986: Daly, 1984). In sea-ice growth both frazil and platelets (which frazil can grow into) are especially important. This is because these crystals are a more efficient method for ice growth than columnar ice in supercooled water (Smedsrud and Jenkins, 2004).

While the cause of frazil crystals in sea ice is fairly well explained, the origin of platelet crystals is less clear. The proximity of ice shelves 5 to regions where platelet ice is commonly found suggests that the shelves may be important to their formation (Martin, 1981; Jenkins and Bombosch, 1995: Gow et al., 1998: Smedsrud and Jenkins, 2004). Supercooled water from the ice shelves may flow along the ice-ocean interface and cause nu-

\footnotetext{
${ }^{3}$ The movement of an ice edge over another caused by the collision of two ice floes.

${ }^{4}$ Narrow cracks which form in the ice due to movement of ice floes.

${ }^{5}$ Location where a glacier or an ice sheet has flowed off land and onto water.
} 


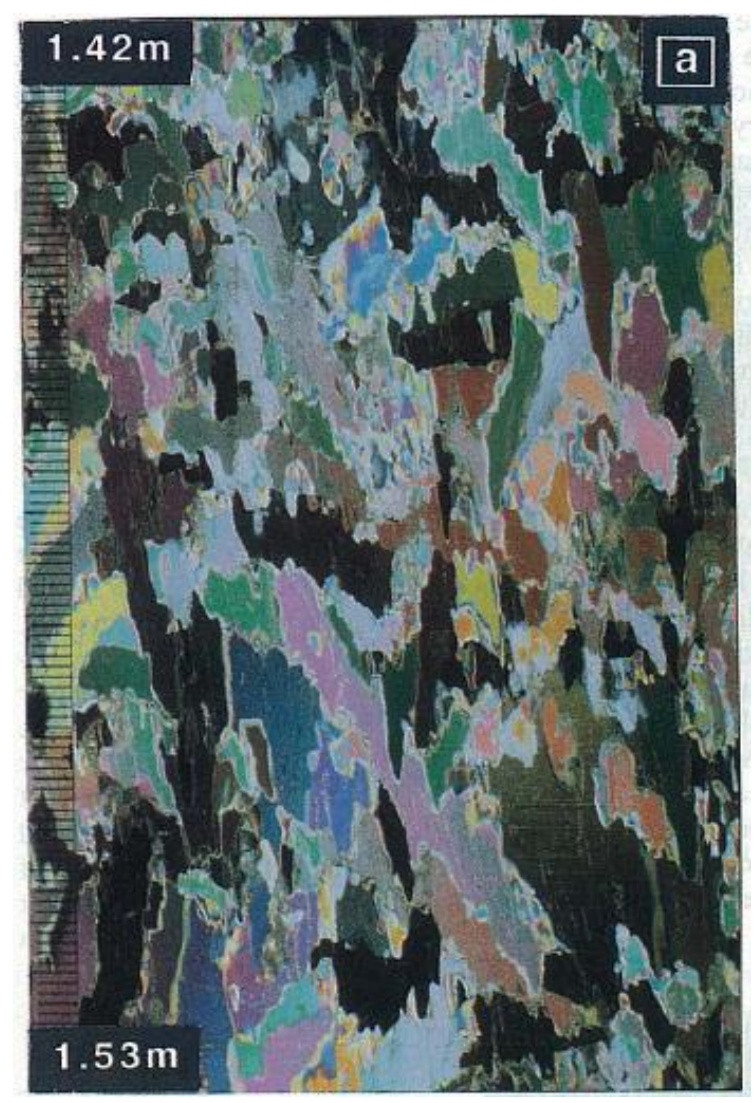

Figure 2.7: A vertical thin section of platelet ice. A platelet layer has a far more random structure than congelation ice (compare with Figure 2.5). From Jeffries et al. (1995).

cleation directly to the ice, allowing platelets to grow. The supercooled water could also allow creation of frazil crystals below the ice cover. Alternatively, the crystals may nucleate below the ice shelves before growing and being transported below the sea ice (Lange, 1988; Eicken and Lange, 1989, Langhorne et al., 2006).

Quantities of platelet ice have been observed at the ice-water interface (Gow et al., 1982). Frazil crystals, in suspension underneath the sea ice, may rise and "stick" to the bottom of the ice. This takes place due to the buoyancy of the frazil discs in a process not dissimilar to sediments dropping out of water or the atmosphere, only in reverse (Steele et al., 1989. 
Smedsrud and Jenkins, 2004). Once against the interface, frazil crystals can grow into the platelets found in ice cores.

The tendency for a frazil crystal to rise out of suspension is strongly affected by both its own dimensions and the magnitude of turbulence in the ocean. Depending on the situation, the velocity required to keep the crystal in suspension may be given by the Shields criterion (Jenkins and Bombosch, 1995; Miller et al., 1977) or Stokes' Law (Streeter and Wylie, 1975).

It is interesting to note that platelets often only appear in ice cores below a depth of $1 \mathrm{~m}$ (Smith et al. 2001; Leonard et al., 2006). The timing of supercooled water and frazil's appearance from below the ice shelf (Gow et al., 1998), as well as the strength of the turbulence under the sea ice ( $\mathrm{M}^{c}$ Guinness et al. 2009), have been suggested as a possible reason for this delayed inclusion. This puzzle will be a key focus throughout this thesis and will be developed further in the following chapters.

Figure 2.7 shows a vertical thin section of an attached platelet layer. As the crystals' growth is largely due to the supercooled water below the ice, they do not need to be orientated so as to enhance the heat flow from the ocean to the atmosphere. Hence the more random structure observed in the ice for platelet crystals does not indicate a slower rate of growth.

\subsection{Salinity}

Ice-water dynamics in the Antarctic are strongly affected by the salt in seawater and its rejection from the growing ice. Not only does it enhance turbulence and drive global currents, but it can also alter the various physical properties of sea ice. While diffusion of salt does occur (and is important in systems where seawater is being cooled from below), when convection acts it is a far more effective mechanism for the removal of salt from the interface (Lake and Lewis, 1970). 
Wettlaufer et al. (1997a|b) found that, even though the salty water initially trapped in a mushy layer is dense, it remains in the growing ice until the ice has reached a critical thickness. The critical value depends, in part, on the surface temperature and initial concentration of the system.

Once the desalination process begins, much of the highly concentrated brine is flushed out of the mushy zone and is replaced by fresher water which freezes into the gaps in the mushy zone. Even though the majority of the salt is removed from the ice, some of the brine can still remain trapped within (Weeks and Lofgren, 1967). Over time this remaining brine decreases, and a variety of methods for this loss have been suggested (Lake and Lewis, 1970).

Both Untersteiner (1967) and, more recently, Notz (2005) have described and investigated the more likely mechanisms for the brine loss from the ice after it has formed. The four key possibilities are:

- Brine pocket diffusion - Isolated pockets of brine move down through the ice as, due to the temperature gradient in the ice (and thus through the brine pocket), a salinity gradient is created in the brine. As the salt diffuses down through the pocket, the now lesssaline upper portion of the pocket freezes while the greater salinity at the bottom causes the lower boundary to melt, creating a slow movement of the pocket towards the warmer region.

- Gravity drainage - As with brine pocket diffusion, the temperature gradient through the ice creates a salt gradient in brine channels with more concentrated, denser brine at the top. This unstable situation can cause convection in the brine channels through the mushy zone.

- Flushing - Flushing only occurs during the summer months as the pressure required to force the brine through the tubes is created by melt water on top of the ice.

- Brine expulsion - With ice having a lesser density than water, the expansion of ice as it forms causes a pressure gradient in the brine 
tubes. This can force brine through the tubes, though the direction of expulsion can be either up or down.

Notz (2005) found that of these methods, gravity drainage and flushing were the only two which caused a significant loss of brine from ice after its initial rejection; and, of these two, only gravity drainage occurs during the winter.

Salinity profiles of first-year sea ice have been measured using a variety of techniques. Two examples of such profiles, one each from Antarctica and Alaska, can be seen in Figures 2.8 and 2.9. respectively. Whilst the coring method of removing samples from sea ice (as discussed in section 2.2.4 is known to cause pressure gradients in the core and may cause drainage of brine from the ice, similar profiles have been found using insitu measurements (Nakawo and Sinha, 1981; Purdie et al., 2006; Ingham et al. 2008). The typical C-shaped salinity profile for first-year sea ice can clearly be seen in both figures.

The profiles show an increase in salinity towards the ice-water interface which, when found in coring measurements, were thought to have been partly caused by brine drainage as mentioned. However, newer methods produce similar results, suggesting that newly formed ice does indeed have a higher content of brine. The salinity can then be seen to decrease rapidly during the early stages of growth. Nakawo and Sinha (1981) found that a significant percentage of the brine loss from ice occurred within its first week of formation. Throughout the rest of the ice, a reasonably constant salinity of around 5-6 psu was found.

Though this shows that the quantity of brine in ice is diminished due to drainage into the water below, the remaining brine still effects the properties of the ice. How the amount of brine and its concentration, along with the solid salts which can freeze in place in the ice, alter these properties has been subject to a number of investigations (for example see Schwerdtfeger (1963); Yen (1981); Koslowski (1986)). These ideas will be introduced where appropriate throughout this thesis. 


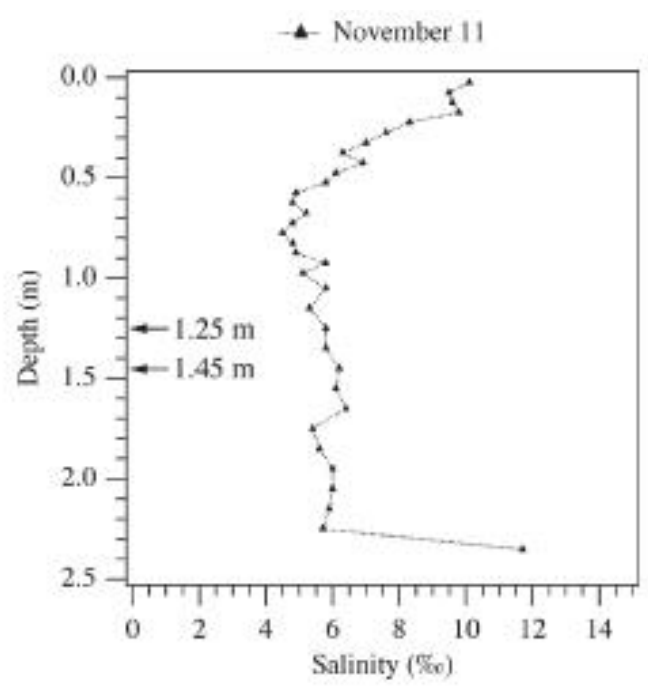

Figure 2.8: Salinity profile of first-year sea ice in $\mathrm{M}^{c}$ Murdo Sound, Antarctica. The typical C-shaped curve is evident. Some melting may have occurred causing a slightly higher salinity reading at the top of the ice. Reprinted from Backstrom and Eicken (2006) with permission from Elsevier.

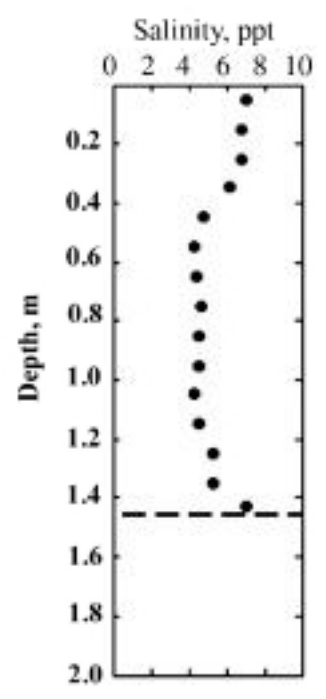

Figure 2.9: Salinity profile in first-year sea ice taken from a site near Barrow, Alaska by Ingham et al. (2008) using a cross-borehole resistivity technique. Dotted line is the ice-water interface. 


\subsection{Turbulence}

Sub-ice turbulence, introduced in Section 2.1. is important in sea ice growth through the creation of a mixed layer, its effect on heat and solute transport (and thus the supercooling of the mixed layer) and in the creation of frazil ice (Omstedt, 1985; $\mathrm{M}^{\mathrm{c}}$ Phee, 1992). Turbulence can be caused by a number of factors, including shear flow (from the tides), thermal convection and brine drainage from the ice (Weber, 1977).

The release of brine during sea ice growth contributes to the turbulence in the mixed layer as it is heavier than the water below. However, this alone is not enough to prevent the build up of salt at the interface. Turbulence from tidal flow plays an important role in dispersing the salt throughout the mixed layer. Turbulence is also a far more efficient method for transferring heat than diffusion and has a significant effect on the heat flux between the ice and the mixed layer.

In modelling heat and salt fluxes at the ice-water interface, it is often noted that they depend primarily on the difference between the temperature or salinity (respectively) at the interface and at a set distance into the mixed layer, and on the friction velocity ( $\mathrm{M}^{c}$ Phee, 1992, Holland and Jenkins, 1999: Notz, 2005). The friction velocity is a characteristic velocity scale which can depend on both shear flow and free convection, which is caused by the change in temperature in the water. It is defined as

$$
u_{*}=\sqrt{\frac{\tau}{\rho_{w}}}
$$

where $\tau$ and $\rho_{w}$ are the shear stress and water density at the wall (icewater interface), respectively (van den Hurk and Holtslag, 1997; Mahrt et al. 1998; $\mathrm{M}^{\mathrm{c}}$ Phee and Morison, 2001). 


\subsubsection{Turbulence and frazil suspension}

Turbulence is well known in sedimentation theory to keep mud, silt and pebbles in motion and to prevent them from settling against a river- or seabed (e.g. Miller et al., 1977, Reid and Frostick, 1994; Winterwerp, 2001; Robert, 2003). The movement of frazil rising up to stick to the underside of an ice-cover can be thought of as a reverse-sedimentation process. In this case the frazil ice is less dense than the seawater and hence turbulence is acting to prevent the crystals from floating up to the ice-water interface. With research into the effects of turbulence on frazil crystals being sparse, the analogy between rising frazil and settling sediments will be used at various points in this thesis.

\section{Shear flow}

Currents and tides create a shear flow beneath sea ice which, due to friction at the ice-water interface, creates a turbulent flow ( $\mathrm{M}^{c}$ Phee, 1987). This turbulence has the potential to keep frazil crystals from settling and adhering to the interface, either by keeping them in motion near the ice (Miller et al. 1977), or by suspending them away from the interface (van Rijn, 1984: Leeder et al. 2005). While it may be expected that shear-induced turbulence will act equally both towards and away from the ice, Bagnold (1966) showed that there was, in fact, a net velocity away from the interface, which they surmised was due to anisotropy in the turbulence. More recently, it has been shown that even isotropic turbulence can lead to either an increase or decrease in the rise velocity of a particle, depending on its relative density in the fluid and the strength of the turbulence (Friedman and Katz, 2002; Nielsen, 2007).

The Shields criterion was developed to estimate the strength of turbulence required to keep a sediment particle from settling against a river or sea bed. The Shields parameter value (a dimensionless bed shear stress) can be calculated for a given sediment and, if it exceeds a critical value 
(found experimentally), then the grain is prevented from settling against the interface (Miller et al., 1977). Jenkins and Bombosch (1995) suggested that this could be used for frazil crystals in a buoyant plume of water travelling up the underside of an ice shelf. In Section 3.5 it will be used to estimate the critical friction velocity above which crystals are kept in motion beneath a sea ice cover.

\section{Brine plumes}

$\mathrm{M}^{c}$ Guinness et al. (2009) suggested that an alternative method for keeping frazil in suspension could be the dense, salty water rejected from ice during growth. If these brine plumes have a strong enough velocity, they may counteract the rise velocity of the crystals and keep them from rising to the interface. The concentration of exit points in the ice, the downwards velocity created by the plumes and the effect of the growing ice on their strength will all be considered in greater detail in Chapter 4

\subsection{Frazil induced turbulence damping}

It seems apparent that fluid turbulence should have a significant effect on a frazil crystal. What is not so clear is whether the turbulence will be affected by a concentration of suspended crystals. In investigating this, the lead will again be taken from sedimentation theory.

In general, when a frazil concentration profile is set up, the number (and mass) of crystals increases towards the ice-water or air-water interface (Liou and Ferrick, 1992; Svensson and Omstedt, 1998; Morse and Richard, 2009). This implies that the density increases with increasing depth, producing a stabilising gradient. This is analogous to a sediment profile increasing towards a river- or seabed (van Rijn, 1983: Ghoshal and Mazumder, 2005). Though the full effects of sediment on a turbulent flow are still in dispute (Winterwerp, 2001), it is generally accepted that a stabil- 
ising density profile weakens turbulence ( $\mathrm{Li}$ and Gust, 2000; Ghoshal and Mazumder, 2005).

Quantifying the strength of stabilisation is more difficult. A number of different methods have been proposed. Two of these centre on the parameters in the logarithmic law of the wall,

$$
U=\frac{u_{*}}{\kappa} \ln \left(\frac{z}{z_{0}}\right)
$$

where $U$ is the shear flow strength at depth $z, \kappa$ is the von Kármán constant and $z_{0}$ is the roughness length at the solid-water interface (e.g. Turner. 1979). Though strictly only appropriate near the interface, it is often used as an approximation over the depth of a flow (for further details see Section 6.2.

Experiments in the 1940's and 1950's suggested that the von Kármán constant decreased from its clear water value in the presence of a sediment concentration (Vanoni et al. 2006). Similar results were found by Bennett et al. (1998) and a formula for the decrease in $\kappa$ suggested by Ippen (1971), though some of his conclusions have been questioned (van Rijn, 1984).

An alternative method proposed was to model the damping effect of a sediment concentration through a decrease in the friction velocity. Adams and Weatherly (1981) suggested that a reduction of up to $40 \%$ in $u_{*}$ was possible. A method proposed by Soulsby and Wainwright (1987) to calculate $u_{*}$ based on a measured shear flow will be investigated further in Section 6.2.2.

\subsection{Summary}

This chapter had provided some of the background knowledge which will form the basis for the work carried out in the rest of this thesis. Further discussion of relevant research will be included where appropriate. 
Of central importance is that, after its initial formation, first-year sea ice has two key mechanisms which increase its thickness - congelation growth and platelet inclusions. Whilst congelation ice is the predominant method of growth in the Arctic, platelet ice plays a major role in certain regions of Antarctica. However, observations of ice cores consistently show that the platelet crystals only appear after around a metre of congelation growth has occurred.

One proposed theory for the creation of platelet ice is the rise of frazil crystals up to the interface. After attaching to the sea ice, they continue to grow. These frazil crystals may be swept in from below an ice shelf or nucleate directly below the ice or in nearby leads. Why these crystals may be delayed in settling against and adhering to the ice-water interface will be one of the key themes throughout this thesis. 


\section{Chapter 3}

\section{Shear flow, frazil and platelet ice}

After its initial formation, two types of growth are key in the development of an ice cover. Congelation ice is the primary source of growth in most Arctic regions. However, in some locations in Antarctica, significant portions of ice cores have been found to consist of platelet ice. Rather than being formed by heat conduction through the ice, platelet ice may begin as smaller frazil crystals which form directly beneath the ice or are swept in from nearby ice shelves. They can then rise and attach to the ice-water interface where they may continue to grow in size.

An interesting point which has been observed of the platelet inclusions is that, consistently, they are only found after around $1 \mathrm{~m}$ of congelation growth. This delayed appearance is yet to be satisfactorily explained. This chapter will ask whether a shear flow, created by tides and currents beneath the sea ice, is strong enough to keep the crystals from attaching to the ice-water interface.

\subsection{Frazil ice or platelet ice?}

Frazil ice and platelet ice each play an important role in the growth of sea ice. As discussed in Section 2.1. frazil ice initially forms and grows in the turbulent, upper regions of the ocean. The accretion of this frazil 
forms pancakes which, when packed tightly enough together, freeze in place creating an initial ice cover on the ocean (Lock, 1990; Eicken, 2003). When ice cores are taken, both frazil and platelets are found to contribute to the thickness of the ice layer. However their contribution depends on both the age of the ice and its location.

The terms 'frazil ice' and 'platelet ice' often appear to be used in an interchangeable fashion. Frazil ice has been used for some time to describe both the crystals which create the pancake layer and the small disordered discs which sometimes appear throughout the ice. However, platelet ice was rarely detailed until Gow et al. (1982) described a platelet layer which they discovered beneath the ice. Later, Lange (1988) found platelet ice incorporated into ice cores from the Weddell Sea region. He defined them as having "large, elongated grains (diameters of up to a few centimetres, lengths of up to several centimeters)". He also noted that some platelets appeared similar to congelation ice and the two could previously have been mistaken when ice cores were analysed using thick sections and horizontal thin sections. More recently, platelets have been viewed in $\mathrm{M}^{c}$ Murdo Sound (Jeffries et al. . 1993). These were distinct from congelation ice and appear in thin sections similar to those seen in Figure 2.7 Tison et al. (1998) suggested that platelets were a larger form of frazil crystals which have nucleated and grown in the supercooled water near ice shelves.

Crystals which create the initial pancake layer are always referred to as frazil ice. While these can grow up to $5 \mathrm{~mm}$, crystals larger than $2.5 \mathrm{~mm}$ are rare (Martin, 1981; Jenkins and Bombosch, 1995; Svensson and Omstedt, 1998: Smedsrud and Jenkins, 2004). Crystals which grow beneath the sea ice or the ice shelf and travel in plumes have been called both frazil and platelets. The key difference between these two ice types is their size, with the smaller frazil crystals becoming platelets at a certain size, though the exact cut off is inexact. Both crystals can contribute to ice growth after its initial formation. The mechanisms for this will be discussed in the 
following section. When found in first-year ice during ice coring, incorporated crystals are generally called attached platelets (Smith, 2001). These can either be in pure platelet layers or in regions of mixed congelationplatelet growth. As mentioned in Section 2.2.5. platelet growth is, in general, distinguishable from congelation ice when ice cores are analysed using vertical thin sections and fabric diagrams.1 While columnar growth occurs with crystals aligned vertically to enhance the transfer of heat flux, platelet crystals are typified by having random orientations (Smith et al. 2001: Smith, 2001: Langhorne et al., 2006).

\subsection{Mechanisms for growth}

As discussed, frazil and platelets play different roles in ice growth depending on the age and location of the ice. Common to both the Antarctic and the Arctic is the frazil which forms the initial ice cover or pancake layer. This was discussed in Section 2.1. In Antarctic regions frazil ice can also contribute greatly to the growth of multi-year sea ice. Four causes for the inclusion of this frazil have been suggested (Lange and Eicken, 1991: Tison et al. 1998). See also Figure 3.1 .

- An ice floe slides below an adjacent floe. The frazil in the initial layer of the lower floe will now appear midway through a core taken of the two floes.

- Leads appear in the ice due to rafting effects. The thin narrow regions lose heat rapidly to the cold air. Along with the wind- and wave-induced turbulence, this provides ideal conditions for frazil formation (Martin, 1981). As the lead refreezes, frazil which was stirred below by convection may rise back and adhere to the underside of the ice.

\footnotetext{
${ }^{1}$ Fabric diagrams are used in sea ice analysis to indicate the orientation of crystals in an ice core section.
} 


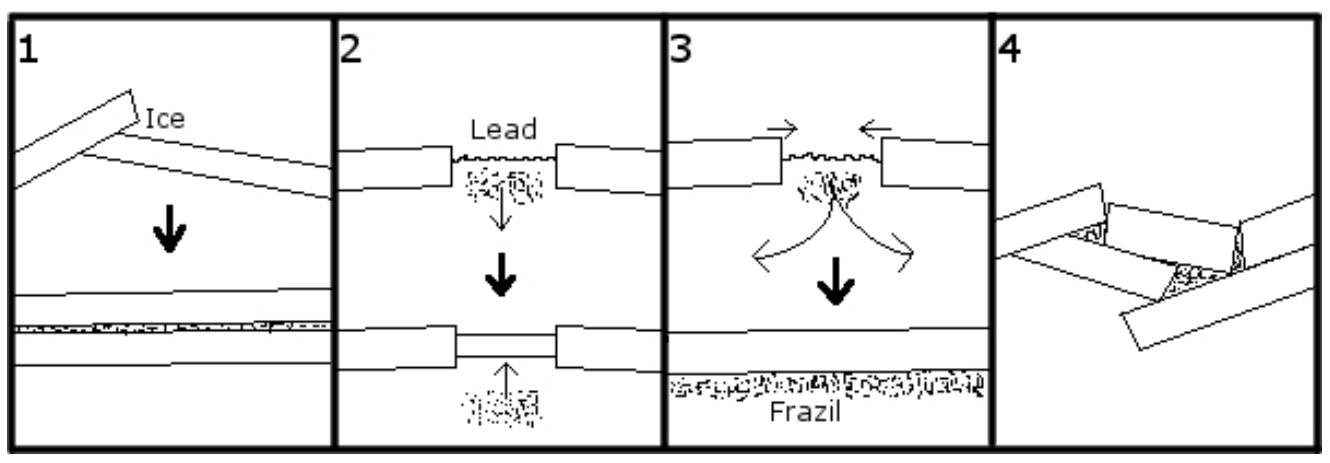

Figure 3.1: The four mechanisms of multi-year frazil growth. See text for details. Following Lange and Eicken (1991).

- Frazil formed in the same process as above may be stirred below adjacent floes.

- Finally, frazil may form in gaps left by rafted floes.

Due to the rarity of ridging and rafting events in first-year ice, these methods contribute little to the growth of a newly formed ice layer. In the Arctic, growth of first-year ice is dominated by congelation ice. This is not true in Antarctica, however, where in various regions a significant percentage of the ice layer has been found to consist of platelet ice (Langhorne et al. 2006). The exact origin of the platelet crystals in the sea ice is still not certain. There are two common explanations, frazil ice adhering to the ice-water interface before growing to become platelet crystals, and supercooled water causing direct nucleation of platelets at the interface. These are explained further in the remainder of the section.

The greatest quantities of platelet ice have been found in ice cores from the Weddell Sea and $\mathrm{M}^{c}$ Murdo Sound. Both of these regions have ice shelves in close proximity, which are known to be conducive to frazil formation (Jenkins and Bombosch, 1995). This occurs in turbulent plumes of water which are known to rise along the underside of the ice shelves. As the freezing point of water is colder at lower depths, the rising water will be supercooled unless it is warmed by its surroundings. If sufficient heat 


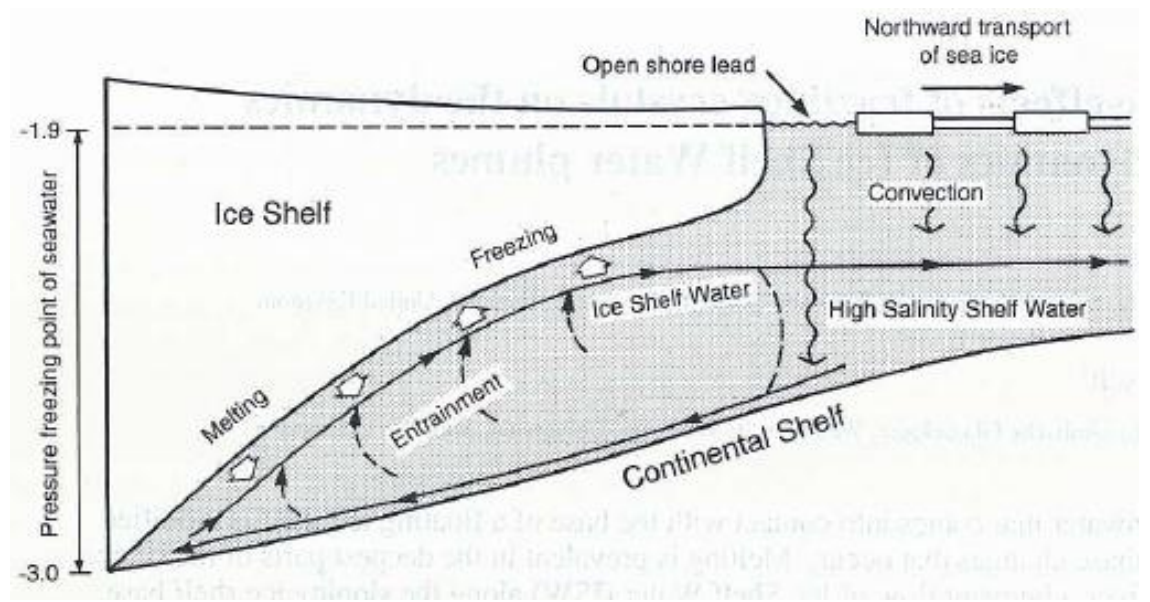

Figure 3.2: Plumes of water follow the solid central arrow, rising near the base of the ice shelf and becoming supercooled in the process. If seeded by ice crystals, frazil crystals can form. These are then transported under the ice. Note that in land fast sea ice the lead shown would not exist. From Jenkins and Bombosch (1995).

is not supplied to a turbulent plume then, seeded by crystals from the ice shelf, it may produce frazil crystals (Martin, 1981; Tison et al., 1998; Smedsrud and Jenkins, 2004). After a period of time, the crystals will be transported away from the ice shelf and swept below nearby sea ice, continuing to grow as they move. Alternatively, crystals may form directly beneath sea ice (Jeffries and Weeks, 1992). Dieckmann et al. (1986) observed platelet crystals at a depth of $250 \mathrm{~m}$ near the Filchner Ice Shelf in Antarctica. In either case, crystals of varying sizes can then rise up below sea ice, forming a platelet layer which may consolidate and stick to the interface (Lange. 1988: Eicken and Lange, 1989). Gow et al. (1982) observed a platelet layer at a majority of sites during coring in $\mathrm{M}^{c}$ Murdo Sound.

The second theory for platelet inclusion in sea ice is also based on supercooled water from below the ice shelves. In this case, as the supercooled water passes below the sea ice, it allows nucleation and platelet growth directly onto the ice-water interface (Eicken and Lange, 1989; Gow et al., 1998; Tison et al., 1998). 
Which of these mechanisms dominates, if either, is at present uncertain. Gow et al. (1998) argued that a horizontally layered structure would be expected if platelets were rising up and attaching to the interface, the torque on the crystals turning them to lie flat against the interface (Smith, 2001). The platelets they observed were disordered, leading them to favour the direct nucleation method. However, they did observe a large number of unattached platelet crystals appearing in the holes left by coring. Eicken and Lange (1989) also found quantities of platelets underneath the ice which were easily dispersed. These free crystals are more likely to have been created elsewhere and swept underneath the sea ice.

\subsection{Quantity of growth}

This section will briefly discuss the contribution of congelation, frazil and platelet ice to sea ice growth. When comparing the different types of ice, frazil which has attached at the ice-water interface and grown in place (as described at the end of the previous section) is regarded as platelet ice.

In the Arctic, both first-year and multi-year ice are dominated by congelation growth. Weeks and Gow $(1978,1980)$ found that fast-ice growth in the Beaufort, Chukchi and Kara seas in the Arctic Ocean had a distinct crystal orientation with the c-axis predominantly aligned in the horizontal direction, indicating congelation ice (Weeks and Ackley, 1986). Similarly, multi-year ice cores taken in the Arctic by Thomas et al. (1995) found that $86 \%$ of ice was columnar. The remainder was primarily frazil in the initial pancake layer. Undeformed first- and multi-year ice observed by Gow and Tucker III)(1991) in the Fram Strait had an average 85\% congelation ice. They also mention that previous studies, solely on first-year ice, showed an even higher congelation component.

Similar results to those from the Arctic have been found in some Antarctic locations. Notably, Gow et al. (1982) found that congelation ice was the dominant mechanism for growth in first-year ice in $\mathrm{M}^{c}$ Murdo 
Sound with minimal amounts of frazil. Interestingly they also found a platelet layer (loose platelets), several centimetres thick, below the ice. However, there is much more variety in the constituents of Antarctic sea ice. Studies of the Weddell Sea pack ice by Gow et al. (1982), reanalysed by Weeks and Ackley (1986), found that, on average, multi-year ice contained $75 \%$ frazil ice and just $19 \%$ congelation ice. For first-year ice the values were $46 \%$ and $47 \%$ respectively. Lange and Eicken (1991) reviewed a number of first-year sea ice measurements in the Weddell Sea. The results showed that the frazil ice content varied from $41.9 \%$ of the core up to $69.5 \%$. The average growth for all the expeditions was $56.9 \%$ frazil ice and $43.1 \%$ congelation ice. The greater quantity of frazil ice in multi-year cores can be attributed to rafting and ridging processes in Antarctic sea ice. Frazil in first-year ice is largely due to the initial pancake formation (Lange and Eicken, 1991).

More recently, platelet ice has become accepted as a significant mechanism for growth in certain regions of first-year Antarctic sea ice. Lange (1988) observed platelets in the eastern and southern regions of the Weddell Sea. He noted that it resembled "underwater" ice which had been reported previously by Russian sources. Estimates of the volume fraction of platelet ice were given as between 20 and 30\%, with frazil and congelation ice being $50-60 \%$ and $20-30 \%$ respectively (smaller amounts of snow ice were also observed). Platelet inclusions have been found frequently since. Eicken and Lange (1989) found that platelets averaged $11 \%$ of the sea ice, though individual cores could contain up to 50\%. Jeffries et al. (1993) found that frazil was insignificant in cores in $\mathrm{M}^{c}$ Murdo Sound. Instead, congelation ice contributed $62.1 \%$ and platelet ice $28.3 \%$. He also described a platelet/congelation mix which accounted for $9.3 \%$ of ice growth. In this, interstitial congelation ice grew between the platelet crystals. Also in $\mathrm{M}^{c}$ Murdo Sound, Gow et al. (1998) found platelet ice averaged 13\% of the growth with $15 \%$ in an initial transition layer. The remainder was congelation growth. Both Jeffries et al. (1993) and Gow et al. (1998) believed 


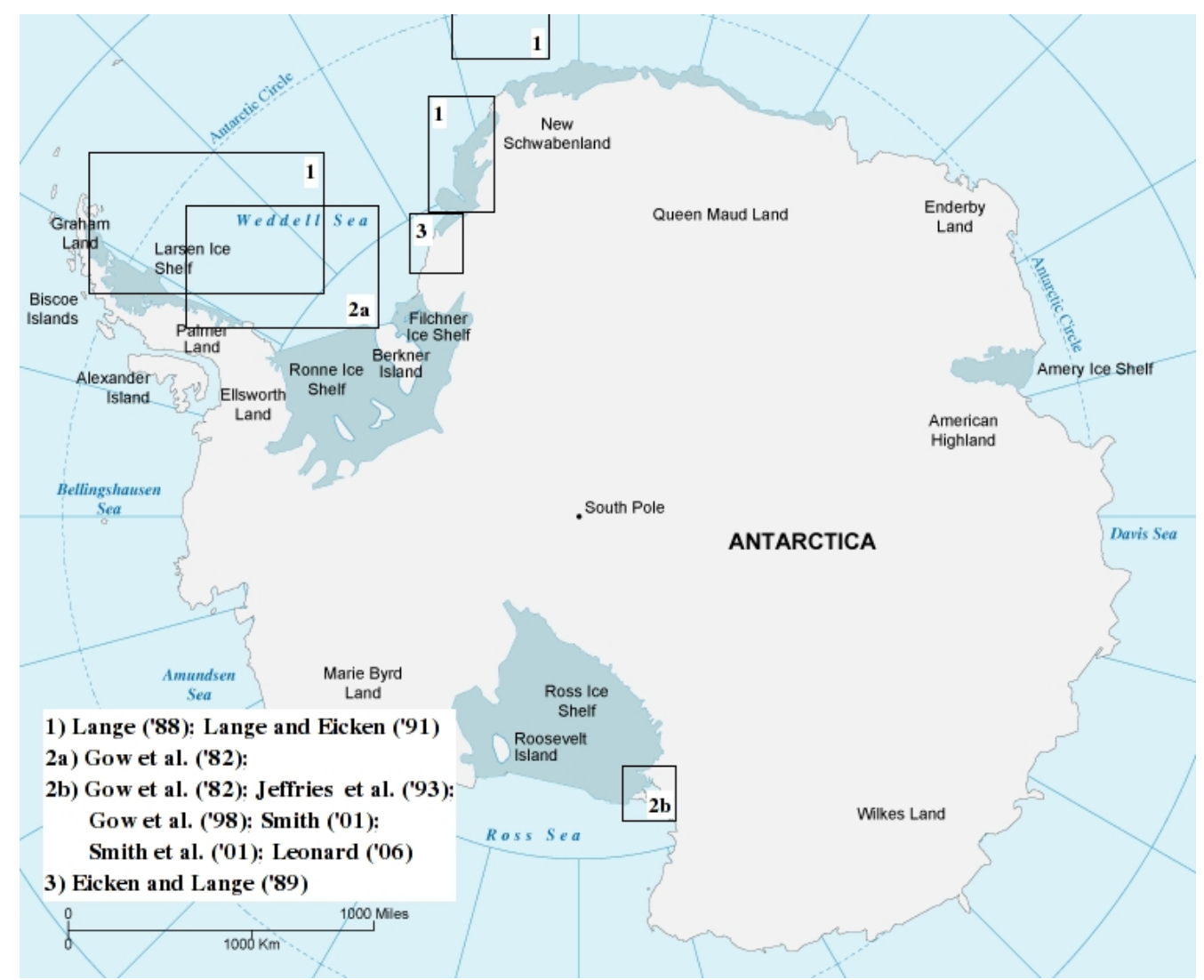

Figure 3.3: Sea ice survey locations for the references described in the text. All are performed close to the Weddell Sea and $\mathrm{M}^{c}$ Murdo Sound regions due to the proximity of research stations.

they underestimated the quantity of platelet ice. This was due either to the commencement of the melt season (causing platelet ablation) or measurements being made before all platelet attachment could occur. Table 3.1 gives platelet percentage results from $\mathrm{M}^{c}$ Murdo Sound as found by Smith et al. (2001), Smith (2001) and Leonard et al. (2006). These show platelet percentages varying from $26 \%$ up to $49 \%$ of the total growth. Analysis of a variety of data in $\mathrm{M}^{c}$ Murdo Sound was carried out by Langhorne et al. (2006). They showed that, though the location and relative quantities of frazil was similar from year to year, the amount of frazil could vary significantly. They also presented results which show significant amounts of 


\begin{tabular}{|c|c|c|c|}
\hline Source & Date & $\begin{array}{c}\text { Platelet } \\
\text { percentage }\end{array}$ & $\begin{array}{c}\text { Initial depth of } \\
\text { platelets (m) }\end{array}$ \\
\hline Smith et al. (2001) & Nov. 1997 & 49 & 0.80 \\
\hline Smith et al. (2001) & Nov. 1997 & 45 & 1.20 \\
\hline Smith (2001) & Oct. 1999 & 29 & $1.20-1.40$ \\
\hline Smith (2001) & Oct. 1999 & 32 & 1.45 \\
\hline Smith et al. (2001) & Oct. 2000 & 26 & 1.50 \\
\hline Smith et al. (2001) & Oct. 2000 & 38 & 1.30 \\
\hline Leonard et al. (2006) & Sep. 2003 & 43 & 1.13 \\
\hline
\end{tabular}

Table 3.1: The percentage of sea ice consisting of platelets and the depths at which they first appeared. Taken from a number of seasons work by Smith et al. (2001), Smith (2001) and Leonard et al. (2006). From Leonard et al. (2006).

unconsolidated (loose) platelet ice beneath the ice-water interface.

Platelet ice has also been found in the Arctic (Eicken, 1994; Jeffries et al. 1995). However, Jeffries et al. (1995) noted that these are unlikely to be caused by the smaller Arctic ice shelves. Instead they are probably due to melt ponds, where regions of the ice are heated, creating fresh water which interacts with the seawater below to create platelets. It is doubtful that this is a significant source of platelet ice in Antarctica as there is little melt water during times of platelet growth (Smith, 2001).

\subsection{Platelet inclusion in sea ice}

Table 3.1 also reveals an interesting phenomenon of platelet ice. With one exception, platelets only appear in an ice core after at least $1 \mathrm{~m}$ of growth has occurred. Similar results are shown in Figure 3.4 where platelet or mixed congelation/platelet ice first appear after a significant period of congelation growth. Few reasons have been given to explain this delay. Gow and Tucker III (1991) suggested that platelet ice's late appearance in 


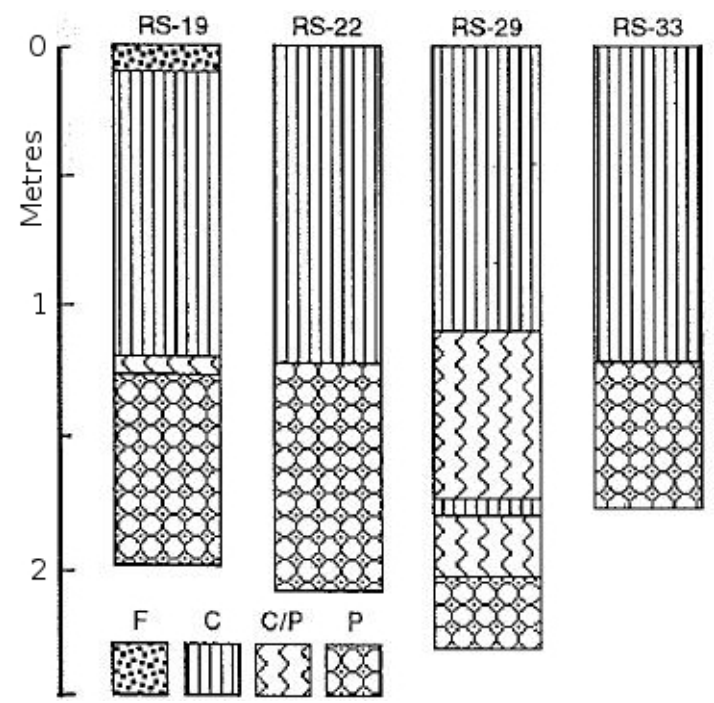

Figure 3.4: Four cores taken by Jeffries et al. (1993) in $\mathrm{M}^{c}$ Murdo Sound. Columnar (C), columnar/platelet $(\mathrm{C} / \mathrm{P})$ and platelet ice $(\mathrm{P})$ dominate the growth with only a small amount of initial frazil ice (F) in core RS-19. Platelets only appear after at least $1 \mathrm{~m}$ of ice growth.

$\mathrm{M}^{c}$ Murdo Sound could be "related in some way to changes in the composition or circulation patterns of seawater".

Frazil and platelet ice have been observed at the ice-water interface and below without being found in ice cores (Gow et al. 1982; Leonard et al. 2006). Jeffries and Weeks (1992) also discuss platelet accumulation at the interface before interstitial congelation ice freezes them in place. Again, no reason is given as to why this only occurs in the latter part of the winter season. The remainder of this chapter will look at the velocities required to keep crystals in suspension and the possibility that tidal flow may be sufficient to achieve this. Chapter 4 will then build on a theory developed in $M^{c}$ Guinness et al. (2009), considering what effect brine rejection from the growing ice may have on the rising crystals. 


\subsection{The Shields Criterion}

One of the first investigations into frazil motion was performed by Jenkins and Bombosch (1995) who considered the motion of frazil in a buoyant water plume underneath an ice shelf. As the plume swept below the shelf, they wanted to predict the possibility of frazil being deposited on to the bottom of the ice shelf. In doing so they used the Shields criterion to predict a critical velocity above which the frazil would be kept in suspension. The Shields criterion is a theory traditionally used to predict the fluid velocity required to lift sediment from an ocean or river bed (Miller et al. 1977). This section will extend the work of Jenkins and Bombosch (1995) for a greater range of frazil sizes, being kept in motion below an ice-water interface.

For the case of a frazil crystal in the ocean, the Shields parameter is a dimensionless variable which, when it exceeds a critical value, indicates that the crystal will be kept in motion. It would therefore be prevented from adhering to the interface. For a sphere it is defined as

$$
\theta_{s}=\frac{\rho_{w} u_{*}^{2}}{\left(\rho_{w}-\rho_{i}\right) g d_{e}}
$$

where $\rho_{w}$ and $\rho_{i}$ are the density of sea-water and ice respectively, taken to be constant and equal to $1030 \mathrm{~kg} \cdot \mathrm{m}^{-3}$ and $910 \mathrm{~kg} \cdot \mathrm{m}^{-3}$, while $g$ is the acceleration due to gravity $\left(9.81 \mathrm{~m} . \mathrm{s}^{-1}\right)$ and $u_{*}$ the friction velocity (e.g. Miller et al. (1977); Reid and Frostick (1994); Jenkins and Bombosch (1995); Robert (2003)). To adjust the criterion for a disc, $d_{e}$ (normally the sphere diameter) becomes an effective diameter. This is the diameter of a sphere which would contain the same volume as the frazil crystal. The volume of a disc is

$$
V=\pi r_{d}^{2} t_{d}=2 \pi r_{d}^{3} \epsilon
$$


where $r_{d}$ is the radius of the disc, $t_{d}$ the thickness and $\epsilon$ the aspect ratio (crystal thickness divided by its diameter). This gives an effective radius of

$$
r_{e}=\frac{d_{e}}{2}=\left(\frac{3}{2} \epsilon\right)^{\frac{1}{3}} r_{d}
$$

The critical friction velocity is a measure of the flow speed which will keep a crystal in suspension (explained further in Section 3.6.1). By solving Equation 3.1 at the critical value of the Shields parameter, $\theta_{s c}$ and substituting Equation 3.3 this becomes

$$
u_{*, c r}=\eta \sqrt{\epsilon^{\frac{1}{3}} \theta_{s c} r_{d}}
$$

where

$$
\eta=\sqrt{\left(\frac{3}{2}\right)^{\frac{1}{3}} \frac{\left(\rho_{w}-\rho_{i}\right) g}{\rho_{w}}} \approx 1.14 .
$$

As well as the diameter of the frazil crystal, the critical velocity also depends on the aspect ratio of the crystal. This is a tricky feature to measure and a wide range of values can be found in the literature. Daly (1984) estimated it to be between 0.01 and 0.2, Holland and Feltham (2005) used a value of 0.02, Gosink and Osterkamp (1983) experimentally found 0.05, while Jenkins and Bombosch (1995) estimated 0.001 to 0.025 using numerical methods. A number of values will be compared in this work.

In Jenkins and Bombosch (1995) one of the key requirements was that the dimensionless grain Reynolds number was greater than 1 . The grain Reynolds number is a ratio of inertial forces to viscous forces and is defined as

$$
R e_{g}=\frac{u_{*} d}{\nu}
$$




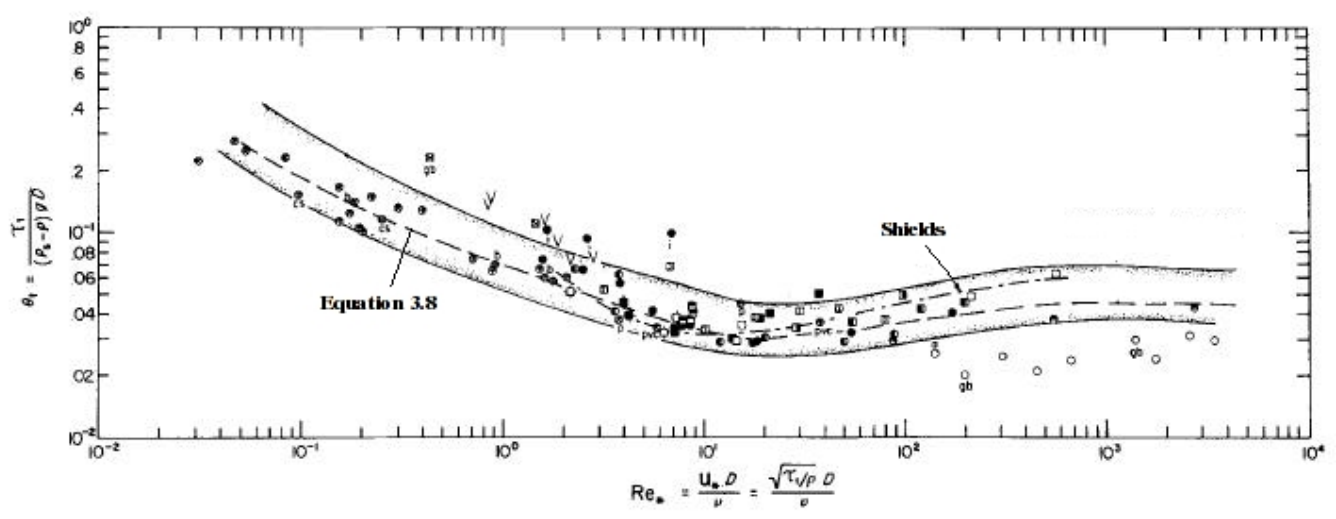

Figure 3.5: Curve describing the change in Shields parameter with grain Reynolds number, based on a large quantity of experimental data, as calculated in Miller et al. (1977). Also shown are Shields' approximation to his original curve (which did not include any data below an $R e_{g}$ of 1 ) and Equation 3.8

where $d$ is the diameter of the frazil disc and $\nu$ is the kinematic viscosity of the fluid (Miller et al., 1977; Gosink and Osterkamp, 1983; Jenkins and Bombosch, 1995). A crystal with a low grain Reynolds number behaves as though in a laminar region, while one with a high value acts as if in a turbulent region.

The requirement that $R e_{g}$ be greater than 1 was due to the change in the Shields parameter with grain Reynolds number. This variation is well documented in Miller et al. (1977) who, on the basis of a large collection of experimental data, defined a threshold curve for the Shields parameter. This curve, shown in Figure 3.5, describes a range of values for a single grain Reynolds number due to the variation in the commencement of sediment motion. For $R e_{g}$ greater than 1 the Shields parameter is, to a reasonable approximation, constant. Jenkins and Bombosch (1995) estimated it to be between 0.025 and 0.08 . However, as $R e_{g}$ decreases below $1, \theta_{s c}$ increases significantly.

A grain Reynolds number of 1 , given a kinematic viscosity of $1.83 \times 10^{-6} \mathrm{~m}^{2} . \mathrm{s}^{-1}$ for sea-water $\left(\right.$ at $\left.0^{\circ} \mathrm{C}\right)$ and a friction velocity of $1 \mathrm{~cm} \cdot \mathrm{s}^{-1}$ 
(see Section 3.6.1), implies a crystal radius of around $1 \mathrm{~mm}$. An increase in disc size gives a larger Reynolds number. This matches the value found by Jenkins and Bombosch (1995). It is also similar to results from Daly (1984), who found discs changing from acting as though in a laminar environment to a turbulent one at a grain Reynolds number of this order. In a natural environment, crystals with a radius greater than $1.4 \mathrm{~mm}$ are rare (Daly, 1984: Holland et al., 2007). Crystals smaller than $1 \mathrm{~mm}$ are common. This indicates that extending the work for the Shields parameter below a grain Reynolds number of 1 is important.

In his original work Shields suggested that, for $R e_{g}$ less than 1 , a function of the form

$$
\theta_{s c} \propto R e_{g}^{-0.5}
$$

was appropriate. However, as Shields had no data in this range, it could not be confirmed (Miller et al., 1977). Amongst others, Miller et al. (1977) and Cao et al. (2006) have provided alternative formulations. These are, respectively,

$$
\begin{aligned}
& \theta_{s c}=0.075 R e_{g}^{-0.41} \\
& \theta_{s c}=0.1414 R e_{g}^{-0.2306} .
\end{aligned}
$$

Knowing the value of the Shields parameter, and using Equation 3.4. it is possible to find the critical friction velocity required to keep a frazil crystal in suspension. Figure 3.6 shows how $u_{*, c r}$ varies with the radius for different Shields parameter values. Above a crystal radius of $1 \mathrm{~mm}$ a range of Shields parameter values are plotted. These show that a greater $\theta_{s c}$ results in a greater critical friction velocity. The equations describing $\theta_{s c}$ below $1 \mathrm{~mm}$ are single line approximations. As such they do not indicate the range of values which the Shields parameter may take. However, the 


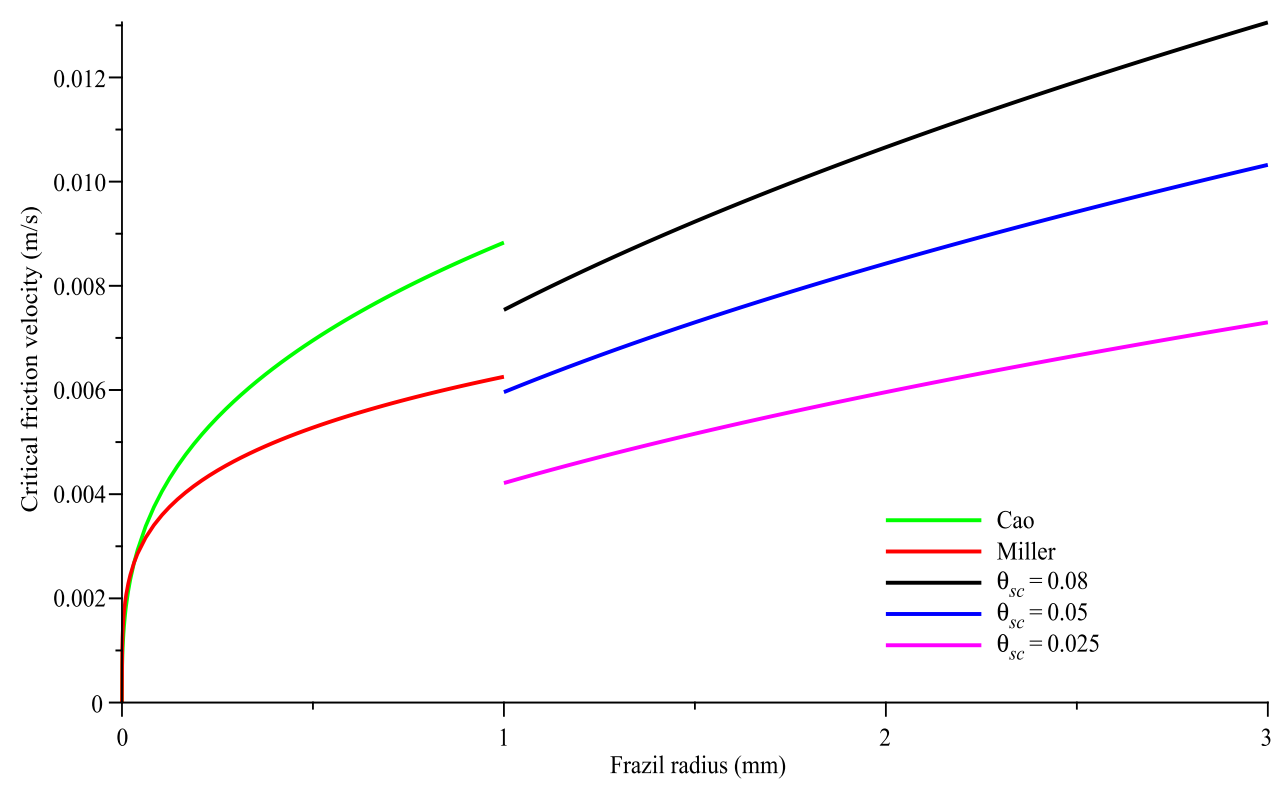

Figure 3.6: Critical friction velocities for the Shields criterion for different values of the Shields parameter $\theta_{s c}$. For a given radius, friction velocities above the curves will keep a frazil disc in suspension. The aspect ratio is set to 0.02 .

equation from Cao et al. (2006) is close to the top of the range shown in Figure 3.5 and thus is taken as a maximum bound. Assuming a smooth transition between the two regions, Miller et al.'s (1977) approximation appears a more accurate representation

Figure 3.7 compares the effects of different aspect ratios. Crystals with a greater aspect ratio (and therefore a greater volume) are more buoyant. They therefore require greater turbulence to remain in suspension. Again, Cao's (2006) formula, especially for the largest aspect ratio, appears to predict an overly high critical friction velocity. 


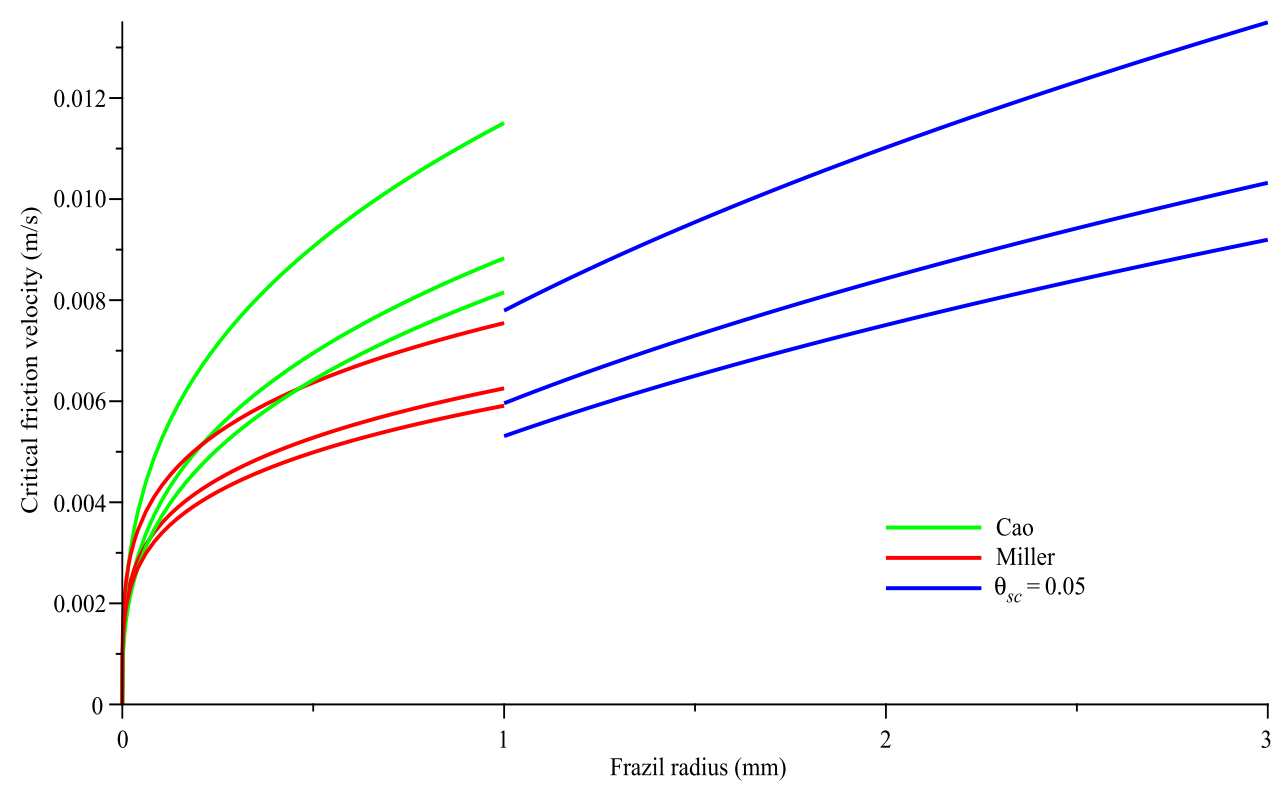

Figure 3.7: Critical friction velocities for the Shields criterion for varying values of the aspect ratio $\epsilon$. For each set of plots the aspect ratio, $\epsilon$, is, from top to bottom, $0.2,0.02$ and 0.01 . For a given radius, friction velocities above the curves will keep a frazil disc in suspension. The Shields parameter is set to 0.05 for radii greater than $1 \mathrm{~mm}$.

\subsection{Shear results}

\subsubsection{Tidal and friction velocity}

This section will investigate the possibility that shear induced turbulence is strong enough to keep frazil crystals in motion. Comparisons will be made between the friction velocity induced by tidal flow below sea ice with the critical velocities found in Section 3.5. The possibility that this is a valid explanation for the late appearance of platelets in first-year sea ice cores will then be discussed.

The tides show various patterns over different time scales. $\mathrm{M}^{c}$ Murdo Sound experiences both a daily (24-hour) change and a fortnightly (13.7day) change (Arrigo et al., 1995: Leonard et al., 2006). A similar pattern has 
been observed in the Weddell Sea (Isla et al. 2006). During these periods the velocities cycle between a maximum and minimum value. As well as the time dependence, tidal velocities also vary with depth. The flow has a maximum velocity equidistance from the ice-water interface and the ocean bottom. This is caused by friction slowing the water movement (Heath, 1971).

Tidal flow acts horizontally on to the ice-water interface. As frazil crystals are rising vertically, the entire flow does not act to impede the ascent of the crystals. Instead the natural roughness of the sea ice creates a mechanism for the water to become turbulent. The friction velocity is a measure of this turbulence ( $\mathrm{M}^{c}$ Phee, 1987) and, if it exceeds the critical value found using the Shields criterion, will keep frazil from settling against the interface. It can be parameterized in terms of the local shear velocity and a dimensionless drag coefficient $K$ (Omstedt and Wettlaufer, 1992; Jenkins and Bombosch, 1995: Holland and Jenkins, 1999), such that

$$
u_{*}^{2}=K U^{2} .
$$

Values found for $K$ are of the order of $10^{-3}$. Some examples include 0.0025 in Jenkins and Bombosch (1995), 0.0015 in Holland and Jenkins (1999), and 0.0054 from Shirasawa and Ingram (1997).

The shear velocity is based on both the tidal flow, any prevailing current and the velocity of the sea ice itself. For land-fast sea ice the ice movement is minor and will not be considered further. Velocity flow measurements have been made at a variety of depths. Between $400 \mathrm{~m}$ and $500 \mathrm{~m}$ deep in the Weddell Sea, Isla et al. (2006) found tidal velocities measuring from $0 \mathrm{~cm} . \mathrm{s}^{-1}$ to over $30 \mathrm{~cm} \cdot \mathrm{s}^{-1}$, averaging between $7.7 \mathrm{~cm} . \mathrm{s}^{-1}$ and $9.5 \mathrm{~cm} \cdot \mathrm{s}^{-1}$. Comparable results were found at depths of $100 \mathrm{~m}$ to $250 \mathrm{~m}$ (Foldvik et al., 1985). Tidal flow strengths in $\mathrm{M}^{c}$ Murdo Sound are similar, though Heath (1971) found a maximum average value of $28 \mathrm{~cm} \cdot \mathrm{s}^{-1}$ at $200 \mathrm{~m}$. However, as mentioned, the flow drops away closer to the inter- 


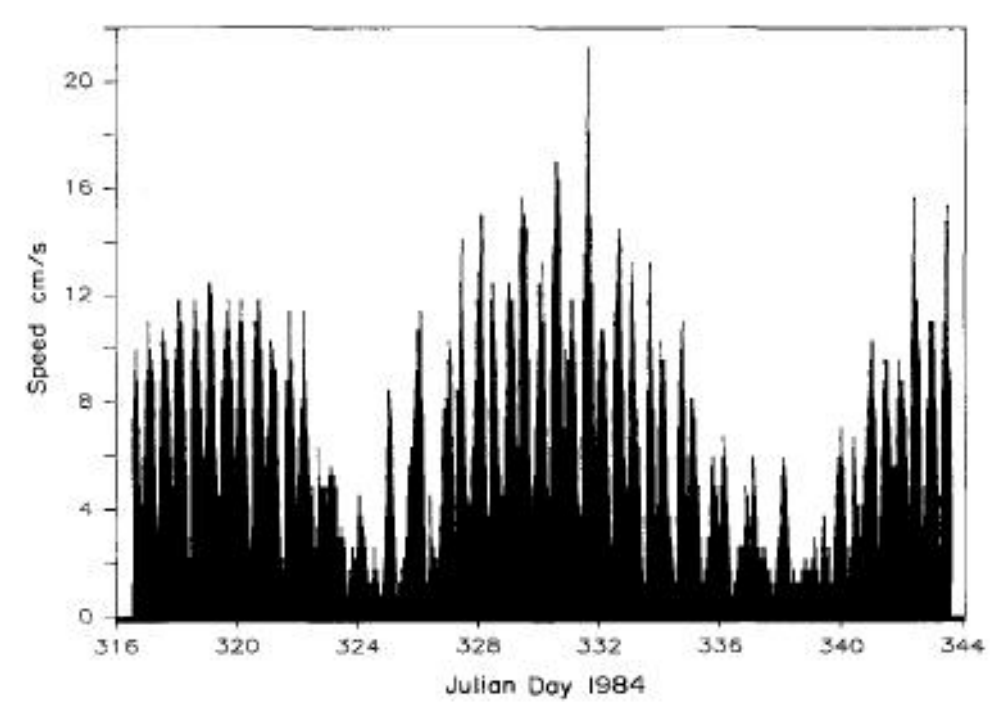

Figure 3.8: Tidal velocities are shown for a location in $\mathrm{M}^{c}$ Murdo Sound. Clearly visible are both the daily and fortnightly tidal strength cycles. The maximum velocity is just over $20 \mathrm{~cm} \cdot \mathrm{s}^{-1}$. From Barry and Dayton (1988).

face. In Heath's study, close to the edge of the sea ice, an average surface velocity of $11 \mathrm{~cm} \cdot \mathrm{s}^{-1}$ was measured. Barry and Dayton (1988) found velocities up to $21 \mathrm{~cm} \cdot \mathrm{s}^{-1}$ with a mean of $7.6 \mathrm{~cm} \cdot \mathrm{s}^{-1}$ at the surface. More recent measurements in $\mathrm{M}^{c}$ Murdo Sound by Leonard et al. (2006) show a maximum of around $20 \mathrm{~cm} \cdot \mathrm{s}^{-1}$.

Given an average shear flow of $10 \mathrm{~cm} \cdot \mathrm{s}^{-1}$, Equation 3.10 predicts friction velocities of between $0.5 \mathrm{~cm} \cdot \mathrm{s}^{-1}$ and $0.8 \mathrm{~cm} \cdot \mathrm{s}^{-1}$ depending on the value of $K$. During periods of maximum flow, however, $u_{*}$ can rise to over $2 \mathrm{~cm} \cdot \mathrm{s}^{-1}$. $\mathrm{M}^{c}$ Phee (1992, 1994) made field measurements of the friction velocity. In the $\mathrm{M}^{c}$ Murdo Sound he found it varied between $0 \mathrm{~cm} \cdot \mathrm{s}^{-1}$ and $2 \mathrm{~cm} . \mathrm{s}^{-1}$, averaging $1 \mathrm{~cm} \cdot \mathrm{s}^{-1}$ at $1 \mathrm{~m}$ depth. More recent work in the Weddell Sea found friction velocities up to $3 \mathrm{~cm} \cdot \mathrm{s}^{-1}$ with a mean value of $1.5 \mathrm{~cm} \cdot \mathrm{s}^{-1}$ ( $\mathrm{M}^{c}$ Phee et al. 1999). The difference between the (average) calculated results and those measured could be due to uncertainty in the value of $K$. With the results of $\mathrm{M}^{c}$ Phee being direct measurements made in the regions of interest, these are favoured. Therefore, as in Notz (2005), 
a friction velocity of $1 \mathrm{~cm} \cdot \mathrm{s}^{-1}$ will be used for the majority of the work.

\subsubsection{Frazil in suspense?}

A comparison between the friction velocity induced by tidal flow and the velocity required to keep frazil in suspension is now possible. Figure 3.9 shows the critical velocity required to keep frazil in suspension for average values of the Shields parameter and the aspect ratio. When compared with a friction velocity of $1 \mathrm{~cm} \cdot \mathrm{s}^{-1}$ nearly all crystals smaller than a radius of $3 \mathrm{~mm}$ are unable to rise and stick to the interface. In fact, even increasing $\theta_{s c}$ to 0.08 or $\epsilon$ to 0.2 (not shown), frazil larger than $1.5 \mathrm{~mm}$ remain in suspension. A similar result is found if the friction velocity is reduced to $0.7 \mathrm{~cm} \cdot \mathrm{s}^{-1}$. Given that frazil larger than $1.4 \mathrm{~mm}$ are rarely found beneath the ice-water interface (Daly, 1984; Holland et al., 2007), this suggests that tidal-induced turbulence is strong enough to prevent the inclusion of frazil into the ice during growth.

However, tidal flow as the sole cause of oceanic stirring fails to answer some key questions:

- Tidal flow is not dependent on ice thickness. As raised in Section 3.4 . platelets (possibly the end result of frazil inclusion) are only observed after sea ice has grown to a depth of $1 \mathrm{~m}$. However, tidal flow does not decrease as the ice thickens. Hence, if frazil is kept in suspension initially, it will remain unattached without a decrease in the flow strength.

- As apparent in Figure 3.8, tidal flow drops greatly as the tide turns. Though all turbulence may not dissipate before the flow picks up again (with prevailing currents remaining), a drop in its strength could potentially allow frazil to stick (up) to the ice. This could occur at any ice thickness. 


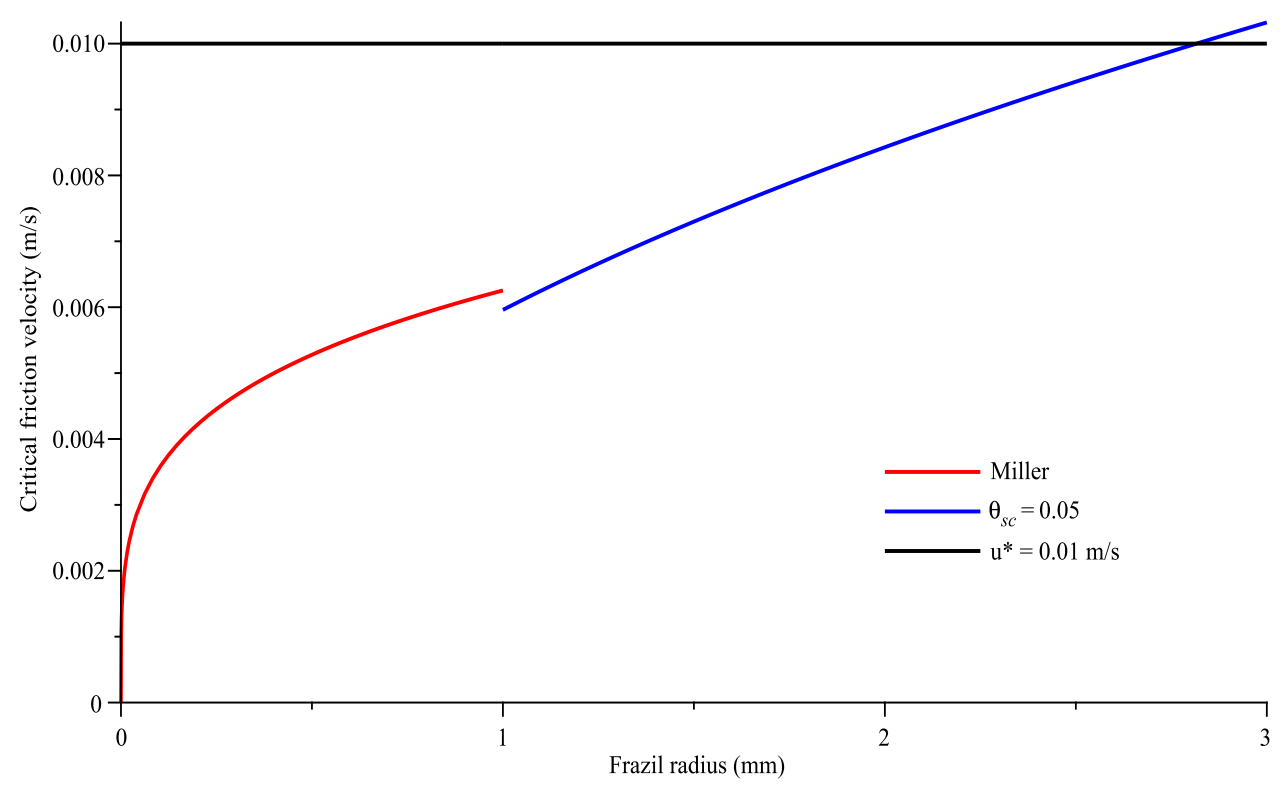

Figure 3.9: A comparison between the friction velocity required to keep frazil ice in suspension as predicted by the Shields criterion and that present at the interface. The Shields parameter values are those predicted by Miller et al. (1977), below $R_{g}=1$, and a constant value of 0.050 above. Crystals are predicted to stay in suspension until they are nearly $3 \mathrm{~mm}$ in radius.

\subsection{Summary}

This chapter has discussed the difference between frazil and platelet crystals and introduced the platelet puzzle. This is the phenomenon whereby, though platelet ice is known to be a significant method of growth in certain regions of the Antarctic, the platelets appear in an ice cover only after around one metre of congelation growth has occurred. Also introduced was the idea that frazil crystals, which may form directly beneath the ice or be transported from nearby ice shelves, could rise and attach to the icewater interface. These could then grow into the platelet ice found in ice cores.

Shear flow, caused by tidal and current movement, was suggested as a possible explanation as to why frazil crystals cannot be incorporated into 
the ice cover early on in the winter growth season. The water movement keeps the crystals in motion and prevents them from settling against the interface. The Shields criterion was used to determine the friction velocity which would be required to keep a crystal in motion, depending on its radius. It was shown that a typical friction velocity of $1 \mathrm{~cm} \cdot \mathrm{s}^{-1}$ would keep crystals from sticking to the interface until they were nearly $3 \mathrm{~mm}$ in radius. This is large for a naturally occurring frazil crystal.

However, this alone does not explain the platelet puzzle. A crystal kept in suspension early on in the growth season will be kept in suspension even after the one metre ice thickness threshold has been passed. There is nothing in this system which changes as the ice grows. If the shear flow remains sufficiently strong throughout the growth season, another factor must be included which could "damp" the turbulence. This would need to build up as the winter season progressed. This idea will be discussed in Chapter 6 .

One other question which was raised is what happens when the tide turns. Though a prevailing current may still exist, a decrease in the tidal flow could significantly lower the friction velocity. During these periods, frazil crystals may be able to rise and settle against the ice-water interface. However, again, this is not a factor which changes as the ice grows. Hence, there would need to be another element in the system which could keep the crystals away from the interface during these periods of low tidal flow. Ideally, this would decrease as the ice thickness increased, allowing the crystals to rise after a period of growth. This will be the focus of the following chapter. 


\section{Chapter 4}

\section{Stirring due to brine rejection}

In the previous chapter the effect of tidally induced shear flow on frazil was investigated. It was shown that, on average, these tides are sufficiently strong to prevent frazil from settling against the interface and sticking in place. However, this did not explain the phenomenon that platelet crystals, which frazil can become after adhesion to the interface, do not appear until significant growth of sea ice occurs. It also failed to explain why, during times of low shear flow, such as a drop off in the turbulent velocity during the turning of the tides, frazil did not attach to the growing ice cover.

$\mathrm{M}^{c}$ Guinness et al. (2009) suggested a new theory in an attempt to answer these two questions. Their idea was that brine, released by sea ice during freezing, could counteract the frazil crystals' rise velocity, keeping them in suspension. While shear flow may keep frazil in motion, as the tides turn, brine rejection could become the dominant turbulence mechanism. As the sea ice grows thicker less brine is rejected, decreasing the velocity associated with brine rejection. Eventually, crystals may be able to rise and stick to the interface during periods of low shear flow. The attached frazil could then grow into platelets as the next tidal flow prevents further seeding. 


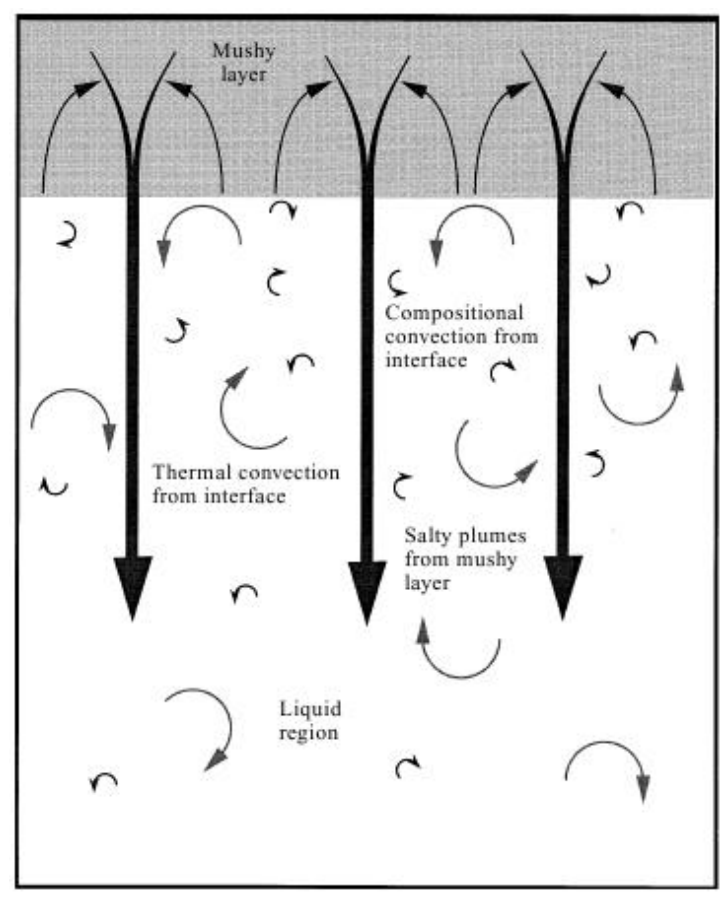

Figure 4.1: Brine channels (large central arrows) release a significant salt flux. Turbulence may also be created from salt released at the interface as it advances through freezing. The highly concentrated brine is replaced in the ice by less salty seawater. From Wettlaufer et al. (1997a).

\subsection{Brine Rejection}

While salts can dissolve easily in water, in ice they are nearly insoluble. Therefore, as ice freezes it rejects highly concentrated brine into the sea below. As the congelation ice forms, some brine remains between the ice dendrites (the projecting ice crystals) which grow downwards. Small ice "bridges" form between adjacent dendrites and trap the brine (Wadhams. 2003). The brine becomes more concentrated as water from the mixture freezes, forcing the mixture into a smaller area. However, as long as the temperature remains above the eutectic temperature ${ }^{1}$ for a given salt, the

\footnotetext{
${ }^{1}$ The temperature at which the remaining mixture of salt and water freezes at the same time.
} 
brine remains in liquid form (Vrbka and Jungwirth, 2005). Brine pockets and channels exist throughout the ice, and move through it until a system of long, thin channels is formed through which the brine can escape (Eicken, 2003). These channels have been observed to emit a significant salt flux. The turbulence patterns they can potentially create can be seen in Figure 4.1 (Wettlaufer et al., 1997a). As discussed in Section 2.3, work by Notz (2005) found that, in winter, gravity drainage was the dominant mechanism in the movement of brine out of the ice.

Systems of brine tubes generally consist of a larger central brine channel to which a number of smaller tubes are linked. The central channels can extend well into the ice, up to $1 \mathrm{~m}$ in length and several centimetres wide, with a frequency in the region of 1 per $10 \mathrm{~cm}^{2}$ (Wettlaufer et al. 1997a: Eicken, 2003). Smaller brine tubes, with diameters in the order of $1 \mathrm{~mm}$ or less, are far more concentrated. Figure 4.2 shows a vertical ice section with a large drainage channel extending from top to bottom. Surrounding it, and with a greater concentration near the interface, are brine tubes varying in diameter from $0.3-0.5 \mathrm{~mm}$. In the experiments of Lake and Lewis (1970) these tubes had an average concentration of 42 tubes per $\mathrm{cm}^{2}$.

It has been found that there is a delay in the onset of brine release from the sea ice. Instead of commencing as ice begins to freeze, growth of up to $8 \mathrm{~cm}$ can occur before any significant salt flux is seen (Wettlaufer et al. 1997a b; : Worster and Wettlaufer, 1997). If frazil crystals were able to rise and stick to the ice-mixture during this time, however, they would be largely indistinguishable from the frazil layer and transition zone which normally occur at the onset of sea ice growth (Section 2.2). This delay is therefore unimportant in the following analysis.

At the interface brine tubes have a spacing of, on average, around $1.2 \mathrm{~mm}$ between adjacent tubes. Frazil with the largest rise velocities can have diameters of up to $2.8 \mathrm{~mm}$. It is therefore likely that even near the interface, before the turbulence induced by the ejected brine plume begins 


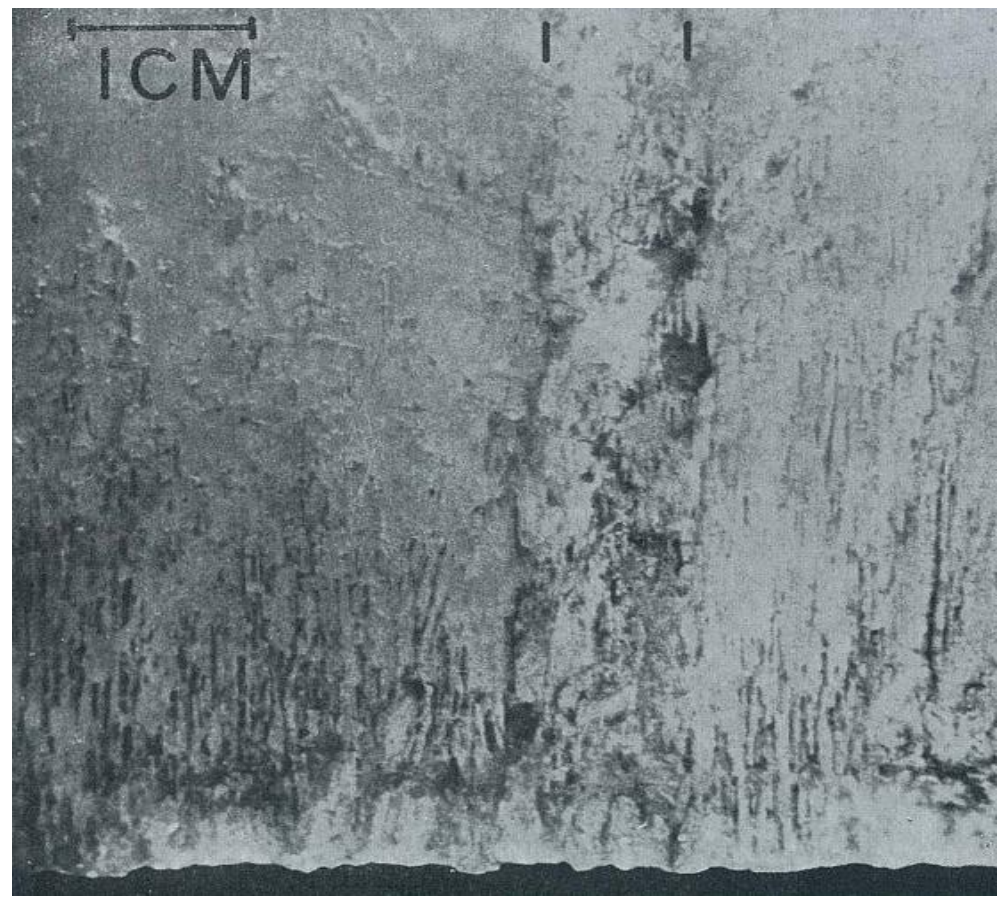

Figure 4.2: A vertical sea ice thin section from an experiment of Lake and Lewis (1970). A large central brine channel can be observed running the entire length of the ice, its width marked by the black lines. Smaller brine tubes are also visible and increase in concentration towards the interface.

to spread, there will be interaction between the crystals and the dense water. It seems reasonable to assume that this will have an effect on the rise rate of the frazil.

\subsection{Stokes' flow}

In the previous chapter, the Shields criterion was used to calculate whether a horizontal flow may prevent frazil crystals from rising. With brine plumes, the velocity opposing the frazil's motion is acting vertically. In this situation it is possible to use Stokes' law to model the rise velocities of the crystals (Streeter and Wylie, 1975). Though used primarily for a Reynolds number less than 1, a comparison will be made to check its va- 
lidity over the range of natural crystal radii. The calculated rise velocity can then be compared to the brine plume velocity to find if frazil is kept in suspension.

Stokes' law balances the buoyant force and the drag force on an object,

$$
\begin{aligned}
\text { Buoyancy } & =V_{s}\left(\rho_{w}-\rho_{i}\right) g \\
\text { Drag } & =6 \mu \pi r_{s} u_{S t}
\end{aligned}
$$

where $\mu$ is the dynamic viscosity of seawater, while $V_{s}$ and $r_{s}$ are the volume and radius of a rising sphere, respectively. This gives the rise velocity predicted by Stokes' Law as

$$
u_{S t}=\frac{V_{s}\left(\rho_{w}-\rho_{i}\right) g}{6 \mu \pi r_{s}} .
$$

This must be modified to allow for a disc as opposed to a sphere. In this situation, $V_{s}$ simply becomes $V$, the volume of the disc. An effective radius, $R$, is substituted for $r_{s}$. Daly (1984) used the radius of a sphere with the same volume as the disc (as for Shields' criterion, Equation 3.3) to calculate the rise velocity of frazil crystals. However, a more accurate $R$ can be found in Lamb (1932). He found, by analysing the stream lines around a disc, that $R$ for a disc moving with its flat side perpendicular to the direction of motion was equal to $8 r_{d} / 3 \pi$ (where $r_{d}$ is the radius of the disc). For a disc rising with its face parallel to the direction of motion, resistance to movement decreases. $R$ becomes $16 r_{d} / 9 \pi, 2 / 3$ that of the perpendicular case. This raises the question of the orientation of a rising frazil crystal.

\subsubsection{Crystal buoyancy}

Those in the literature who note the nature of a rising crystal agree that the most likely orientation is with the flat side parallel to the ice-water or 


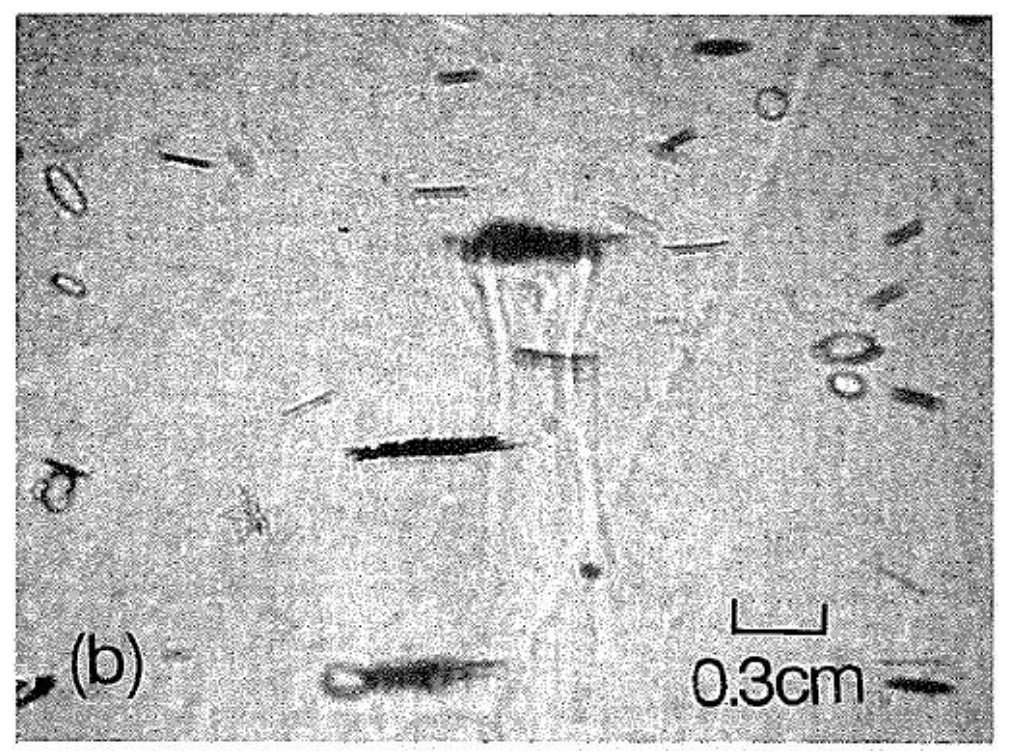

Figure 4.3: Image taken in still water which shows frazil rising as streams of brine descend from the sides of the growing crystals. It can be seen that the discs are rising predominantly with their flat sides parallel to the ice-water interface. From Ushio and Wakatsuchi (1993).

air-water interface Gosink and Osterkamp (1983); Daly (1984); Wuebben (1984). This would have them moving with the flat side perpendicular to the direction of motion in the terms described above. Laboratory experiments by Ushio and Wakatsuchi (1993) have shown that, in still water, this rise position appears to be the most stable for rising frazil (see Figure 4.3).

The motion of a buoyant frazil crystal has a close parallel to that of a falling disc. A disc dropping with its face parallel to its motion has a lower drag coefficient and theoretically a more rapid descent (Lamb, 1932). However, whether or not a disc will retain a given orientation depends on the disc's Reynolds number,

$$
R e_{d}=\frac{u d}{\nu}
$$

where $u$ is the velocity of the moving disc, $d$ is its diameter and $\nu$ is the 


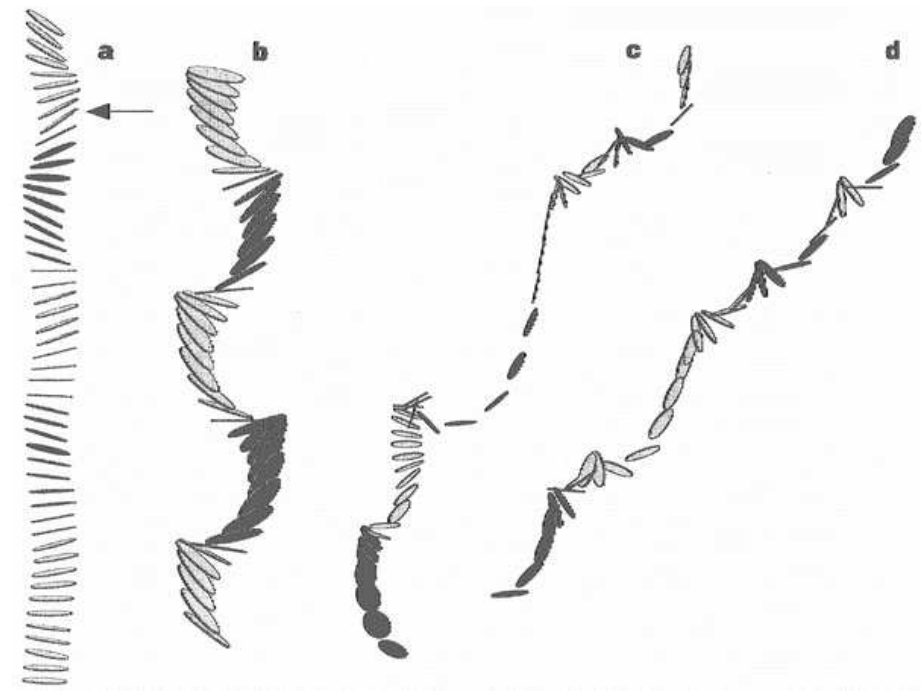

Figure 4.4: Possible trajectories of a descending disc with various Reynolds numbers. (a) shows a disc keeping a steady position with its face perpendicular to its motion at lower Reynolds numbers. For higher $R e_{d}$ and increasing dimensionless moment of inertia; (b) shows periodic-oscillating motion; (c) is chaotic motion with tumbling and oscillations; and (d) is tumbling motion with the disc drifting in one direction. From Field et al. (1997).

kinematic viscosity of the fluid (Willmarth et al., 1963, 1964). Values of the Reynolds number are very similar to those for the grain Reynolds number, in the region of 1 for a $1 \mathrm{~mm}$ crystal (Section 3.5).

Experiments on discs of various sizes and densities in still water are difficult for a Reynolds number less than 1. However, Field et al. (1997) found that, for low Reynolds numbers, a disc dropped with any initial orientation would adjust itself until it fell with its face perpendicular to its motion. Similar results were found by Willmarth et al. (1963, 1964) for $R e_{d}$ between 1 and 100. Higher Reynolds numbers lead to chaotic motion where the disc may tumble, rotate, or pitch side to side. These trajectories are described in Figure 4.4 . 
Also important is the dimensionless moment of inertia,

$$
I=\frac{I_{\text {disc }}}{\rho_{w} d}=\frac{\pi \rho_{i} \epsilon}{64 \rho_{w}}
$$

where $I_{\text {disc }}$ is the inertia of the disc (Field et al., 1997). As $I$ increases a crystal experiences greater oscillations and tumbling motions (moving from $b$ to d in Figure 4.4. For a mid-sized frazil crystal $I \sim 10^{-3}$. This indicates that frazil motion will be similar to that described by $\mathrm{a}$ and $\mathrm{b}$ in Figure 4.4 . depending on the size of the Reynolds number. For the most part, a crystal in still water will therefore rise with its face perpendicular to its direction of motion, even though this gives greater resistance. Similar conclusions were reached by Smith (2001).

External fluid turbulence may affect a crystal's motion causing a more chaotic ascension. Daly (1984) noted that, in experiments performed in turbulent water, the crystals tend to "oscillate, glide and tumble", increasing drag. As this will slow the crystals' movement, the calculated rise velocities can be regarded as an upper bound. This assumption has also been used in Morse and Richard (2009).

\subsubsection{Rise velocities}

Substituting $R=8 r_{d} / 3 \pi$ for a frazil crystal rising flat side perpendicular to its motion into Equation 4.3 , the rise velocity for a frazil crystal can be modelled. In Figure 4.5 this is plotted for aspect ratios $\left(\frac{\text { thickness }}{\text { diameter }}\right)$ of 0.01 , 0.02 and 0.1 . The model results are compared with experiments performed by Gosink and Osterkamp (1983). It was noticed in these experiments that a smaller crystal may become entrained in a larger crystal's wake; hence the data for the smallest frazil may overestimate the rise velocity of a single crystal.

A crystal with a higher aspect ratio (and therefore a greater volume) has a more rapid rise velocity. However, it is apparent that an aspect ratio 


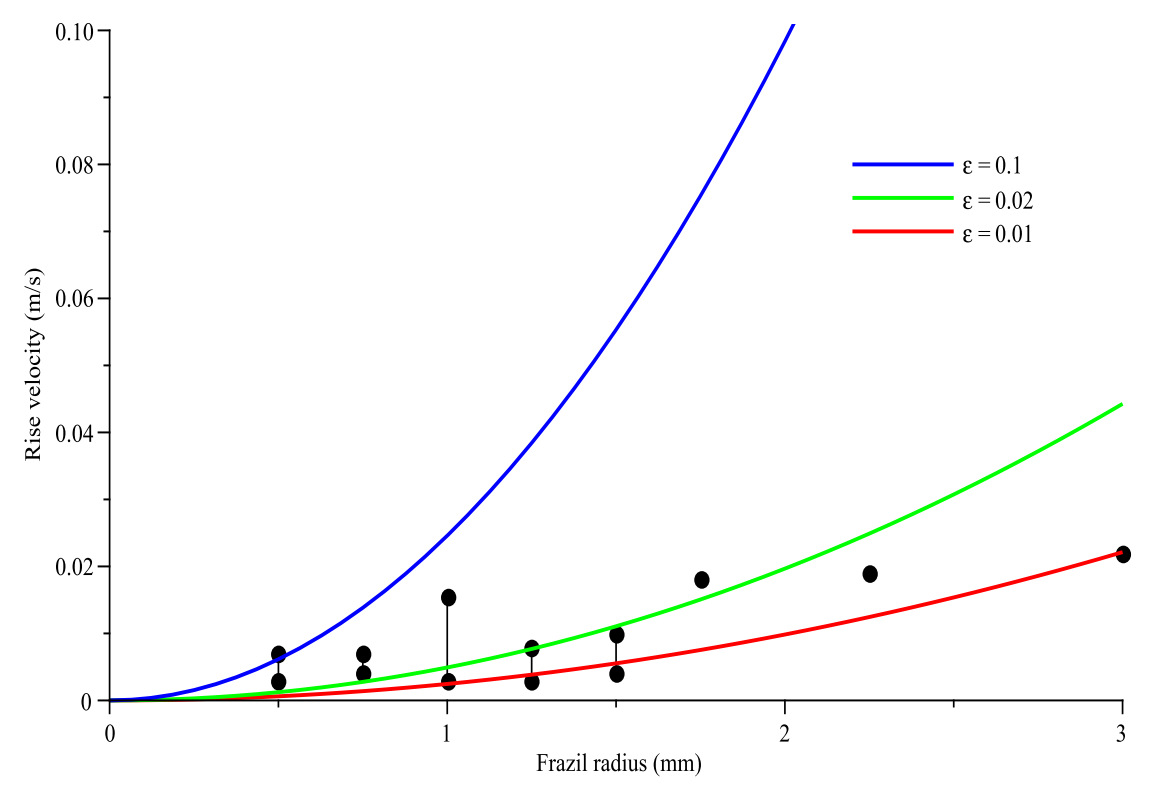

Figure 4.5: The rise velocity for a crystal with a radius up to $3 \mathrm{~mm}$ with its face parallel to the ice-water interface. Results are compared with values from Gosink and Osterkamp (1983). Plots for various values of the aspect ratio are shown.

of 0.1 greatly over-predicts the ascension rate of a frazil crystal. With few frazil crystals larger than $1.4 \mathrm{~mm}$, measurements in this range are sparse and thorough comparisons difficult. Even so, aspect ratios of 0.01 and 0.02 provide accurate predictions over the entire range.

The rise velocities of the frazil crystals is now known. For comparison, a model for the average downwards velocity of the brine plumes is required. This will be introduced in the following section.

\subsection{Brine rejection velocity}

Unlike friction velocities caused by tidal flow, measurements of the velocities of brine plumes are rare. Hence we follow the theory developed in $\mathrm{M}^{c}$ Guinness et al. (2009). Considering times of low shear, an alternative to the friction velocity used in Section 4.2.1 must be found. This brine- 
induced velocity can then be compared with the frazil rise velocities.

$\mathrm{M}^{c}$ Phee and Morison (2001) stated that, when turbulence is induced by a 'destabilizing buoyancy flux', $B$, (for example due to rapid freezing) it is appropriate to use the convective scale velocity,

$$
w_{*}=(\lambda B)^{\frac{1}{3}}
$$

where $\lambda$ is the length scale of the dominant eddies and

$$
B=\left\langle w^{\prime} b^{\prime}\right\rangle=\frac{g}{\rho_{w}}\left\langle\rho^{\prime} w^{\prime}\right\rangle
$$

where $g$ is the acceleration due to gravity and $\rho_{w}$ is the density of the seawater at the interface (see also Turner, 1979). The angle brackets can be regarded as the averaged, large-scale properties of the flow. As such, $\left\langle\rho^{\prime} w^{\prime}\right\rangle$ is the average downwards flux of density variations in the mixed layer (McGuinness et al. 2009).

The eddy length scale varies with the season. During times where there is little change in ice thickness, turbulence is localised below the interface with regions of largely isolated turbulence throughout the mixed layer. When significant melting occurs, the warmer, less saline water released is more buoyant than the mixed layer and provides a stabilising influence. Regions of turbulence still exist lower in the mixed layer. During ice growth, brine released during freezing creates a destabilising turbulence which extends the entire length of the mixed layer ( $\mathrm{M}^{c} \mathrm{Phee}$ and Morison, 2001). This is held in check by the halocline (Section 2.1) which is gradually entrained through the winter season (Leonard et al., 2006). The length scale is thus given as a fraction of the the mixed layer,

$$
\lambda=\kappa z_{m l}
$$




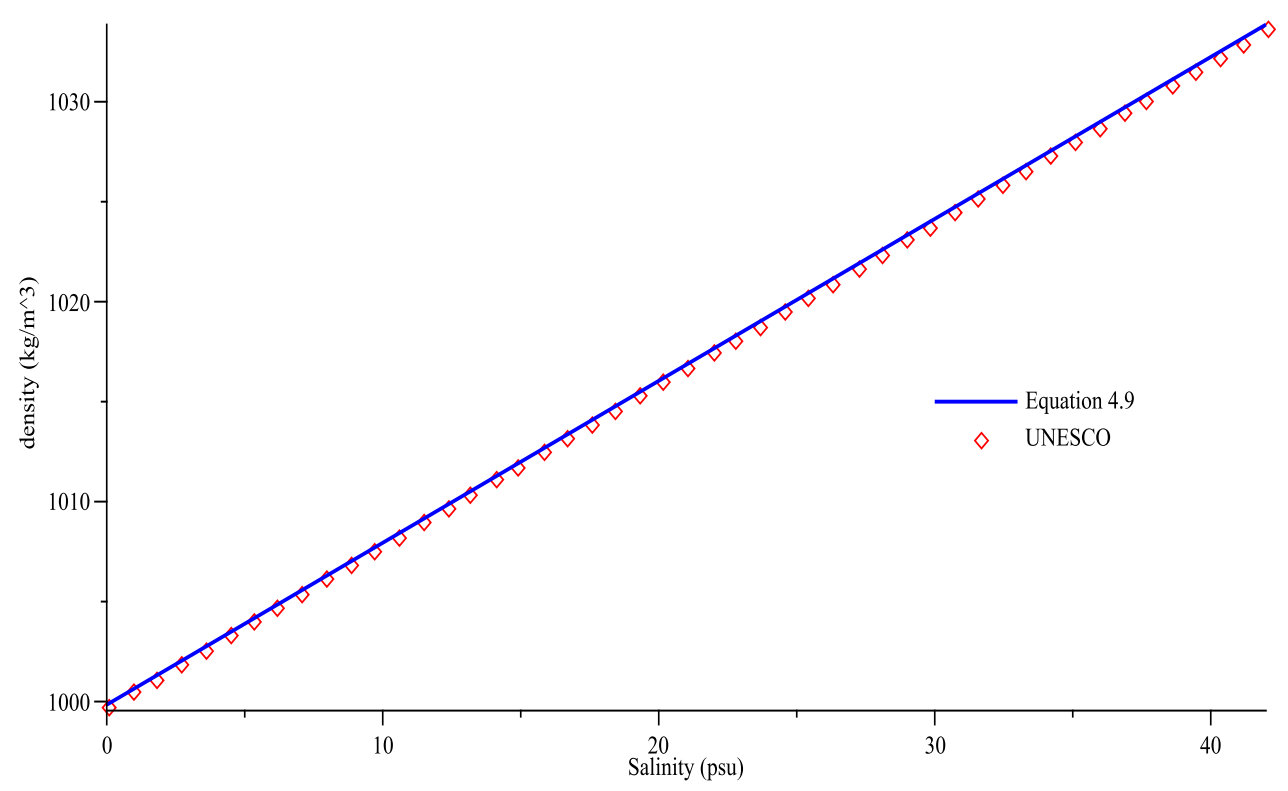

Figure 4.6: Comparing the equation of state for seawater density from UNESCO (1980) with Equation 4.9 for $\mathrm{T}=-1.89^{\circ} \mathrm{C} . \frac{d \rho_{w}}{d S}$ is set to $0.81 \mathrm{~kg} \cdot \mathrm{m}^{-3} \cdot \mathrm{psu}^{-1}$.

where $z_{m l}$ is the depth of the mixed layer and $\kappa$ is the von Kármán constant (McPhee and Morison, 2001).

\subsubsection{Density of seawater}

To find the flux of seawater density variations, the change of density with salinity and temperature is important. The "International Equation of State of Seawater" was published in UNESCO (1980). For the range of temperatures found below sea ice this equation is almost constant, with a far stronger dependency on the salinity. Given that the temperature at the ice-water interface is at or near freezing (between 0 and $-2{ }^{\circ} \mathrm{C}$ ), the density of seawater can be simplified to

$$
\rho_{w}=999.84+\frac{d \rho_{w}}{d S} S_{w}
$$


A comparison between this approximation and the original UNESCO equation for $\mathrm{T}=-1.89^{\circ} \mathrm{C}$ is shown in Figure 4.6 with a value of $0.81 \mathrm{~kg} \cdot \mathrm{m}^{-3} \cdot \mathrm{psu}^{-1}$ for $\frac{d \rho_{w}}{d S}$, the change in density with salinity. For example, a salinity of 35 psu gives a density of $1030 \mathrm{~kg} \cdot \mathrm{m}^{-3}$.

The equation of state for seawater in UNESCO (1978) is valid from 0 to $42 \mathrm{psu}$. Further work in UNESCO (1991) extended this to $50 \mathrm{psu}$. However, maximum salinities, especially in the brine tubes, may be greater than this. There is currently an investigation into extending the range of validity for density (and other seawater properties) up to $110 \mathrm{psu}$ using a Gibbs potential function (Feistel and Marion, 2007; $\mathrm{M}^{c}$ Dougall et al. 2009). Work so far has shown that a linear assumption for the change in density with salinity (for a constant temperature) remains accurate above 42 psu (Feistel and Marion, 2007). Comparing Equation 4.9 with the formula given in Feistel (2003) indicates that the approximation remains valid for a constant temperature up to $110 \mathrm{psu}$ (not shown).

Given that the theory considers a constant, average density, the buoyancy flux in Equation 4.7 becomes

$$
B=\frac{\frac{d \rho_{w}}{d S} g\left\langle S_{w}^{\prime} w^{\prime}\right\rangle}{\rho_{w}}
$$

where $\left\langle S_{w}^{\prime} w^{\prime}\right\rangle$ is a measure of the rate of salt flux out of the interface. This is found by taking the salt flux from the ice (see Appendix A) and dividing by the density of the seawater below. This gives

$$
\left\langle S_{w}^{\prime} w^{\prime}\right\rangle=\dot{h} \frac{\rho_{i}}{\rho_{w}}\left(S_{w}-S_{i}\right)
$$

with $\rho_{i}$ the density of the ice and $\dot{h}$ the rate of growth of the ice-water interface. $S_{i}$ is the salinity of the ice. Schmidt et al. (2004) found that the ice salinity was proportional to the salinity of the seawater from which it froze, such that $S_{i}=f S_{w}$. An appropriate value of $f$ for sea ice is 0.14 , 
while $S_{w}$ is approximated as the salinity of the mixed-layer, about $35 \mathrm{psu}$ in $\mathrm{M}^{c}$ Murdo Sound (see Section 4.5.1).

Substituting Equations 4.8, 4.10 and 4.11 into Equation 4.6 gives the average brine plume velocity, to be compared with the frazil crystal rise velocities, as

$$
w_{*}^{3}=\kappa z_{m l} g \frac{\rho_{i}}{\rho_{w}^{2}} S_{w}(1-f) \frac{d \rho_{w}}{d S} \dot{h}
$$

\subsection{Ice growth data}

Ice growth rates can vary greatly depending on location. However, both empirical formulae based on observation and theoretical equations are reasonably easy to find, a variety of which will be used in this work to estimate $h$. Anderson (1961) fitted a curve for ice thickness of between $10 \mathrm{~cm}$ and $80 \mathrm{~cm}$ from Thule, Greenland. Maykut (1986) cites the empirical results of Zubov from the Cape Schmidt region in Russia, and of Lebedev calculated from a range of stations throughout the Soviet Arctic. Ice thickness limits are not given for these equations, but they match well with Anderson's approximation up to 200 days of growth.

In Figure $4.7 \mathrm{a}$ the empirical results are compared, along with plots based on equations developed by Nakawo and Sinha (1981) and Maykut (1986). Including the effects of a constant snow cover on the ice, these equations are, assuming a linear temperature gradient in the snow and ice,

$$
\begin{aligned}
& \theta=\frac{\rho_{i} L}{2 k_{i}} h^{2}+\frac{\rho_{i} L h_{s}}{k_{s}} h \\
& \theta=\frac{\rho_{i} L}{2 k_{i}} h^{2}+\left(\frac{\rho_{i} L h_{s}}{k_{s}}+\frac{\rho_{i} L}{c_{t}}\right) h
\end{aligned}
$$

where $L$ is the latent heat due to freezing of seawater, $k_{i}$ and $k_{s}$ the thermal conductivities of ice and snow respectively and $h_{s}$ the thickness of the 


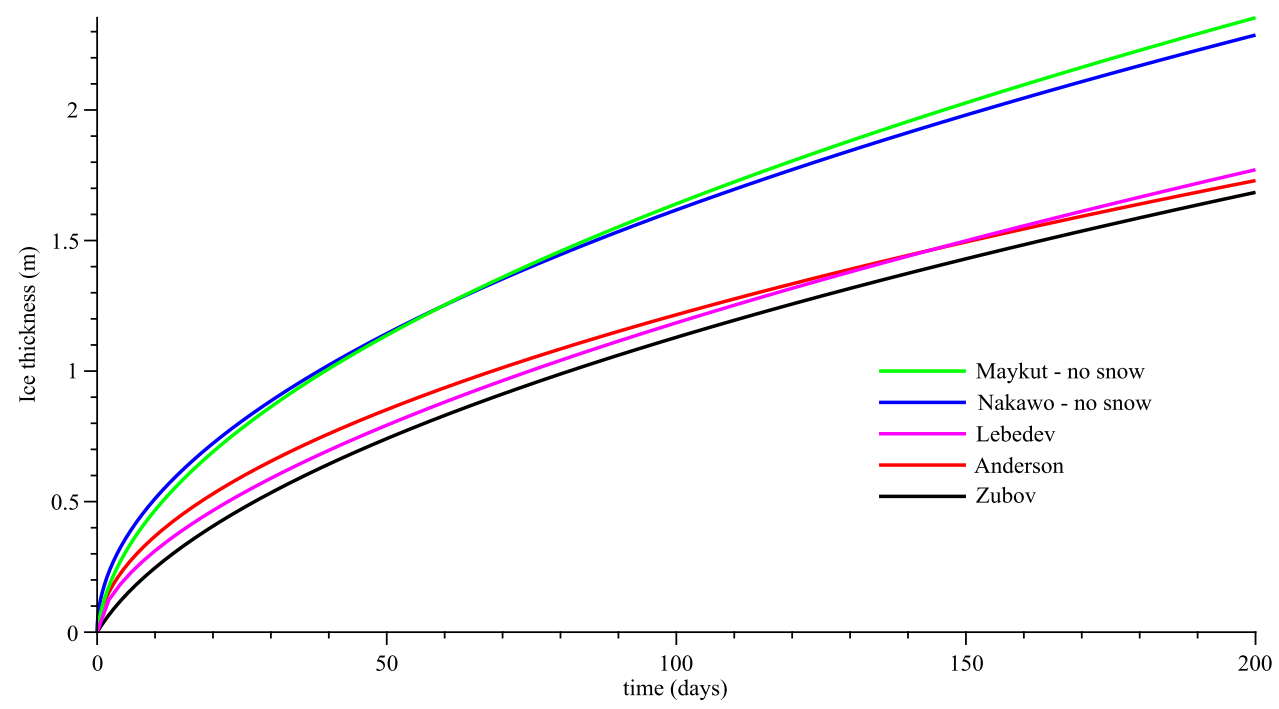

(a) Days

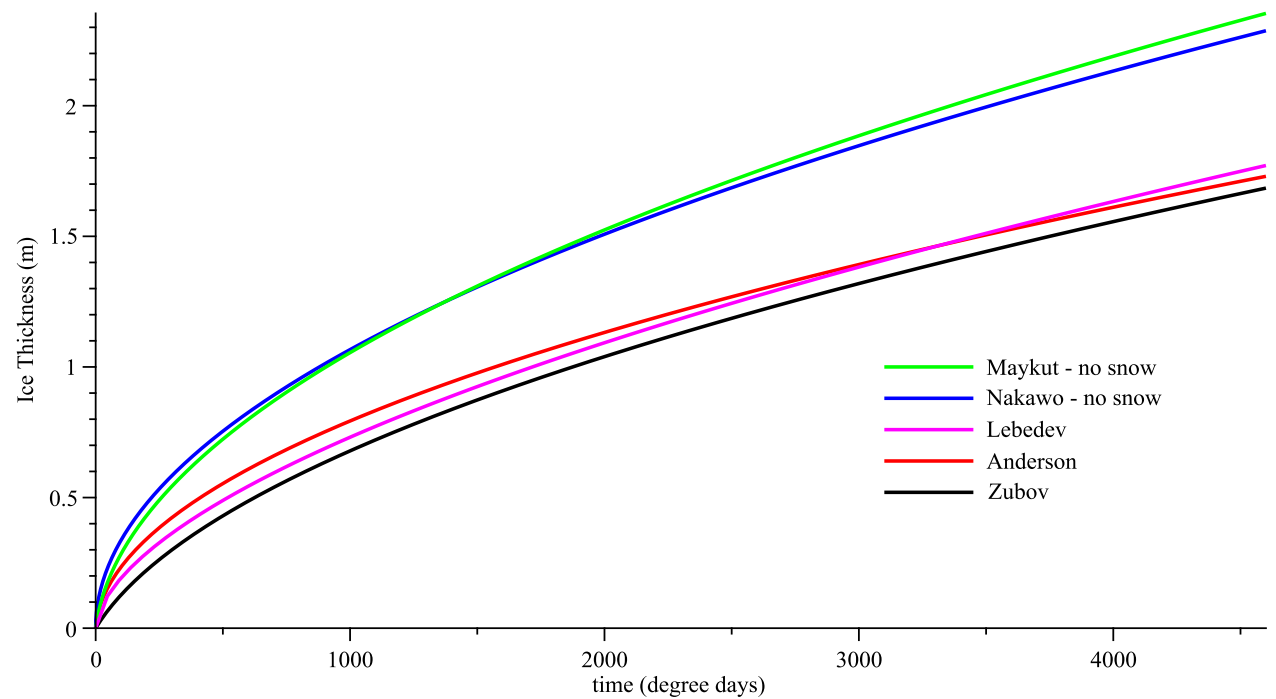

(b) Degree-days

Figure 4.7: Plotted are 5 equations used to describe sea ice growth. The lower 3 curves (Anderson, Zubov and Lebedev) are directly from Arctic data. The 2 curves indicating greater growth are from formulae developed by Nakawo and Maykut, assuming no snow cover. Figure $4.7 \mathrm{a}$ is plotted against days, while Figure $4.7 \mathrm{~b}$ is plotted against degrees days assuming a freezing point temperature of $-1.89^{\circ} \mathrm{C}$ and an air temperature of $-25^{\circ} \mathrm{C}$. This allows comparison between days and degree-days. 
snow layer. The heat transfer coefficient, $c_{t}$, takes into account the effects of both sensible and latent heat exchange (Maykut, 1986). $\theta$ is defined as the degree-day of freezing,

$$
\theta=\int_{0}^{t}\left(T_{f}-T_{a}\right) \mathrm{d} t
$$

where $T_{f}$ is the freezing temperature of seawater and $T_{a}$ is the air temperature. Freezing degree-days give a measure of the coldness of the ice and the length of time it has been at that temperature. One day at a temperature 1 degree below freezing is 1 degree-day (Penner, 1962). $T_{a}$ is often taken to be the mean air temperature for the days of measurement (Nakawo and Sinha, 1981). The ice growth data plotted against degreedays is shown in Figure $4.7 \mathrm{~b}$.

For an average snow depth of around $5 \mathrm{~cm}$, Equations 4.13 and 4.14 are both in close agreement with the three observation-based plots. The extra $\frac{\rho_{i} L}{c_{t}}$ term in Equation 4.14 has only a minor effect as it is small compared with $\frac{\rho_{i} L h_{s}}{k_{s}}$ (given that $c_{t} \approx 24 \mathrm{~J} \cdot \mathrm{m}^{-2} \cdot \mathrm{s}^{-1} \cdot{ }^{\circ} \mathrm{C}^{-1}$ ). Figure 4.7 includes the 2 equations plotted for no snow cover $\left(h_{s}=0 \mathrm{~m}\right)$. These give an indication of the maximum possible growth rate as snow reduces heat flux to the atmosphere.

Due to the relative abundance of Arctic ice growth measurements, the plots shown are based on data from the northern regions. Though Antarctic growth can be affected by the adherence of frazil at the interface, platelet growth does little to enhance the rate of brine release. Therefore data based solely on congelation growth, on which the brine plume velocity depends, is preferable.

\subsection{Brine plumes and frazil}

It would be excessive to consider all of these models for ice growth for the remainder of the work in this chapter. In Figure 4.7 there are two distinct 


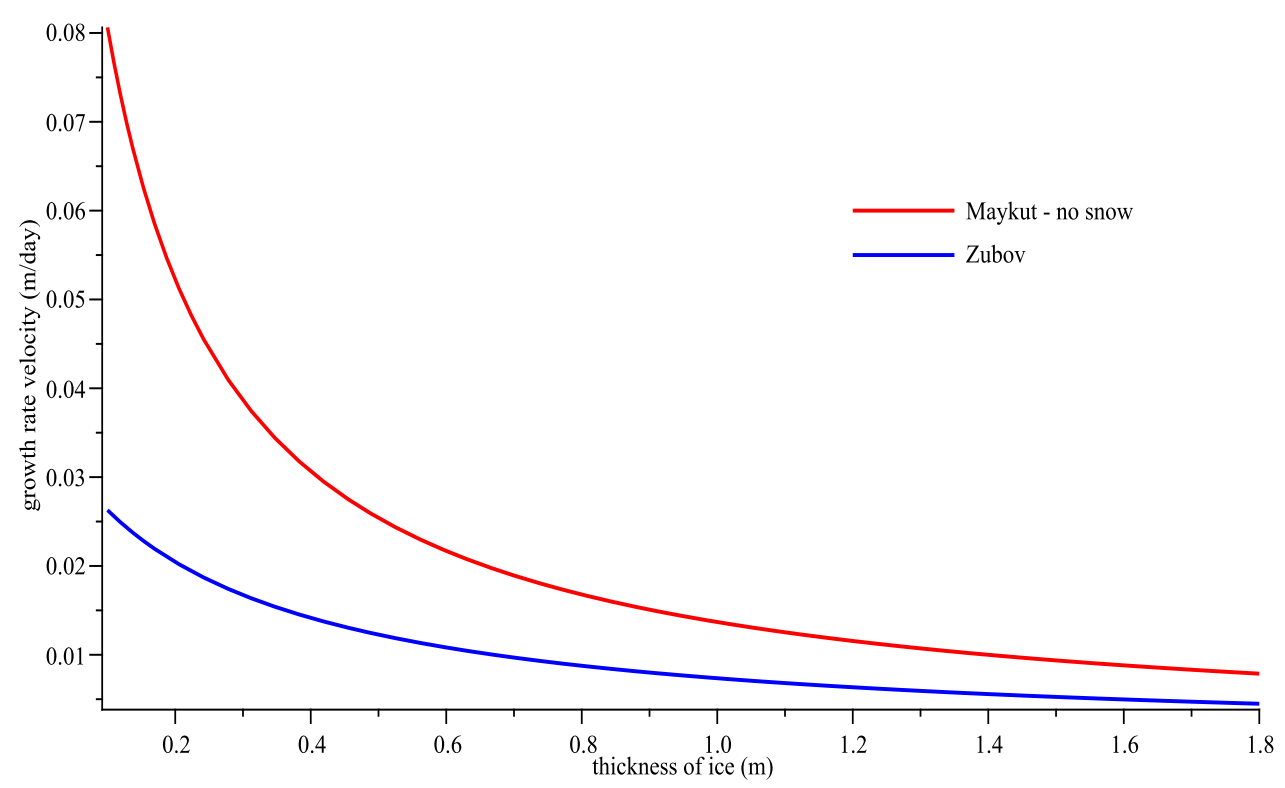

Figure 4.8: The ice growth rate calculated from field work near Cape Schmidt by Zubov and a flux-based theory, assuming no snow cover, developed by Maykut (Maykut, 1986).

groups for the data, one based on Arctic field work and the other a maximum growth indication assuming zero snow cover. Zubov's results from near Cape Schmidt and Maykut's Equation 4.14 will be used as representative of the two groups.

After noting that Zubov's data is best fitted by

$$
2 h^{2}+h=\frac{\theta}{625}
$$

where $h$ is the interface position in metres and $\theta$ the time in degree-days (Maykut, 1986), the next step is to calculate the growth rate of the interface. This is required to find the velocity of the brine plumes and can be found using Equations 4.14 and 4.16 . The results are shown in Figure 4.8. A significantly faster initial growth rate is seen in the no snow case; however, similar rates are reached towards the end of the growth period. 


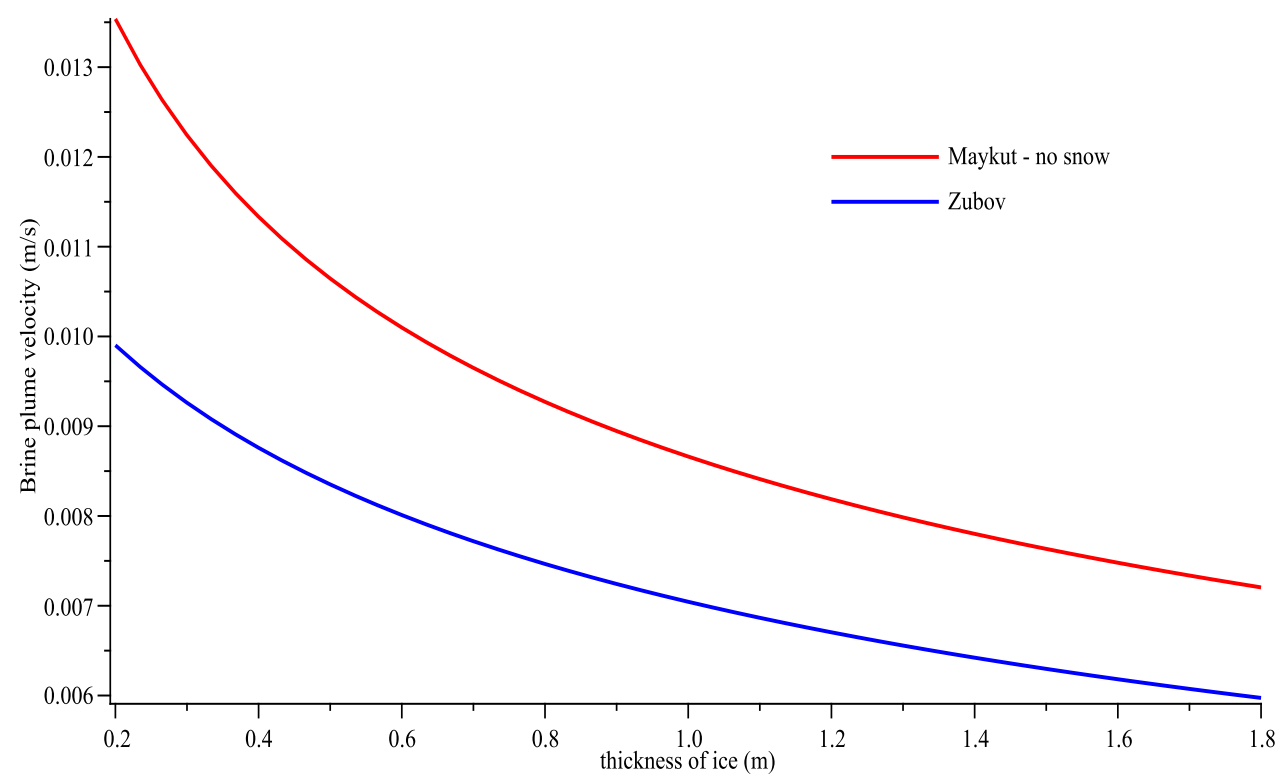

Figure 4.9: The average brine plume velocity, as calculated using Maykut's no snow equation and Zubov's growth rate data, is shown. Both decrease at similar rates, though Zubov's data predicts a slower velocity.

By substituting the growth rates into Equation 4.12 , the average downwards velocity of the brine plumes are found. These are shown in Figure 4.9. As the ice gets thicker, it grows less rapidly. This leads to less salt being forced out and hence the decrease in brine plume velocity as the ice grows. Also worth noting is that Zubov's field measurements indicate a slower growth rate than Maykut's no snow equation, resulting in a slower average brine plume velocity.

It may be asked whether the downflow due to brine rejection would have an equivalent upflow as the water is replaced from below. The buoyancy flux is, however, an average measure of the movement of density variations and, as such, takes into account the flow in both directions producing a net fluid movement down driven by the ice growth.

Also of key importance in this case is whether a frazil crystal will be prevented from adhering to the interface. Considering the underside of 
the ice, there is a far greater area between the brine tubes than there is made up by the tubes. Therefore, even ignoring the ice growth, the downflow must move much faster than the seawater replacing it. Given that most crystals will interact with a brine tube it seems likely that the more rapid downflow will at least keep a crystal in motion, assuming the criteria developed in this chapter are met.

The brine plume velocity can now be compared with the frazil rise velocities calculated in Section 4.2.2. Figure 4.10 displays the ice thickness at which a frazil crystal of a certain radius will rise out of suspension. Crystals with a radius above the appropriate curve at a certain thickness will remain in suspension. Given both estimates for the brine plume velocity, all crystals larger than $1.45 \mathrm{~mm}$ will initially rise to the interface. When the ice reaches $1 \mathrm{~m}$ in thickness, crystals larger than between $1.2 \mathrm{~mm}$ and $1.3 \mathrm{~mm}$ are able to overcome the movement of the brine plumes and stick to the growing ice cover. This suggests that, by the time at which platelets are first found in ice cores, brine rejection has become weak enough to allow larger frazil crystals to become incorporated into the ice.

By keeping frazil crystals in suspension until a period of growth has occurred, brine rejection provides a plausible explanation for the late appearance of platelet crystals (which grow from the incorporated frazil). However, experimental verification is required before it can be regarded as the sole cause of the phenomenon. The most concerning aspect of the analysis is the slow rate of change of the frazil disc radius able to rise out of suspension as the ice thickness increases. Over an entire winter's growth season, the change in the frazil radius is only $0.5 \mathrm{~mm}$. Such a small change may not be enough to cause the late appearance of frazil on a consistent basis. 


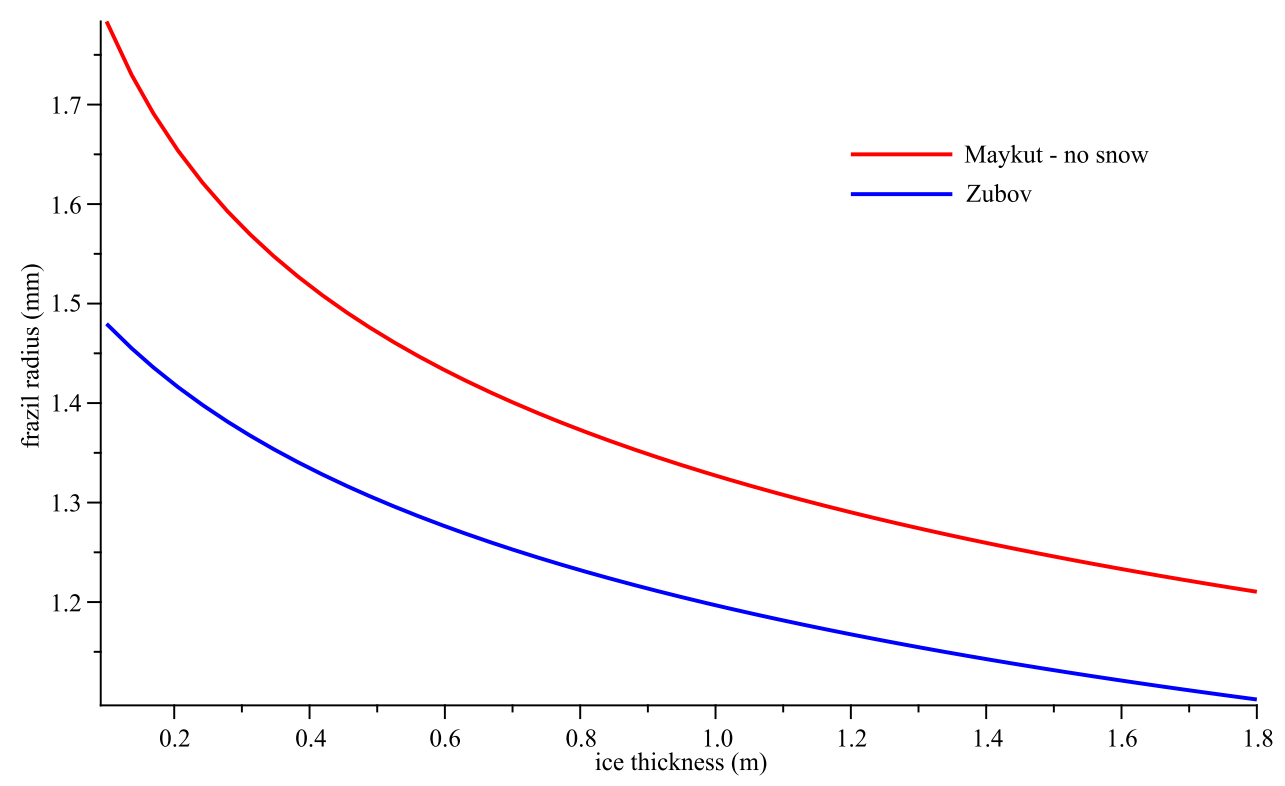

Figure 4.10: Critical ice thickness at which a frazil crystal may rise out of suspension and stick to the interface, found by comparing brine rejection rates with frazil rise velocities.

\subsubsection{Air temperature and seawater salinity}

Both air temperature and seawater salinity can vary with the location of the growing ice. Typical values for $\mathrm{M}^{c}$ Murdo Sound, Antarctica, have been used in the analysis so far. These are now altered to investigate the effect these parameters have on the system.

Even though Antarctica experiences 4 to 6 months with virtually no sunlight during winter, air temperatures still vary significantly. Field data from $\mathrm{M}^{c}$ Murdo Sound (personal communication, Patricia J. Langhorne and Craig R. Purdie, 2007) show temperatures ranging from $-45^{\circ} \mathrm{C}$ to $-5^{\circ} \mathrm{C}$. Over the measurement period, an average of $-25^{\circ} \mathrm{C}$ is found. Changing the average temperature by $5^{\circ} \mathrm{C}$ has only a minor effect on the size of frazil able to rise out of suspension, with a maximum change of $0.05 \mathrm{~mm}$ for the critical frazil radius (Figure 4.11). This occurs as, by increasing the ice growth rate, a colder air temperature increases the brine 


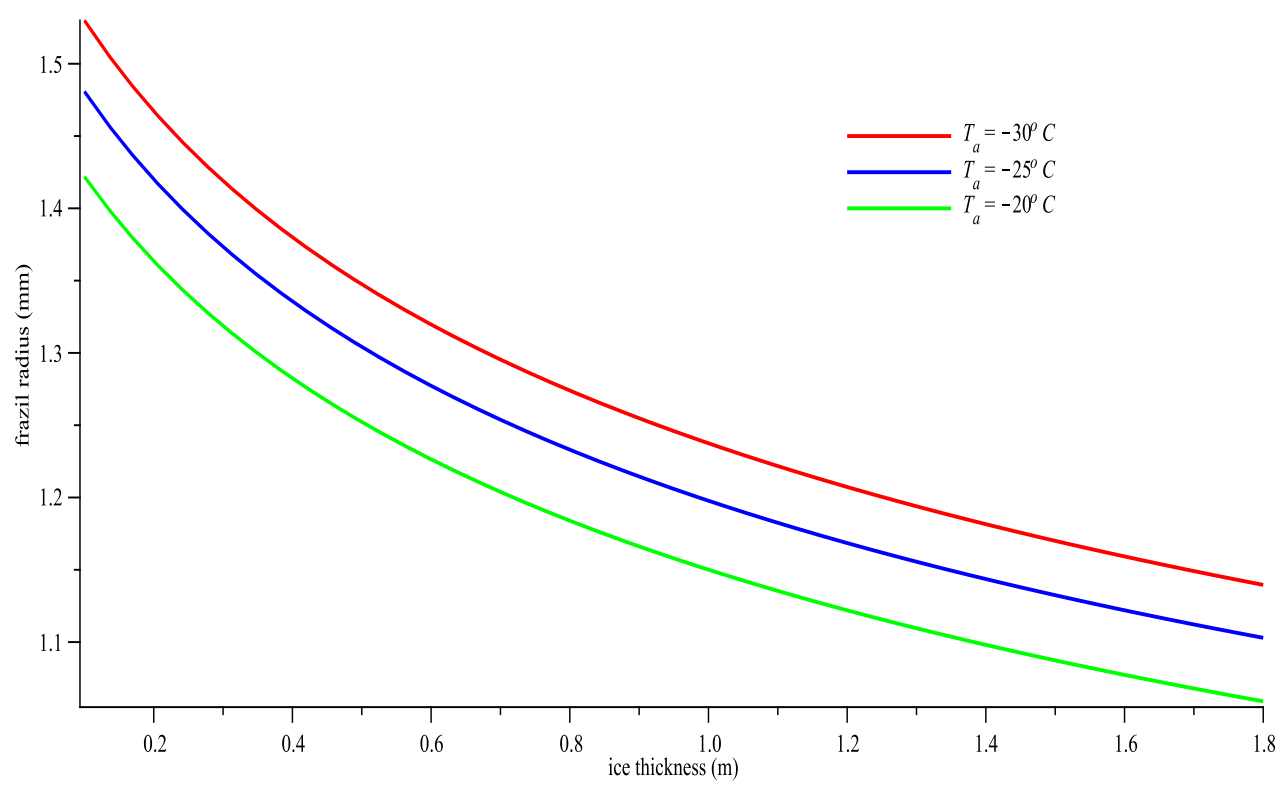

Figure 4.11: The effect on the size of frazil crystal which can rise out of suspension if the average air temperature is altered. A colder temperature results in larger crystals staying unattached below the interface. Zubov's ice growth approximation is used.

plume velocity and the size of the crystals remaining unattached.

The salinity of the seawater is taken to be equal to the mixed layer salinity. Leonard et al. (2006) measured the mixed layer salinity in $\mathrm{M}^{c}$ Murdo Sound and found it increased from $34.3 \mathrm{psu}$ in mid-April to $34.7 \mathrm{psu}$ by early September. Weeks and Gow (1978) approximated the seawater salinity to be $35 \mathrm{psu}$. This value is adopted for use in this work. Increasing or decreasing the salinity by 5 psu does little to effect the size of the frazil discs which remain in suspension, as shown in Figure 4.12. A larger salinity results in a greater number of crystals remaining unattached. This is caused by the increase in the brine plume velocity as the ice must reject the more highly concentrated brine. Not included in the model, however, is the fact that a greater seawater salinity would result in a slower growth rate and hence a slower brine rejection velocity. This is due to the extra cooling required to bring the water down to the freezing point. 


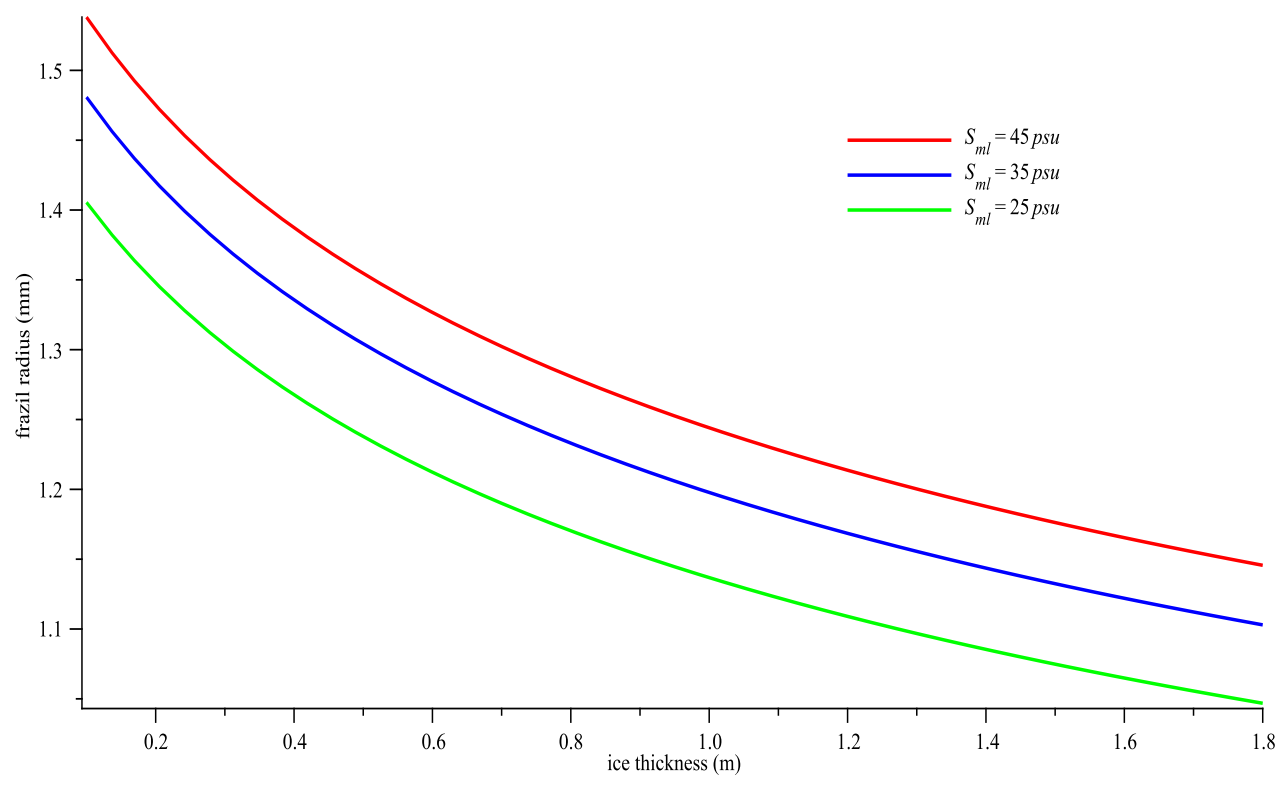

Figure 4.12: The effect on the size of frazil crystal which can rise out of suspension if the seawater salinity is altered. An increase in the seawater salinity results in larger crystals being kept in suspension.

Also interesting to note is that supercooling the mixed layer by as much as $0.1^{\circ} \mathrm{C}$ has no effect on the size of the frazil rising to the interface. Again, this would likely change if the change in ice growth due to the supercooling was included.

\subsubsection{Varying mixed layer depth}

As the brine plumes leave the ice-water interface region, they are much denser than the mixed layer and hence sink. The mixed layer has a constant density so the plumes convect all the way down to the top of the halocline (Washington and Parkinson, 2005). This suggests that the depth of the mixed layer is important in the strength of the brine plumes.

Constant mixed layer depth assumptions are often used in sea ice growth models (Parkinson and Washington, 1979: Wu et al., 1997). In this chapter, the average depth of the mixed layer has been taken from the 


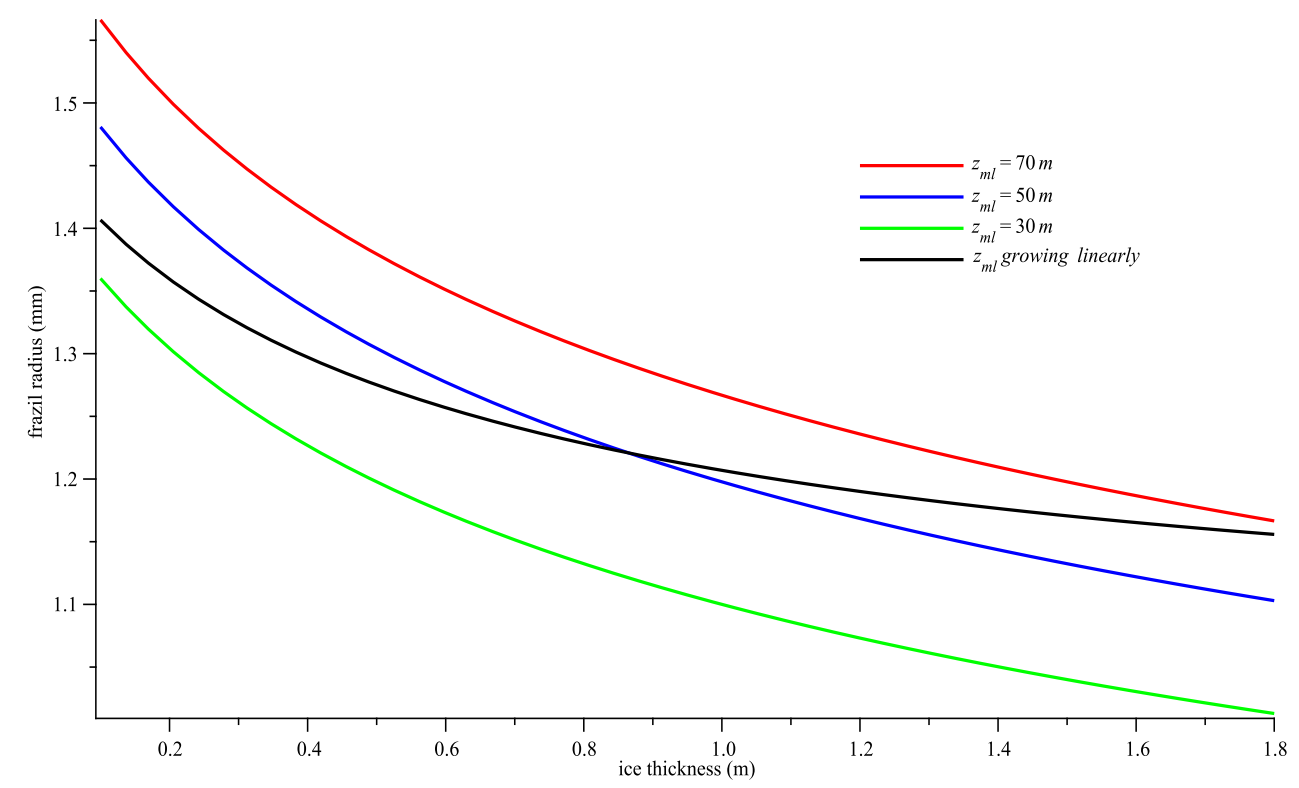

Figure 4.13: The effect on the size of frazil crystal which can rise out of suspension if the mixed layer depth is altered. Also included is a model prediction based on a linearly growing mixed layer. A deeper mixed layer results in a more rapid brine plume velocity, keeping more crystals in suspension.

measurements of Leonard et al. (2006). These show a mixed layer which is initially smaller than $50 \mathrm{~m}$, growing to and beyond this depth.

As discussed in Notz (2005), the mixed layer grows rapidly at the start of winter and delays the onset of ice growth. This is because the seawater entrained into it must be cooled to the freezing temperature (Washington and Parkinson, 2005); hence the mixed layer reaches a reasonable depth before the majority of ice growth and the associated brine rejection has commenced. This initial transition period will therefore not be considered further.

Figure 4.13 shows that changing the mixed layer depth by $20 \mathrm{~m}$ has a noticeable effect on the size of the crystals remaining in suspension. For a $30 \mathrm{~m}$ mixed layer depth, frazil crystals $0.1 \mathrm{~mm}$ smaller than those for a $50 \mathrm{~m}$ mixed layer will be able to rise to the interface. This is because 
the turbulent velocity scales to the mixed layer depth with the plumes travelling until they reach the halocline (Stull, 1988; $\mathrm{M}^{c}$ Phee and Morison, 2001). Hence, the brine plumes have a greater velocity with a larger mixed layer. Also shown is the effect of a mixed layer growing linearly, with the depth of the ice, from $30 \mathrm{~m}$ to $70 \mathrm{~m}$. This indicates a much slower rate of change of frazil radius which can rise out of suspension as the ice thickens.

\subsection{Brine rejection in a turbulent environment}

In $\mathrm{M}^{c}$ Guinness et al. (2009), it was proposed that the rise velocity of frazil crystals in a turbulent environment may be similar to that of diesel droplets, due to the similarity in their relative densities ( 0.9 for frazil in water as compared to 0.85 for diesel). It is known that fluid turbulence can alter the settling velocity of solid particles, or the rise velocity of buoyant particles and bubbles. Depending on the relative density of the particle, and the level of turbulence, its velocity may be increased or decreased (Nielsen, 2007). This was surmised to be due to the pattern of vortices which exist in the turbulence. A particle may get trapped in the stationary points of the vortices or get fast-tracked through them.

Nielsen (2007) noted, based on the experimental data of Friedman and Katz (2002), that smaller drops of diesel are affected by turbulence in a similar manner to particles which are denser than water. The drops spend more time in the upflow regions of the vortices, enhancing the diesel rise velocities. Friedman and Katz (2002) summarise their results as follows:

- At relatively high turbulence levels all droplets approach the speed $\frac{u_{*}}{4}$, with the exception of the two lowest turbulence levels

- At low turbulence levels all droplets are expected to approach the still water rise velocity

- At intermediate turbulence levels the results depend on the relative inertia of the droplets. 


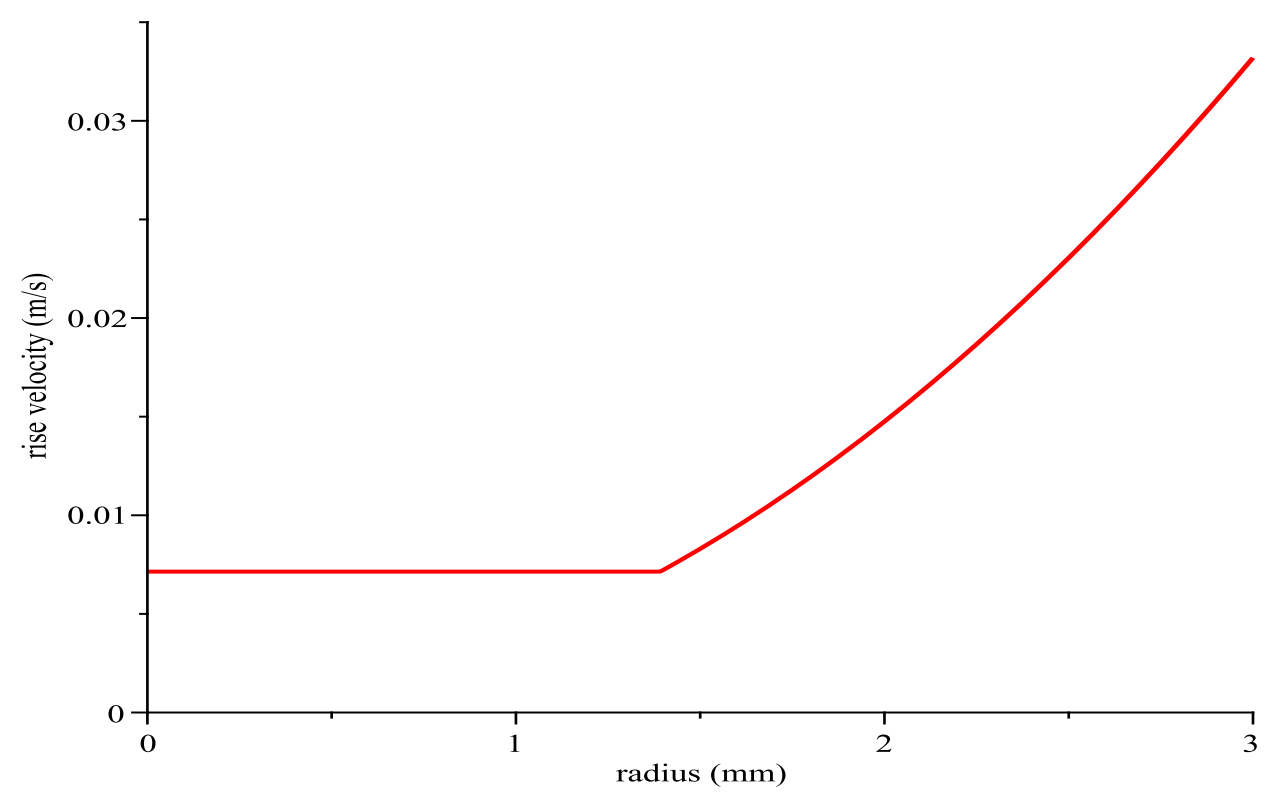

Figure 4.14: The rise velocity of a frazil crystal in a turbulent environment is shown. Crystals up to nearly $1.5 \mathrm{~mm}$ in radius have a constant rise velocity, equal to $\frac{u_{*}}{4}$. Larger crystals have the same rise velocity as in still water.

The levels of turbulence found in these experiments range between 30 and $180 \mathrm{~mm} \cdot \mathrm{s}^{-1}$, slightly greater than the measured friction velocities found beneath sea ice (see Section 3.6.1). Therefore it is likely that the rise velocities associated with the two lowest turbulence levels will be the most appropriate here. These give a constant velocity of $\frac{u_{*}}{1.5}$ and $\frac{u_{*}}{0.7}$ for small enough drop sizes. This was summarised in $\mathrm{M}^{c}$ Guinness $e t$ al. (2009), who noted that large droplets rise at the same velocity as in still water. However, small droplets rise faster than the still water equivalent. They approach the speed $\frac{u_{*}}{4}$ for high turbulence, but are closer to $\frac{u_{*}}{0.7}$ for turbulence levels nearest those observed beneath an ice cover. This latter fraction is used to plot a rise velocity in Figure 4.14 , using a friction velocity of $0.5 \mathrm{~cm} \cdot \mathrm{s}^{-1}$.

It was also noted by $\mathrm{M}^{c} \mathrm{Guinness}$ et al. that this led to the possibility of a sudden jump in the size of frazil crystal which may be kept in motion in 


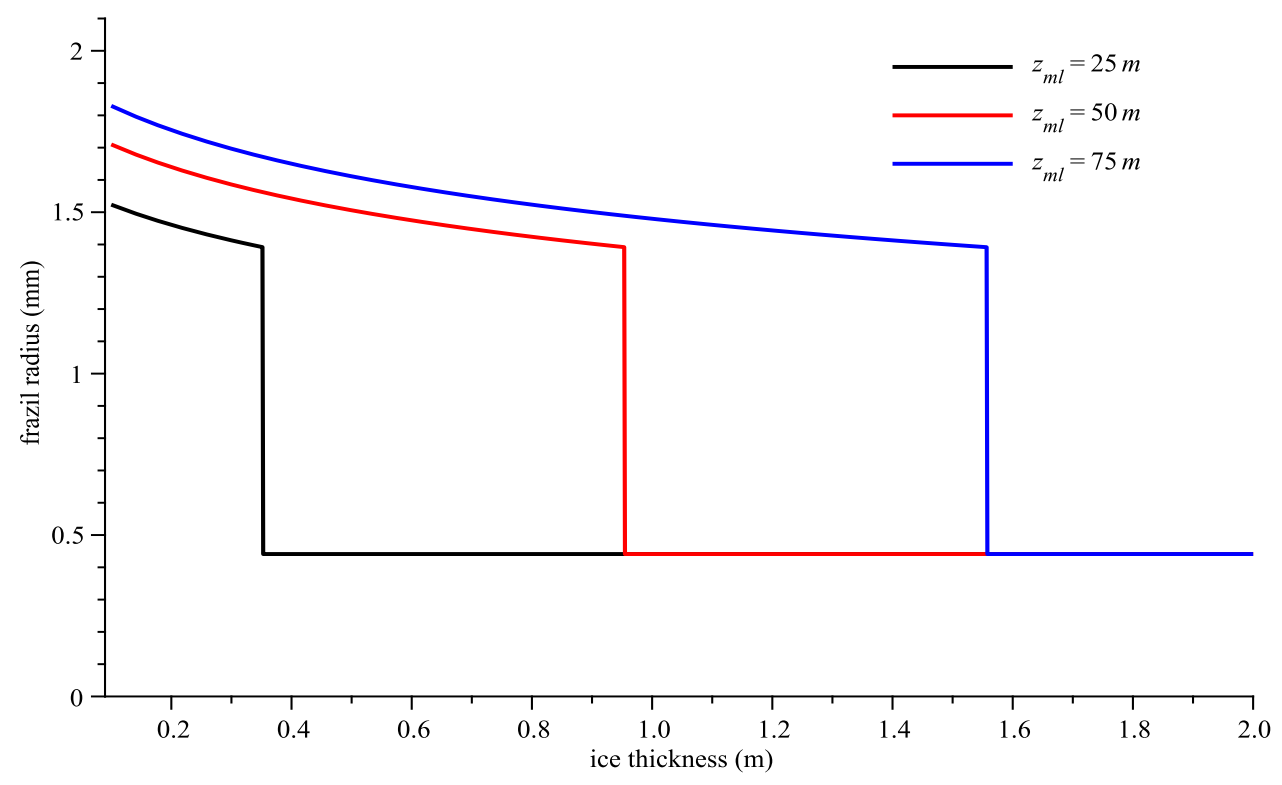

Figure 4.15: The effect of assuming a turbulence-induced minimum for the rise velocity on the mobilisation of frazil crystals is shown. A friction velocity of $0.5 \mathrm{~cm} . \mathrm{s}^{-1}$ is used. Three different thicknesses of the mixed layer are given. For $z_{m l}=50 \mathrm{~m}$, the radius of frazil which can be kept in suspension decreases slowly from $1.7 \mathrm{~mm}$ to $1.4 \mathrm{~mm}$. At an ice thickness of $1 \mathrm{~m}$ there is a sudden drop in this radius, decreasing to $0.45 \mathrm{~mm}$. Crystals smaller than this are always kept in motion (given by the Shields criterion).

a turbulent environment. This is because, if the velocity associated with brine rejection drops below the constant rise velocity value of the smaller crystals, all of those crystals (not kept in motion by the the turbulence) will be able to settle out of suspension.

Figure 4.15 illustrates the potential effect of a turbulence-induced minimum for the rise velocity on frazil mobilisation. In this case, the rise velocity shown in Figure 4.14 is compared with the brine plume velocity of Equation 4.12 using Zubov's ice growth data.

The most interesting feature of Figure 4.15 is the sudden deposition of frazil crystals after a certain ice thickness has been reached. This occurs as the brine plume velocity, dependent on the ice growth rate, decreases 
beneath the constant rise velocity value of $\frac{u_{*}}{0.7}$. At this point, all crystals which are larger than the critical value for motion, calculated using the Shields criterion (see Figure 3.9), will settle out of suspension. For a mixed layer thickness of $50 \mathrm{~m}$, this would occur at an ice thickness of just less than $1 \mathrm{~m}$, a promising result.

It should be noted that, in Figure 4.15, a friction velocity of $0.5 \mathrm{~cm} . \mathrm{s}^{-1}$ is used. This is smaller than the value which was used predominantly in the previous chapter. This is partly because using a larger value of $1 \mathrm{~cm} . \mathrm{s}^{-1}$, using the Shields criterion, was found to keep all crystals up to nearly $3 \mathrm{~mm}$ in radius in motion. This is not changed by the increased (constant) rise velocity for the smaller crystals in a turbulent environment.

Also important is the effect of the various parameters on the critical ice thickness at which the drop in radius occurs. Indeed, Figure 4.15 shows that increasing or decreasing the mixed layer thickness by $25 \mathrm{~m}$ alters the critical ice thickness by around $0.5 \mathrm{~m}$. A similar change is found if the mixed layer salinity is changed by $15 \mathrm{psu}$ or the air temperature by $15^{\circ} \mathrm{C}$.

\subsection{Torque on a frazil crystal}

One of the disputes with the idea that frazil is formed at depth and rises up the interface is the fact that thin sections, taken from ice cores, find the included frazil and platelet ice to be random in structure (see Section 2.2.5). Frazil whose buoyancy has allowed it to stick to the interface may be expected, no matter at what angle it makes contact with the interface, to turn so as to sit flat against the ice-water boundary. This would suggest a more coherent structure in the ice core. There are two potential arguments against this. One is that the interface is rough. A crystal arriving at the interface may therefore do so at an angle, adhere, and then grow until it meets an obstruction (other crystals). The second is whether the torque on a crystal is strong enough to turn the crystal parallel to the interface (Gow et al., 1998). Smith (2001) suggested that a crystal, if free to turn, would 


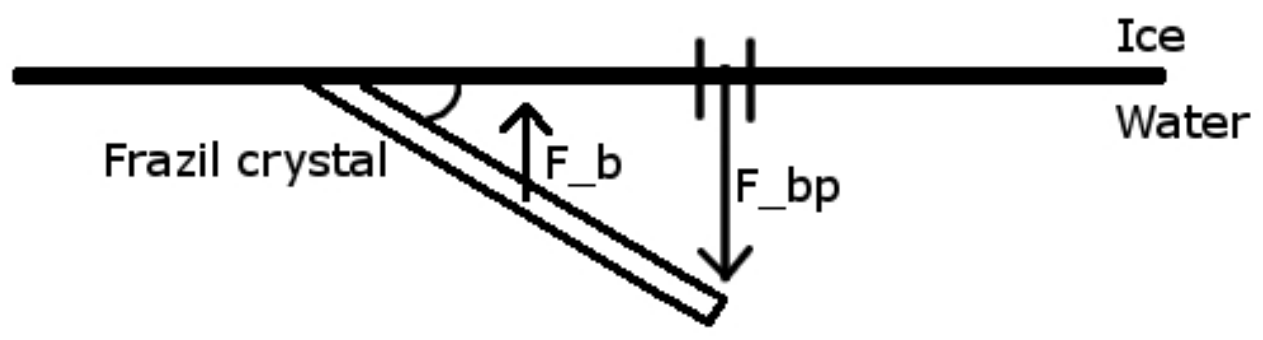

Figure 4.16: A simple force balance on a frazil crystal settling at the ice-water interface. The key forces on the crystal are the buoyancy, $F_{b}$, and the force due to the brine rejection from a brine tube, $F_{b p}$. The angle between the crystal and the flat interface is $\psi$.

have sufficient torque to do so. What has not been considered is the effect a brine plume may have on a turning crystal. This section will calculate whether brine rejection may be strong enough to prevent a crystal from sitting flat against the ice cover.

The situation is described in Figure 4.16. The simplest case is drawn. This assumes a flat interface and a thin crystal where the movement of the suspended end of the crystal occurs rapidly compared to any movement of the settled end. A buoyant force acts at the centre of the crystal. In Section 4.1 it was noted that there was an average space of around $1.2 \mathrm{~mm}$ between the brine exit tubes. Therefore, a crystal with a radius of up to $0.6 \mathrm{~mm}$ may encounter the brine rejected from a single brine tube acting on it. Anything larger than this would likely feel the effects of at least one plume.

The force due to buoyancy, $F_{b}$, acting at the crystal's centre of mass and normal to the crystal's flat side, is simply

$$
\begin{aligned}
F_{b} & =m g \cos (\psi) \\
& =2 \pi r_{d}^{3} \epsilon \rho_{i} g \cos (\psi)
\end{aligned}
$$


where $m=\rho_{i} V$ is the mass of the crystal and $\psi$ is the angle which the crystal makes with the interface. The force due to the brine rejection is slightly more complicated. When the brine makes contact with the frazil crystal it is deflected along the face of the crystal, reducing the force acting on the disc. It is simpler to calculate the force acting normal to the face of the crystal. The force due to the brine plume is then

$$
F_{b p}=-\dot{m} w_{*} \cos (\psi)
$$

The mass flow rate $\dot{m}=\rho_{w} Q=\rho_{w} w_{*} A$ where $Q$ is the volume flow rate, $w_{*}$ the velocity associated with the brine plume and $A$ the area of the brine plume, assumed not to have expanded in the short distance between the brine tube and the crystal. This gives

$$
F_{b p}=-\rho_{w} w_{*}^{2} A \cos (\psi)
$$

The maximum torque due to the brine plume would occur if it struck the crystal at the opposite end from the one touching the interface. The torques acting on the crystal are then

$$
\begin{aligned}
\tau_{b} & =2 \pi r_{d}^{3} \rho_{i} g r_{d} \cos (\psi) \\
\tau_{b t} & =-2 r_{d} \rho_{w} w_{*}^{2} A \cos (\psi) .
\end{aligned}
$$

The ratio is of these torques is

$$
\left|\frac{\tau_{b}}{\tau_{b t}}\right|=\frac{\pi r_{d}^{3} \epsilon \rho_{i} g}{\rho_{w} A w_{*}^{2}}
$$

and if this exceeds 1 the crystals can turn to stick flat against the interface. 


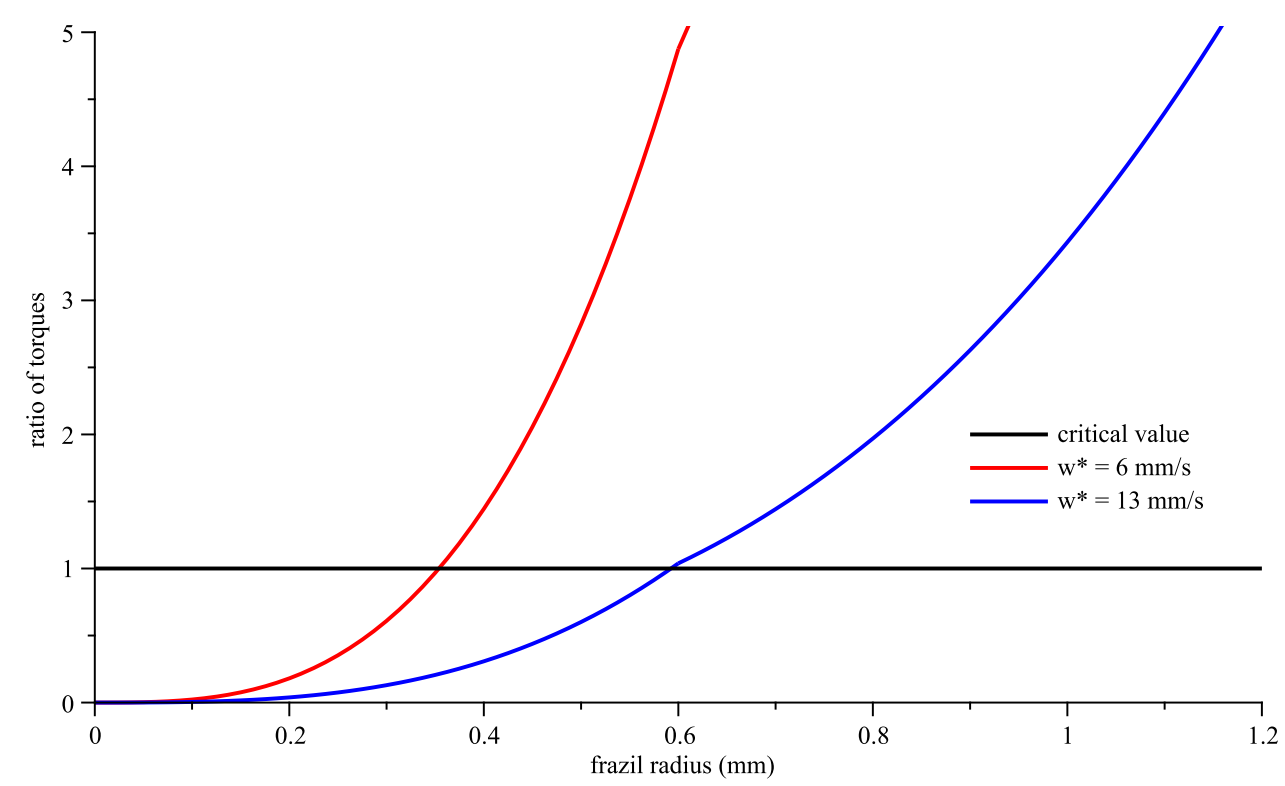

Figure 4.17: The ratio of the torque due to buoyancy versus the maximum possible torque due to one or more brine tubes is shown. A value over 1 (black line) indicates that the frazil crystal will turn until it settles against the (assumed) flat interface.

A crystal between $0.6 \mathrm{~mm}$ and $1.2 \mathrm{~mm}$ in radius may encounter an equivalent force from brine rejected by a second tube. This would create a torque acting at (to provide the greatest strength) an average of $1.2 \mathrm{~mm}$ closer to the pivot.

Figure 4.9 shows that the velocity associated with the brine plume can be between $6 \mathrm{~mm} . \mathrm{s}^{-1}$ and $13 \mathrm{~mm} . \mathrm{s}^{-1}$. These values are used to plot the torque ratio in Figure 4.17 . The results suggest that the force exerted due to brine rejection is strong enough to keep the smaller crystals from settling against the interface. Depending on the strength of the brine rejection, frazil smaller than between $0.3 \mathrm{~mm}$ and $0.6 \mathrm{~mm}$ may not settle flat against the interface if they make contact at an angle. The critical value will decrease if the brine plume hits a crystal closer to the pivot. It can also be noted that, within the possible range, the density of the brine has little effect on the results. 


\subsection{Summary}

It is well known that ice is much less saline than the water from which it freezes. In this chapter it was asked whether the desalination process which must therefore accompany ice growth could affect the rise of a frazil crystal and, in fact, keep it in suspension. To investigate this the rise velocity of a crystal was calculated and compared with the downwards velocity associated with brine rejection.

Stokes' law was used to find the frazil rise velocity. Though strictly only appropriate for smaller crystals (those with a Reynolds number smaller than 1), comparisons with experimental and other modelled results gives justification to extending its use to larger frazil radii. They also show that the aspect ratio (the ratio of the crystal's thickness to diameter) is a key factor in the rise velocity. When compared with the extensive review of frazil rise velocities by Morse and Richard (2009), aspect ratios between 0.01 and 0.02 provide a good match. An aspect ratio of 0.1 , on the other hand, is at the very maximum of modelled rise velocities.

Brine plumes ejected from the ice drive an unstable buoyancy flux due to their greater density than the underlying seawater. The exit holes of the brine tubes are closely enough spaced that it is likely that all rising crystals will be affected by a descending plume. These plumes were shown to be strong enough to keep crystals with a radius up to nearly $1.8 \mathrm{~mm}$ in suspension as ice growth commenced. This decreases as the ice thickens as the brine rejection is, in part, controlled by the growth rate of the ice.

Brine rejection has potential as an explanation for the platelet puzzle. It provides a mechanism which keeps most crystals in suspension initially, but decreases as winter progresses and the ice gets thicker. However, the rate of change of the size of crystals allowed to rise out of suspension is slow. At an ice thickness of $1.8 \mathrm{~m}$ only crystals around $0.4 \mathrm{~mm}$ smaller than can initially rise to the interface are now able to do so. This alone seems unlikely to explain the phenomenon of platelets appearing in ice 
cores after $1 \mathrm{~m}$ of growth.

An attempt to combine the turbulence induced by shear and the effect of brine rejection on the suspension of frazil crystals was also shown. Though efforts have been made to combine shear and buoyancy into a single friction velocity (an example of which will be shown in Chapter 5), the different directions at which shear and brine act make this a tricky proposition. It was noted that, in a turbulent environment, smaller crystals may tend to a constant rise velocity, which depends on the strength of the turbulence. This leads to a critical value of the ice thickness at which a significant drop in the radius of frazil held in suspension occurs. Though strongly dependent on the parameter values, a friction velocity of $0.5 \mathrm{~cm} . \mathrm{s}^{-1}$ gave a drop in frazil radius which could settle against the interface from $1.4 \mathrm{~mm}$ to $0.45 \mathrm{~mm}$ at an ice thickness of $1 \mathrm{~m}$. 


\section{Chapter 5}

\section{A two-phase sea ice model}

The Stefan problem, that of a moving boundary with a phase change, was introduced in Section 2.2. It was so named due to the pioneering work of Jǒsef Stefan in the late $19^{\text {th }}$ century. In this chapter, a Stefan problem will be presented and solved numerically for first-year sea ice. The key ideas in this model will be the effect of salt and its expulsion from the growing ice cover, and the effects of convective transport at the interface. Significantly, it will be shown that salt transport is an important factor in the growth of sea ice, significantly decreasing the quantity of ice formed.

One of the more complicated features of a sea ice model is in the interactions at the ice-water interface. Many models consider only heat transport (ignoring salt) (Maykut and Untersteiner, 1971; Leppäranta, 1993) or transport by diffusion alone (Weber, 1977). While some sea ice models can be solved exactly, as greater detail is added asymptotic or numerical methods are required (Maykut and Untersteiner, 1971; Semtner, 1976; Parkinson and Washington, 1979: Crocker and Wadhams, 1989). The model described in this chapter can be solved using both asymptotic and numeric methods.

This chapter will begin by introducing the Stefan solution, one of the earliest analytic solutions to the sea ice growth problem. The new model will then be introduced before numerical solutions are presented. These 
will be compared to asymptotic solutions presented in $\mathrm{M}^{c}$ Guinness (2009). By solving numerically, the effects of a varying air temperature can be considered, as well as the turbulence-induced removal of salt from the interface.

\subsection{Stefan solution}

The Stefan problem is a class of boundary value problems in which the boundary (or location of a phase transition) moves with time. They are so named due to the work on them completed by Jožef Stefan, who developed an analytic solution to the problem in relation to ice growth. It is included here as enlightening comparison for the results developed later in this chapter. The theory behind the Stefan solution (introduced in Section 2.2.2) is that heat, released by water as it freezes, is conducted entirely through the ice to the atmosphere. A constant temperature gradient exists throughout the ice. Leppäranta (1993) summed up the key assumptions as

1. The ice is unable to store heat

2. No heat is produced inside the ice

3. The temperature at the ice-atmosphere interface is known

4. There is no heat flux at the ice-water (phase change) interface.

When applied to the one-dimensional heat conduction equation (Equation 2.2.

$$
\frac{\partial}{\partial t}\left(\rho_{i} c_{i} T\right)=\frac{\partial}{\partial z}\left(k_{i} \frac{\partial T}{\partial z}\right)+q
$$


the internal heat source term, $q$, is set to zero by the second assumption. Additionally, the first assumption implies that the temperature, $T$, does not change with time leaving

$$
\frac{\partial}{\partial z}\left(k_{i} \frac{\partial T}{\partial z}\right)=0
$$

Given a constant thermal conductivity in the ice, this can be solved to find that

$$
\frac{\partial T}{\partial z}=\frac{T_{f}-T_{a}}{h}
$$

Equation 2.5

$$
\rho_{i} L \frac{d h}{d t}=\left.k_{i} \frac{\partial T}{\partial z}\right|_{h^{+}}-Q_{T}
$$

which describes the movement of the ice-water interface, becomes

$$
\rho_{i} L \frac{d h}{d t}=k_{i} \frac{T_{f}-T_{a}}{h}
$$

where $Q_{T}$, the ice-ocean heat flux, is set to zero (assumption 4) and substituting Equation 5.2, the temperature gradient throughout the ice. This can be rearranged to give

$$
h \frac{d h}{d t}=\frac{1}{2} \frac{d\left(h^{2}\right)}{d t}=\frac{k_{i}\left(T_{f}-T_{a}\right)}{\rho_{i} L}
$$

and solving to find

$$
h^{2}=\frac{2 k_{i}}{\rho_{i} L} \theta+h_{0}^{2}
$$




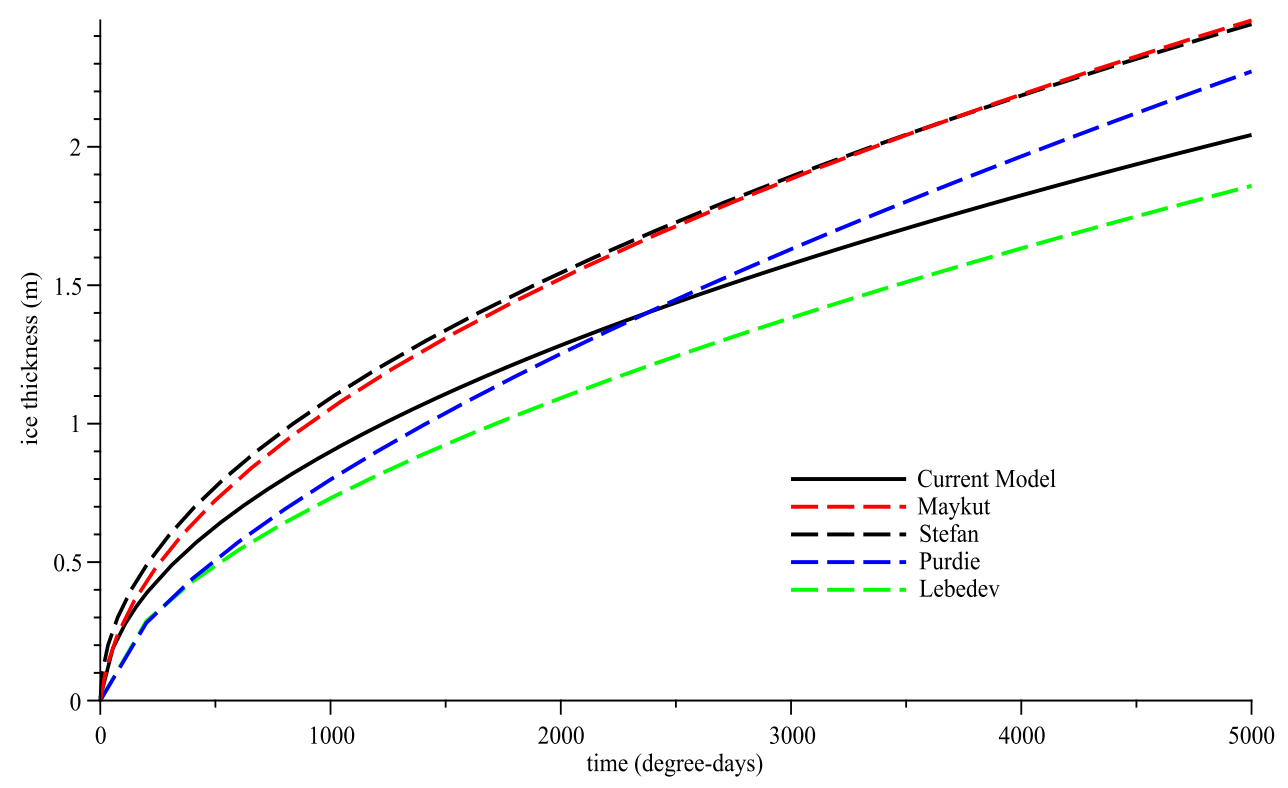

Figure 5.1: Numerical solutions to the ice growth model are compared with an empirical equation fitted to data and other model solutions. When compared with Maykut's model (assuming no snow cover), significantly less growth is found. However the growth is still greater than found by the measurements of Lebedev. Antarctic measurements show an initially slower growth, however the growth rate does not drop off as rapidly, resulting in a greater depth of ice by 5000 degree-days. Also shown is Stefan's solution, Equation 5.5 .

where $\theta$ is the number of degree-days of cooling as defined in Section 4.4 and $h_{0}$ is the depth of the ice at $t=0$. Except when being compared with field data, all of the model plots begin at an initial ice thickness of $10 \mathrm{~cm}$. This is to represent the initial pancake layer which forms before the modelled ice growth commences (see Section 2.1).

Using a constant air temperature of $-25^{\circ} \mathrm{C}$ and a mixed layer at $-1.89^{\circ} \mathrm{C}$, the predicted ice growth over 5000 degree-days (around 210 days) is shown in Figure 5.1. The height grows monotonically with time as expected. The ice thickness is found to be proportional to the square root of time in Stefan's solution and this is used as a comparison in many models. However, due to the assumptions made, the predictions of the Ste- 
fan solution tend to overestimate the final thickness of the ice (Lock, 1990 Leppäranta, 1993).

\subsection{Model regions}

The model described in this chapter has two significant changes from the Stefan problem: the expulsion of salt from the ice during growth is considered, and the effects of convective transfer at the ice-water interface are included. The first 3 assumptions described in Section 5.1 are retained. The basic layout of the model can be seen in Figure 5.2

\subsubsection{In the ice}

The water from which sea ice freezes is not pure. Hence, a model which considers salt movement must also take into account the brine which remains in the ice after freezing. While brine rejection does continue during ice growth, much of the salt is lost during its early formation. Therefore, it is reasonable to assume a sea ice salinity which is constant with time. This idea is supported by salinity profiles, for example Figures 2.8 and 2.9 which show salinity varying by only $2-3$ psu over nearly the entire depth (and therefore age) of the ice. As introduced in Section 4.3.1, sea ice salinity $\left(S_{i}\right)$ can be assumed to be proportional to the salinity at the ice-water interface $\left(S_{w}\right)$, as

$$
S_{i}=f S_{w}
$$

where $f$ is the fraction of seawater salinity retained in the ice, given by Schmidt et al. (2004) as 0.14 .

As with the Stefan solution, assuming a constant temperature gradient throughout the ice leads to Equation 5.3. It is important to consider the 


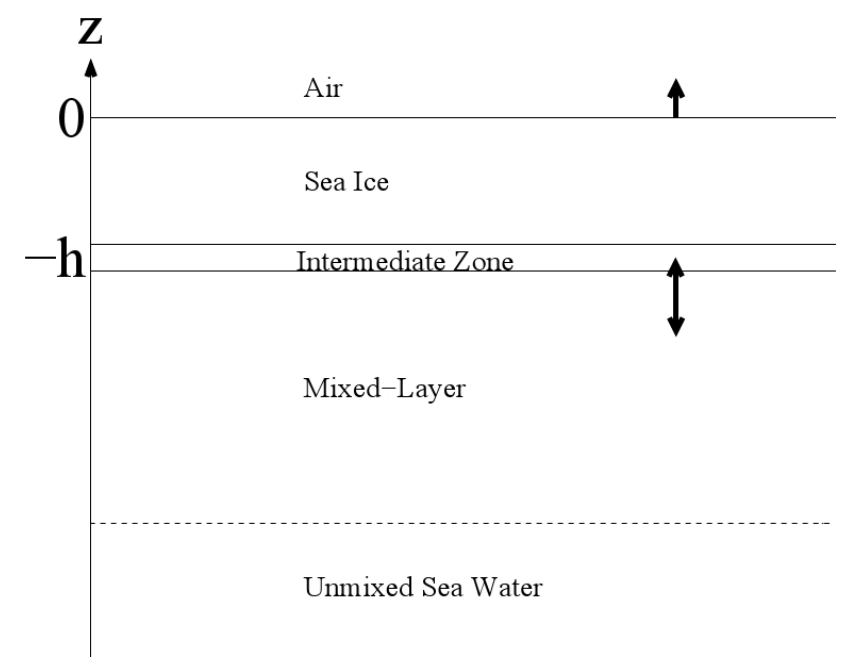

Figure 5.2: The two-phase model is split into several regions to allow for an easier description of the heat and salt transport. An interfacial region separates the sea ice from the ocean below. The ocean is split into a well-mixed region and a lower, unmixed region. The arrows indicate fluxes at the ice-atmosphere and ice-water interfaces.

effect of the salinity on the sea ice properties in this equation - the density, the thermal conductivity, the thermal capacity and the latent heat.

\section{Density}

The density of sea ice is known to be affected by the change in salinity with its age. Freshly formed ice, still retaining a significant amount of salt from the seawater, has a density of between 920 and $930 \mathrm{~kg} \cdot \mathrm{m}^{-3}$ (Gow and Tucker III, 1991). As the brine drains from the ice air pockets are left, decreasing the density of the ice. In older first-year ice it can drop to $900 \mathrm{~kg} \cdot \mathrm{m}^{-3}$. This effect is even more pronounced in multi-year ice where densities can drop as low as $800 \mathrm{~kg} \cdot \mathrm{m}^{-3}$ (Gow et al., 1982, Pringle et al. 2006). With this model being used to predict the growth of first-year ice only, it is reasonable to assume a constant density (Leppäranta, 1993). This is taken to be $910 \mathrm{~kg} \cdot \mathrm{m}^{-3}$ (e.g. Leppäranta, 2004). 


\section{Thermal conductivity}

In developing Equation 5.3, a constant thermal conductivity was assumed. Though this is not strictly true near the freezing point temperature (where conductivity decreases rapidly), it is only near the intermediate zone where the temperature rises towards this value. Over a significant portion of the ice, the thermal conductivity varies little. In their work, Maykut and Untersteiner (1971) calculated the conductivity of sea ice to be

$$
k_{i}=2.033+0.117 \frac{S_{i}}{T} .
$$

This would give an average value of around $1.98 \mathrm{~W} \cdot \mathrm{m}^{-1} \cdot{ }^{\circ} \mathrm{C}^{-1}$ for sea ice with a salinity of $5 \mathrm{psu}$. However, this was developed for multi-year ice, and first-year ice, with fewer air pockets, is known to have a greater conductivity. In experiments, Schwerdtfeger (1963), and later Pringle et al. (2006), found the conductivity to vary between $2.05 \mathrm{~W} \cdot \mathrm{m}^{-1} \cdot{ }^{\circ} \mathrm{C}^{-1}$ and $2.16 \mathrm{~W} \cdot \mathrm{m}^{-1} .{ }^{\circ} \mathrm{C}^{-1}$ for first-year ice of a similar salinity. An average value of $2.1 \mathrm{~W} \cdot \mathrm{m}^{-1} \cdot{ }^{\circ} \mathrm{C}^{-1}$ will be used in this work.

\section{Thermal capacity}

The specific heat (or thermal capacity) of sea ice has been calculated experimentally to be

$$
c_{i}=2113+7.5 T-0.0034 S_{i}+0.8 S_{i} T+18.04 \frac{S_{i}}{T^{2}}
$$

(Schwerdtfeger, 1963: Pringle et al., 2006). The $S_{i}$ and $S_{i} T$ terms are negligible for the salinities encountered in sea ice, so the equation can be simplified to

$$
c_{i}=2113+7.5 T+18.04 \frac{S_{i}}{T^{2}}
$$


where $c_{i}$ is measured in $\mathrm{J}_{\mathrm{kg}}{ }^{-1} \cdot{ }^{\circ} \mathrm{C}^{-1}(\mathrm{Yen}, 1981)$.

\section{Latent heat}

The latent heat of fusion for sea ice is known to be less than that of pure ice (Schwerdtfeger, 1963; Weber, 1977; Yen, 1981). This is largely because, due to the brine remaining trapped in the sea ice, less ice is frozen during its formation. For temperatures between $0^{\circ} \mathrm{C}$ and $-8.2^{\circ} \mathrm{C}$, Yen (1981) proposed that the latent heat of fusion for sea ice to be

$$
L=4187\left(79.68-0.505 T-0.0273 S_{i}+4.3115 \frac{S_{i}}{T}+0.0008 S_{i} T-0.009 T^{2}\right)
$$

He found the final two terms to be negligible, which allowed Equation 5.10 to be simplified to

$$
L=4187\left(79.68-0.505 T-0.0273 S_{i}+4.3115 \frac{S_{i}}{T}\right) .
$$

As the latent heat is released during the ice's formation, the temperature at the interface seems a reasonable approximation for $T$. With growth assumed to commence after an initial $10 \mathrm{~cm}$ layer of ice has formed, the interfacial temperature is within the range given by Yen. Given a temperature equal to the mixed layer at its freezing point $\left(-1.89^{\circ} \mathrm{C}\right)$ and a sea ice salinity of $5 \mathrm{psu}$, Equation 5.11 predicts a latent heat of $289,000 \mathrm{~J} \cdot \mathrm{kg}^{-1}$. This is around $10 \%$ less than that for pure ice.

In their numerical simulations of first-year sea ice, Cox and Weeks (1988) used a constant value of $293,000 \mathrm{~J} \cdot \mathrm{kg}^{-1}$ for the latent heat. With a more complicated description of $L$ they found unrealistically high salinities and growth rates. Numerical solutions to the model presented in this 
chapter find that, when taking $T$ as the interfacial temperature, results using Equation 5.11 and a constant value of $289,000 \mathrm{~J} . \mathrm{kg}^{-1}$ produce identical results. Hence, for simplicity, the constant value is used.

\subsubsection{The intermediate zone}

The intermediate zone is an interfacial region at $z=-h$. It is defined by Mellor et al. (1986) as "an indefinitely thin control volume surrounding the seawater, sea-ice interface". Effectively, it can be regarded as the ice-water interface where the phase change occurs. Therefore, boundary conditions are needed for the heat and salt transport across this interface. These are developed in Appendix $\mathrm{A}$ and give

$$
\begin{aligned}
L \rho_{i} \dot{h} & =-k_{i} \frac{\partial T}{\partial z}-Q_{T} \\
\left(S_{i}-S_{w}\right) \rho_{i} \dot{h} & =Q_{S}
\end{aligned}
$$

where $h$ is the rate of growth of the ice-water interface and $Q_{T}$ and $Q_{S}$ are the turbulent fluxes of heat and salt respectively (see also Notz et al., 2003: Schmidt et al., 2004).

This gives two equations for the three unknowns and hence a third equation is required. This is found by assuming that the intermediate zone is at the freezing temperature of the adjacent seawater, such that $T=T_{f}\left(S_{w}, h\right)$ is a function of the seawater salinity and the interface position. However, following (for example) Weber (1977) and $\mathrm{M}^{c}$ Phee et al. (1987), the dependence on depth can be assumed to be dominated by the change due to salinity, giving

$$
T_{f}=-a S_{w}
$$


By fitting a straight line to the UNESCO formula for the freezing point of seawater, ' $a$ ' is found to be $54.11 \times 10^{-3}{ }^{\circ} \mathrm{C}$ (UNESCO, 1983).

\subsubsection{Below the ice}

Two regions are defined in the ocean below the sea ice. Directly beneath the ice is the mixed layer, as described in Section 2.1. This is created by turbulent stirring and is characterised by having a constant temperature and salinity throughout its depth. Beyond the mixed layer is the region including the halocline. This strong salinity gradient resists the growth of the mixed layer (and allows for the formation of ice). As winter progresses, fluid from the halocline is gradually entrained into the mixed layer, increasing the latter's depth.

Still unknown in Equations 5.12 and 5.13 are the turbulent fluxes of heat and salt to or from the mixed layer. The heat flux case has been investigated in some depth, e.g. $\mathrm{M}^{c}$ Phee (1992, 1994); $\mathrm{M}^{c}$ Phee et al. (1999) and Holland and Jenkins (1999). $\mathrm{M}^{c}$ Phee (1992) describes the heat transfer as being dependent on both the friction velocity at the interface and the difference between the temperature of the mixed layer and the temperature at the interface. This leads to a turbulent oceanic heat flux of

$$
Q_{T}=\rho_{w} c_{p}\left\langle w^{\prime} T^{\prime}\right\rangle
$$

where $\rho_{w}$ is the density of the water adjacent to the interface, $c_{p}$ the specific heat of water and

$$
\left\langle w^{\prime} T^{\prime}\right\rangle=C_{T} u_{*}\left(T_{m l}-T_{f}\right)
$$

with $C_{T}$ a turbulent Stanton number (or heat transfer coefficient), $u_{*}$ the friction velocity and $T_{m l}$ the temperature of the mixed layer. 
Yaglom and Kader (1974) found, in laboratory tests, that near a rough wall the Stanton number varied with the velocity scale (or equivalently the Reynolds number). However, $\mathrm{M}^{c}$ Phee et al. (1999) discovered that, under naturally growing sea ice, this dependence was weak. In their experiments the Stanton number varied from 0.005 to 0.006 with an average value of 0.0056. This is used as a constant value for $C_{T}$.

Using the same method as for the heat flux, the turbulent salt flux can be represented as

$$
Q_{S}=C_{S} u_{*}\left(S_{m l}-S_{w}\right) \rho_{m l}
$$

where $C_{S}$ is a turbulent salt coefficient and $\rho_{m l}$ and $S_{m l}$ are the density and salinity of the mixed layer respectively.

Though $C_{T}$ is reasonably well defined, measured values for $C_{S}$ are harder to find. However, $\mathrm{M}^{c}$ Phee et al. (1987) specified the turbulent coefficients as

$$
\frac{1}{C_{T, S}}=b_{1}(R e)^{\frac{1}{2}}\left(\frac{\nu}{\alpha_{T, S}}\right)^{\frac{2}{3}}
$$

where Re is the Reynolds number, $b_{1}$ is a constant, $\frac{\nu}{\alpha_{T}}$ is the Prandtl num$\operatorname{ber}(\operatorname{Pr})$ and $\frac{\nu}{\alpha_{S}}$ is the Schmidt number $(S c) . \nu$ is the kinematic viscosity and $\alpha_{T, S}$ are the thermal diffusivity and the mass diffusivity of salt respectively. Using this it is easy to see that

$$
\frac{C_{S}}{C_{T}}=\left(\frac{P r}{S c}\right)^{\frac{2}{3}}
$$

or

$$
C_{S}=C_{T}\left(\frac{P r}{S c}\right)^{\frac{2}{3}}
$$


allowing the turbulent salt coefficient to be calculated.

In his work on sea ice, $\mathrm{M}^{c}$ Phee (1987) found typical values of $P r$ and $S c$ to be 13.8 and 2432 respectively, which leads to a turbulent salt coefficient of

$$
C_{S}=0.032 C_{T}=1.8 \times 10^{-4}
$$

In Chapter 3, values for the friction velocity, $u_{*}$, were presented. The friction velocity in this case is caused by the shear flow beneath the sea ice. This stays constant throughout the growth of the ice, and will be used primarily in this chapter. However, in Section 5.4, a formula for the friction velocity induced by brine rejection will be developed.

\subsection{The two-phase model}

As for the Stefan solution, a constant temperature gradient is assumed. The density at the interface is given by Equation 4.9. Substituting this, along with Equations 5.6, 5.14, 5.15, 5.16 and 5.17/into Equations 5.12 and 5.13. the governing equations for this model become

$$
\begin{aligned}
L \rho_{i} \dot{h}= & -k_{i} \frac{a S_{w}+T_{a}}{h} \\
& -c_{p} C_{T} u_{*}\left(T_{m l}+a S_{w}\right)\left(\rho_{0}+\frac{d \rho_{w}}{d S} S_{w}\right) \\
(f-1) S_{w} \rho_{i} \dot{h}= & C_{S} u_{*}\left(S_{m l}-S_{w}\right) \rho_{m l}
\end{aligned}
$$

where $\rho_{0}=999.84 \mathrm{~kg} \cdot \mathrm{m}^{-3}$ and $\frac{d \rho_{w}}{d S}=0.81 \mathrm{~kg} \cdot \mathrm{m}^{-3} \cdot \mathrm{psu}^{-1}$. The variables are $S_{w}$ and $h$. From experience, non-dimensionalising these equations with appropriate time and length scales greatly simplifies the problem. 


\subsubsection{Ice growth in the presence of shear flow}

Choosing non-dimensional variables; $h=H_{0} \tilde{h}, t=t_{0} \tilde{t}$ and $S_{w}=S_{0} \tilde{S_{w}}$ and, similarly to simplify the temperature, Equations 5.22 and 5.23 become

$$
\begin{aligned}
L \rho_{i} \frac{H_{0}}{t_{0}} \frac{\partial \tilde{h}}{\partial \tilde{t}}= & -k_{i} \frac{a S_{0} \tilde{S_{w}}+T_{0} \tilde{T}_{a}}{H_{0} \tilde{h}} \\
& -c_{p} C_{T}\left(T_{0} \tilde{T_{m l}}+a S_{0} \tilde{S_{w}}\right)\left(\rho_{0}+\frac{d \rho_{w}}{d S} S_{0} S_{w}\right) \\
(f-1) S_{0} \tilde{S_{w}} \rho_{i} \frac{H_{0}}{t_{0}} \frac{\partial \tilde{h}}{\partial \tilde{t}}= & C_{S} u_{*} S_{0}\left(1-\tilde{S_{w}}\right) \rho_{m l}
\end{aligned}
$$

where the overbar, , indicates the value is non-dimensional. $S_{0}$ is set to the salinity of the mixed layer ( $35 \mathrm{psu}$ ). For convenience the temperature scale, $T_{0}$, is set to $35^{\circ} \mathrm{C}$, close to the maximum variation in temperature during the winter period. This is used to non-dimensionalise both the air and mixed layer temperatures.

After manipulation, it becomes apparent that appropriate scales for the length and time are

$$
\begin{aligned}
H_{0} & =\frac{(1-f) k_{i} T_{0}}{L C_{S} u_{*} \rho_{m l}} \approx 0.12 \mathrm{~m} \\
t_{0} & =\frac{(1-f)^{2} k_{i} T_{0} \rho_{i}}{C_{S}^{2} u_{*}^{2} \rho_{m l}^{2} L} \approx 0.57 \text { days }
\end{aligned}
$$

reducing the key equations, in non-dimensional form, to

$$
\begin{aligned}
& \dot{h}=-\frac{T_{a}+A S_{w}}{h}-\beta\left(T_{m l}+A S_{w}\right)\left(1+A_{1} S_{w}\right) \\
& \dot{h}=\frac{S_{w}-1}{S_{w}}
\end{aligned}
$$


where the tildes have been dropped. $\beta, A$ and $A_{1}$ are non-dimensional constants where

$$
\begin{aligned}
\beta & =\frac{(1-f) c_{p} C_{T} T_{0} \rho_{0}}{C_{S} L \rho_{m l}} & \approx 12.5 \\
A & =a \frac{S_{0}}{T_{0}} & =0.054 \\
A_{1} & =\frac{S_{0}}{\rho_{0}} \frac{d \rho_{w}}{d S} & \approx 0.028
\end{aligned}
$$

assuming a friction velocity of $1 \mathrm{~cm} . \mathrm{s}^{-1}$ (as used in Section 3.6.1).

\subsubsection{Results}

Asymptotic solutions to this problem are presented in $\mathrm{M}^{c} \mathrm{Guinness}$ (2009), with the exception that he assumed the density at the ice-water interface to be constant and equal to that in the mixed layer. This has no noticeable effect on the final results. Assuming air temperatures much colder than the freezing point temperature, $\mathrm{M}^{c}$ Guinness found that a reasonable approximation for the thickness of the ice is

$$
h^{2}+\gamma_{1} h \approx \frac{2 k_{i}}{\rho_{i} \mathcal{L}} \theta
$$

where

$$
\begin{aligned}
\gamma_{1} & =\frac{1.7 k_{i}\left|T_{a}\right|}{u_{*} C_{S} \rho_{m l} \mathcal{L}} \\
\mathcal{L} & =L-\frac{(1-f) C_{T} c_{p} T_{m l}}{C_{S}} .
\end{aligned}
$$




\section{Numerical solutions}

The remainder of this section will be used to develop numerical solutions which allow the asymptotic solutions to be extended. Comparisons will be made between a constant air temperature and a variable temperature, and the effect of varying the friction velocity will be investigated.

By equating Equations 5.28 and 5.29, a (non-dimensional) cubic in $S_{w}$ is found,

$$
\begin{aligned}
S_{w}^{3}\left(\beta A A_{1} h\right) & +S_{w}^{2}\left(A+\beta A h+\beta T_{m l} A_{1} h\right) \\
& +S_{w}\left(T_{a}+h+\beta T_{m l} h\right)-h=0,
\end{aligned}
$$

which can be solved for $S_{w}$. Substituting the physical solution into either Equation 5.28 or 5.29 gives a differential equation in $h$. This can then be solved numerically.

In Figure 5.1, the model presented above is compared with the growth rates initially introduced in Section 4.4 . The parameter values are based on standard values for sea ice, while an average air temperature of $-25^{\circ} \mathrm{C}$ is used. The validity of this assumption will be investigated in greater depth in Section 5.3.4. Also shown are the Stefan solution, Equation 5.5, and an equation fitted to the Antarctic data of Purdie et al. (2006).

When compared with the classic model of Stefan, and Maykut's (1986) model equation (assuming no snow cover), the model presented above predicts a significant drop in the growth rate. The reasons for this will be discussed in the following sections, but of particular importance is the inclusion of salt in the current model.

The Arctic field measurements of Lebedev indicate a smaller depth of ice being formed, largely due to an initially slower growth rate. This could be because the current model ignores the effects of a snow cover. The lower conductivity of snow would have a greater effect on the growth rate of thinner ice (Maykut, 1986). 
Significantly different from the other results is the equation fitted to data from Purdie et al. (2006) from the $\mathrm{M}^{c}$ Murdo region of Antarctica. Though initially growing at a similar rate to Lebedev's empirical formulae, between 1500 and 2000 degree-days the ice does not undergo as rapid a decrease in growth rate. At this point the ice is around $1 \mathrm{~m}$ thick. As the data was gathered in Antarctica, the possibility exists that the extra growth could be due to the platelet phenomenon discussed in the previous two chapters. Instead of being caused solely by heat conduction through the ice, frazil crystals may be produced in supercooled water below the ice or be swept in from nearby ice shelves. These crystals can then attach to the interface, increasing the total growth. However, as the creation of frazil is not involved in the heat balance used in this model, the comparison to the data of Purdie et al. (2006) will not be considered further here. It may, however, point to the importance of platelet growth in regions of Antarctic sea ice growth.

\subsubsection{Role of salt}

To investigate the effect salt has on the ice growth process, Stefan's solution, Equation 5.5, is compared with the asymptotic solution of $\mathrm{M}^{c}$ Guinness (2009), Equation 5.33. Assuming no initial ice growth, the key differences are the addition of the $\gamma_{1} h$ term in Equation 5.33 and the change in the latent heat term $L(\mathcal{L})$.

Figure 5.1 shows the difference between the salt-inclusive model and Stefan's solution. Salt transport significantly slows the rate of ice growth. As $C_{S}$, the turbulent salt coefficient, is an order of magnitude smaller than that of heat, $C_{T}$, the heat convects more rapidly away from the ice-water interface, creating a build-up of salt. By decreasing the freezing point temperature at the interface, this increases the heat flux from the ocean to the ice and slows the growth.

A similar salt-induced growth decrease is discussed in Weber (1977). 
However, his model ignores the oceanic heat flux and only considers diffusive salt transport. Weber also deals with only very thin ice. Due to this, the colder ice-water interface (due to the salt build-up) has a more significant impact on the ice growth. This effect becomes less important for a thicker ice cover.

If the rate of salt transport is increased, salt is transported more rapidly away from the interface and the ice grows more quickly. In fact, as $C_{S} \rightarrow$ $\infty, \mathcal{L} \rightarrow L$ and $\gamma_{1} \rightarrow 0$. In this case, Equation 5.33 reverts back to the Stefan solution, as "physically" the salt instantly disappears from the interface and growth is controlled by the flow of heat alone.

Salt transport is also affected by the friction velocity. This will be discussed further in the following section.

\subsubsection{Model Sensitivity}

\section{Air Temperature}

In the results presented so far a constant air temperature has been assumed. This is a commonly used approximation in sea ice growth models (e.g. Nakawo and Sinha (1981); Maykut (1986)). In his paper, $\mathrm{M}^{c}$ Guinness (2009) discusses the penetration and oscillation of heat due to varying air temperatures. The ice acts to damp out the rapid changes, allowing for the assumption of a running average or constant temperature to be used. In this section, the constant air temperature results will be compared with the effect of a varying temperature using 150 days of Antarctic air temperature data.

The Antarctic data shows temperature variations between $-5^{\circ} \mathrm{C}$ and $-45^{\circ} \mathrm{C}$. Figure 5.3 plots the air temperature along with a linear approximation. This indicates an average decrease in temperature as winter progresses.

In order to solve Equations 5.22 and 5.23 using the temperature data, a fourth-order Runge-Kutta method was used (see, e.g., Gerald and Wheat- 


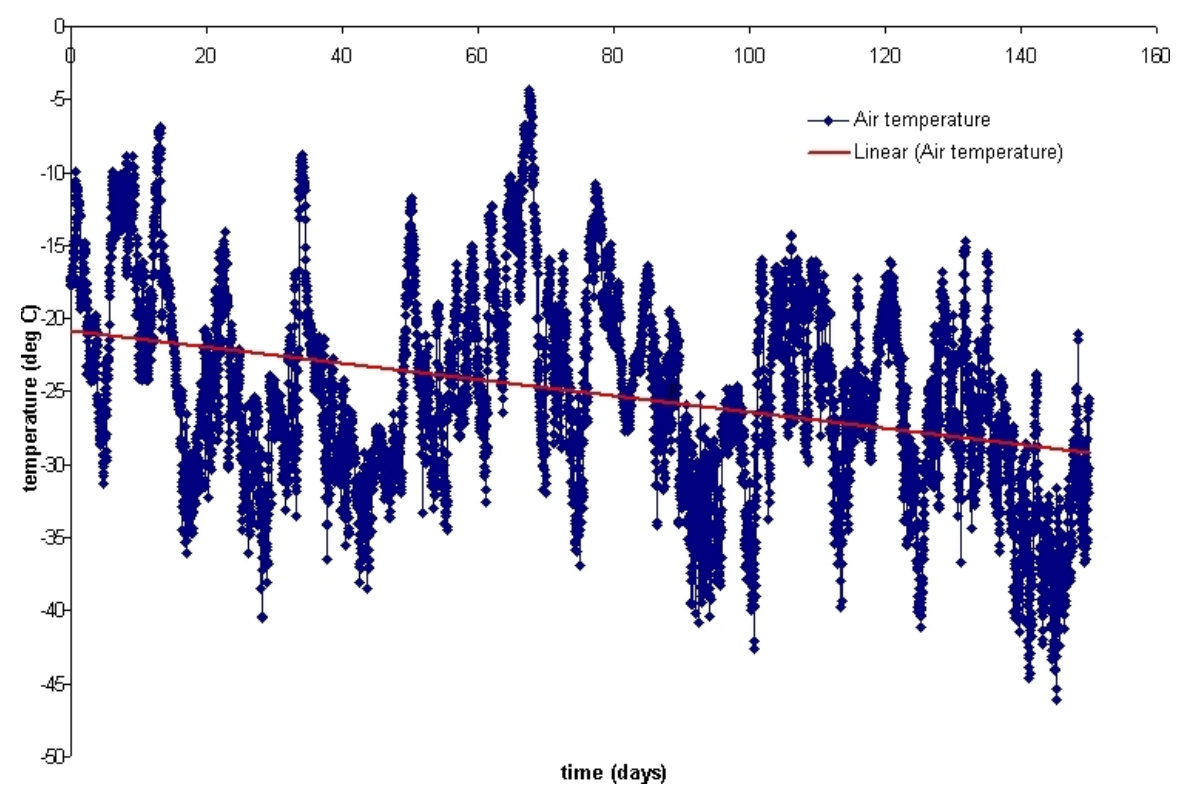

Figure 5.3: 150 days worth of field data from Antarctica give the air temperatures in winter. The linear fit shows a steady decrease in the average temperature as winter progresses.

ley (1999)). This was written in Matlab v7.5.0. The code used can be found in Appendix B Results for both the Runge-Kutta method and the RungeKutta-Fehlberg method (a combination of a fourth- and fifth-order RungeKutta schemes) were compared with those from a constant air temperature. These showed virtually identical levels of accuracy and hence the Runge-Kutta method was chosen for its more rapid execution time.

Figure 5.4 compares, in days, the growth predicted by the model using the Antarctic air temperature data and a constant temperature of $-25^{\circ} \mathrm{C}$. It is noticeable that, until it nears the end of the 150 day period, the databased model predicts a smaller ice thickness. In fact, from day 10 to day 100, apart from a 10-day period starting on day 50 , the difference is quite significant. Beyond day 100, the real temperature projection steadily catches that of the constant assumption.

The difference in the predicted growth can be explained by the linear 


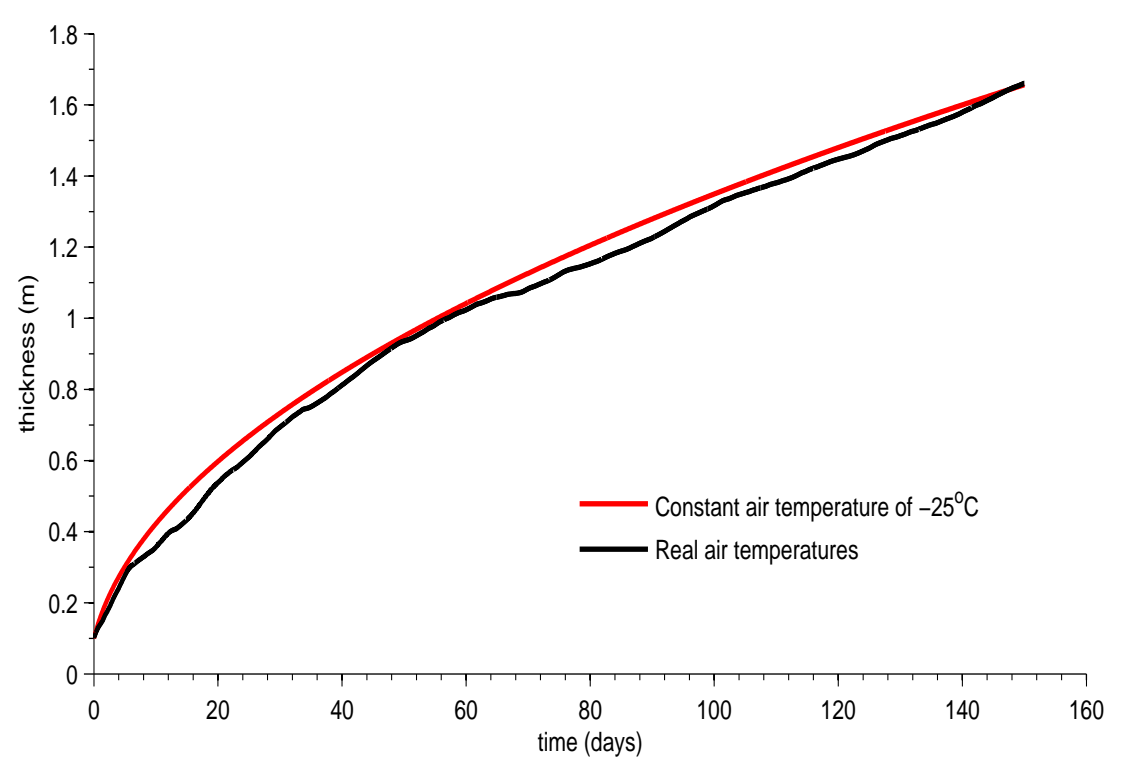

Figure 5.4: Ice growth comparison between the model prediction for an average air temperature of $-25^{\circ} \mathrm{C}$ and for recorded Antarctic air temperatures. Thinner ice growth is predicted when real temperatures are used, except at the very end of the 150 day period.

approximation to the temperature in Figure 5.3. In the data of Langhorne and Purdie, the average air temperature decreases during winter. The average temperature early in the growth season is greater than the winter long average $\left(-25^{\circ} \mathrm{C}\right)$. This leads to a smaller temperature difference through the ice and slower growth. By the end of the measurements, the air temperature averages below $-25^{\circ} \mathrm{C}$ and more rapid growth occurs. With such a limited quantity of data available, it cannot be certain whether this is a regular phenomenon or merely due to the weather patterns of a single year.

As is to be expected, plotting the numerical solutions for the ice growth using the varying air temperatures against degree days (not shown) predicts an almost identical rate of growth for the constant air temperature assumption. 


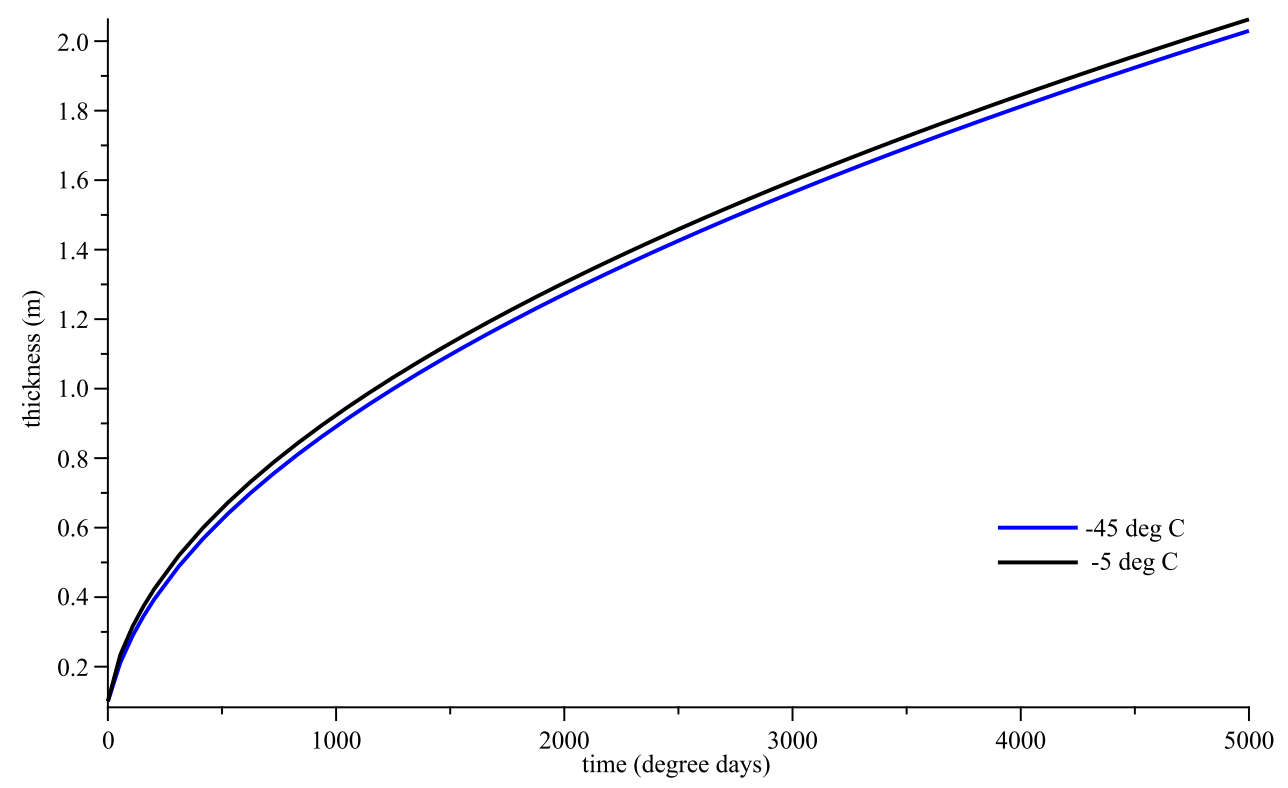

Figure 5.5: The ice thickness is shown for two values of the air temperature, greater and smaller than the typical average Antarctic temperature. Ice growth varies little for the different temperatures, though growth becomes slightly more rapid as the air temperature increases. This is due to a greater ratio in the atmospheric to oceanic heat flux.

The numerical results confirm the asymptotic solutions found by $\mathrm{M}^{c}$ Guinness (2009). Altering the air temperature (when considered in degree-days) has little effect on the growth, as show in Figure 5.5. Over 5000 degree-days there is little difference in ice growth, with greater growth occurring when the air temperature is warmer. This is caused by a larger ratio of atmospheric heat flux to oceanic heat flux. For $T_{a}=-5^{\circ} \mathrm{C}$, the ratio is initially 2.6 , increasing only slightly during growth. For colder temperatures $\left(-25^{\circ} \mathrm{C}\right.$ and $\left.-45^{\circ} \mathrm{C}\right)$ this ratio begins closer to 2.2 and 1.8 , respectively. Comparatively, these increase far more rapidly and all ratios tend towards around 2.6. See Section 5.5 for further discussion on the heat fluxes. 


\section{Mixed layer temperature}

To simplify the ice growth equations, many early models assumed that oceanic heat flux was negligible compared to the atmospheric heat flux (e.g. Leppäranta (1993) and Weber (1977)). However, more recent studies have found heat transfer between the ocean and the ice-water interface to be significant (Mellor et al., 1986; McPhee, 1987; Steele et al., 1989;: Omstedt and Wettlaufer, 1992).

As the oceanic heat flux is important, the temperature and salinity of the mixed layer must be considered. Given equilibrium conditions, the mixed layer temperature will be equal to the freezing point temperature of the salinity present. For a standard mixed layer salinity of $35 \mathrm{psu}$ this gives a temperature of $-1.89^{\circ} \mathrm{C}$. Figure 5.6 shows the effects of altering the mixed layer temperature by $0.5^{\circ} \mathrm{C}$ (and changing the salinity to match). Though this alters the temperature at the ice-water interface, there is no significant change in the temperature difference between this boundary and the iceatmosphere interface. The atmospheric heat flux therefore remains nearly identical. A more significant change, however, occurs in the oceanic heat flux.

Intuitively, a warmer mixed layer suggests a greater heat flux into the ice. This would lead to a slower rate of growth. As can be seen in Figure 5.6, this is not the case. In fact, the higher mixed layer temperature (and equivalent drop in its salinity) leads to an increase in the interfacial temperature. The change in temperature at the interface is greater than that prescribed in the mixed layer. Hence, there is a drop in the oceanic heat flux and an increase in the ice thickness. The opposite is true for a lesser mixed layer temperature.

Antarctic conditions can lead to the water dropping below the freezing temperature (see Section 2.1). It is not uncommon to see supercooling of $0.01{ }^{\circ} \mathrm{C}$ in the mixed layer in the $\mathrm{M}^{c}$ Murdo Sound region (Leonard et al. 2006). Smedsrud and Jenkins (2004) predicted supercooling levels of $0.02{ }^{\circ} \mathrm{C}$ in a model for frazil ice growth beneath Antarctic ice shelves, 


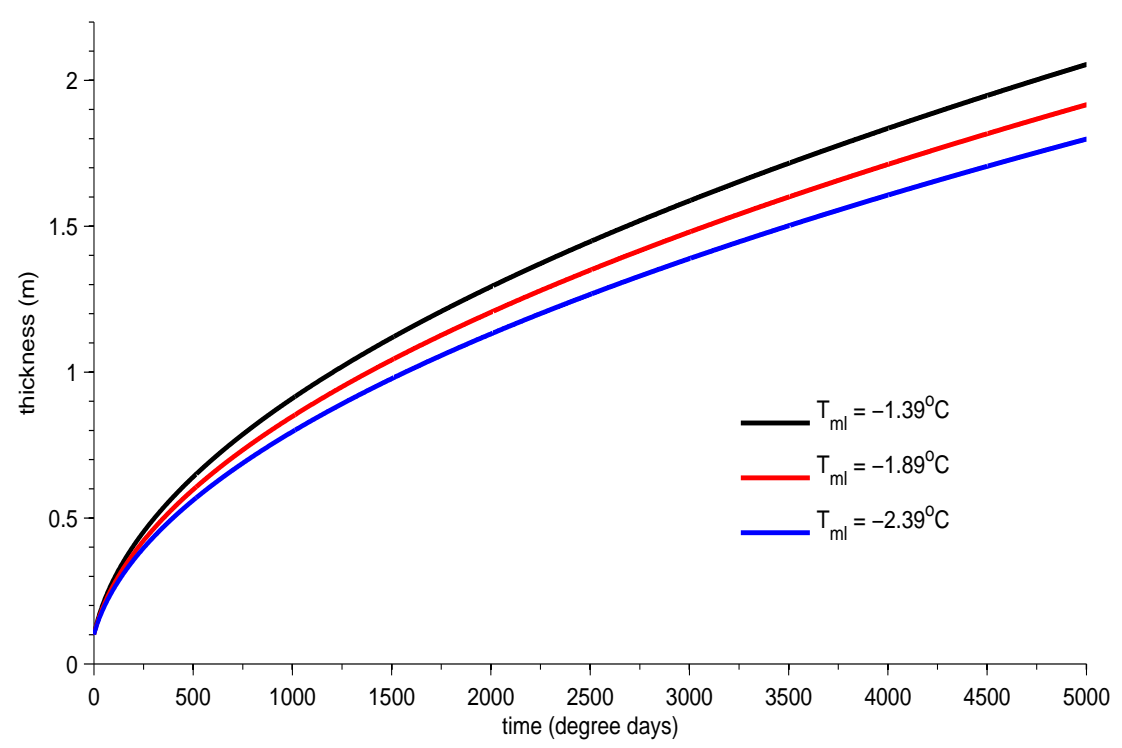

Figure 5.6: The effect on the ice growth of changing the mixed layer temperature. An increase in the mixed layer temperature (decreasing its salinity) decreases the oceanic heat flux resulting in more rapid ice growth. The opposite is true for a cooler mixed layer.

though they also mention measurements made of levels up to $0.05^{\circ} \mathrm{C}$. Similarly, Skogseth et al. (2009) discuss temperatures dropping as much as $0.06^{\circ} \mathrm{C}$ below the freezing temperature in the Antarctic.

In supercooled water a lower temperature is not linked with an equivalent increase in salinity. Due to this, and in contrast to a linked temperature and salinity, (super)cooling of the mixed layer now produces more rapid growth. With a small supercooling $\left(0.01^{\circ} \mathrm{C}\right)$, Figure 5.7 shows an equivalent increase in the growth rate. This is caused by a slight drop in the oceanic heat flux to the ice.

The effect of a $0.06^{\circ} \mathrm{C}$ supercooling is more pronounced. In this case, a small drop in the atmospheric heat flux is outweighed by a significant decrease in the oceanic flux. Given a sufficient supercooling, the temperature at the interface may rise above that of the mixed layer. The oceanic heat 


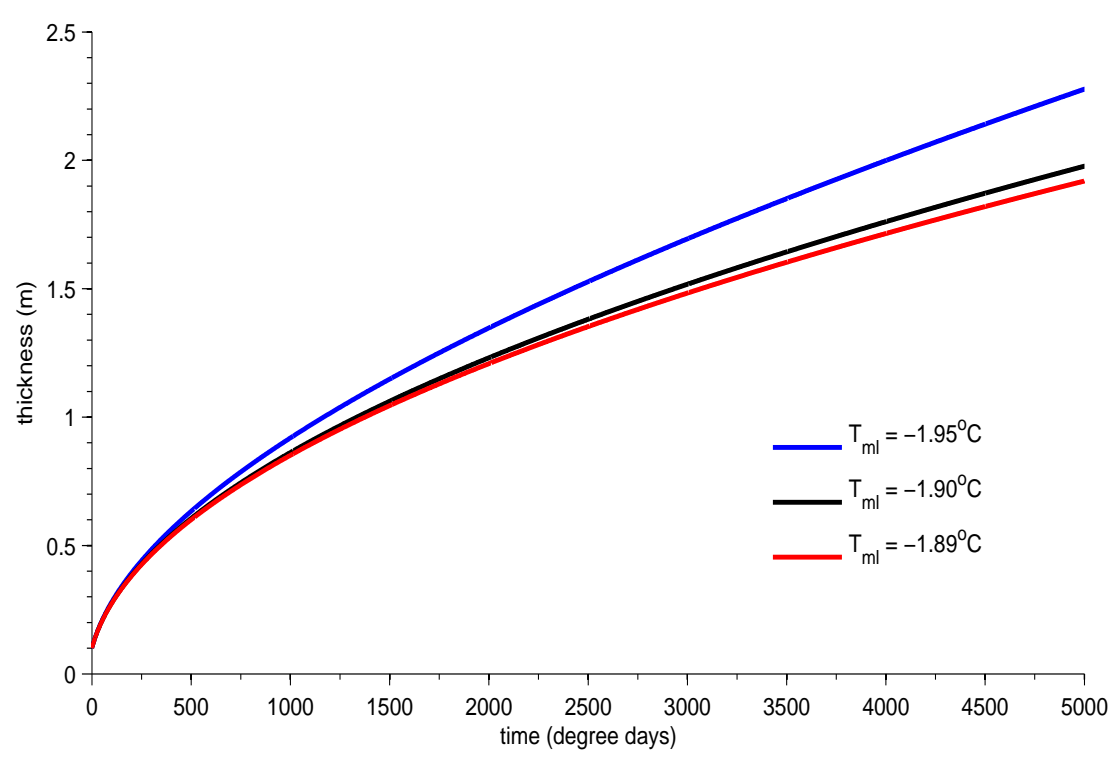

Figure 5.7: The effect of a supercooled mixed layer on the ice growth. A typical supercooling (in the $\mathrm{M}^{c}$ Murdo Sound region) of $0.01^{\circ} \mathrm{C}$ has a small but noticeable effect. For a supercooling of $0.06{ }^{\circ} \mathrm{C}$ (as measured by Skogseth et al. 2009) the increase in the growth rate is more pronounced.

flux would then be directed from the ice to the ocean. With the mixed layer acting as a heat sink, growth continues rapidly without bound. Realistically, unless heat was continually removed from the bottom of the mixed layer, the water would be expected to warm back towards the interfacial temperature and the oceanic heat flux would reach an equilibrium. Alternatively, frazil nucleation and growth could act to relieve the supercooling.

\section{Friction velocity}

The friction velocity plays an important role in regulating the salt buildup at the interface. The greater $u_{*}$ is, the more rapidly salt, rejected from the ice, can be dispersed through the mixed layer. Indeed, considering Equation 5.34, as $u_{*} \rightarrow \infty, \gamma_{1} \rightarrow 0$. Equation 5.33 reverts back to the form of the Stefan solution (Equation 5.5) and the growth rate increases. 


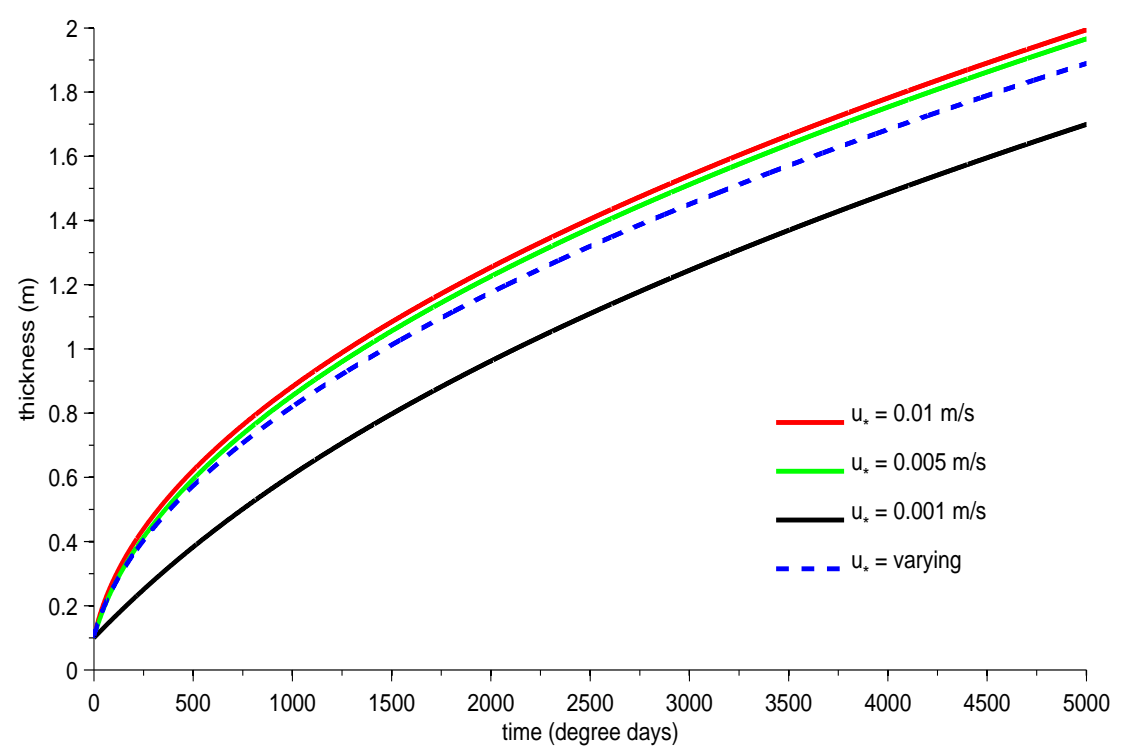

Figure 5.8: Small friction velocities can have a significant role in slowing ice growth. Above $0.5 \mathrm{~cm} \cdot \mathrm{s}^{-1}$ there is little change in the growth rate as $u_{*}$ is increased. Below this value, salt build-up causes a depression in the freezing point. This leads to a greater oceanic heat flux and slower growth. Also shown is an example of a varying $u_{*}$ in which the friction velocity varies both diurnally and fortnightly.

However, the adjusted latent heat term, $\mathcal{L}$, remains - more heat must be removed to freeze the water.

The friction velocity also assists the transport of heat away from the interface. Therefore, there is a value of the friction velocity above which increasing $u_{*}$ does little to increase the growth rate. The growth is restricted by the ratio of the turbulent transfer co-efficients. Given reasonable Antarctic conditions, little extra growth occurs if $u_{*}$ is increased above $0.5 \mathrm{~cm} \cdot \mathrm{s}^{-1}$. However, decrease the friction velocity sufficiently and a significant drop in the rate of growth can be observed (Figure 5.8). This is caused by salt build-up at the interface, resulting in a drop in the freezing point and a greater oceanic heat flux from the ocean to the ice.

In reality, a constant friction velocity throughout the ice growth season is unlikely. With the friction velocity depending on the shear flow (Equa- 
tion 3.10, $u_{*}$ will vary with both the diurnal and fortnightly tidal cycles, as in Figure 3.8 .

One example of a varying friction velocity can be seen in Figure 5.8 Shown is a $u_{*}$ which varies from still water to a maximum (due to the simultaneous daily and fortnightly maximum tides) of $2 \mathrm{~cm} . \mathrm{s}^{-1}$, with an average of $1 \mathrm{~cm} \cdot \mathrm{s}^{-1}$. This produces a significant decrease in the ice growth when compared to the equivalent (average) constant friction velocity cases. The most interesting period occurs as the friction velocity drops to its smallest values (reaching $0 \mathrm{~cm} \cdot \mathrm{s}^{-1}$ ). At this stage there is a significant salt build-up at the interface. This results in a large oceanic heat flux from the mixed layer which produces periods of almost no growth.

It is unlikely, however, that the friction velocity would drop away completely. Prevailing (residual) currents have been found to be up to $10 \%$ of the tidal maximum (pers. comm. Craig Stevens, 2009). Brine rejection, as introduced in Chapter 4, would also become a factor as the shear flow weakened. These would prevent such an excessive build-up of salt at the interface. The latter of these two ideas will be discussed in the following section.

\subsection{The effects of brine rejection on ice growth}

During ice growth the rejected brine contributes to the turbulence at the interface. It is difficult to calculate the combined effect of shear and brine rejection on a frazil crystal due to the differing directions at which they act. However, in this situation, the total friction velocity produced beneath the ice has a close analogy to heating over land or water. In these cases, wind provides a shear flow near the surface. At the same time, plumes of hot air, warmed by the underlying surface, rise, creating a flow of air (Redelsperger et al. 1999). This movement has been referred to as a "gustiness" factor (Godfrey and Beljaars, 1991; Grachev et al., 1998; Mahrt et al. 1998), the horizontal flow caused by a vertical convective velocity. 
Beljaars (1994) proposed that Equation 3.10 could be extended to

$$
u_{*}^{2}=K\left(U^{2}+\left(\beta_{1} w_{*}\right)^{2}\right)
$$

where $\beta_{1}$ is an empirical constant of order 1 . Equation 4.12 defines $w_{*}$ in which the model results can be used to eliminate $h$. Substituting Equations 5.13 and 5.17 give

$$
w_{*}=\beta_{2} u_{*}\left(S_{w}-S_{m l}\right)
$$

where

$$
\beta_{2}=\kappa z_{m l} g \frac{\rho_{m l} l}{\rho_{w}^{2}} C_{S} \frac{d \rho_{w}}{d S}
$$

and $\beta_{1}$ is set to 1 .

Figure 5.9 compares two examples for the combined shear and buoyancy model with a constant shear case. In the first example, the shear velocity is set to a constant $0.28 \mathrm{~m} \cdot \mathrm{s}^{-1}$, equivalent to a friction velocity of $1 \mathrm{~cm} . \mathrm{s}^{-1}$ if brine rejection is ignored. In the previous section it is shown that increasing the friction velocity beyond $1 \mathrm{~cm} \cdot \mathrm{s}^{-1}$ had little effect on the growth rate. The velocity associated with brine rejection, $w_{*}$, acts to increase the friction velocity yet is always much smaller than $U$. Hence, ice growth is similar to the constant shear case.

In the second example, the shear flow is allowed to vary, changing with the tides as in Figure 3.8. In this case, brine rejection plays a more significant role by preventing a complete reduction in the friction velocity as the tide turns. This means that there is a much smaller build-up of salt at the interface. Hence, there is a far smaller drop off in the growth rate at these times and the growth rate is, again, similar to that of the constant shear case. 


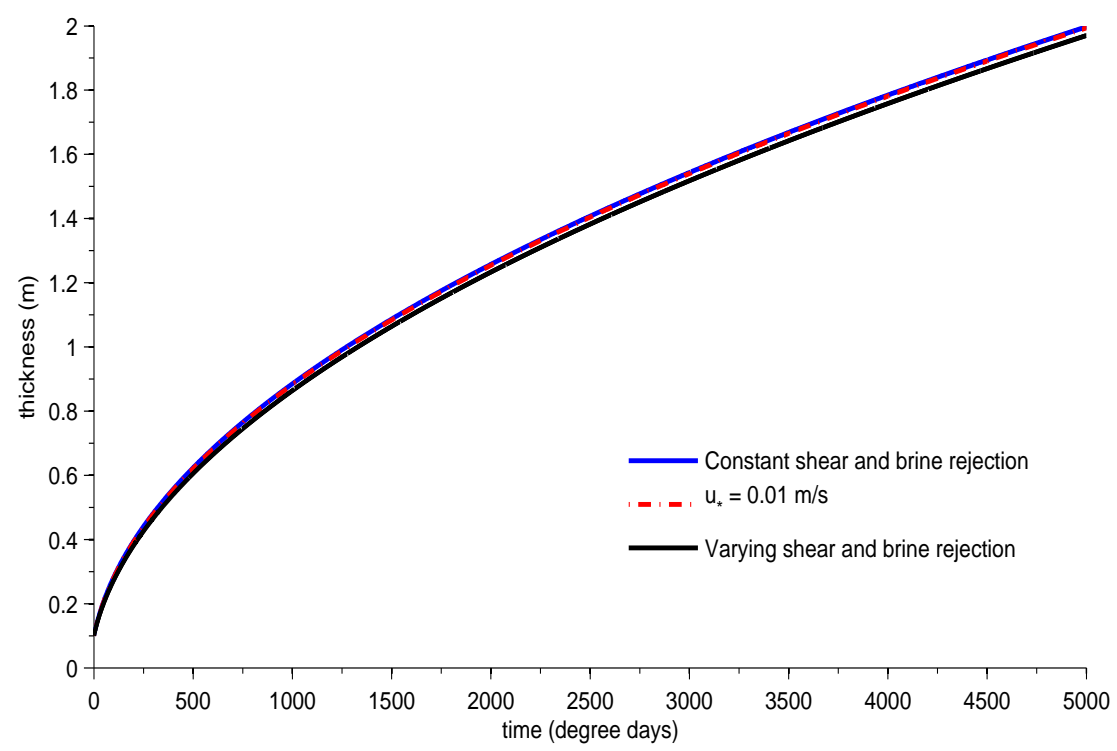

Figure 5.9: The effect of including both shear and brine rejection in the ice growth model are shown. Both a constant shear example (with a shear flow equivalent to a friction velocity of $0.01 \mathrm{~m} . \mathrm{s}^{-1}$ without brine rejection) and a varying shear case (average $u_{*}$ of $0.01 \mathrm{~m} . \mathrm{s}^{-1}$ without brine rejection) are compared with a constant friction velocity. The increase in the friction velocity due to brine rejection is minor; however, it does prevent a significant build-up of salt at the interface if the shear flow is reduced.

Though not shown here, it is also interesting to note that varying the depth of the mixed layer (which affects the brine rejection) by up to $25 \mathrm{~m}$ has no noticeable effect on the growth rate.

\subsection{Heat flux}

Figure 5.10 shows the oceanic and atmospheric heat fluxes for the three ice growth cases described in Figure 5.5. For each given air temperature the atmospheric heat flux (ice to atmosphere) is greater than the oceanic equivalent (ocean to ice). Unsurprisingly, the colder air temperature provides a greater atmospheric heat flux. This also results in a larger oceanic 


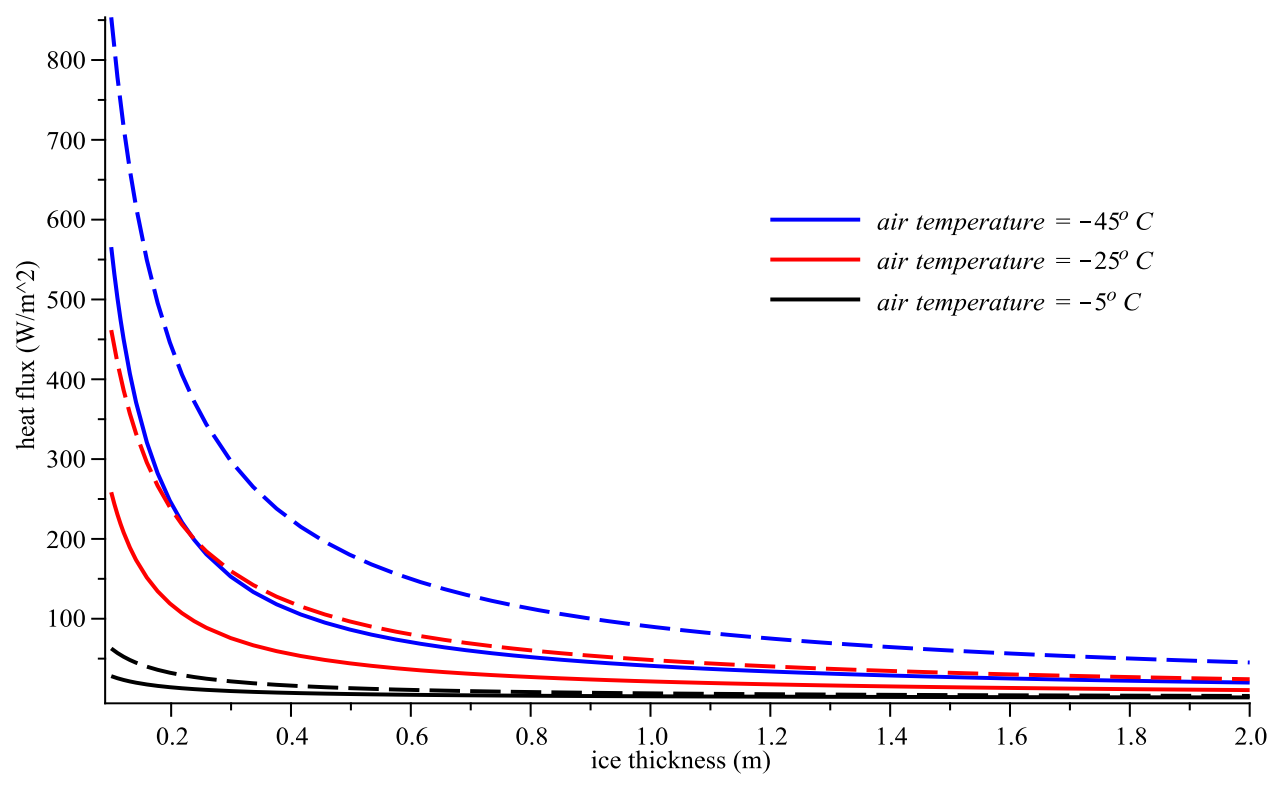

Figure 5.10: The atmospheric (dashed lines) and oceanic (solid lines) heat fluxes are shown for three air temperatures. Warmer temperatures lead to smaller heat fluxes. All fluxes experience a rapid initial drop in size as the ice thickens quickly.

heat flux due to a cooler ice-water interface.

Atmospheric heat flux is greatest after the initial formation of an ice cover. Heat is transferred rapidly through the thin layer. With a large difference between the heat fluxes, the ice grows rapidly. As the ice thickens it acts as an insulator and the flux decreases. At the same time a similar, though smaller, drop occurs in the oceanic heat flux. This is because the temperature at the growing interface is increasing from near the air temperature towards the freezing temperature.

Maykut (1978, 1986) made measurements of the conductive (atmospheric) heat flux in the central Arctic. These were taken for different ice thicknesses throughout the year. He found that, for ice between 0 and $10 \mathrm{~cm}$ thick, the average heat flux was $543 \mathrm{~W} \cdot \mathrm{m}^{-2}$. The model, using an air temperature of $-25^{\circ} \mathrm{C}$, has a flux of $465 \mathrm{~W} \cdot \mathrm{m}^{-2}$ at $10 \mathrm{~cm}$. However, a comparison for a thickness smaller than $10 \mathrm{~cm}$ may not be entirely accurate. 
This is as the model assumes this initial growth to be due to the accumulation of frazil crystals and pancake formation. Maykut's results show that, for an ice thickness between 10 and $20 \mathrm{~cm}$, the average heat flux has decreased to $280 \mathrm{~W} \cdot \mathrm{m}^{-2}$. This drops to $173 \mathrm{~W} \cdot \mathrm{m}^{-2}$ from 20 to $40 \mathrm{~cm}$ and to $99 \mathrm{~W} \cdot \mathrm{m}^{-2}$ up to $80 \mathrm{~cm}$. This compares with values of $314 \mathrm{~W} \cdot \mathrm{m}^{-2}, 159 \mathrm{~W} \cdot \mathrm{m}^{-2}$ and $80 \mathrm{~W} \cdot \mathrm{m}^{-2}$ respectively for the model, taken at the middle of each depth interval, with an air temperature of $-25^{\circ} \mathrm{C}$. Given the potential difference in air temperature, snow thickness and ice conditions, comparisons can only be made as a guide, but do seem to show a reasonable similarity.

Measurements of the oceanic heat flux for multi-year ice or over clear water are relatively easy to come by. Maykut (1978) notes that oceanic heat fluxes for open water can be over $900 \mathrm{~W} \cdot \mathrm{m}^{-2}$. However, as soon as an ice cover is in place, it acts as insulator, significantly decreasing the oceanic heat flux. Measurements of the flux for a thin growing cover are harder to find. $\mathrm{M}^{c}$ Phee et al. (1999) is one exception. Their measurements were based on seasonal drifting ice, where the movement can cause large short-term fluctuations due to changes in the underlying ocean. The presented oceanic heat fluxes have average values of $23.4 \pm 4.3 \mathrm{~W} . \mathrm{m}^{-2}$, $51.5 \pm 6.7 \mathrm{~W} \cdot \mathrm{m}^{-2}$ and $27.4 \mathrm{~W} \cdot \mathrm{m}^{-2}$. The largest of these is noted to have spent a long period over a warm eddy, suggesting it is anomalously high. As the readings were made over different periods of time, the average air temperature is difficult to discern. Given $\mathrm{M}^{c}$ Phee et al.'s thermistor string readings, the ice thickness for their measurements is around $70 \mathrm{~cm}$. For a similar thickness, with an air temperature of $-25^{\circ} \mathrm{C}$, the model gives a flux of $31 \mathrm{~W} \cdot \mathrm{m}^{-2}$.

Approximations of the oceanic heat flux were also made by Allison (1979) during a study of Antarctic ice growth. Measurements were made in Mawson, an Australian continental research station, which is only just within the Antarctic Circle. The average air temperature was around $-20^{\circ} \mathrm{C}$. Allison's findings show a similar pattern to the model results. Ten days after the initial ice formation (an ice thickness of around $30 \mathrm{~cm}$ ) the 
oceanic heat flux is found to be between 20 and $45 \mathrm{~W} \cdot \mathrm{m}^{-2}$. At the same depth, the modelled flux is around $58 \mathrm{~W} \cdot \mathrm{m}^{-2}$ for an average temperature of $-20^{\circ} \mathrm{C}$. Allison's measurements drop rapidly and by the end of the growth season are found to be averaging closer to $10 \mathrm{~W} \cdot \mathrm{m}^{-2}$. This is similar to the average temperature results.

Additionally, flux measurements from Molodezhnaya and Halley Bay were given in Allison (1979). Both locations are nearly 10 degrees south of Mawson, suggesting a cooler average air temperature. The findings commence later in the season, around 20 days after initial formation (approximately $0.5 \mathrm{~m}$ of growth). At this stage, the oceanic heat flux was found to be between 45 and $50 \mathrm{~W} \cdot \mathrm{m}^{-2}$. This compares to $44 \mathrm{~W} \cdot \mathrm{m}^{-2}$ for the average temperature model $\left(-25^{\circ} \mathrm{C}\right)$. Both regions decrease to similar values as at Mawson.

There is one notable difference between the model results and the season long measurements at the three stations. Between 100 and 150 days a second, smaller peak in the heat flux was observed. At this stage, the flux jumps around $10 \mathrm{~W} \cdot \mathrm{m}^{-2}$ to between 15 and $20 \mathrm{~W} \cdot \mathrm{m}^{-2}$. Allison suggests that this is caused by "large scale north-south circulation", where heat and salt is transported into the mixed layer due to a maximum in the sea-ice extent and increasing solar radiation. Such events are not considered in the model presented in this chapter.

It is apparent that atmospheric heat fluxes are heavily influenced by the local air temperature. Somewhat more surprising is the role it plays, through the change in the ice-water interface temperature, in the oceanic heat flux. In Figure 5.11, the oceanic heat flux estimated by the model using the Antarctic temperature data is compared with a constant $-25^{\circ} \mathrm{C}$ run. The equivalent ice thicknesses can be seen in Figure 5.4 . Beyond $0.5 \mathrm{~m}$ of growth, the assumption of a constant air temperature provides a good approximation. Prior to this there are two periods when the real temperature results are significantly below that for the average temperature. The first of these occurs immediately following the initial ice formation. Being 


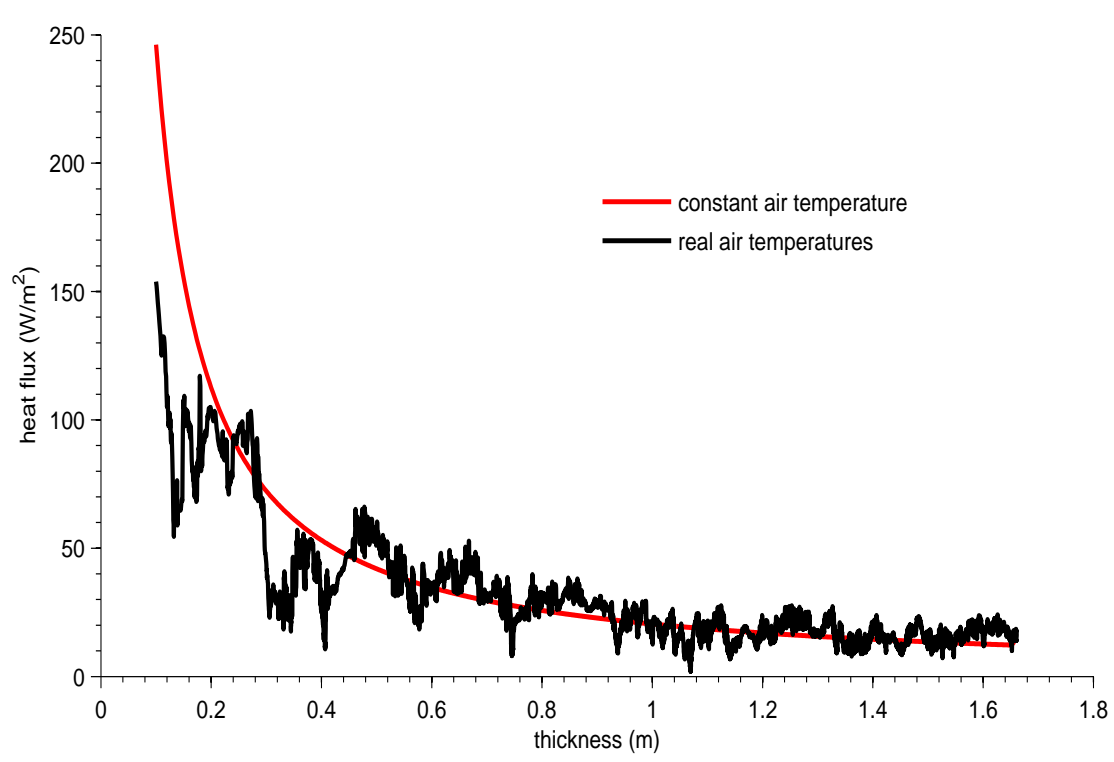

Figure 5.11: The oceanic heat flux is shown for the model based on both real and average temperature values. Plots for the atmospheric heat flux follow an almost identical pattern. The heat flux predicted for the real temperature based model is significantly less initially, and again between 30 and $45 \mathrm{~cm}$ of growth. After $50 \mathrm{~cm}$ the models show a reasonable match.

early in the growth season, temperatures are warmer than the average and hence the fluxes are smaller.

\subsubsection{Frazil production}

One of the important Antarctic ice growth processes that this model does not account for is the inclusion of platelet crystals in the ice cover. This may be caused by frazil crystals, created beneath the ice itself or transported from below nearby ice shelves, rising up and settling against the ice-water interface. Though including this in the model is beyond the scope of this work, a first approximation can be made to estimate the maximum mass of frazil which could be created below the sea ice. This estimate is based on assuming that the oceanic heat flux is due solely to the growth 
of frazil crystals.

The oceanic heat flux is primarily driven by the temperature (and hence the salinity) at the interface. As the ice thickens the interface warms and, with the mixed layer temperature assumed constant, the heat flux decreases.

If the heat removed from the ocean is assumed to lead solely to the formation of frazil crystals, then the quantity of frazil ice formed is directly related to the heat flux. In this situation, the mass of ice formed beneath a unit area can be given by

$$
m_{f}=\frac{\int_{0}^{5000} Q_{T} d t}{L_{i}}
$$

where $L_{i}$ is the latent heat of freezing of pure ice. $Q_{T}$ is taken from the model presented in this chapter.

In order to find the potential ice thickness the frazil could produce, $m_{f}$ is divided by the density of accumulated frazil. The maximum possible density is simply the density of ice. However, there is evidence that frazil does not pack this tightly. In field experiments, Perham (1980) measured the density of frazil sections attached to lines in rivers in New Hampshire and Vermont. He found that the density averaged around $460 \mathrm{~kg} \cdot \mathrm{m}^{-3}$. Given this density range, and using Equation 5.40, it is found that a frazil layer between $1.2 \mathrm{~m}$ and $2.3 \mathrm{~m}$ in thickness could be formed during the winter season.

This is a very simple approximation. It seems unlikely that the oceanic heat flux would be associated solely with frazil formation. It is also possible that significant quantities of crystals may be swept in from beneath nearby ice shelves. Further research, including more accurate measurements on the oceanic heat flux, the origin of the frazil crystals and the initial density of the frazil layer is needed. However, these calculations do show that there is sufficient heat flux to account for significant quantities 
of frazil ice in the mixed layer.

\subsection{Summary}

In this chapter, a one-dimensional first-year sea ice growth model was presented. It is solved numerically and the results compared with a number of other models and field results. A reasonable match is found in general. One notable exception is with the Antarctic measurements made by Purdie et al. (2006), which show a significantly faster growth rate than the model after the ice is $1 \mathrm{~m}$ thick. One possible explanation for this is the inclusion of platelet crystals at this stage, as described in the previous chapters.

This model also describes a significantly slower ice growth rate when compared with the seminal work of Stefan from the 1880's and 1890's. This is due to the importance of salt removal from the ice and its presence at the ice-water interface. A build-up of salt at the interface leads to a depression in the freezing point of the water. This means more heat must be removed before the water can freeze.

The friction velocity has a vital role to play in this system as it controls the rate at which salt is dispersed from the interface. A weaker friction velocity leads to a greater quantity of salt and a slower growth rate. Equation 5.37 was proposed as a method for combining the friction velocity due to shear flow and brine rejection. While the shear plays the dominant role in inducing turbulence, brine rejection prevents a significant build-up if the shear drops away.

The effects of a change in the mixed layer temperature were also discussed. Surprisingly, an increase in the mixed layer temperature (and equivalent drop in mixed layer salinity) leads to a more rapid rate of ice growth. It was also shown that a consistently supercooled mixed layer can have a significant effect on the rate of growth. Though only limited levels of supercooling are typically observed in the Antarctic, it is interesting that just a small increase in this level could cause a marked increase in the ice 
thickness.

It should be noted that the salt at the interface may have another effect not considered in this chapter. The interface has been assumed to be an infinitesimally thin, planar region. In reality, a mushy zone (as discussed in Section 2.2.4) is likely to form. This occurs as the heat diffuses away from the interface more rapidly than the salt. This leads to "constitutional" supercooling, whereby the water ahead of the interface falls below the local freezing point temperature. Dendrites in the naturally rough interface grow into the supercooled region, creating the mushy zone (Fowler, 1985. Worster, 1986). This is beyond the scope of this thesis. 


\section{Chapter 6}

\section{Shear stabilisation of platelet ice}

Chapter 3 investigated whether a friction velocity, resulting from a shear flow, could prevent a frazil crystal from adhering to an ice cover. It was shown that, for a typical friction velocity, crystals up to nearly $3 \mathrm{~mm}$ in radius would remain unattached. Frazil of this size is rarely seen in a natural environment and hence it was presumed that most frazil would be prevented from sticking to the interface.

The work in Chapter 3 calculated the effect of the shear flow on the crystals. What was not considered was the simultaneous effect a concentration of crystals may have on the shear flow itself. This will be the primary focus of this chapter. As in Chapter 3 , the lead will be taken from sedimentation theory and adapted, where necessary, for the inverse situation of rising frazil. Firstly, the method of transport for frazil crystals will be considered. The effect of frazil on the friction velocity will follow. Finally it will be asked whether or not frazil should be regarded as a "cohesive sediment".

\subsection{Bedload or suspended load}

As noted in the introduction, it was calculated that, under a steady flow with a magnitude typical for Antarctic conditions, most crystals would 
be prevented from attaching to the interface. Depending on their size, the crystals may undergo two types of motion; in sedimentation these are termed bedload transport and suspended load transport. In bedload transport, sediments tend not to deviate far from the solid-fluid interface. However, as long as the shear flow (or friction velocity) remains strong enough, the sediment will continue to move along the interface. As it travels it may potentially bounce or skim along the solid surface. Suspended transport occurs when sediment is prevented from having any contact with the interface. Both bedload and suspended load layers can co-exist.

The Shields criterion, used in Section 3.5 to predict sediment motion, does not discern between bedload and suspended load motion. In this section, a suspension criterion will be used to enhance the picture of subice frazil motion.

\subsubsection{Suspended load criteria}

The theory of sediment suspension criteria is based on the ability of the vertical components of turbulence to keep a grain in suspension (Leeder et al., 2005). The Rouse number, a ratio of the upward turbulent forces acting on a sediment to its settling velocity, was used by Bagnold (1966) to develop a critical Shields parameter for suspension. At different critical values of the Rouse number sediment is said to move in a different transport regime.

Bagnold (1966) defined the ratio $\frac{v_{u p}^{\prime}}{w_{s}}$, where $v_{u p}^{\prime}$ are the upward fluctuations of the velocity components and $w_{s}$ is the settling velocity of the sediment. He predicted that the threshold for suspension would occur at a critical value of this fraction, less than 1 . A complete concentration profile would be created at another critical value, greater than 1 . By approximating $v_{u p}^{\prime}$ as proportional to the friction velocity, $u_{*}$ (setting $v_{u p}^{\prime}=1.25 u_{*}$ ), and assuming the critical value of the ratio to be equal to 1 , Bagnold rewrote 
Equation 2.6 in terms of the settling velocity as

$$
1.25^{2} \tau=\rho_{w} w_{s}^{2}
$$

Substituting $\tau=\theta_{s s}\left(\rho_{s e d}-\rho_{w}\right) g d_{e}$, where $\theta_{s s}$ is the critical Shields parameter for suspension, $\rho_{\text {sed }}$ the density of the sediment and $d_{e}$ the effective diameter, a suspension criterion can be found. If a grain's Shields parameter value is greater than the critical value, it will remain in suspension. The critical value is given as

$$
\theta_{s s}=0.64 \frac{w_{s}^{2}}{g d_{e}} \frac{\rho_{w}}{\rho_{s e d}-\rho_{w}} .
$$

While Bagnold's suspension theory is generally accepted, there are still some questions about the exact relationship between the vertical velocity fluctuations and the friction velocity (Leeder $e t$ al. 2005). It was stated in van Rijn (1984) that experimental results found $v_{u p}^{\prime}$ to be approximately equal to $u_{*}$, altering Bagnold's Equation 6.2 accordingly. A similar modification is made in Leeder et al. (2005). Van Rijn (1984) also presented results from a second study which found the critical value of the ratio $\frac{v_{u p}^{\prime}}{w_{s}}$ (or $\left.\frac{u_{*}}{w_{s}}\right)$ to be 0.25 . His own experiments suggested that some suspension may occur between this lower criterion and that of Bagnold's. He proposed that a full concentration profile could occur when Bagnold's modified criterion was satisfied, though some suspension may occur at the lower critical value.

These criteria can be altered for the inverse situation of frazil crystals rising up to meet an ice cover. The suggestions for the critical $u_{*}$,

$$
\begin{array}{lr}
u_{*}=w_{s} & \text { (modified Bagnold) } \\
u_{*}=\frac{w_{s}}{4} & \text { (van Rijn) }
\end{array}
$$


can be substituted into the equation for the Shields parameter, Equation 3.1 ,

$$
\theta_{s}=\frac{\rho_{w} u_{*}^{2}}{\left(\rho_{w}-\rho_{i}\right) g d_{e}}
$$

where $d_{e}$ is the diameter of a sphere with the same volume as the frazil disc. The rise velocity, modified for a frazil disc from Equation 4.3 in Section 4.2, is substituted for $w_{s}$ so that

$$
w_{s}=\frac{V\left(\rho_{w}-\rho_{i}\right) g}{6 \mu \pi R}
$$

where $V$ is the volume and $R$ the effective radius of the frazil disc, as given in Section 4.2. This is as opposed to the grain diameter used in Bagnold (1966), van Rijn (1984) and Leeder et al. (2005).

Combining the two conditions given above with the original Shields curve results in a modified Shields diagram, Figure 6.1. It shows the critical Shields parameter value, not only for preventing a crystal from remaining stationary, but also for ensuring that a crystal would stay in suspension.

Figure 6.1 is split by the Shields curve (red curve) and the two suspension criteria (blue and green lines) into 4 quadrants. In quadrant 1 a crystal is kept fully in suspension, away from contact with the interface. As the size of the crystal increases, it may cross the suspension criterion into the second quadrant. In this region, turbulence is sufficient to keep a crystal in motion but is not strong enough to keep it a significant distance from the interface. Van Rijn (1984) suggested that the difference between the two suspension criteria may be that, when a crystal's Shields parameter exceeds the lower critical value, enough turbulence is provided for suspension of a few individual crystals. If Bagnold's criterion is exceeded, a concentration profile may be created. Van Rijn's experimental sediment 


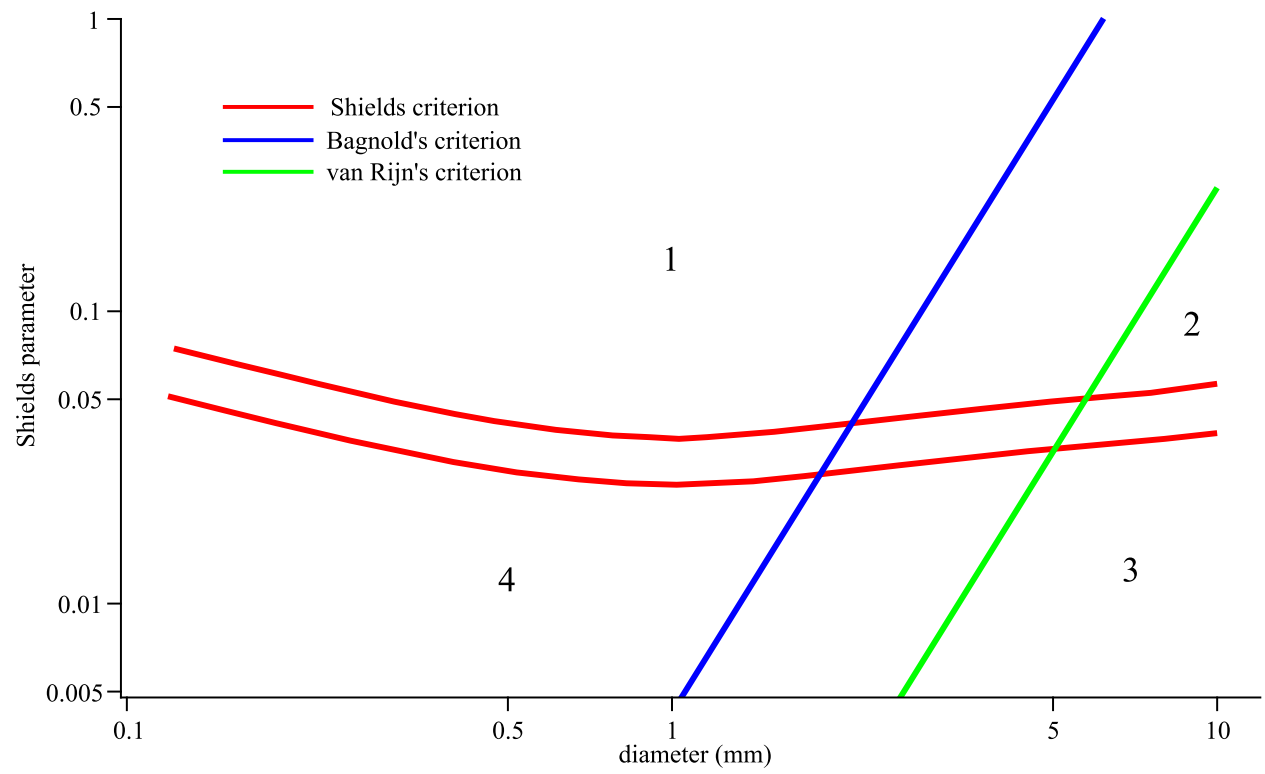

Figure 6.1: A modified Shields diagram which shows the Shields parameter required for suspension (1) and movement (2). A crystal in region (3) will rise and remain against the interface. In region (4) a crystal, introduced from depth, may remain in suspension even though it is below the traditional Shields criterion for initiation of movement. The effective radius used is that for a crystal rising with its flat side parallel to the ice-water interface, as given in Section 4.2 .

results showed some suspension of individual crystals for a band of parameter values between the two presented criteria.

In both Bagnold's (1966) and van Rijn's (1984) sediment versions of Figure 6.1, the suspension criteria cease at the Shields curve. Below this curve it is assumed that no motion is possible. Leeder et al. (2005), however, extended Bagnold's criterion below the curve, dividing this region into 2 further sections. Of these sections, quadrant 3 is identical to the region below the Shields curve in Figure 3.5 where turbulence is too weak to move the crystals. The fourth quadrant is also in the traditional region at which crystal motion would not occur. As opposed to the larger grains in quadrant 3, however, Leeder et al. (2005) suggested that smaller sediment may be able to stay in suspension if they were introduced into the 
system away from the interface. This applies to the smaller frazil crystals in the sea ice system. If a crystal's Shields parameter falls in this quadrant then, if it rises from depth, the turbulence will be sufficient to keep it in suspension. On the other hand, if it was created (unattached) adjacent to the interface or arrived as bedload (for example from nearby ice shelves or leads), the turbulence would be too weak to maintain its motion and it would settle against the interface.

Using Bagnold's criterion, Figure 6.1 suggests that crystals, if above the threshold for initiation of motion, will predominantly be moved in suspension if those crystals are smaller than around $1 \mathrm{~mm}$ in radius. As the crystal size increases, however, the critical Shields parameter for suspension (and hence the friction velocity) becomes significantly greater than for bedload motion. For a $2.5 \mathrm{~mm}$ radius frazil disc, $\theta_{s}$ must be an order of magnitude greater to keep it travelling as part of the suspended load as opposed to near the interface. The smaller criterion shows an identical trend for the primary stages of suspension. In this case, individual crystals may appear to jump, or "burst", away from the interface (van Rijn, 1984). For frazil crystals this may begin, for discs with a Shields parameter near the critical value for initiation of movement, at a radius of around 2.5 to $3 \mathrm{~mm}$.

In Chapter 3 it was shown that, for a friction velocity of $0.01 \mathrm{~m} . \mathrm{s}^{-1}$, a frazil crystal would remain in motion if it was smaller than around $3 \mathrm{~mm}$ in radius. This is shown again in Figure 6.2. The decreasing black lines describe the Shields parameter value of a frazil crystal for a given $u_{*}$ as the crystal radius increases. As can be seen, the line describing $u_{*}=1 \mathrm{~cm} . \mathrm{s}^{-1}$ cuts the Shields criterion at a radius of around $3 \mathrm{~mm}$. However, using the modified Bagnold criterion, it can be noted that crystals smaller than this, but larger than $1.4 \mathrm{~mm}$, will travel as bedload near the interface. Smaller crystals will be kept fully in suspension. If the friction velocity is decreased to $0.5 \mathrm{~cm} . \mathrm{s}^{-1}$, crystals are now in one of two quadrants. Frazil smaller than $1 \mathrm{~mm}$ in radius will move in the suspended load; larger than this and they 


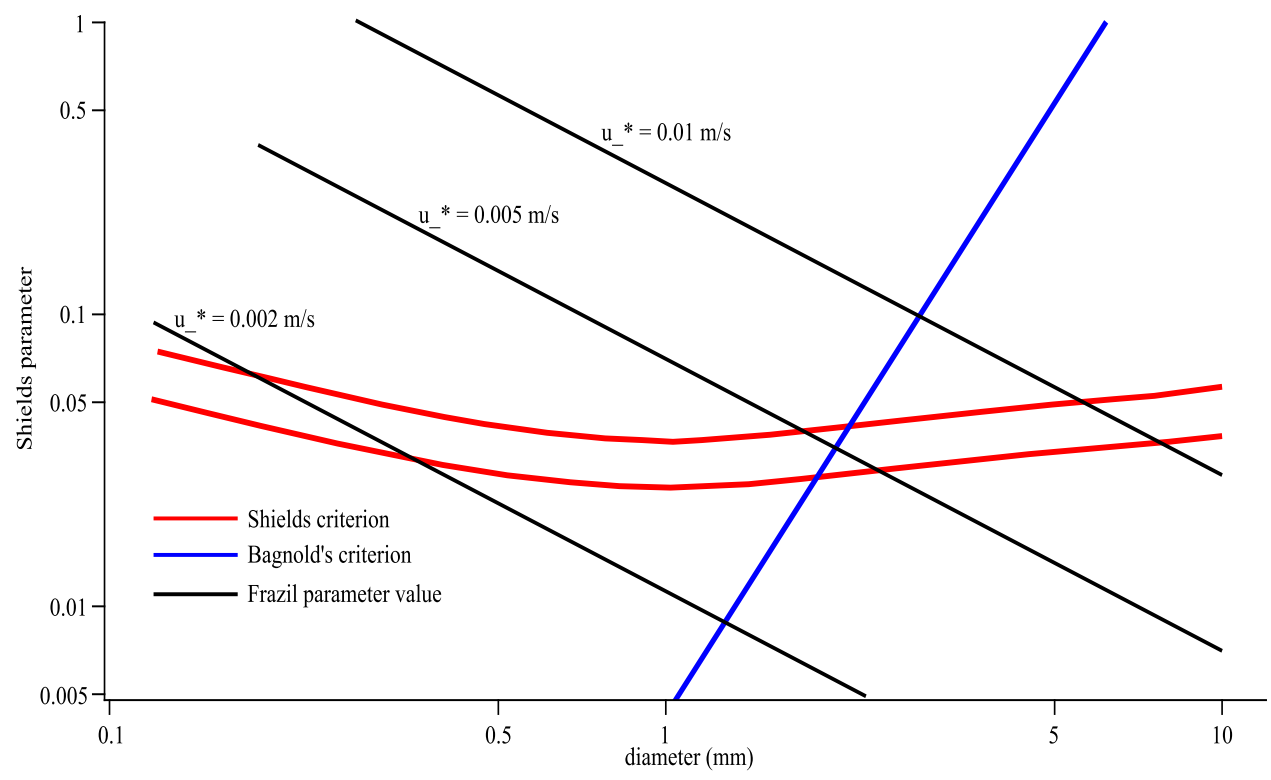

Figure 6.2: Plotting the Shields' parameter values for frazil crystals (with varying friction velocity) on the modified Shields diagram. With a $u_{*}$ of $1 \mathrm{~cm} . \mathrm{s}^{-1}$, most crystals are kept from settling (suspended load or bedload). As the friction velocity drops to $0.5 \mathrm{~cm} \cdot \mathrm{s}^{-1}$ most frazil is either in suspension or, if larger than $1 \mathrm{~mm}$ radius, not moving at all. At $0.2 \mathrm{~cm} \cdot \mathrm{s}^{-1}$ only very small frazil or frazil which has been introduced from depth is able to stay in suspension.

will rise up and settle against the interface. For an even weaker friction velocity, it is possible that only small crystals, already in suspension, would find the turbulence strong enough to keep them from rising up to the interface.

One final comparison can be made with the sediment results in Bagnold (1966) and van Rijn (1984). Bagnold (1966) notes that, for grain diameters $\left(d_{e}\right)$ larger than $2 \mathrm{~mm}$, the fall velocity becomes proportional to $\sqrt{d_{e}}$. Hence the (critical) Shields parameter value tends to a constant value. A similar assumption for the rise velocity was made by Daly (1984) for frazil crystals with a diameter larger than $2.8 \mathrm{~mm}$, though he elects to ignore this region as being too large for a frazil crystal in a natural environment. The use of the Stokes' equation for the frazil rise velocity was shown to 
match well with the measurements of Gosink and Osterkamp (1983) in Section 4.2 .2 up to $3 \mathrm{~mm}$, though recordings become more sparse as the crystal size increases. It was also found to compare reasonably with the equations given by Morse and Richard (2009).

A change in the rise velocity to a $\sqrt{d_{e}}$ dependency would decrease the friction velocity required to keep the larger crystals in full suspension (as opposed to part of the bedload). This would affect the results in both Figures 6.1 and 6.2 by causing a levelling off of Bagnold and van Rijn's critical criteria. Assuming this occurred for crystals with a radius larger than $3 \mathrm{~mm}$, for Bagnold's criterion this would only affect large crystals with high Shields parameter values. These would require a smaller parameter value to be lifted into suspension. For the lower criterion (predicting the initial stages of suspension), the change in the rise velocity almost completely eliminates region (2). This would imply that nearly all crystals which are kept in motion will spend some time in suspension.

\subsubsection{Suspension criterion}

All the work presented so far has focused on the effect of turbulence on an individual crystal. What has not been considered is the effect of turbulence on a mass of crystals or, indeed, the simultaneous effect a concentration of frazil may have on the flow it is immersed in. In this section a criterion, analogous to the Shields criterion, is used to calculate the mass of frazil ice which could be held in suspension by a given turbulent flow.

Hiscott (1994) hypothesized that, if suspension of a sediment load was governed solely by a comparison between the friction and deposition velocities, then one might expect that, at any level in the deposit, the sediment size should be reasonably uniform. This is because, as the flow slowed, allowing for deposition, similar sized grains would drop out of suspension at the same time. However, he noted that observations by Pettijohn et al. (1987) indicated that this was not the case. This suggests that 
the suspension criterion alone cannot predict the carrying capacity of a turbulent flow. The picture for frazil included in an ice cover is complicated by the ability of the crystals to continue to grow after settling against the interface. It seems reasonable to assume, though, that, as for sediment, the total mass of frazil will be a factor in a flow's ability to keep the crystals in suspension.

In order to keep a mass of crystals from rising to the interface, a downward stress must be exerted to counteract their buoyancy. In terms of sediment, Bagnold (1966) argued that, as the mass of the sediment load increased, so must the stress required to keep them in suspension. He also added that a limit to this stress must exist to allow for the observed phenomenon of otherwise suspendible material being found to drop out of suspension. If turbulence was isotropic (uniform in all directions), sediment would experience an equivalent downwards force as upwards and hence would continue to fall with gravity. As this did not occur for suspended sediment, shear turbulence was assumed to be anisotropic.

It is noted here that, more recently, it has been argued that isotropic turbulence can also alter the rise velocity of particles (Friedman and Katz, 2002: Nielsen, 2007). Nielsen (2007) suggested that this could be due to vortex fields. In strong turbulence, particles heavier than the surrounding fluid experience an acceleration in their settling velocity as they get "fast tracked" along the downwards sections of the vortices. For light particles and bubbles, Nielsen found that they tended to spiral inwards, getting caught in the stationary points of the vortices, resulting in a decrease in their rise velocity. However, he noted that Friedman and Katz (2002) had observed small diesel droplets (which are lighter than water) to behave similarly to heavy particles, reaching a constant value for their rise velocities.

Leeder et al. (2005) found that experimental evidence suggested an increase in the vertical turbulent velocity from the solid-fluid interface to a maximum value $\left(v_{\max }^{\prime}\right.$ at $\left.z=h_{m}\right)$. This implies a positive acceleration, 
$A_{z}=\frac{d v^{\prime 2}}{d z}$, away from the interface (see also Bagnold, 1966). Integrating to find the vertical stress component gives

$$
\tau_{z z}=\rho_{w} \int_{0}^{h_{m}} A_{z} d z=\rho_{w}\left(v_{\max }^{\prime}\right)^{2} .
$$

Leeder et al. (2005) predicted that, if this was less than the stress due to the total weight of the suspended load, then sediment would begin to drop out of suspension (see Appendix C). This led to his criterion for a maintained suspended load:

$$
\Lambda=\frac{\rho_{w}\left(v_{\max }^{\prime}\right)^{2}}{m_{i, A}\left(1-\frac{\rho_{w}}{\rho_{i}}\right) g} \geq 1
$$

where $m_{i, A}$ is the dry mass (the mass of the sediment if it was removed from the water) of suspended sediment above a unit area. As for the Shields criterion, this is a ratio of stresses, though it applies for a suspended load as opposed to motion of a single grain. The maximum of the vertical turbulence fluctuations $\left(v_{\max }^{\prime}\right)$ has been found experimentally to be equal to the friction velocity (Kreplin and Eckelmann, 1979; Bennett et al. 1998: Leeder et al., 2005).

Applying this inequality to the sub-ice system, the frazil dry mass kept in suspension above a unit area by a given turbulence can be calculated. Dividing by $z_{m l}$ (the depth of the mixed layer) converts this into an average mass of ice per unit volume in the mixed layer. Figure 6.3 shows how this average is affected by a change in the friction velocity. A stronger $u_{*}$ can keep a greater mass of frazil crystals in suspension. For $u_{*}=0.01 \mathrm{~m} \cdot \mathrm{s}^{-1}$, a density of $0.0018 \mathrm{~kg} \cdot \mathrm{m}^{-3}$ can be prevented from rising to the interface.

As the only effect of the mixed layer depth is to convert the mass per unit area into a mass per unit volume, a change in $z_{m l}$ can have a noticeable effect on the results. Halving $z_{m l}$ will double the density which can be held in suspension, and vice-versa. This does not affect the total predicted mass 
of crystals beneath an ice cover.

Accurate measurements of the mass or density of frazil crystals beneath sea ice are difficult to find. In Skogseth et al. (2009), the total modeled concentration of frazil ice (using data from an arctic polynya) varied from a maximum of $0.012 \mathrm{~kg} \cdot \mathrm{m}^{-3}$ at the water surface to $0.0004 \mathrm{~kg} \cdot \mathrm{m}^{-3}$ just below $5 \mathrm{~m}$. Using a similar surface current speed as in their work, Figure 6.3 gives an average frazil mass concentration of $0.0005 \mathrm{~kg} \cdot \mathrm{m}^{-3}$, near their lower limit. There are certain key differences between the work of Skogseth et al. (2009) and that in this chapter. The open top of the polynya will affect the friction velocity induced by the current while also allowing a build up of crystals at the water surface. Also, their model (and measurements) only extend down to $5 \mathrm{~m}$. As the total frazil concentration has been well-documented to decrease with depth (e.g. Svensson and Omstedt, 1998; Ye and Doering, 2003: Morse and Richard, 2009), it seems fair to assume that the concentrations would continue to be lower below $5 \mathrm{~m}$.

The average mass of ice per unit volume can be difficult to comprehend. A more intuitive measure may be the number concentration, the number of crystals in a unit volume of water. To do this accurately, however, a comprehensive knowledge of the frazil ice distribution is required. As has already been discussed in this section, this is difficult to measure. A simpler method, as used by Omstedt (1985) and Svensson and Omstedt (1998), is to assume a constant radius for the crystals. The number of crystals per unit volume can then be calculated for various radii, assuming all crystals are that size. Though not ideal, this at least gives an indication of the number of crystals which can be supported beneath an ice cover.

A range of different values have been suggested for the average size of a frazil crystal. Photographs taken by Osterkamp and Gosink (1983) showed river frazil crystals with a diameter predominantly between $0.1 \mathrm{~mm}$ and $1 \mathrm{~mm}$. The modeling of Svensson and Omstedt (1998) indicated frazil with a mean diameter of $0.35 \mathrm{~mm}$ near an ice-water interface. This dropped quickly to average around $0.1 \mathrm{~mm}$ at $10 \mathrm{~m}$ and remained 


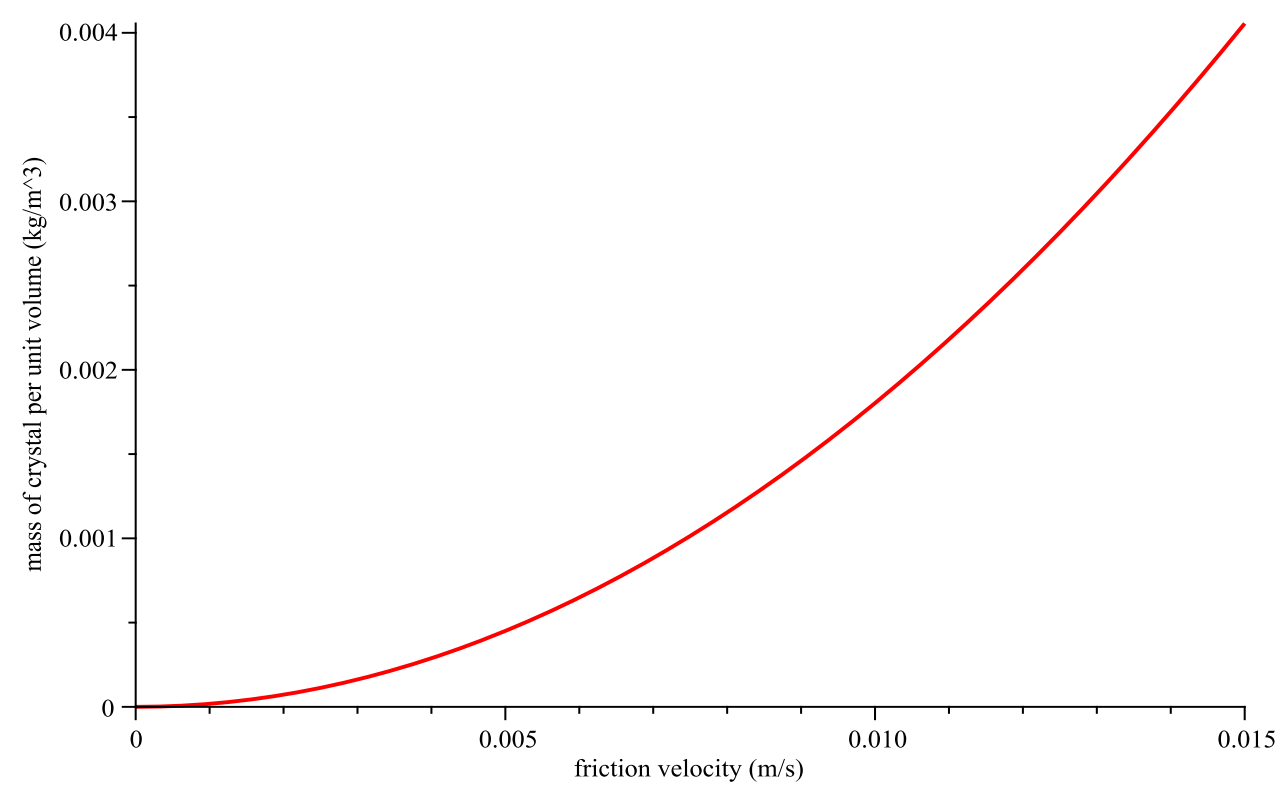

Figure 6.3: The average mass of crystals held in suspension per unit volume by a given friction velocity. Increasing the friction velocity leads to an increase in the average mass of frazil crystals kept in suspension in the mixed layer.

near this size over the lower $25 \mathrm{~m}$. Measurements of the rise velocity of frazil on the St. Lawrence River in Quebec by Morse and Richard (2009) indicated average and median values of $0.92 \mathrm{~cm} . \mathrm{s}^{-1}$ and $0.76 \mathrm{~cm} . \mathrm{s}^{-1}$ respectively. This gives $3.15 \mathrm{~mm}$ and $2.85 \mathrm{~mm}$ for the diameter. However, their equipment could only measure crystals larger than $0.5 \mathrm{~mm}$, which may bias their averages upwards. Daly (1984) stated that $2.8 \mathrm{~mm}$ was large for a crystal diameter and that frazil was rarely seen larger than this. Modeling based on the Filchner-Ronne Ice Shelf in Antarctica by Holland and Feltham (2005) found the largest number of crystals to be of diameters from $0.3 \mathrm{~mm}$ up to $1 \mathrm{~mm}$, increasing with the supercooling, while Wang et al. (2004) predicted an average of $1 \mathrm{~mm}$.

The value used for the radius of the frazil crystals has a significant effect on the average number concentration in the water (Figure 6.4). If all crystals have a diameter smaller than $0.5 \mathrm{~mm}$, the number of crystals 


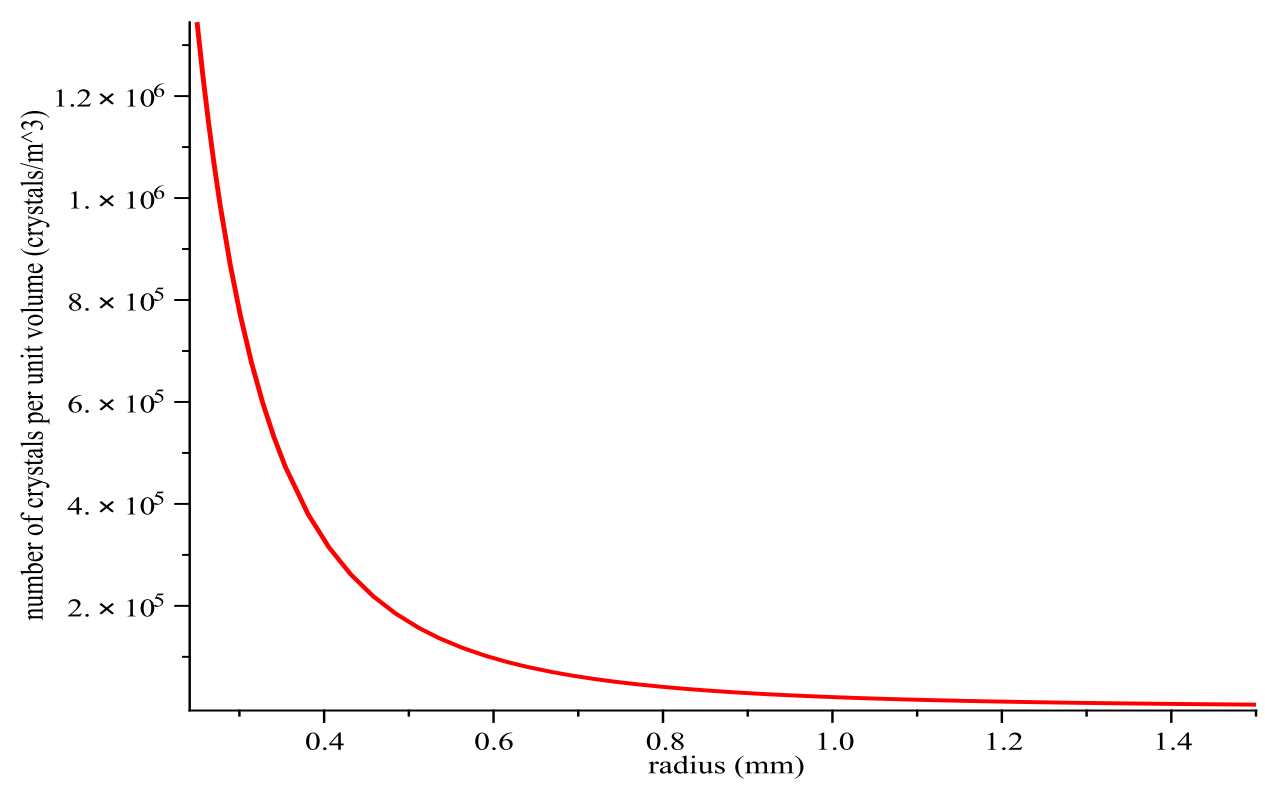

Figure 6.4: The average number concentration of frazil crystals per unit volume kept in suspension, assuming a constant radius for all crystals. The number concentration increases rapidly as the radius decreases, varying from thousands if all crystals were over $2 \mathrm{~mm}$ in diameter up to millions for the smaller crystals.

would be upwards of 1 million. If the crystal size was generically $2 \mathrm{~mm}$, then the number would be closer to 25,000 .

Also worth noting is the effect of the aspect ratio, $\epsilon$ (the ratio of the thickness to the diameter of a crystal). A decrease in $\epsilon$ decreases the volume and so increases the number of crystals for a given radius. A value of $\epsilon=0.015$ has been used in Figure 6.4. Varying this from 0.01 to 0.02 (see Section 4.2.2), does not affect the order of magnitude of the number concentration of crystals (not shown).

A limited number of frazil ice concentration measurements have been made in rivers. These indicate that the number of crystals may range from 10,000 crystals to 1 million crystals (Liou and Ferrick, 1992), or even up to 10 million crystals per cubic metre (Osterkamp and Gosink, 1983). Though approximate, these measurements do match up reasonably with the re- 
sults in Figure 6.4. The latter maximum value was found in a region where crystal radii were predominantly between $0.05 \mathrm{~mm}$ to $0.5 \mathrm{~mm}$. Svensson and Omstedt (1998), whose data-based oceanic modeling showed a mean crystal radius of between $0.05 \mathrm{~mm}$ and $0.15 \mathrm{~mm}$, found the number of crystals could exceed 13 million crystals per cubic metre. If Figure 6.4 is extended down to $0.05 \mathrm{~mm}$, the crystals' concentration increases to around 17 million. These comparisons, though promising, require further in situ measurements before any definitive conclusions can be made.

\subsection{The effect of frazil on the flow}

In the previous section it was shown that a concentration of frazil can be kept in suspension in a turbulent flow. This section will consider how a mass of crystals may alter the flow which is keeping it from rising to the ice-water interface.

In general, frazil profiles show concentration increasing towards the interface (Liou and Ferrick, 1992; Svensson and Omstedt, 1998; Morse and Richard, 2009). This suggests a stabilising density gradient in the mixed layer as the density of the frazil-water mixture increases with increasing depth (away from the interface). This is similar to stabilisation induced by sediment concentration increasing towards the river- or seabed (e.g. van Rijn, 1983; Bennett et al., 1998; Ghoshal and Mazumder, 2005). The density difference between frazil ice and the seawater is small, only around $10 \%$. Hence, for an average maximum frazil suspension, as suggested in the previous section, the stratification is slight. This may be complicated by the presence of a "bedload" at the interface where the density of the icewater mixture may decrease significantly.

A literature review of the effects of suspended sediment can be found in Winterwerp (2001) or Vanoni et al. (2006). Briefly discussed here are those aspects which may be appropriate to the case of frazil ice. In the 1940 's and 1950's experiments on fluid-sediment mixtures by Vanoni (1946) 
(results reproduced in Vanoni et al. (2006)) and Einstein and Chien (1955) (see Winterwerp (2001)) suggested that the von Kármán "constant", in fact, decreased through the mixture. This effect became more pronounced as the sediment concentration increased. Vanoni hypothesized that this was caused by the sediment reducing the turbulent effect of the flow. Energy is required to keep the sediment in suspension. This energy is supplied by, and therefore removed from, the turbulence. This leads to the damping effect.

This idea was first disputed in the 1980's as the application of the logarithmic velocity profile (the law of the wall),

$$
\begin{aligned}
\frac{\partial U}{\partial z} & =\frac{u_{*}}{\kappa z} \\
U & =\frac{u_{*}}{\kappa} \ln \left(\frac{z}{z_{0}}\right)
\end{aligned}
$$

over the entire depth of the flow was questioned. The roughness length, $z_{0}$, is defined as the location at which the velocity becomes 0 , while $U$ and $u_{*}$ are the flow and friction velocities, respectively. The work countering a reduced von Kármán constant has itself been questioned, however, and any change in $\kappa$ with concentration is still unresolved (Bennett $e t$ al. 1998 Winterwerp, 2001).

One suggested solution has been to modify the law of the wall using a flux Richardson number, $R i_{f}$, (see Section 6.2.1) to represent the suppression of turbulence in the flow due to the density gradient (Bennett $e t a l$. 1998). Equation 6.8a becomes

$$
\frac{\partial U}{\partial z}=\frac{u_{*}}{\kappa z}\left(1+\alpha R i_{f}\right)
$$

where $\alpha$ is a constant which depends on the level of stratification. If $R i_{f}$ is also assumed to be constant, this can in fact be rewritten in the same form as Equation $6.8 \mathrm{~b}$ 


$$
U=\frac{u_{*}}{\kappa^{\prime}} \ln \left(\frac{z}{z_{0}}\right)
$$

where $\kappa^{\prime}$ is a modified von Kármán constant, altered according to

$$
\kappa^{\prime}=\frac{\kappa}{1+\alpha R i_{f}}
$$

(Adams and Weatherly, 1981).

Adams and Weatherly noted that Equation $6.8 \mathrm{~b}$ was often used when current speeds were known near the interface to calculate the friction velocity. It is apparent from Equation 6.11 that a positive flux Richardson number will reduce $\kappa^{\prime}$. Given a constant value for $U$, this will lead to a reduction in the friction velocity. Hence a sediment concentration with $R i_{f}>0$ has a stabilising effect. The opposite is true for a negative $R i_{f}$. In this case, the concentration increases $u_{*}$ and is destabilising. Adams and Weatherly (1981) calculated that a drop in $u_{*}$ of nearly $40 \%$ could be induced by a stabilising sediment concentration. This suggests that values of the friction velocity calculated in Section 3.6.1 may not be appropriate when a frazil concentration is present. This modification will be the focus of the remainder of this section.

\subsubsection{The flux Richardson number}

The flux Richardson number, introduced briefly in the preceding section, is often used to describe the strength of stabilisation that buoyancy has on a turbulent shear flow. It is based on the turbulent kinetic energy equation and is defined as the ratio of the buoyancy destruction and shear production terms,

$$
R i_{f}=\frac{-g\left\langle\rho_{m}^{\prime} w^{\prime}\right\rangle}{\rho_{m}\left\langle u^{\prime} w^{\prime}\right\rangle \frac{\partial U}{\partial z}}
$$


where the angled brackets and the primes represent the mean $(<>)$ of the fluctuating parts $\left({ }^{\prime}\right)$ of the respective components. The density of the water-frazil ice mixture is given as $\rho_{m}$, while $u$ and $w$ are the horizontal and vertical components of velocity respectively (Turner, 1979; Winterwerp et al. 2001).

The average downwards flux of density differences, $\left\langle\rho_{m}^{\prime} w^{\prime}\right\rangle$, was defined in Section 4.3 for clear water (no ice) when the density gradients were due to a salt difference. In this case the change in density is caused by the frazil concentration and can be rewritten

$$
\left\langle\rho_{m}^{\prime} w^{\prime}\right\rangle=\frac{\rho_{i}-\rho_{w}}{\rho_{i}}\left\langle c^{\prime} w^{\prime}\right\rangle
$$

where $\left\langle c^{\prime} w^{\prime}\right\rangle$ is the average vertical variation in the concentration fluctuations (Soulsby and Wainwright, 1987; Winterwerp, 2001). The concentration is measured in mass of ice per unit volume of mixture $\left(\mathrm{kg} . \mathrm{m}^{-3}\right)$.

Rewriting $\left\langle u^{\prime} w^{\prime}\right\rangle$ in terms of the eddy viscosity profile, $\nu_{T}$, and the velocity profile gives

$$
\left\langle u^{\prime} w^{\prime}\right\rangle=-\nu_{T} \frac{\partial U}{\partial z}
$$

(Turner, 1979; van Maren et al., 2005). The eddy viscosity is related to the momentum transfer by the turbulent eddies, and is analogous to the dynamic viscosity in still water. It is a property of the flow as opposed to a property of the fluid and is not normally constant over the depth of the flow (Mathieu and Scott, 2000).

Substituting these into Equation 6.12 gives

$$
R i_{f}=g\left(\frac{\rho_{i}-\rho_{w}}{\rho_{i} \rho_{m}}\right) \frac{\left\langle c^{\prime} w^{\prime}\right\rangle}{\nu_{T}\left(\frac{\partial U}{\partial z}\right)^{2}} .
$$

This can be further simplified by assuming the logarithmic velocity profile for a shear flow, Equation 6.8a, and assuming the density of the ice-water 
mixture to be equal to sea water density, $\rho_{m}=\rho_{w}$ (valid given the low concentration of ice). Given a sediment concentration being held in suspension, there is a balance between the downwards mixing and rise of the frazil, so that $\left\langle c^{\prime} w^{\prime}\right\rangle=-c w_{s}$ where $w_{s}$ and $c$ are the local rise velocity (taken positive upwards) and concentration respectively (Soulsby and Wainwright, 1987; Winterwerp, 2001; van Maren et al., 2005).

The eddy viscosity is more difficult to define and this will be discussed further in Section 6.3.2. Soulsby and Wainwright (1987) assumed that the eddy viscosity for a sediment-fluid mixture increased linearly above the river- or sea-bed. A parabolic eddy viscosity distribution was used by Morse and Richard (2009) when investigating frazil concentrations in the St. Lawrence River, Canada. These are written

$$
\begin{array}{lr}
\nu_{T}=\kappa u_{*} z & \text { (linear) } \\
\nu_{T}=\kappa u_{*} z\left(1-\frac{z}{h}\right) & \text { (parabolic) }
\end{array}
$$

where $z$ is the vertical position, positive downwards from the origin at the ice-water interface, and $h$ is the extent of the flow, in this case taken to be equal to the depth of the mixed layer, $z_{m l}$.

Trying to find the Richardson number at a given depth requires, finally, knowledge of the concentration profile and the rise velocity in terms of $z$. For the two viscosity profiles the variation in concentration becomes (see Appendix D

$$
\begin{aligned}
\frac{c}{C_{a}} & =\left(\frac{z}{z_{a}}\right)^{-b} \\
\frac{c}{C_{a}} & =\left(\frac{h-z}{z} \frac{z_{a}}{h-z_{a}}\right)^{b}
\end{aligned}
$$


where $b$ is the Rouse number (see Section 6.1.1), defined in this case as $\frac{w_{s}}{\kappa u_{*}}$, and $C_{a}$ is the reference concentration at a depth, $z_{a} . C_{a}$ and $z_{a}$ are extremely difficult to find for frazil distributions. For example, extensive field measurements by Morse and Richard (2009) recorded only arbitrary units for concentration. This is because the relationship between their measured acoustic strength and the frazil concentration was unknown. They also noted that there was no definitive instrument for making frazil concentration readings in the field. Following Soulsby and Wainwright (1987), the approximation for sediment proposed by Smith and $\mathrm{M}^{c}$ Lean (1977) is modified, giving

$$
\begin{aligned}
C_{a} & =\frac{\xi_{1} \rho_{i} T_{s}}{1+\xi_{2} T_{s}} \\
z_{a} & =\frac{\xi_{3} \rho_{w} u_{*, c r}^{2} T_{s}}{g\left(\rho_{w}-\rho_{i}\right)}
\end{aligned}
$$

where

$$
T_{s}=\frac{u_{*}^{2}-u_{*, c r}^{2}}{u_{*, c r}^{2}}
$$

and $u_{*, c r}$ is the critical friction velocity for initiation of motion of a sediment (or crystals). The three empirical constants $\left(\xi_{1}, \xi_{2}\right.$ and $\left.\xi_{3}\right)$ are given as $0.00156,0.0024$ and 26.3 respectively (Soulsby, 1998).

In their application in sedimentation theory, the equations for the reference concentration and depth assume that there is sufficient sediment such that, if a flow can suspend a certain quantity of grains, it will. While this may be a reasonable assumption at a river- or seabed, where ample loose sediment is available, this may not be the case for frazil crystals beneath an ice cover. This is because crystals which settle against the ice-water interface can become incorporated into the cover, unlike sediments which are resuspendable. This suggests that the $\xi$-constants may be different for the frazil case, in particular, leading to a decrease in $\xi_{1}$ and $\xi_{3}$. 
It is also important to note that, by using the reference concentrations of Smith and McLean (1977), it is assumed that there is no maximum in the mass of crystals which can be suspended. Again, a reduction in the mass, and therefore the concentration, of the crystals would weaken the damping effect on the turbulence. Hence the stabilisation effect found in this section should be regarded as a maximum value.

Substituting Equation $6.8 \mathrm{a}$ and the appropriate choice from Equations 6.16 or 6.17 into Equation 6.15 gives the flux Richardson number for the linear and parabolic eddy viscosity assumptions

$$
\begin{aligned}
& R i_{f}=-\frac{\rho_{i}-\rho_{w}}{\rho_{i}} \frac{\kappa g w_{s} C_{a} z_{a}}{\rho_{m} u_{*}^{3}}\left(\frac{z}{z_{a}}\right)^{1-b} \\
& R i_{f}=-\frac{\rho_{i}-\rho_{w}}{\rho_{i}} \frac{\kappa g w_{s} C_{a} h}{\rho_{m} u_{*}^{3}}\left(\frac{z}{h-z}\right)^{1-b}\left(\frac{z_{a}}{h-z_{a}}\right)^{-b}
\end{aligned}
$$

where Equation 6.20a is that proposed by Soulsby and Wainwright (1987). The critical friction velocity for frazil crystals, developed in Section 3.5 . will be used. To calculate the change in rise velocity beneath the ice, a thorough knowledge of the frazil size distribution with depth would be required. As measurements are sparse, the simplest approximation, that of a constant frazil size, is used. The rise velocity developed in Section 4.2 is substituted for $w_{s}$.

As the flux Richardson number increases, the stabilising effect of the sediment on the flow becomes more pronounced. Soulsby and Wainwright (1987) suggested that a significant decrease in the friction velocity may occur when $R i_{f}$ exceeds 0.03 . The strength of this effect may not be constant over the depth of the flow. Figure 6.5 shows that, $10 \mathrm{~cm}$ below the ice-water interface, $R i_{f}>0.03$ if the frazil crystals have a constant radius between $0.1 \mathrm{~mm}$ and $0.7 \mathrm{~mm}$. Further from the interface, the flux Richardson number is greater for smaller crystals (which are more readily distributed deeper into the mixed layer by the shear flow). However, 


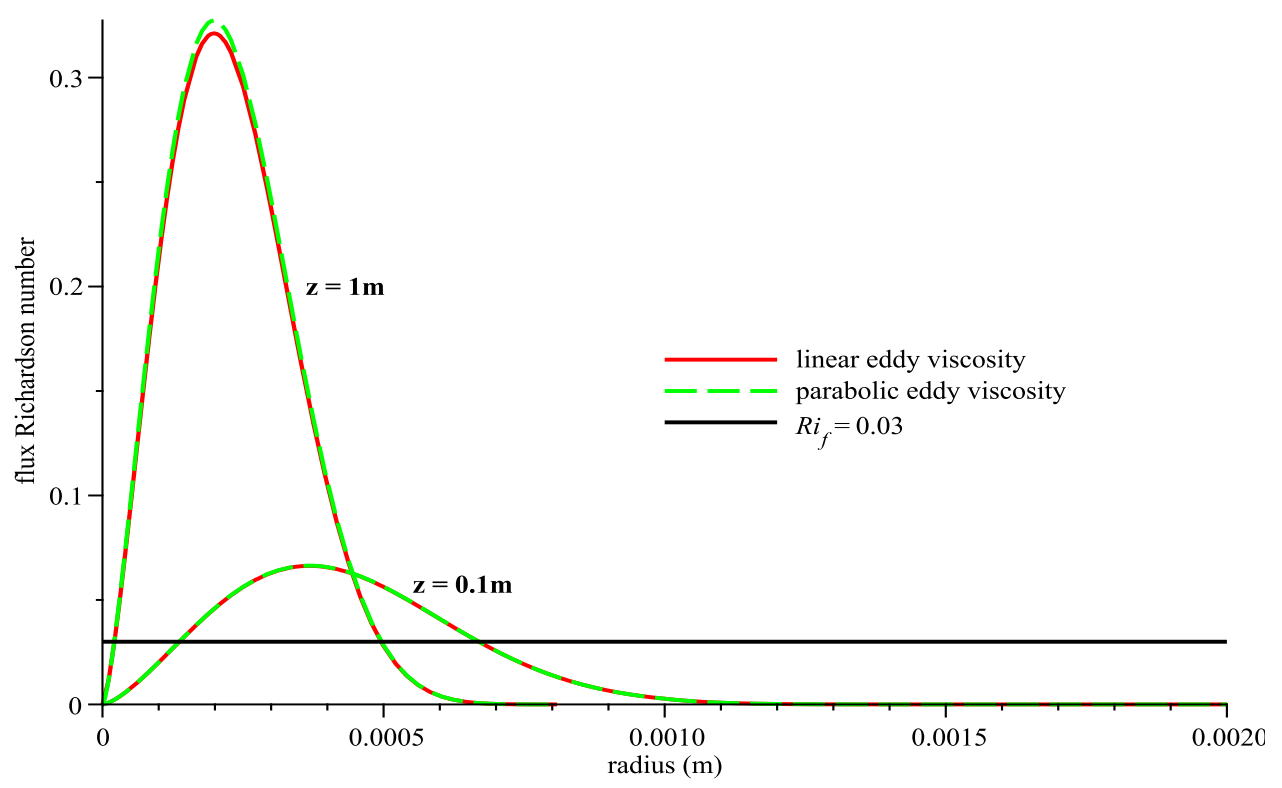

Figure 6.5: Comparing the effect of assuming either a linear or a parabolic eddy viscosity on the flux Richardson number. The change in $R i_{f}$ with crystal radius (assumed constant for the frazil concentration) is shown for two depths, assuming a constant shear flow of $10 \mathrm{~cm} \cdot \mathrm{s}^{-1}$. Ri i is greater at a depth of $1 \mathrm{~m}$ for a constant frazil radius up to around $0.45 \mathrm{~mm}$. For a constant crystal radius greater than $1 \mathrm{~mm}$, a suspension has little effect on the flow outside of $10 \mathrm{~cm}$ from the interface.

$R i_{f}>0.03$ in a smaller range, occurring only where the radius is less than $0.5 \mathrm{~mm}$. For crystals of constant radius, the stabilising effect is more pronounced at $\mathrm{z}=0.1 \mathrm{~m}$ when $\mathrm{r} \gtrsim 0.45 \mathrm{~mm}$. For $\mathrm{r} \geq 1 \mathrm{~mm}$, a suspension will have little effect on the flow at either $\mathrm{z}=0.1 \mathrm{~m}$ or $1 \mathrm{~m}$. The choice of a linear or parabolic eddy viscosity profile has only a minor effect on $R i_{f}$.

The range of radii in which the frazil concentration has a significant effect increases with the strength of the shear flow, and hence the friction velocity (Figure 6.6). This occurs as the turbulence becomes strong enough to keep larger crystals and denser concentrations in suspension. 


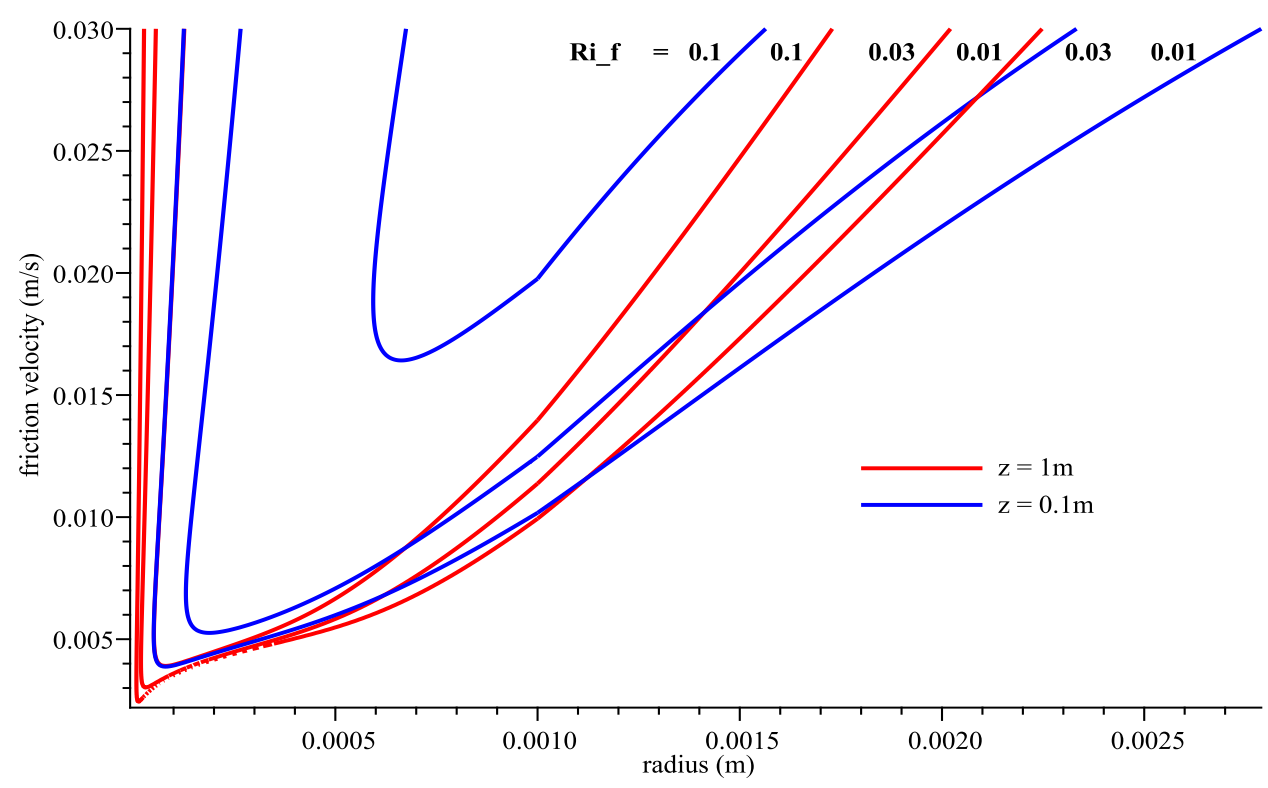

Figure 6.6: Three contours of the flux Richardson number are plotted, assuming a linear eddy viscosity, at two depths. As $u_{*}$ increases so does the range in frazil radii in which the suspension has a significant effect on the flow.

\subsubsection{Reduction in $\mathbf{u}_{*}$}

The final step is to approximate the damping effect a frazil concentration could have on the flow. In order to account for the change in the eddy viscosity induced by a suspension,

$$
\nu_{T}=\frac{\kappa u_{*} z}{1+\alpha R i_{f}}
$$

has been suggested, where the denominator is the same as that used in Equation 6.11 (Smith and $\mathrm{M}^{c}$ Lean, 1977; Soulsby and Wainwright, 1987). Atmospheric experiments have found $\alpha$ to vary between 3 and 9, increasing with weakening stratification (Adams and Weatherly, 1981). By retaining a reasonably simple expression for the eddy viscosity, Soulsby and Wainwright (1987) found an explicit expression for the shear velocity profile, 


$$
U=\frac{u_{*}}{\kappa}\left[\ln \frac{z}{z_{0}}+\frac{1}{b} \ln \left(1-\frac{\zeta b}{1-b}\left(\left(\frac{z}{z_{0}}\right)^{1-b}-1\right)\right)\right]
$$

where

$$
\zeta=\frac{\alpha \kappa g w_{s}\left(\rho_{i}-\rho_{w}\right) z_{a} C_{a}}{\rho_{i} \rho_{w} u_{*}^{3}}
$$

and $\alpha$ is set to 4.7. The roughness length, $z_{0}$, depends on the state of the ice. Leppäranta (2004) stated that, for undeformed sea ice, $z_{0}$ varied between $0.1 \mathrm{~cm}$ and $1 \mathrm{~cm}$ while, for deformed sea ice this can increase to $10 \mathrm{~cm}$.

Given the uncertainty in the roughness depth and the potential range in the measurement height $(z)$, the variable $\frac{z}{z_{0}}$ is used. Equation 6.22 can be used to calculate the friction velocity for a given shear flow with a suspended sediment concentration. This can be compared to the $u_{*}$ found using Equation $6.8 \mathrm{~b}$ for clear water conditions. This will give the reduction in the turbulence.

Using $\frac{z}{z_{0}}=100$, Figure 6.7 shows that $u_{*}$ is influenced by frazil radius more in a stronger flow. This is as expected, as a greater $U$ would keep a larger frazil concentration in suspension to interact with the shear velocity. A maximum reduction of over $30 \%$ in $u_{*}$ is seen for $U=0.3 \mathrm{~cm} . \mathrm{s}^{-1}$. This effect is greatest for a concentration of $0.5 \mathrm{~mm}$ frazil crystals. It decreases as the shear flow slows, as does both the radius at which the minimum $u_{*}$ occurs and the range over which there is a significant change in the friction velocity. For $U=10 \mathrm{~cm} \cdot \mathrm{s}^{-1}$ the maximum reduction in $u_{*}$ is around $7 \%$.

Given a measured shear velocity of $10 \mathrm{~cm} . \mathrm{s}^{-1}$, Figure 6.8 gives the damping as $\frac{z}{z_{0}}$ is changed. Close to the interface, where the given $U$ produces a larger friction velocity, the effect of a suspension decreases $u_{*}$ by up to $13 \%$. The peak occurs at a constant frazil radius of around $0.9 \mathrm{~mm}$. As $\frac{z}{z_{0}}$ increases, the same measured $U$ gives a weaker friction velocity. The reduction due to damping also decreases. For $\frac{z}{z_{0}}>25$ the greatest reduc- 


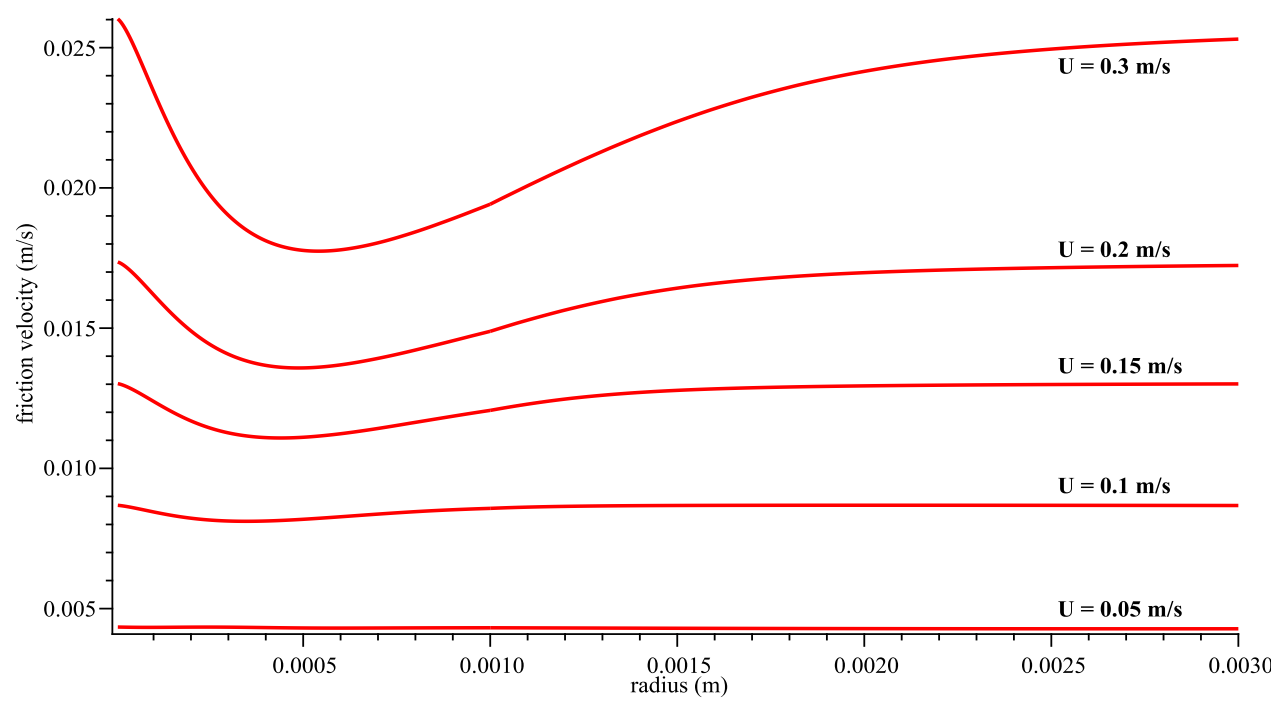

(a) Reduction in $\mathrm{u}_{*}$

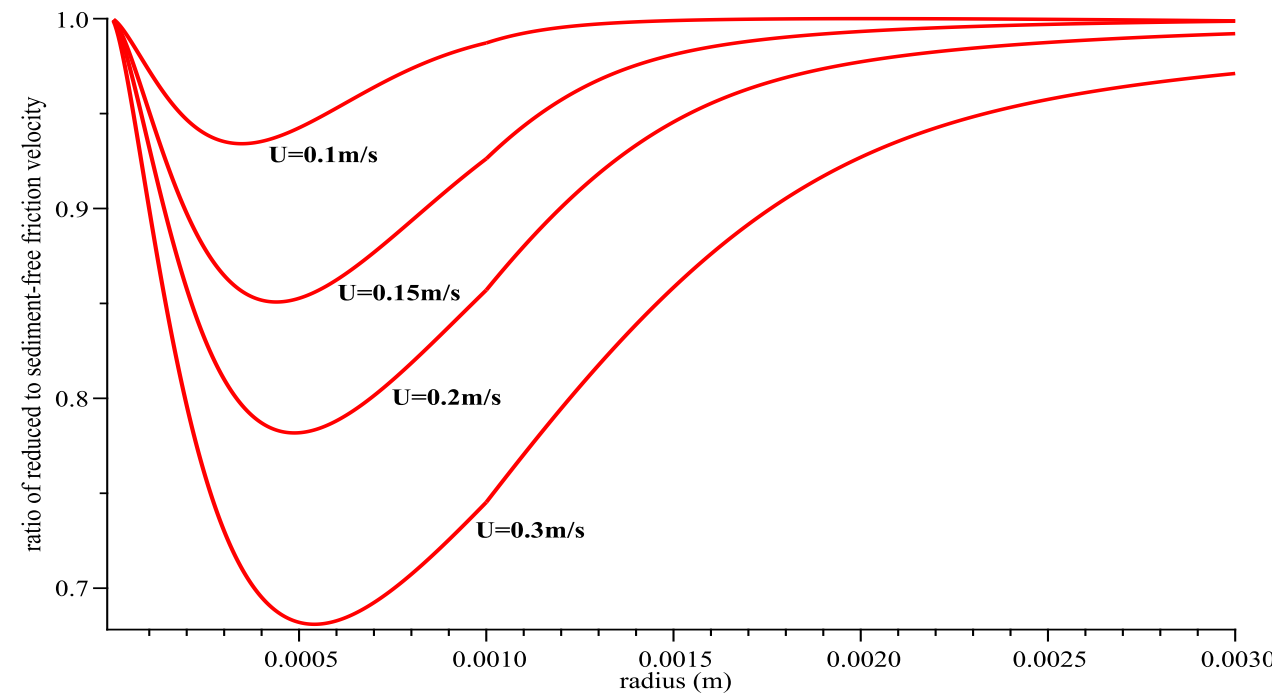

(b) Ratio of reduced $\mathfrak{u}_{*}$ to sediment-free $\mathfrak{u}_{*}$

Figure 6.7: The friction velocity is shown for various strengths of shear flow, to illustrate the damping effect of a suspension of frazil crystals of constant radius. The damping effect weakens as the shear flow decreases. 


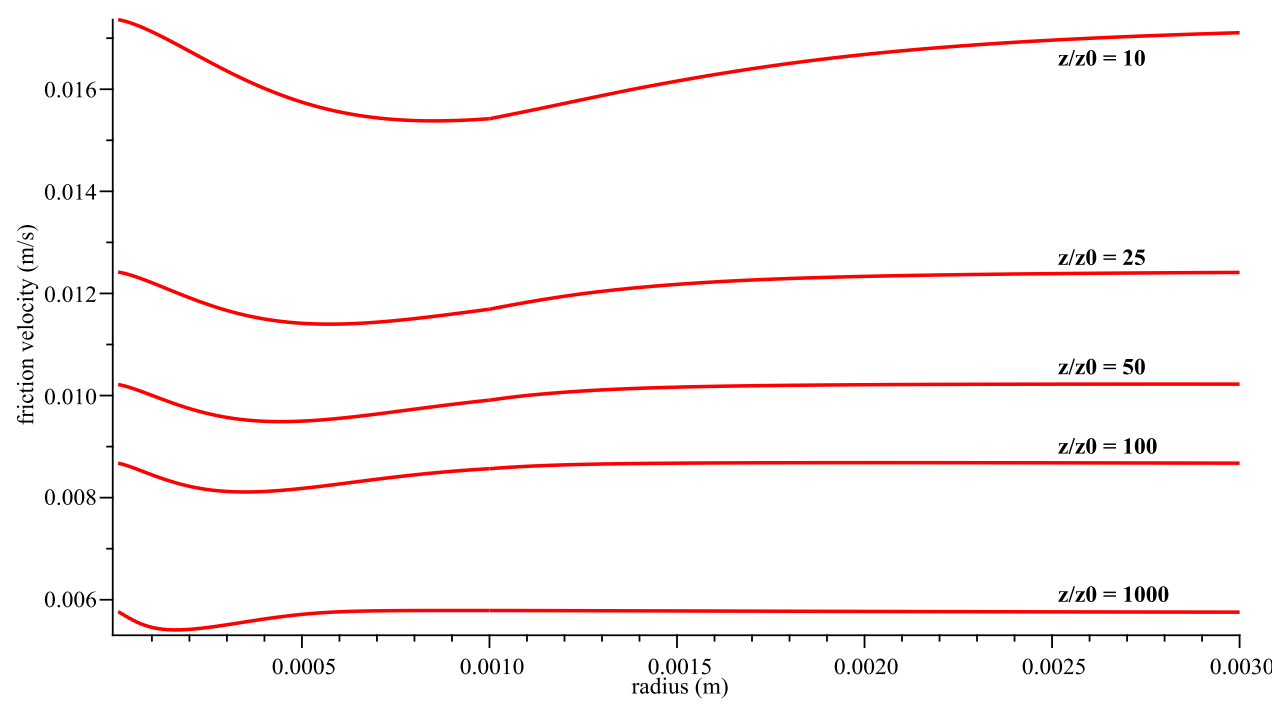

(a) Reduction in $\mathrm{u}_{*}$

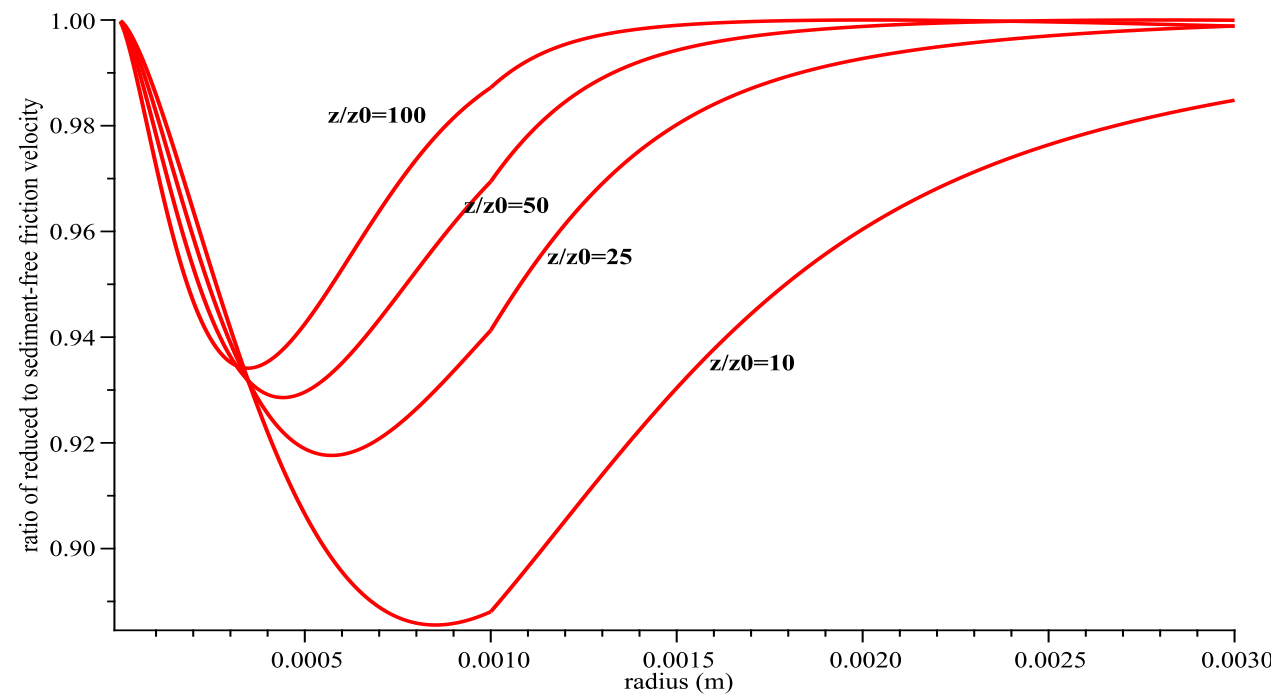

(b) Ratio of reduced $\mathfrak{u}_{*}$ to sediment-free $\mathfrak{u}_{*}$

Figure 6.8: The effects of a suspension on the friction velocity as the depth (normalised on the roughness depth) is increased, for a suspended load with a constant frazil size. The greatest reduction in $u_{*}$ occurs near the interface. 
tion in $u_{*}$ is $8 \%$. For increasing $\frac{z}{z_{0}}$, there is a decrease in the frazil radius at which the maximum reduction in the friction velocity occurs.

In Section 3.6.2 it was shown that, for a friction velocity of $1 \mathrm{~cm} . \mathrm{s}^{-1}$ (a shear flow of around $10 \mathrm{~cm} . \mathrm{s}^{-1}$ ), individual crystals smaller than $2.8 \mathrm{~mm}$ in radius would remain in suspension. Figure 6.8 shows that a suspended load may significantly decrease the friction velocity. This can be viewed as a lowering of the black (constant $u_{*}$ ) lines in Figures 3.9 or 6.2. However, even assuming the maximum reduction in $u_{*}(13 \%)$, the frazil size able to rise out of suspension reduces only to $2.2 \mathrm{~mm}$ from $2.8 \mathrm{~mm}$. A reduction in friction velocity would, though, decrease the mass of crystals which can be kept in suspension (Figure 6.3). A number of crystals, equivalent to this drop in suspended mass, would then ascend to the ice-water interface.

It is noted again here that it has been assumed that there are enough crystals present for a full concentration profile to be set up. Frazil can adhere to the interface, meaning it is unable to be resuspended. This may reduce the concentration in suspension. This would result in a reduction of the damping effects described in this section. A similar effect occurs if it is assumed that there is a maximum mass which can be kept in suspension, as described in Section 6.1.2. Indeed, if Equation 6.7 is used to calculate this maximum, then the greatest reduction in the friction velocity is found to be less than $7 \%$. This varies little with the depth or the shear flow strength.

\subsection{Collapse of turbulence}

In Section 6.2.1, the flux Richardson number was introduced to describe the strength of the effect of buoyancy on shear produced turbulence. It was suggested that, at a given height, a significant reduction in the friction velocity occurred when $R i_{f}>0.03$ (Soulsby and Wainwright, 1987). Turner (1979) emphasized the importance of the flux Richardson number, noting that, even though buoyancy's direct contribution to energy dissipa- 
tion was small, its effect on the turbulence overall could still be significant. He also described a critical value $\left(R i_{f, c r}\right)$ which, if exceeded, could cause a complete collapse of the turbulent field. Even though the energy destruction due to buoyancy matches shear production at $R i_{f}=1$, experimental and theoretical analysis suggests that $R i_{f, c r}$ is between 0.05 and 0.4 .

This suggests that a sufficiently large frazil concentration could produce a stabilising buoyancy which would lead to a collapse of the turbulent system keeping the frazil in suspension. In theory, a percentage of the frazil in suspension (the largest crystals close to the interface) could then settle and adhere to the ice cover. This would decrease the concentration and the stabilisation due to buoyancy, and the turbulent field could re-establish itself. Winterwerp (2001), however, investigated this effect for sediment and found that the result of a turbulent collapse may depend on the type of sediment involved. In particular, he theorised that, while a non-cohesive sediment may behave as described above, a cohesive sediment (where individual particles can stick together to form flocs) could result in a layer of "fluid mud" being formed at the interface. As opposed to a rigid layer, the porous, mobile mud suppresses turbulence production and prevents the re-creation of a turbulent field. This allows the continued deposition of the overlying sediment.

\subsubsection{Cohesive or non-cohesive?}

The important question here is whether or not frazil can be considered to be cohesive. In sedimentation, cohesion generally depends on the size of the particle. As the diameter of a sediment decreases, the ratio of surface area to volume increases. When the particle is sufficiently small, the electrical charges on its surface play a significant role and the sediment can flocculate ( $\mathrm{M}^{c}$ Anally and Mehta, 2001; Shrestha and Blumberg, 2005). While the critical size can vary depending on the composition of the sediment, silts and clays smaller than around $0.06 \mathrm{~mm}$ to $0.07 \mathrm{~mm}$ are regarded 
as being cohesive (Ongley, 1996).

Though most frazil crystals are larger than the limits for cohesive sediment, this does not necessarily make them non-cohesive. It has already been noted that, during the initial formation of an ice cover, frazil will stick together as it accumulates at the ocean surface (see Section 2.1). Martin (1981) and Tsang (1988) observed that frazil crystals in supercooled waters formed flocs which grow through freezing and as they encounter other crystals. The bonds between the crystals form quickly and the frazil flocs attempt to minimise the surface energy ${ }^{1}$ of the frazil (Svensson and Omstedt, 1994). The strength of cohesion depends on the salinity of the water (Martin, 1981) and the level of supercooling (Daly, 1984). This would suggest that frazil can be treated as a cohesive sediment, though interactions between crystals when in suspension may be few due to low frazil concentrations beneath sea ice.

\subsubsection{Criterion for collapse}

Assuming a local balance between settling and mixing, and substituting Equations 6.8a, 6.13 and 6.14 into the flux Richardson number, Equation 6.12 , it becomes

$$
R i_{f}=-g\left(\frac{\rho_{i}-\rho_{w}}{\rho_{i} \rho_{w}}\right) \frac{w_{s} c(z) \kappa^{2} z^{2}}{\nu_{T} u_{*}^{2}}
$$

where $c(z)$ is the concentration profile. This leaves the eddy viscosity $\nu_{T}$ to be defined.

In Winterwerp (2001) and Winterwerp et al. (2001) it was suggested that this flux Richardson number is only valid for a sediment suspension if the sediment-water mixture can be treated as a single-phase fluid. In this situation, the sediments follow the turbulent motions of the water, except for their settling velocity. They argued that this would be true if $W_{s}$,

\footnotetext{
${ }^{1}$ Work required to increase the surface area of a crystal per unit area.
} 
a reduced rise velocity due to turbulence as defined in Equation 6.28, was significantly less than the vertical turbulent velocity fluctuations (approximated as the friction velocity). For frazil below sea ice, $W_{s}$ is around one tenth of the still water rise velocity. Hence, a $u_{*}$ of $1 \mathrm{~cm} \cdot \mathrm{s}^{-1}$ is at least an order of magnitude greater than $W_{s}$ for crystal radii up to around $1.5 \mathrm{~mm}$. It was also observed by Jenkins and Bombosch (1995) that frazil crystals were small in comparison with the turbulent eddies and were free to move with the water motion.

\section{Eddy viscosity}

In Section 6.2.1 the linear (Equation 6.16a) and parabolic (Equation 6.16b) parameterizations of the eddy viscosity were introduced. These are the simplest approximations (excluding $\nu_{T}=$ constant) and were used to allow for a simple form for $R i_{f}$. A more complicated form is the Businger-Arya model, where a linear term is modulated by an exponential decay (varying with depth) (Hsu and Jan, 1998; Absi, 2006). This can be written

$$
\nu_{T}=c_{1} \kappa z u_{*} \exp \left(-c_{2} \frac{z}{h_{\max }}\right)
$$

where $z=h_{\text {max }}$ is the location of maximum viscosity and $c_{1}$ and $c_{2}$ are empirical constants ( 1 and 1.12 respectively). This was derived for motion in the planetary boundary layer, but was also found to match measurements over mobile sediment beds in steady channel flow (Absi, 2006). Absi also notes that it is more suitable for modeling suspended sediment concentrations. M $M^{c}$ Phee (1994) suggested that the location of maximum viscosity depended on the mixing length, which varies with the strength of the buoyancy flux. Depending on the stabilizing effect of this flux, $h_{\max }$ can vary from $2 \mathrm{~m}$ to $12 \mathrm{~m}$. In lieu of an exact model for the eddy viscosity below seasonal sea ice, these approximations will be used.

In the following equations the parabolic viscosity profile is used as an 
example. Substituting $\nu_{T}$ into Equation 6.24 and solving for the concentration profile at the critical flux Richardson number gives

$$
\begin{array}{rlr}
c_{s}(z) & =-\frac{\rho_{i} \rho_{w}}{\rho_{i}-\rho_{w}} \frac{R i_{f, c r} u_{*}^{2}}{g w_{s}} \frac{\nu_{T}}{\kappa^{2} z^{2}} \\
& =\frac{\rho_{i} \rho_{w}}{\rho_{w}-\rho_{i}} \frac{R i_{f, c r}}{g \kappa} \frac{u_{*}^{3}}{h w_{s}}\left(\frac{h}{z}-1\right) \quad \text { (parabolic) }
\end{array}
$$

where $c_{s}(z)$ is the critical concentration profile which, if exceeded, would lead to a collapse of the turbulent field. Examples of such profiles for each viscosity profile can be seen in Figure 6.9. The critical flux Richardson number used is 0.15 (Turner, 1979). An average value is set for the rise velocity in still water. As discussed in Section 6.1.2, the rise velocity of $9.2 \mathrm{~mm} \cdot \mathrm{s}^{-1}$ calculated by Morse and Richard (2009) may be considered an upper limit. An average radius of $1 \mathrm{~mm}$ would give a rise velocity of $3.7 \mathrm{~mm} . \mathrm{s}^{-1}$ and this is used in Figure 6.9 . The linear and parabolic eddy viscosity assumptions give similar critical concentration profiles while the Businger-Arya model, with $h_{\max }=12 \mathrm{~m}$, indicates a slightly smaller concentration. As $h_{\max }$ decreases, so does the concentration required for collapse.

It is difficult to judge whether a sediment concentration exceeds a given profile. Winterwerp (2001) proposed a more convenient parameter, the depth-averaged critical sediment concentration,

$$
C_{s}=\frac{1}{h} \int_{z_{0}}^{h} c_{s} d z=\frac{\rho_{w} \rho_{i}}{\rho_{w}-\rho_{i}} \frac{R i_{f, c r}}{\kappa} \frac{u_{*}^{3}}{g W_{s}}
$$

where the integration is performed over the depth of the flow (e.g. Winterwerp et al. 2001; Winterwerp and van Kesteren, 2004). This is taken to be from the interface (at the roughness length $z_{0}$ ) to the bottom of the mixed layer, $h . W_{s}$ was referred to by Winterwerp (2001) as an "effective settling velocity". This can be interpreted as the reduced settling (rise) velocity 


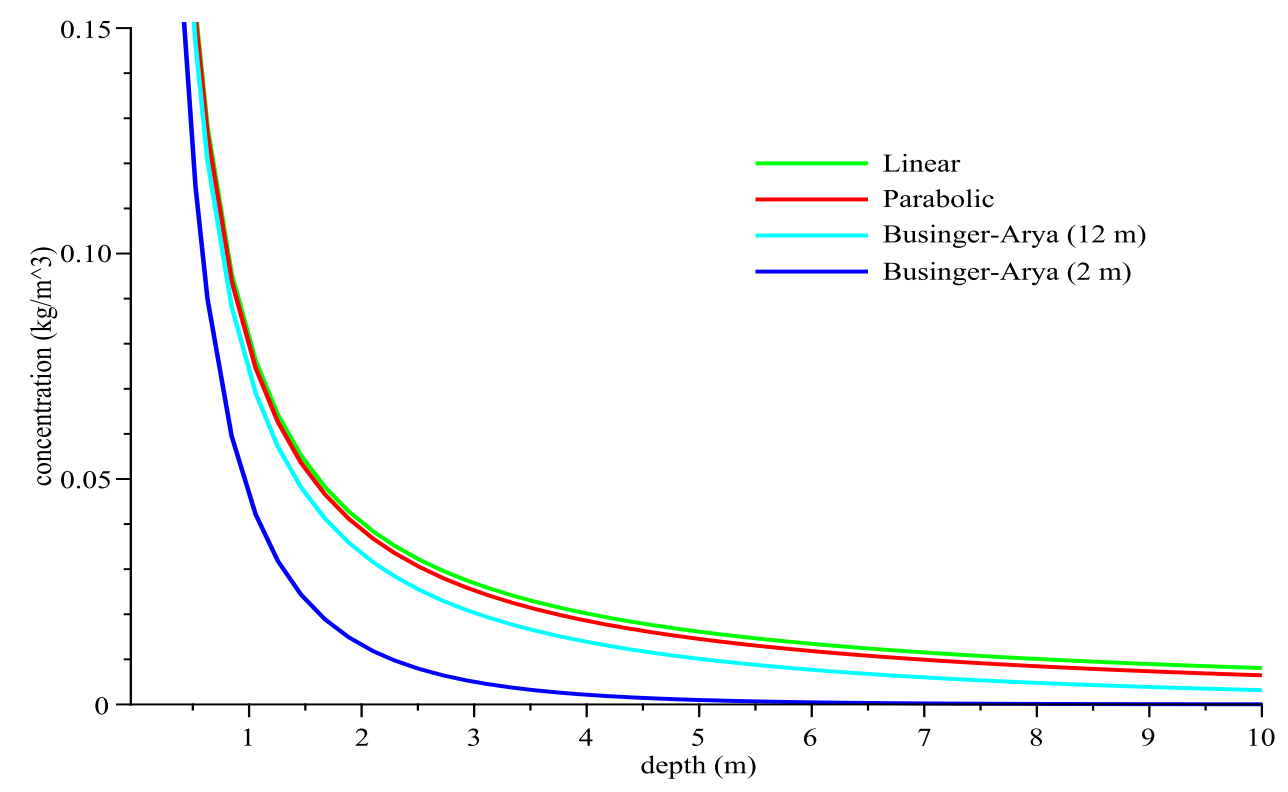

Figure 6.9: The critical concentration profile at which a collapse in the turbulent field will occur. It is predicted that, if the concentration exceeds these profiles, then a large quantity of the crystals will be able to rise out of suspension. This is shown for 3 different viscosity profiles, with two values of $h_{\max }(12 \mathrm{~m}$ and $2 \mathrm{~m})$ for the BusingerArya viscosity model.

of sediment (frazil) due to the turbulent environment. For the parabolic viscosity profile

$$
\frac{1}{W_{s}}=\int_{z_{0}}^{h} \frac{1}{w_{s}}\left(\frac{1}{z}-\frac{1}{h}\right) d z
$$

Given an average still water rise velocity, $W_{s}$ is about an order of magnitude smaller than $w_{s}$.

In Table 6.1, the depth-averaged critical sediment concentrations are shown for the values used to plot Figure 6.9 (first row). Given below this is the effect of altering the flux Richardson number, the average crystal radius (equivalent to altering the rise velocity) and the friction velocity.

It is immediately apparent that the results for an average set of param- 


\begin{tabular}{|c|c|c|c|c|c|}
\hline & & linear & parabolic & BA $(12 m)$ & $\mathrm{BA}(2 \mathrm{~m})$ \\
\hline \multicolumn{2}{|c|}{$\begin{array}{c}R i_{f, c r}=0.15 \\
r_{d}=1 \mathrm{~mm} \\
u_{*}=0.01 \mathrm{~m} . \mathrm{s}^{-1}\end{array}$} & 0.018 & 0.016 & 0.014 & 0.011 \\
\hline \multirow{2}{*}{$R i_{f, c r}=$} & 0.05 & 0.0058 & 0.0053 & 0.0047 & 0.0037 \\
\hline & 0.4 & 0.047 & 0.042 & 0.037 & 0.030 \\
\hline \multirow{2}{*}{$r_{d}(\mathrm{~mm})=$} & 0.5 & 0.070 & 0.064 & 0.057 & 0.045 \\
\hline & 1.6 & 0.0070 & 0.0064 & 0.0057 & 0.0045 \\
\hline \multirow{2}{*}{$u_{*}\left(\mathrm{~m} \cdot \mathrm{s}^{-1}\right)=$} & 0.005 & 0.0022 & 0.0019 & 0.0018 & 0.0014 \\
\hline & 0.02 & 0.14 & 0.13 & 0.11 & 0.092 \\
\hline
\end{tabular}

Table 6.1: Values of the critical depth-averaged sediment concentration, $C_{s}$, and the effect of altering the flux Richardson number, the average crystal radius and the friction velocity. BA stands for the Businger-Arya viscosity profile, given for $h_{\max }=$ $12 \mathrm{~m}$ and $2 \mathrm{~m}$. The results are given in $\mathrm{kg} \cdot \mathrm{m}^{-3}$.

eters are 5 to 10 times in excess of the average loads (of between 0.0005 and $0.004 \mathrm{~kg} \cdot \mathrm{m}^{-3}$ ) which were predicted as able to stay in suspension in Section 6.1.2. This would suggest that a critical collapse would not occur through a build-up of frazil in a steady shear flow beneath the ice. For such a collapse to occur, the dynamics of the system would need to change. This could be through a decrease in the friction velocity or due to a sudden influx of frazil, possibly from the nearby ice shelves.

In comparing the results in Table 6.1, it is noticeable that the difference between the viscosity profiles, while significant, is not as large as Figure 6.9 seems to imply. This is especially true in the case of the BusingerArya model with $h_{\max }=2 \mathrm{~m}$. This is because at smaller depths, where the concentration is greatest, the viscosity profiles are similar. Due to the higher concentrations in this region, it has a more significant role when calculating $C_{s}$. As the variation in concentration between the profiles in- 
creases, the critical concentration decreases.

Looking at the effect of varying the parameters, a change in $R i_{f, c r}$ leads to a corresponding linear change in the depth-averaged critical concentration. The radius, due to the square dependency of rise velocity on $r$, has a more marked effect on $C_{s}$. However, it is the friction velocity which has the most significant influence on $C_{s}$ due to the $u_{*}^{3}$ term in Equation 6.28 Doubling or halving the friction velocity leads to a increase or decrease in the $C_{s}$ by nearly an order of magnitude.

\subsection{Critical flux Richardson number}

In this final section, the depth at which various critical values of the flux Richardson number occur, corresponding to significant turbulence destruction, is investigated. It will then be possible to see if these depths are likely to occur within the mixed layer. The flux Richardson number was introduced in Section 6.2.1 as the ratio of the energy produced by shear to that destroyed by buoyancy. It can be defined as in Equation 6.24.

$$
R i_{f}=-g\left(\frac{\rho_{i}-\rho_{w}}{\rho_{i} \rho_{w}}\right) \frac{w_{s} c(z) \kappa^{2} z^{2}}{\nu_{T} u_{*}^{2}},
$$

where the concentration profile, $c(z)$, and the eddy viscosity profile, $\nu_{T}$, still need to be given.

Experiments have led to a critical value for $R i_{f}$ of between 0.05 and 0.4 being proposed for the complete destruction of a turbulent field. Also worth considering, however, are a critical value of 1 , where the rate of buoyancy destruction of energy equals its production by shear, and the point where $R i_{f} \rightarrow \infty$, at which stage all the turbulent energy is "instantly" destroyed.

In Section 6.2.1. eddy viscosity profiles which depend on the depth below the ice-water interface were used. This allowed for an algebraic solution for the critical concentration to be found. However, in Section 6.2.2, an 
eddy viscosity profile which depends on the flux Richardson number (and hence the concentration in suspension) was proposed (Equation 6.21),

$$
\nu_{T}=\frac{\kappa u_{*} z}{1+\alpha R i_{f}}
$$

(Smith and $\left.\mathrm{M}^{c} \mathrm{Lean}, 1977\right)$. As the stabilising concentration increases, so does $R i_{f}$, decreasing $\nu_{T}$. From Equation 6.24, as $\nu_{T}$ decreases, $R i_{f}$ increases. This may lead to a continuing snowball effect. Substituting $\nu_{T}$ into $R i_{f}$ and solving for $R i_{f}$ gives

$$
R i_{f}=\frac{-g\left(\rho_{i}-\rho_{w}\right) c(z) w_{s} \kappa z}{\rho_{i} \rho_{w} u_{*}^{3}+g\left(\rho_{i}-\rho_{w}\right) c(z) w_{s} \kappa z \alpha}
$$

which depends on the depth, both explicitly, and through $c(z)$. The form of Equation 6.29 includes the feedback effect between $R i_{f}$ and $\nu_{T}$, with a singularity when the denominator is 0 . As in Section 6.1.2, a constant $w_{s}$ (all crystals being the same radius) is assumed. Plotting the flux Richardson number against $z c(z)$ shows $R i_{f}$ increasing rapidly and tending to infinity near a critical value of $z c(z)$. As the radius of the crystals increases, so does this critical value.

In order to find the depth at which the given values of $R i_{f}$ occur, the concentration profile must be specified. Two versions will be used in this section. The first is Equation 6.17a, the simplest profile proposed. The second is derived in Appendix $\mathrm{D}$, and is based on the eddy viscosity given above. This gives

$$
\frac{c}{C_{a}}=\frac{\left(\frac{z}{z_{a}}\right)^{-b}}{\frac{\zeta b}{1-b}\left[\left(\frac{z}{z_{a}}\right)^{1-b}-1\right]+1}
$$

where 


$$
\zeta=C_{a} z_{a} \bar{\zeta}=\frac{C_{a} z_{a} g \kappa\left(\rho_{i}-\rho_{w}\right) w_{s} \alpha}{\rho_{w} \rho_{i} u_{*}^{3}}
$$

To find where $R i_{f} \rightarrow \infty$, the denominator of Equation 6.29 is set to 0 . Substituting either Equation $6.17 \mathrm{a}$ or 6.30 for $c(z)$ into the denominator and solving for $z$ gives

$$
\begin{aligned}
& z=z_{a}(-\zeta)^{\frac{1}{b-1}} \\
& z=z_{a}\left(\frac{-\zeta}{1-b(\zeta+1)}\right)^{\frac{1}{b-1}}
\end{aligned}
$$

Alternatively, by substituting the concentration profiles into Equation 6.29 and solving for $z$, the depth at which a given value of $R i_{f}$ occurs can be found. This gives

$$
\begin{aligned}
& z=z_{a}\left(-\zeta_{1}\right)^{\frac{1}{b-1}} \\
& z=z_{a}\left(\frac{\zeta b-\zeta_{1}(b-1)}{\zeta b+(b-1)}\right)^{\frac{1}{b-1}}
\end{aligned}
$$

where

$$
\zeta_{1}=\frac{\kappa g w_{s}\left(\rho_{i}-\rho_{w}\right) z_{a} C_{a}\left(1+\alpha R i_{f, c r}\right)}{\rho_{i} \rho_{w} u_{*}^{3} R i_{f, c r}}
$$

As mentioned above, in theory a critical flux Richardson number of 1 leads to the destruction of the shear produced turbulence. However, experimentally, it has been found that the collapse of turbulence may occur at a lower value.

Using the $C_{a}$ and $z_{a}$ given by Equations 6.18a and 6.18b (Smith and $\mathrm{M}^{c}$ Lean, 1977; Soulsby, 1998), and a friction velocity of $1 \mathrm{~cm} . \mathrm{s}^{-1}$, Figure 6.10 shows the depth at which certain values of the flux Richardson 


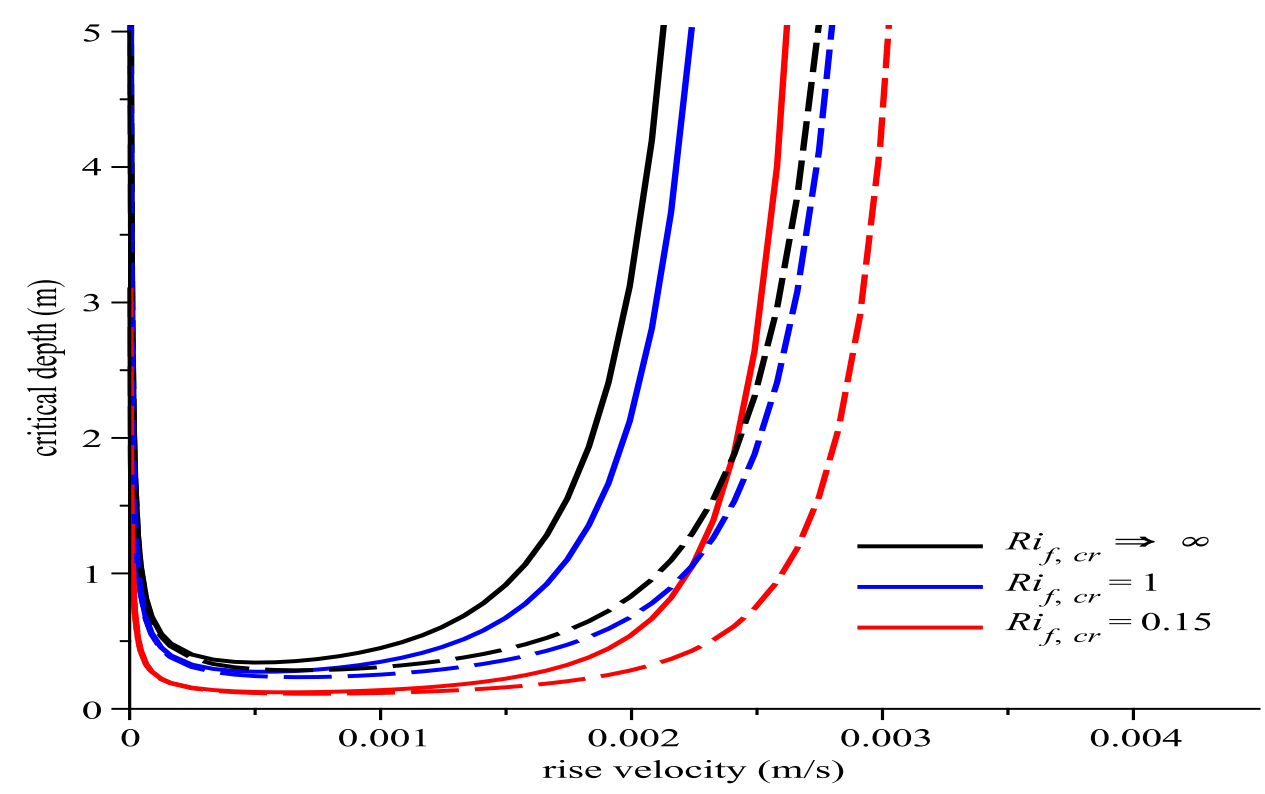

Figure 6.10: The critical depth at which certain values of the flux Richardson number occur, corresponding to the potential collapse of turbulence, for a suspension with a given rise velocity. No maximum has been assumed for the mass of crystals in suspension. The solid lines are plotted using the concentration profile given by Equation 6.17a, the dotted lines use Equation 6.30

number occur, corresponding to the potential collapse of the turbulent field, for a suspension of crystals of a given rise velocity. Using the simpler concentration profile, for a suspension with a rise velocity of $0.5 \mathrm{~mm} . \mathrm{s}^{-1}$, $R i_{f, c r} \rightarrow \infty$ at a depth of $0.5 \mathrm{~m}$. This depth increases rapidly as the rise velocity increases, and is nearly $50 \mathrm{~m}$ for a rise velocity of $2.5 \mathrm{~mm} . \mathrm{s}^{-1}$. This suggests that, for a sufficiently high rise velocity, the critical flux Richardson number will not occur in the mixed layer. Lowering $R i_{f, c r}$ to 1 , at which point all the turbulence produced by shear is destroyed by the stabilising buoyancy gradient, has only a minor effect on the critical depth for a given rise velocity. However, decreasing $R i_{f, c r}$ further results in lower values of the critical depth, and a larger range of rise velocities over which the given value of the flux Richardson number is reached in the mixed layer. For all of these, the depth tends to infinity as the rise velocity ap- 


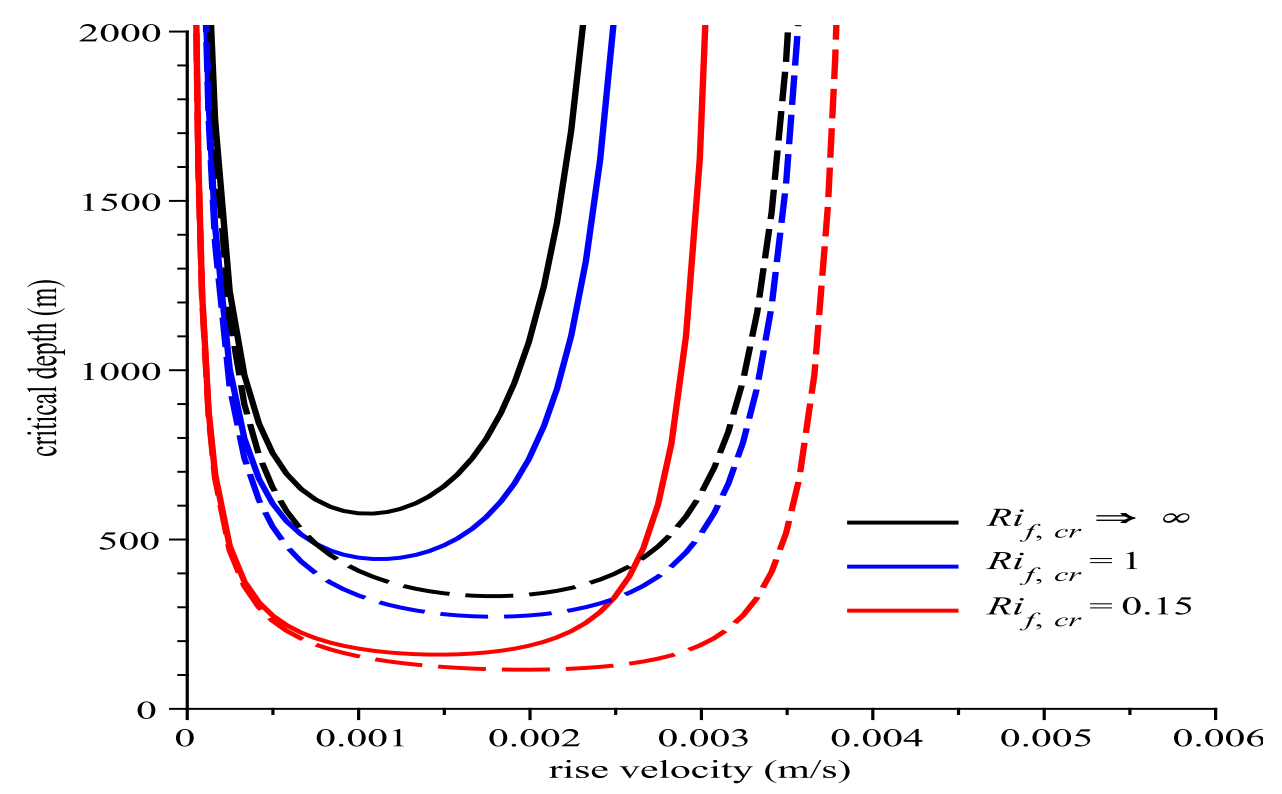

Figure 6.11: The critical depth at which certain values of the flux Richardson number occur, for a suspension with a given rise velocity. In this case, $z_{a}$ and $C_{a}$ are based on there being a maximum mass which can be held in suspension. The solid lines are plotted using the concentration profile given by Equation 6.17a, the dotted lines use Equation 6.30

proaches $4 \mathrm{~mm} \cdot \mathrm{s}^{-1}$, equivalent to a Rouse number of 1 .

Using instead a concentration which varies according to Equation 6.30 . there is a decrease in the critical depth at which $R i_{f}$ occurs for a given rise velocity. This is especially true for larger rise velocities. Hence, again, there is a larger range of rise velocities over which the flux Richardson number occurs.

It should be noted, however, that the reference depth and concentration used to calculate the concentration profiles for Figure 6.10 assume that there is no maximum mass of crystals which can be held in suspension, as predicted in Section 6.1.2. In fact, the average concentration in the mixed layer for a rise velocity of $0.5 \mathrm{~mm} . \mathrm{s}^{-1}$ is nearly three orders of magnitude greater than the maximum predicted by Equation 6.7. Figure 6.11 uses a $z_{a}$ and $C_{a}$ based on this maximum. It is apparent that the reduc- 
tion in the suspended concentration results in a significantly reduced flux Richardson number for a given depth. None of the flux Richardson numbers which are plotted in Figure 6.11 occur within $100 \mathrm{~m}$ of the ice-water interface. This is outside the range of mixed layer depths typically found in the Antarctic. This appears to confirm the findings of the previous section which suggested that a complete collapse of the turbulent field will not occur for concentrations which can be held in suspension.

\subsection{Summary}

The work in Chapters 3 and 4 investigated the effect of turbulence on a single crystal. In this chapter the focus has been on what may happen to a mass of crystals beneath sea ice. Of particular interest has been whether a frazil concentration may suggest any possible explanations to the platelet puzzle introduced in Chapter 2 .

A modification to the Shields diagram showed that crystals up to at least $1 \mathrm{~mm}$ in radius would be kept in suspension if the Shields criterion for motion was met. Crystals larger than this require greater turbulence to lift them from bedload motion to transport in the suspended load. It was also suggested that crystals which rise from depth may be kept in suspension even if they are below the critical Shields criterion for mobilisation.

By comparing the stress due to shear induced turbulence with that caused by a mass of crystals, it was possible to estimate the average mass per cubic metre which could be held in suspension. This increased quadratically with the friction velocity. It was shown that, for a friction velocity of $1 \mathrm{~cm} \cdot \mathrm{s}^{-1}$, a density of $0.002 \mathrm{~kg} \cdot \mathrm{m}^{-3}$ of frazil could be prevented from rising to the interface. Depending on the size of the frazil crystals in suspension, this could indicate anywhere from a few thousand crystals to well over a million per cubic metre. Comparisons with field measurements showed promise. Whether these field readings are near the maximum capacity for their flow depends on their rate of creation or influx into 
the flow. Obviously, however, if the maximum load theory is correct, the number of crystals should not exceed the capacity (over any reasonable time period).

Given a density of crystals near the maximum load limit described above, any further increase in the density of crystals (through growth or influx from the nearby ice shelves) or decrease in the friction velocity (for example, if the tide or current weakens) will lead to a settling out of the largest crystals near the ice-water interface. Even if neither of these occur, there is still the possibility that the density of crystals may affect the flow that is keeping them in suspension. Indeed, it was shown that a crystal concentration can decrease the friction velocity of a flow. This effect is most noticeable if the concentration consists of crystals with a radius of around $0.5 \mathrm{~mm}$. Given a shear flow of $10 \mathrm{~cm} \cdot \mathrm{s}^{-1}$, the maximum decrease in the friction velocity was found to be around $13 \%$. Though this would have little effect on a single crystal, it may have a more significant effect on a mass of crystals held in suspension.

Also considered was whether a concentration of crystals could cause a critical collapse in the turbulent flow due to its stabilising density gradient. Such an effect was suggested for river sediment and occurs when cohesive sediment dampens the flow, forming a porous, mobile mud layer which prevents the creation of turbulence. This may be compared to the layer of loose platelet crystals which has been observed beneath an ice cover during field observations (Gow et al., 1982; Lange, 1988: Eicken and Lange, 1989: Gow et al., 1998; Langhorne et al., 2006).

In quantifying the density of crystals required for a critical collapse of the turbulent field, it was found that the density was greater than that which could be held in suspension by the flow. This suggests that a collapse of turbulence could occur only through an influx of crystals, a drop in the friction velocity, or if the local concentration exceeds the local critical value over a given depth (even though the average value may still be below its critical value). 
This was apparently confirmed in the final section of the chapter. A flux Richardson number tending to infinity implies the destruction of all shear produced turbulence by a stabilising buoyancy gradient. For $R i_{f}=$ 1 , as much turbulence is destroyed as is produced. It is known that the flux Richardson number depends on the eddy viscosity profile. It was proposed by Smith and $\mathrm{M}^{c}$ Lean (1977) that the eddy viscosity may also depend on $R i_{f}$. Combining the equations for $R i_{f}$ and $\nu_{T}$, it was shown that, for a value of $R i_{f}$ of 0.15 or greater to occur within the mixed layer, the average mass of crystals in suspension would need to be greater than the maximum mass predicted earlier in the chapter.

It is possible that crystals could be transported (for example from underneath a nearby ice shelf) to below the sea ice. Depending on the mass of crystals already beneath the ice and the quantity swept in, one of three outcomes could occur:

- no change as the combined mass of crystals does not exceed the maximum suspendable load

- some settling of crystals if the combined mass exceeds the maximum load but is not enough for a critical collapse of turbulence

- a sudden reduction in the number of crystals in suspension if the combined mass is enough to cause a collapse of the turbulent field. 


\section{Chapter 7}

\section{Conclusions}

The main focus of this thesis has been to investigate the platelet ice which makes up a significant portion of sea ice growth in some Antarctic regions. Specifically, it has been asked why, as is commonly observed, do platelet crystals appear only after at least $1 \mathrm{~m}$ of congelation growth has occurred. It was assumed that these platelets form when smaller frazil crystals, beneath the ice, settle against the ice-water interface. Once attached they may grow into the larger platelet crystals seen in ice cores. In this chapter the key results of the thesis will be briefly discussed. Suggestions will also be made for possible extensions to this work.

\subsection{Shear flow}

The first method proposed for keeping frazil from settling against the interface was the shear flow of the water below the ice. The Shields criterion is commonly used in sedimentation theory to estimate when sediment motion will commence at a river- or sea-bed. In Chapter 3 it was used to find the critical friction velocity which, if exceeded, would imply that frazil crystals would be unable to settle at the interface. It was shown that the larger, more buoyant, crystals require a greater friction velocity to keep them moving. 
Shear flow is the combination of the tidal flow, the prevailing currents and the movement of the ice itself. At most times, tidal flow is the dominant mechanism of these three. The friction velocity created by a typical shear flow was found to have sufficient strength to keep crystals of up to nearly $3 \mathrm{~mm}$ in radius from adhering to the interface. This is large for a crystal in a natural environment.

It is important to note that shear flow alone cannot explain the platelet puzzle and their delayed appearance in the sea ice. The shear flow does not decrease as the ice grows. Therefore, a crystal kept in motion initially will still be unable to settle after a growth of $1 \mathrm{~m}$ or more.

As the shear flow is largely due to tidal flow, the question of what may occur as the tides turn was also posed. It was assumed that the time taken for the tides to turn (slack water) would exceed the length of time required for turbulence to dissipate (pers. comm. Craig Stevens). Hence, another mechanism is required to keep the frazil crystals in suspension. Confirming this assumption, either with more accurate calculations of the time scales, or through time-varying measurements of the turbulence beneath the ice, is important in providing a greater knowledge of the turbulent environment in which the crystals are suspended.

\subsection{Rise velocity}

In Chapter 4. Stokes' Law was used to develop a formula for the rise velocity of frazil crystals in still water. Equation 4.3 .

$$
u_{S t}=\frac{V\left(\rho_{w}-\rho_{i}\right) g}{6 \mu \pi R},
$$

was proposed, where $V$ is the volume of the disc and $R$ an effective radius based on the orientation of its ascension. Given calm surroundings, it was found that a crystal will rise with its flat side perpendicular to the vertical. 
This gives an effective radius of $R=8 r_{d} / 3 \pi$ where $r_{d}$ is the radius of the crystal.

While strictly only true for crystals smaller than $1 \mathrm{~mm}$ (with a Reynolds number less than 1), comparing Equation 4.3 with field measurements and other rise velocity equations shows a good match for crystals up to around $3 \mathrm{~mm}$ in radius. Beyond this, measurements are sparse however, the rise velocity may become proportional to the crystal radius (Morse and Richard, 2009) or to the square root of the radius (Daly, 1984).

Also of importance for the rise velocity is the aspect ratio, the ratio of thickness to diameter of a crystal, which enters the equation through the disc volume, $V$. While aspect ratios between 0.01 and 0.1 are often quoted, larger values appear to over-predict the rise velocity. A more definitive knowledge of the aspect ratio, including any potential change in the ratio with the crystal radius, would be useful.

Accurate predictions of the rise velocity are vital for frazil settling theories. Hence, further experimental measurements of the rise velocity, preferably in both still and turbulent conditions, are essential. Turbulence can have a significant effect on the rise velocity of crystals. Turbulent fluctuations may oppose the motion of the frazil, while vortex fields can trap or fast track crystals.

\subsection{Brine rejection}

The velocity associated with brine rejection was suggested as an explanation for the suspension of frazil crystals during periods of negligible shear flow. By comparing this with the crystal rise velocity, it was shown that crystals up to $1.7 \mathrm{~mm}$ in radius could be kept in suspension early in the growth season. Importantly, brine rejection is dependent on the rate of ice growth. Hence, it decreases as the ice increases in depth, which allows progressively smaller crystals to rise to the interface. When the sea ice is $1 \mathrm{~m}$ thick, the radius of the crystals able to rise out of suspension has 
dropped by around $0.4 \mathrm{~mm}$.

This provides a plausible explanation for the delayed appearance of platelet ice in ice cores. However it is not certain that the change in crystal size able to rise out of suspension is sufficient to answer the platelet puzzle. Indeed, it was estimated that, depending on the rate of ice growth, crystals smaller than $1.3 \mathrm{~mm}$ may be kept permanently in suspension.

An extension to this work, from $\mathrm{M}^{c}$ Guinness et al. (2009), was also presented. In it, an attempt was made to develop a model which combines the effect of shear flow and brine rejection. Despite the atmospheric research into the analogous case of wind and buoyant air plumes over land or sea (for example van den Hurk and Holtslag (1997); Mahrt et al. (1998); Grachev et al. (1998)), this remains one of the trickiest problems to deal with. Much of the previously detailed work focuses on combining the two motions into a single friction velocity. However, this is not an appropriate method for considering the competence of brine plumes and tides to keep frazil crystals from settling as, by acting in different directions, they affect the rise velocity of the crystals in different ways.

By comparing frazil crystals with diesel droplets (which have a similar relative density), it was surmised that small crystals may tend to a constant rise velocity in turbulent waters, depending on the friction velocity of the system. As the crystal radius increases, the rise velocity reverts to the still water value. It was shown that, if this is true, the radius at which crystals may rise out of suspension decreases significantly at a critical ice thickness, which represents the point at which the velocity associated with brine rejection drops below the crystal rise velocity. Though sensitive to changes in the parameters, standard values, with a friction velocity of $0.5 \mathrm{~cm} . \mathrm{s}^{-1}$, suggest that this occurs at a critical ice thickness of around $0.95 \mathrm{~m}$.

Again, it is stressed that there is a need for further investigations into the frazil crystals in situ beneath sea ice. Current methods of crystal measurement tend to favour the discovery of larger crystals, due to the difficulty in detecting the smaller discs. This leads to a tendency to overesti- 
mate the average size of a crystal and, hence, its rise velocity.

Of interest, as a further development to this work, is the effect of a more porous structure at the ice-water interface. As mentioned in Section 5.6. the difference between the rates of heat and salt diffusion at the interface can lead to the formation of a mushy zone. This region, with a significant liquid fraction (changing with depth), may affect the velocity associated with brine rejection. While field measurements would be difficult, theoretical results may prove enlightening.

\subsection{Ice growth}

The aim of the ice growth model presented in Chapter 5 was to develop a simple yet accurate model for first-year ice which included the effects of both salt and convective transfer at the ice-water interface. It was shown that a build-up of salt at the ice-water interface significantly decreases the rate of growth. The excess salt occurs as heat is transferred more rapidly away from the interface. As the temperature and salinity are linked, this leads to a depression in the freezing point at the interface and an increased flux from ocean to ice.

One of the most interesting results of the model was the effect of altering the mixed layer temperature. It would seem intuitive that increasing the mixed layer temperature (and decreasing the salinity proportionally) would increase the oceanic heat flux and decrease the growth. This does not occur. This is because the temperature is fixed to be at the freezing point temperature of the salinity. A warmer mixed layer has a lower salinity. This means that there is less salt to be rejected by the ice and therefore the build-up of salt at the interface (which occurs due to the slower diffusivity of salt than heat) is smaller. This increases the temperature at the interface, and the change of temperature is greater than that prescribed in the mixed layer. Therefore, the oceanic heat flux decreases, and the growth rate increases. The opposite is true for a decrease in the mixed layer tem- 
perature.

It was also shown that supercooling of the mixed layer can lead to a significant increase in the growth rate. In this case, the temperature in the mixed layer is decreased without an equivalent increase in the salinity. This leads to a decrease in the oceanic heat flux.

When compared with Antarctic field results, it was apparent that the model predicts significantly less growth. It was surmised that this extra growth may be caused by the inclusion of platelet ice in the Antarctic measurements. This is not included in the model presented. Though some work has been done on adding the effects of platelet growth to sea-ice models (for example Steele et al., 1989; Crocker and Wadhams, 1989), improving on this is vital in order to accurately predict the ice growth in the regions of Antarctica where platelet growth is prevalent.

\subsection{Shear stabilisation}

The focus of the first chapters of this thesis was on the effect of a flow on a single crystal. In Chapter 6, a mass (or density) of crystals in suspension was considered. Not only was the ability of a flow to suspend this mass investigated, it was also asked whether a mass of crystals may, in turn, affect the turbulent environment.

A mass of crystals, beneath a unit area of sea ice, induces an upward stress. This stress of suspension increases with the frazil mass. The turbulence associated with shear flow can counteract this stress. Balancing these, it was found that, for a friction velocity of $1 \mathrm{~cm} \cdot \mathrm{s}^{-1}$, the density of crystals which can be held in suspension is $0.002 \mathrm{~kg} \cdot \mathrm{m}^{-3}$. This implies a crystal concentration in the order of $10^{4}$ to $10^{6}$ crystals per cubic metre (for crystals radii between 0.3 and $1.3 \mathrm{~mm}$ ). The total mass which can be held in suspension per unit volume increases with the friction velocity.

Once again, it is the unavailability of sub-sea ice data on the frazil concentration which is the greatest difficulty in evaluating this result. To aid 
the work in this chapter, further studies into the number of crystals and their size would be interesting. However, most useful would be a direct measurement of the mass of crystals in suspension.

It was suggested that frazil crystals may act like a "cohesive" sediment. A cohesive sediment forms a porous, fluid layer as it settles out of suspension. This layer continues to damp the turbulence and may lead to a critical collapse of the turbulent field. However, the critical average density required for such a collapse was found to exceed the density of crystals which can be held in suspension. Hence, it would be expected that, in most circumstances, the gradual settling of crystals would occur first, preventing the build-up of a sufficient mass of crystals for collapse. An interesting extension to this work would be to analyse whether including the reduction in flow strength as the tides turn has any effect on the critical value for collapse (Winterwerp et al. . 2001).

This does raise the question as to where the significant fraction of frazil formation occurs. If nucleation and growth occurs predominantly beneath the sea ice, a steady build-up in the crystal mass would result. If the flow is sufficient to keep the individual crystals in suspension, the mass of crystals beneath the ice could continue to build until the critical value for suspension is exceeded. At this stage the largest crystals, close to the interface, would rise to the interface and become incorporated into the cover. The timing of their appearance in ice cores would depend on the length of time taken for the crystal mass to build.

Alternatively, the majority of frazil crystals may be swept below the ice from other locations. It is known that a rapidly moving water plume from beneath a nearby ice shelf can contain a quantity of frazil. The movement of the frazil once beneath the sea ice depends on a number of factors. Most notably, the mass of frazil in the plume and any change in the turbulent velocity must be considered. A sufficient mass may result in the critical criterion for the collapse of turbulence being exceeded. It is therefore vital to confirm the origin of the frazil crystals. 


\section{Glossary}

Antarctic Circle Line of latitude, currently at $66.6^{\circ} \mathrm{S}$, south of which all regions experience at least one day of $24 \mathrm{hr}$ sunlight and one of $24 \mathrm{hr}$ darkness.

atmospheric heat flux Heat flux from the ice to the atmosphere. Also called the conductive heat flux.

bedload Transportation of sediment (or ice crystals) near to the solidfluid interface.

brine Seawater with a high salt concentration.

degree-day A combined measure of the temperature below freezing and length of time a region has been at that temperature. One degree-day of freezing is equivalent to 1 day at $1^{\circ} \mathrm{C}$ below freezing.

dendrite Ice crystals which grow more rapidly into the water around them.

dry mass The mass of sediment in a suspended load if it was removed from the fluid supporting it.

eutectic The eutectic point of a mixture is the point at which the temperature and concentration of an alloy are such that both (all) constituents freeze (or melt) at the same time. 
flux Richardson number Ratio of the buoyancy destruction and shear production terms in the turbulent kinetic energy equation. Used to describe the stabilisation effect of buoyancy on shear produced turbulence.

frazil Small, disc-shaped ice crystals which, if provided with nucleation points, form and grow in turbulent, supercooled water. Can range in size from $0.1 \mathrm{~mm}$ to $10 \mathrm{~mm}$ in diameter. In natural environments tend to be on the smaller size.

freezing point temperature The temperature at which seawater of a given salinity will begin to freeze.

friction velocity A characteristic velocity scale which gives a measure of the strength of turbulence in a flow.

grain Reynolds number A ratio of inertial forces to viscous forces. It is used to predict regions of laminar or turbulent flow. A crystal with a low grain Reynolds number will behave as if in laminar flow, even if in a turbulent environment.

halocline A strong, vertical salinity gradient. Present in the Southern Ocean, it plays an important role in maintaining the stratification of the seawater. Holds the depth of the mixed layer in check.

ice core Method of measuring the depth of sea ice and its composition. For shallow ice, a narrow, hollow tube is lowered into the ice to capture a sample.

ice shelf Region of floating ice which is attached to a glacier. It is largely formed on land before "flowing" into the sea. An ice shelf can be much thicker than sea ice. 
lead Narrow cracks of ice, often short-lived, which form in an ice cover due to ice movement.

mixed layer A region directly below the sea ice which has a constant temperature and salinity. Developing during the initial formation of an ice cover, it can grow from $25 \mathrm{~m}$ early in the season to nearly $100 \mathrm{~m}$ in some regions.

oceanic heat flux Heat flux between the ocean and the ice. Usually travels from the ocean up into the ice, unless the mixed layer is significantly supercooled. Generally small in the Arctic, it can have a significant effect on Antarctic ice growth.

pancake ice Ice created by frazil accretion during early season growth. Large circular discs, ranging in size from a few centimetres to a few metres, they are characterised by upturned edges due to collisions with other pancakes. Eventually adhere together to form a continuous ice layer.

platelet A number of definitions can be found for a platelet. In this thesis it is used to describe the larger sizes of frazil crystals. They can be found in large quantities either floating beneath an ice cover (in a platelet layer) or incorporated into it.

Prandtl number A dimensionless number which compares the momentum and thermal diffusivities. It is used to examine the differing rates at which heat and momentum diffuse in a system.

rafting The movement of one ice sheet riding up over another as they press together.

Rouse number Ratio of a sediment's fall velocity due to gravity to the upward turbulent forces acting on it. 
Schmidt number A dimensionless number, analogous to the Prandtl number, except used to compare mass and momentum.

Stanton number A dimensionless number used in forced convection. Gives the ratio of heat transferred to the thermal capacity of the fluid.

Stefan problem Boundary value problem for a (system of) partial differential equation(s) where the boundary can move with time.

suspended load Transportation of sediment (or ice crystals) which are held in suspension away from the solid-fluid interface.

turbulent kinetic energy equation Describes the mean energy per unit mass of eddies in a turbulent flow. 


\section{Appendix A}

\section{Conservation equations}

\section{A.1 Conservation of salt}

In calculating the conservation of salt at a growing ice interface, it is important to consider both the movement of the ice-water interface and the "blowing" effect caused by ice expansion during freezing. It is easiest to do this calculation in a frame of reference moving with the interface, as shown in Figure A.1.

Moving with the reference frame, we have a flux of ice out of ' $a$ ', the top of the reference frame. There is also a flux of water in, at ' $b$ '. The ice expanding, however, acts against the influx of water at ' $b$ '. This creates an additional flux, $\rho_{w} \dot{d}$, where $\dot{d}$ is the "blowing" velocity associated with the ice expansion. The mass conservation equation is then

$$
\rho_{i} \dot{h} \delta A \delta t=\rho_{w} \dot{h} \delta A \delta t-\rho_{w} \dot{d} \delta A \delta t
$$

where $\rho_{i}$ and $\rho_{w}$ are the densities of ice and water respectively, $h$ is the position of the interface, while $\delta A$ and $\delta t$ are a unit area and unit time. The over dot represents differentiation with respect to time. This gives 


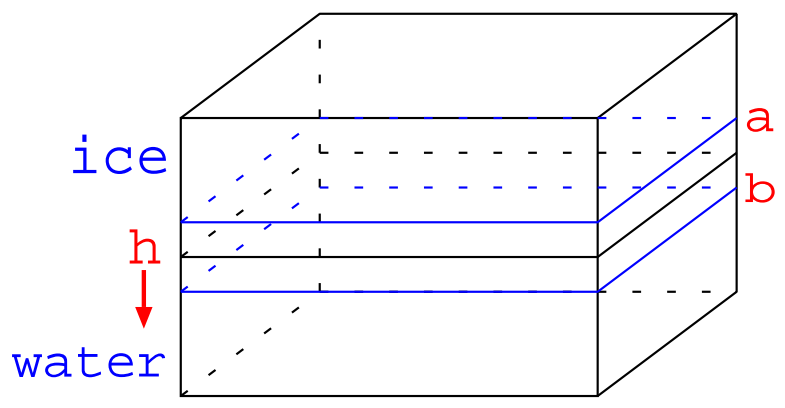

Figure A.1: Diagram of an elementary volume (from a to $b$ ) in a moving reference frame around the ice-water interface, $h$. As the ice freezes, the reference frame moves downwards.

$$
\rho_{w}(\dot{h}-\dot{d})=\rho_{i} \dot{h}
$$

A similar equation exists for salt. However, with ice rejecting salt into the water below, a salt flux term, $Q_{s}$, must be included. The salt conservation equation (omitting the unit area and time) is thus

$$
S_{i} \rho_{i} \dot{h}=S_{w} \rho_{w} \dot{h}-S_{w} \rho_{w} \dot{d}+Q_{s}
$$

where $S_{i}$ and $S_{w}$ are the salinities of the ice just above the interface and the water just below, respectively. This can also be rearranged, giving

$$
\rho_{w}(\dot{h}-\dot{d})=\frac{S_{i} \rho_{i} \dot{h}-Q_{s}}{S_{w}} .
$$

Equating Equations A.2 and A.4 simplifies the conservation of salt to

$$
\left(S_{i}-S_{w}\right) \rho_{i} \dot{h}=Q_{S}
$$




\section{A.2 Conservation of energy}

The conservation of energy (heat) equation is slightly more complicated due to heat conduction through the ice. The equation (again, omitting the unit area and time) becomes

$$
k_{i} \frac{\partial T}{\partial z}+H_{i} \rho_{i} \dot{h}=H_{w} \rho_{w}(\dot{h}-\dot{d})-Q_{T}
$$

where $k_{i}$ is the conductivity of ice, $H_{i}$ and $H_{w}$ are the specific enthalpies of ice and water (at the freezing point temperature) respectively and $\frac{\partial T}{\partial z}$ is the temperature gradient in the ice. $Q_{T}$ is the oceanic heat flux. Combining this with Equation A.2 gives

$$
L \rho_{i} \dot{h}=-k_{i} \frac{\partial T}{\partial z}-Q_{T}
$$

where $L\left(=H_{i}-H_{w}\right)$ is the latent heat of fusion. 


\section{Appendix B}

\section{Matlab M-files}

\section{B.1 M-file 'RungeKuttarealTa'}

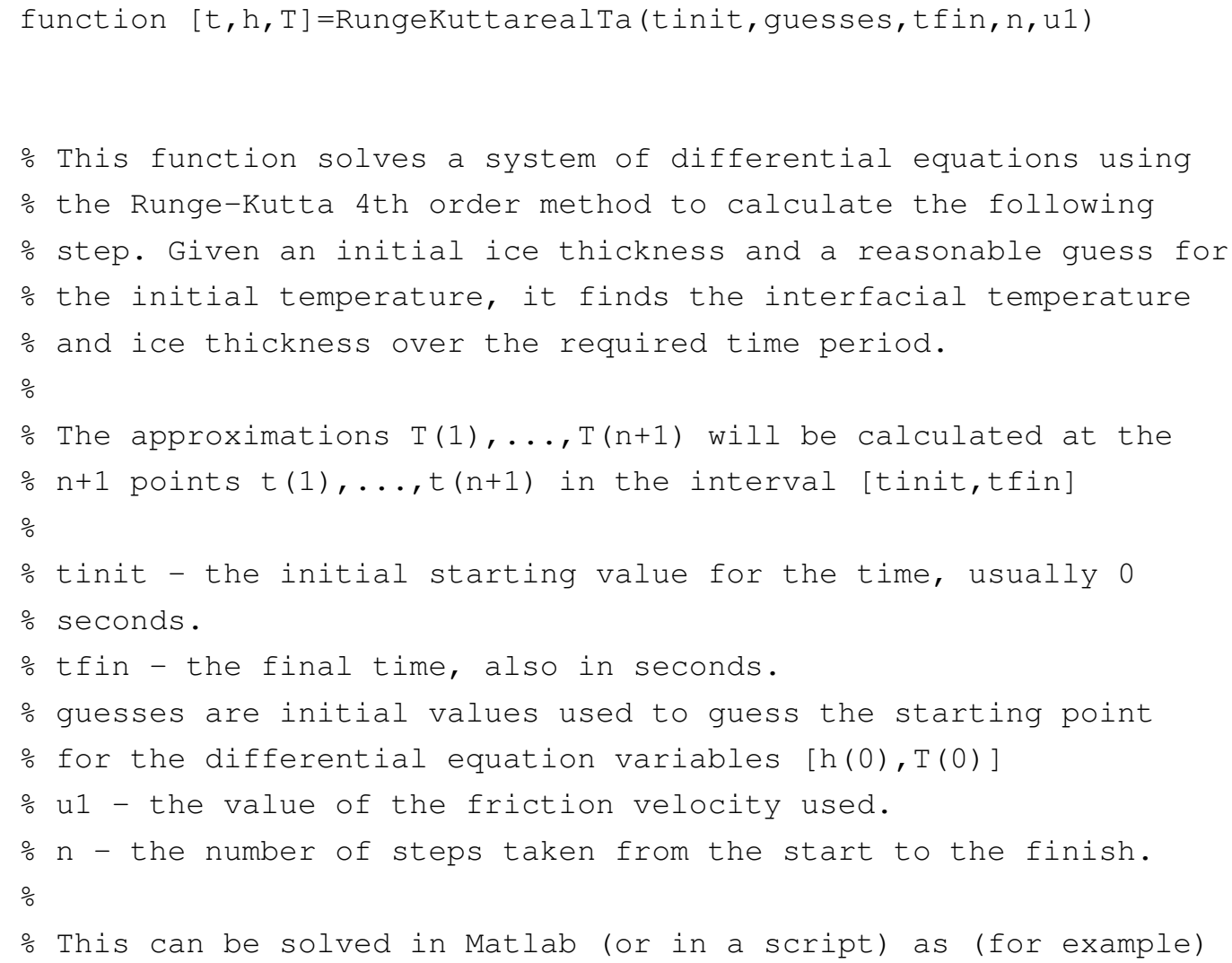


$\div[t, h, T]=$ RungeKuttarealTa $(0,[0.1,-5], 12960000,3800,0.01)$;

$\circ$

\% The data provided has 7600 data points for the 150 days of

\% winter. $n$ must be selected so that each time step is an integer

\% (for the temperature data value). Using 7600 uses all the data

\% values. Factors of 7600 allow for quicker runs.

\%

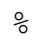

: Firstly loading the constant values, as defined in RealTaeqns \%

global realTa

$\%$

\% Calculating ss from tinit, tfin and $n$, where ss is the step

\% size

$\div$

$s s=($ tfin-tinit) $/ n$;

\%

\% Initializing $t, h, T$ as $n+1$ column vectors... not

\% essential but gives [t $h \mathrm{~T}$ ] in tabular form as $t, h, T$

\% are vectors and helps the program to run more efficiently.

\% This command also stops matlab giving the suggestion of

\% preallocating for $t$.

$\div$

$\mathrm{t}=\operatorname{zeros}(\mathrm{n}+1,1)$;

$\mathrm{h}=\operatorname{zeros}(\mathrm{n}+1,1)$;

$\mathrm{T}=\operatorname{zeros}(\mathrm{n}+1,1)$;

응

defining the initial $h$ and $\mathrm{T}$. 
$\% \mathrm{~h}$ is the initial value for $\mathrm{h}$ given in guesses.

- $T$ is found using the fzero to solve the 2 combined equations

- (combined in RealTaeqns) for the temperature for the given

ice thickness.

$\circ$

h $(1)=$ guesses $(1)$;

$\mathrm{T}(1)=$ fzero (@ ( T) RealTaeqns (h(1), T, u1, 1), guesses (2));

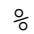

Time (t) is introduced through the steps (i) as, though not

\% explicitly used in the equations, both $\mathrm{h}$ and $\mathrm{T}$ depend on it.

o Ice thickness is calculated at i+1 using the Runge-Kutta

\% fourth-order method.

ㅇ ' $a$ ' is the function for $\mathrm{dh} / \mathrm{dt}$, the growth rate of the

o interface, defined as a seperate function below.

$\circ$

for $i=1: n$

$t(i+1)=t(i)+s s$;

$\mathrm{kal}=\mathrm{a}(\mathrm{h}(\mathrm{i}), \mathrm{T}(\mathrm{i}))$;

$\mathrm{ka} 2=\mathrm{a}(\mathrm{h}(\mathrm{i})+(\mathrm{ss} /(2)) * \mathrm{ka} 1, \mathrm{~T}(\mathrm{i}))$;

$\mathrm{ka} 3=\mathrm{a}(\mathrm{h}(\mathrm{i})+(\mathrm{ss} /(2)) * \mathrm{ka} 2, \mathrm{~T}(\mathrm{i}))$;

$\mathrm{ka} 4=\mathrm{a}(\mathrm{h}(\mathrm{i})+\mathrm{ss} * \mathrm{ka} 3, \mathrm{~T}(\mathrm{i}))$;

$\mathrm{h}(\mathrm{i}+1)=\mathrm{h}(\mathrm{i})+(\mathrm{ss} /(6)) *(\mathrm{ka} 1+2 * \mathrm{ka} 2+2 * \mathrm{ka} 3+\mathrm{ka} 4)$;

$\mathrm{T}(\mathrm{i}+1)=f$ zero $(@(\mathrm{~T})$ RealTaeqns $(\mathrm{h}(\mathrm{i}+1), \mathrm{T}, \mathrm{u} 1, i *(7600 / \mathrm{n})), \mathrm{T}(\mathrm{i}))$;

end

$\%$

- Also needed for definition are the functions for dh/dt as

\% presented in the main body of the thesis

$\frac{\circ}{\circ}$

function derivi=a $(h, T)$ 


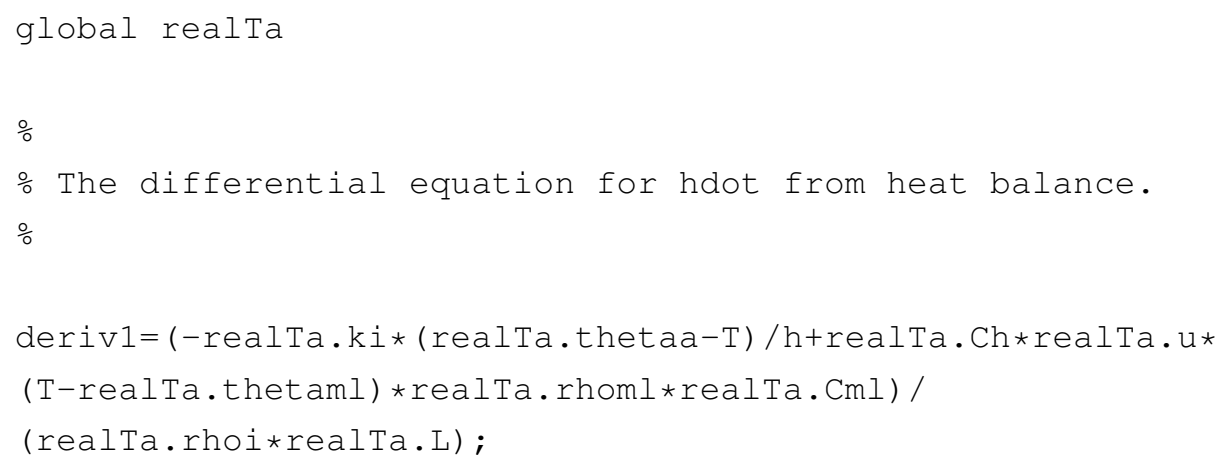




\title{
B.2 M-file 'RealTaeqns'
}

\author{
function Tvalue=Real Taeqns (h, T,ul, ti)
}

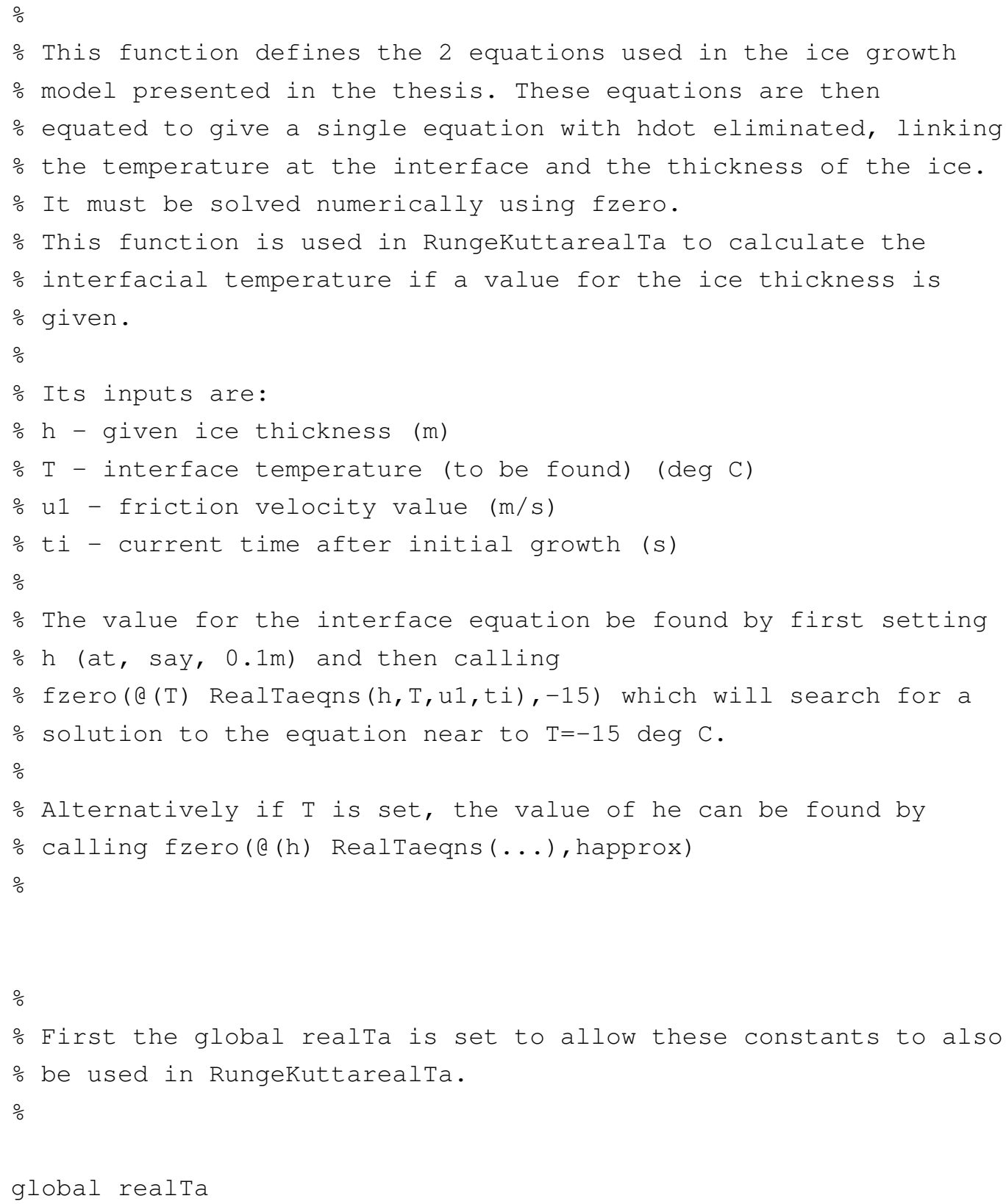




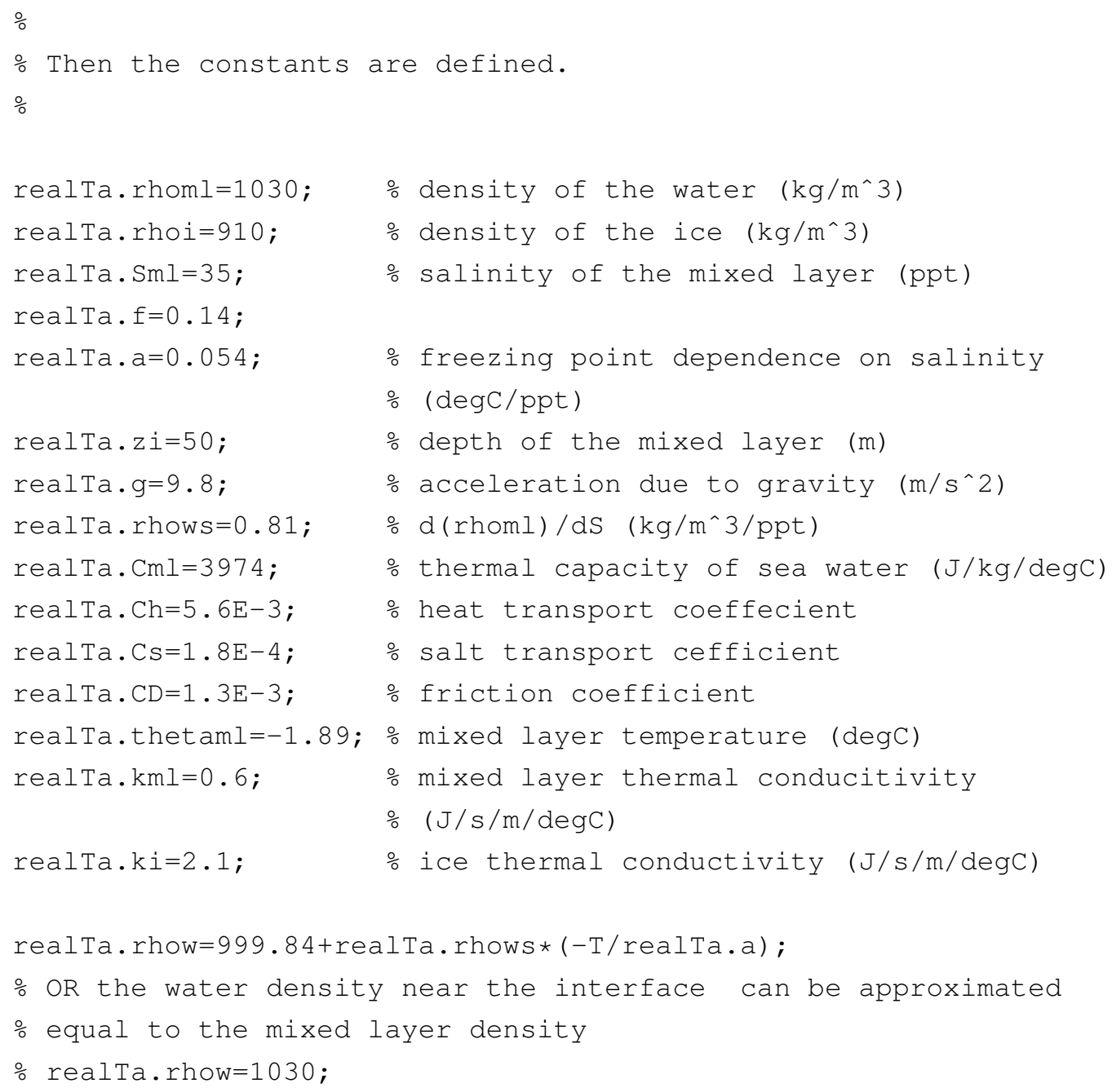


load RealT

orealTa.thetaa $=-25 ; \quad$ overage air temperature $(\operatorname{deg} C)$

orealTa.thetaa $=5 * \sin (2 * \mathrm{pi} * \mathrm{ti} / 86400)-25$;

\% sinusoidal daily variation of temperature

orealTa.thetaa $=5 * \sin (2 * \mathrm{pi} * \mathrm{ti} / 86400)-26 * \exp (-\mathrm{ti} / 172800000)$;

o sinusoidal daily variation of temperature,

: with an exponential increase in temp

o over the winterealTa.

orealTa.thetaa $=5 * \sin (2 * \mathrm{pi} * \mathrm{ti} / 86400)-25.5+6 *$

잉 $\quad(($ ti-8640000)/17280000)^2;

o sinusoidal daily variation of temperature with a

o parabolic decrease then increase in temperature

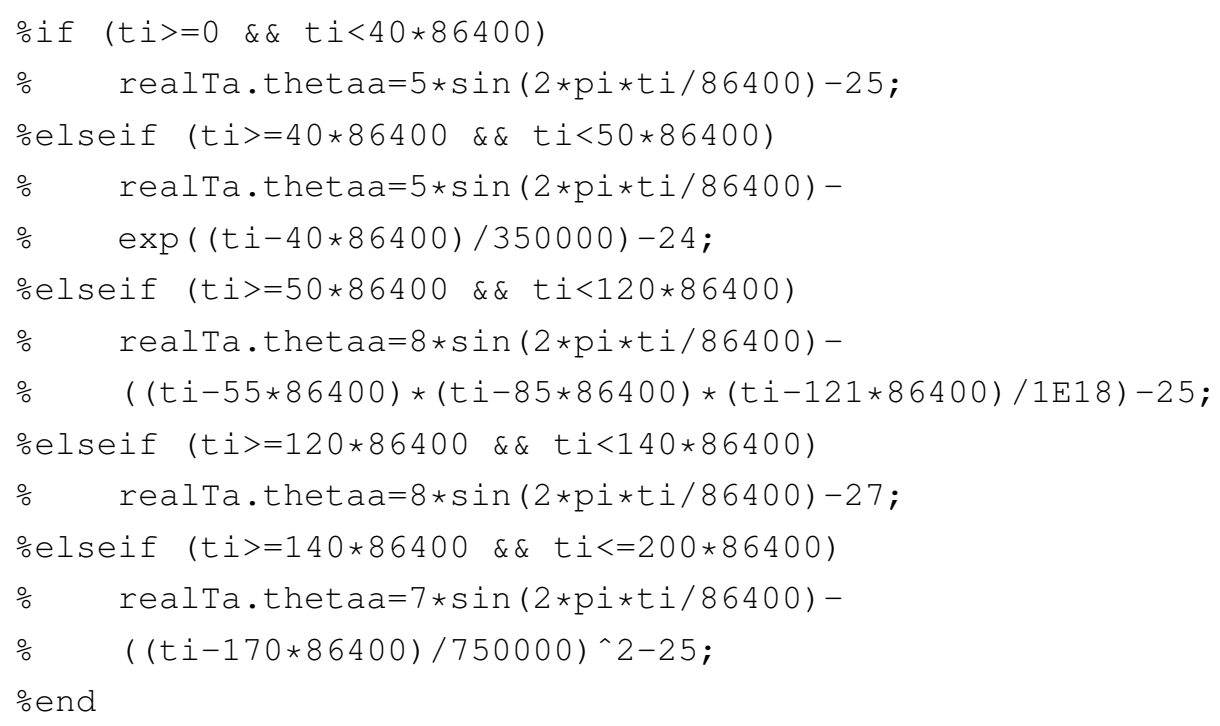


\% or the actual data value, at the given time, ti. 은

realTa.thetaa $=\operatorname{RealT}(\mathrm{ti})$;

$\div$

\% Given the equation for the freezing point temperature. 응

realTa.S $=-\mathrm{T} /($ realTa.a $)$;

\% and the salinity of the ice (dependent on the water below)

realTa.Si=realTa.f*realTa.S;

\% as well as the latent heat of freezing ( J/kg)

\%realTa.L=334000; $\quad$ olatent heat of fusion of pure water realTa. $\mathrm{L}=289000$; $\%$ (constant) latent heat of sea ice fusion Varying latent heat of sea ice orealTa. $\mathrm{L}=(1000 * 4.186 .8) *(79.68-0.505 * \mathrm{~T}-0.273 \mathrm{E}-1 * \mathrm{realTa} . \mathrm{Si}+$ ⒋3115*realTa.Si./T + 0.8E-3*realTa.Si*T - 0.9E-2*T.^2); orealTa.L $=4186.8 *(79.68-0.505 * \mathrm{~T}-27.3 *$ realTa.Si + ㄴ $431.5 *$ realTa.Si./T);

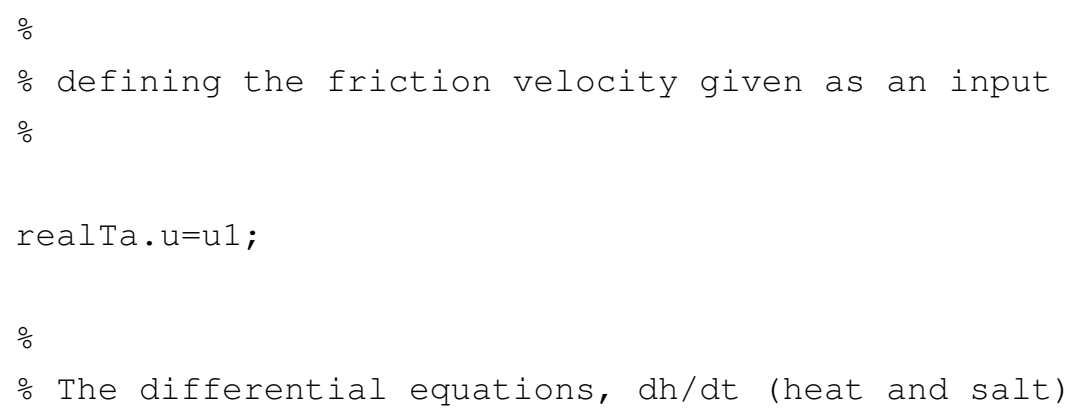


응

$\mathrm{EQ1}=(-r e a 1 \mathrm{Ta} \cdot \mathrm{ki} *($ realTa.thetaa-T)/h+realTa.Ch*realTa.u*

$(\mathrm{T}$-realTa.thetaml)*real Ta.rhow*real Ta. Cml) . /

(realTa.rhoi*realTa.L);

EQ2 $=-($ realTa.Cs*realTa.u* (realTa.S-realTa.Sml)*realTa.rhoml)

/ (realTa.rhoi* (realTa.Si-realTa.S ) );

Tvalue=EQ1-EQ2 ; 


\section{Appendix C}

\section{Stress Due to a Suspended Load}

The stress due to a suspended solid (crystal) load can be found by calculating the upwards force below a $1 \mathrm{~m}^{2}$ section of ice. The net force (upwards) is simply the difference between the weight of the crystals and the resultant buoyancy. Hence

$$
F_{n e t}=\rho_{w} V_{w} g-\rho_{i} V_{i} g
$$

where $\rho_{w}$ and $\rho_{i}$ are the densities of the water and ice respectively, and $\mathrm{g}$ is the acceleration due to gravity. The volume of ice, $V_{i}$, and the water it displaces, $V_{w}$, are equal as the ice is fully immersed. The volume of ice is equal to its dry mass, $m_{i}$, divided by its density. Therefore

$$
F_{n e t}=m_{i} \frac{\rho_{w}-\rho_{i}}{\rho_{w}} g .
$$

Given that the stress is simply the net force divided by the area on which it is acting $(A)$, the stress of the immersed crystals can be given as

$$
\tau_{\text {crys }}=\frac{m_{i}}{A} \frac{\rho_{w}-\rho_{i}}{\rho_{w}} g .
$$




\section{Appendix D}

\section{Concentration profiles}

\section{D.1 Linear eddy viscosity}

Winterwerp and van Kesteren (2004) gave the mass balance for sediment, ignoring horizontal concentration changes, as

$$
\frac{\partial c}{\partial t}-\frac{\partial}{\partial z}\left\langle c^{\prime} w^{\prime}\right\rangle-\frac{\partial}{\partial z}\left(\nu_{T} \frac{\partial c}{\partial z}\right)=0
$$

where $c$ is the concentration, $\left\langle c^{\prime} w^{\prime}\right\rangle$ is the average variation in the concentration fluctuations and $\nu_{T}$ is the eddy viscosity profile. One of the simplest closures to this is to assume that, in steady equilibrium conditions, the Reynolds flux is proportional to the gradient of the sediment concentration (Tropea et al., 2007; Garcia, 2008)

$$
\left\langle c^{\prime} w^{\prime}\right\rangle=-\nu_{T} \frac{d c}{d z}
$$

The net vertical flux of sediment can be given by

$$
F_{s z}=-w_{s} c+\left\langle c^{\prime} w^{\prime}\right\rangle
$$


and, given equilibrium conditions,

$$
\frac{d F_{s z}}{d z}=0
$$

Assuming that the sediment flux vanishes far away from the ice-water interface,

$$
F_{s z}=0
$$

so that

$$
c w_{s}=\left\langle c^{\prime} w^{\prime}\right\rangle
$$

and, substituting Equation D.2.

$$
c w_{s}=-\nu_{T} \frac{d c}{d z} .
$$

Now substituting the linear viscosity profile (Equation 6.16a),

$$
\nu_{T}=\kappa u_{*} z,
$$

gives

$$
c w_{s}=-\kappa z u_{*} \frac{d c}{d z} .
$$

rearranging

$$
\frac{d c}{d z}=-b \frac{c}{z}
$$


and solving

$$
\frac{c}{C_{a}}=\left(\frac{z}{z_{a}}\right)^{-b}
$$

gives the concentration profile, where $b=\frac{w_{s}}{\kappa u_{*}}$ is the Rouse number. The constants of integration are the reference concentration, $C_{a}$, at a depth $z_{a}$ (Soulsby and Wainwright, 1987).

\section{D.2 Parabolic eddy viscosity}

Again substituting Equation D.6 into Equation D.2, but this time using the parabolic viscosity profile, Equation $6.16 \mathrm{~b}$.

$$
\nu_{T}=\kappa u_{*} z\left(1-\frac{z}{h}\right)
$$

gives

$$
\frac{d c}{d z}=-\frac{b c}{z\left(1-\frac{z}{h}\right)} .
$$

Solving this leads to the well-known Rouse profile

$$
\frac{c}{C_{a}}=\left(\frac{h-z}{z} \frac{z_{a}}{h-z_{a}}\right)^{b}
$$

(e.g. Mazumder and Ghoshal, 2006; Morse and Richard, 2009).

\section{D.3 Eddy viscosity varying with $\mathbf{R i}_{f}$}

In this case, Equation 6.21 is substituted into Equation D.2. The concentration then varies as 


$$
\begin{aligned}
\frac{d c}{d z} & =\frac{-c w_{s}}{\kappa u_{*} z}\left(1+\alpha R i_{f}\right) \\
& =\frac{-c w_{s}}{\kappa u_{*} z}-\frac{\alpha c w_{s} R i_{f}}{\kappa u_{*} z} .
\end{aligned}
$$

Given a flux Richardson number of

$$
R i_{f}=\frac{g \kappa z\left(\rho_{i}-\rho_{w}\right) c w_{s}}{\rho_{w} \rho_{i} u_{*}^{3}}
$$

Equation D.15 becomes

$$
\frac{d c}{d z}=-b \frac{c}{z}-\bar{\zeta} b c^{2}
$$

where

$$
\bar{\zeta}=\frac{g \kappa\left(\rho_{i}-\rho_{w}\right) w_{s} \alpha}{\rho_{w} \rho_{i} u_{*}^{3}}
$$

Though this is non-linear differential equation, it is in the form of a Bernoulli equation, and therefore can be solved exactly. Making a change of variables to $v=\frac{1}{c}$ gives

$$
\begin{aligned}
-\frac{1}{v^{2}} \frac{d v}{d z} & =-\frac{1}{v} \frac{b}{z}-\frac{\bar{\zeta} b}{v^{2}} \\
\frac{d v}{d z} & =b \frac{v}{z}+\bar{\zeta} b
\end{aligned}
$$

which has the solution

$$
v=\frac{1}{c}=\bar{\zeta} b\left(\frac{z}{1-b}\right)+k z^{b}
$$


By substituting $c=C_{a}$ when $z=z_{a}$ the constant, $k$, can be found

$$
k=\frac{1}{C_{a} z_{a}^{b}}-\frac{\bar{\zeta} b}{1-b} z_{a}^{1-b}
$$

Combining the above gives the concentration profile

$$
\frac{c}{C_{a}}=\frac{\left(\frac{z}{z_{a}}\right)^{-b}}{\frac{\zeta b}{1-b}\left[\left(\frac{z}{z_{a}}\right)^{1-b}-1\right]+1}
$$

where $\zeta=C_{a} z_{a} \bar{\zeta}$. 


\section{Bibliography}

Absi, R., 2006, “Discussion of 'One-dimensional wave bottom boundary layer model comparison: Specific eddy viscosity and turbulence closure models' by Jack A. Puleo, Oleg Mouraenko and Daniel M. Haynes," J. Waterw. Port C.-ASCE 132(2), 139-141.

Adams, C. E., and G. L. Weatherly, 1981, "Some effects of suspended sediment stratification on an oceanic bottom boundary layer," J. Geophys. Res. 86(C5), 4161-4172.

Ainley, D. G., C. T. Tyann, and I. Stirling, 2003, "Sea ice: A critical habitat for polar marine mammals and birds," in Sea ice - An introduction to its physics, chemistry, biology and geology, edited by D. N. Thomas and G. S. Dieckmann (Blackwell Science Ltd), 240-266.

Allison, I., 1979, "Antarctic sea ice and oceanic heat flux,", in Sea level, ice, and climatic change, Proceedings of the Canberra Symposium (IAHS Publ. No. 131), 161-170.

Anderson, D. L., 1961, “Growth rate of sea ice,” J. Glaciol. 3, 1170-1172.

Arrigo, K. R., 2003, "Primary production in sea ice," in Sea ice - An introduction to its physics, chemistry, biology and geology, edited by D. N. Thomas and G. S. Dieckmann (Blackwell Science Ltd), 143-183.

Arrigo, K. R., G. Dieckmann, M. Gosselin, D. H. Robinson, C. H. Fritsen, and C. W. Sullivan, 1995, “High resolution study of the platelet ice 
ecosystem in $\mathrm{M}^{c}$ Murdo Sound, Antarctica: Biomass, nutrient and production profiles within a dense microalgal bloom," Mar. Ecol.-Prog. Ser. 127, 255-268.

Backstrom, L. G. E., and H. Eicken, 2006, "Capacitance probe measurements of brine volume and bulk salinity in first-year sea ice," Cold Reg. Sci. Technol. 46, 167-180.

Bagnold, R. A., 1966, "An approach to the sediment transport problem from general physics," Geol. Surv. Prof. Paper 422-I.

Barry, J. P., and P. K. Dayton, 1988, “Current patterns in $\mathrm{M}^{c}$ Murdo Sound, Antarctica and their relationship to local biotic communities," Polar Biol. 8, 367-376.

Beljaars, A. C. M., 1994, "The parametrization of surface fluxes in largescale models under free convection," Q. J. Roy. Astron. Soc. 121, 255270.

Bennett, S. J., J. S. Bridge, and J. L. Best, 1998, “Fluid and sediment dynamics of upper stage plane beds," J. Geophys. Res 103(C1), 1239-1274.

Cao, Z., G. Pender, and J. Meng, 2006, "Explicit formulation of the Shields diagram for incipient motion of sediment," J. Hydrol. Eng. 132(10), 1097-1099.

Chiareli, A. O. P., and M. G. Worster, 1992, "On measurement and prediction of the solid fraction within mushy layers," J. Cryst. Growth 125, 487-494.

Comiso, J. C., 2003, "Large-scale characteristics and variability of the global sea ice cover," in Sea ice - An introduction to its physics, chemistry, biology and geology, edited by D. N. Thomas and G. S. Dieckmann (Blackwell Science Ltd), chapter 4, 112-142. 
Cox, G. F. N., and W. F. Weeks, 1988, “Numerical simulations of the profile properties of undeformed first-year sea ice during the growth season," J. Geophys. Res. 93(C10), 12449-12460.

Crocker, G. B., and P. Wadhams, 1989, "Modelling Antarctic fast-ice growth," J. Glaciol. 35(119), 3-8.

Daly, S. F., 1984, Frazil ice dynamics, Monograph 84-1, U.S. Army Cold Regions Research and Engineering Laboratory.

Dieckmann, G., G. Rohardt, H. Hellmer, and J. Kipfstuhl, 1986, “The occurrence of ice platelets at $250 \mathrm{~m}$ depth near the Filchner Ice Shelf and its significance for sea ice biology," Deep-Sea Res. 33(2), 141-148.

Eicken, H., 1994, "Structure of under-ice melt ponds in the central Arctic and their effect on the sea-ice cover," Limnol. Oceanogr. 39(3), 682-694.

Eicken, H., 2003, "Growth, microstructure and properties of sea ice," in Sea ice - An introduction to its physics, chemistry, biology and geology, edited by D. N. Thomas and G. S. Dieckmann (Blackwell Science Ltd), chapter 2, 22-81.

Eicken, H., and M. A. Lange, 1989, "Development and properties of sea ice in the coastal regime of the southeastern Weddell Sea," J. Geophys. Res. 94(C6), 8193-8206.

Evans, Z., 2000, "Pancake Ice,", URL http://photolibrary.usap. gov/.

Feistel, R., 2003, “A new extended Gibbs thermodynamic potential of seawater," Prog. Oceanogr. 50, 42-114.

Feistel, R., and G. M. Marion, 2007, "A Gibbs-Pitzer function for highsalinity seawater thermodynamics," Prog. Oceanogr. 74, 515-539. 
Field, S. B., M. Klaus, M. G. Moore, and F. Norl, 1997, “Chaotic dynamics of falling disks," Nature 388, 252-254.

Foldvik, A., T. Gammelsrød, N. Slotsvik, and T. Tørreson, 1985, “Oceanographic conditions on the Weddell Sea Shelf during the German Antarctic Expedition 1979/80," Polar Res. 3, 209-226.

Fowler, A. C., 1985, "The formation of freckles in binary alloys," IMA J. Appl. Math. 35, 159-174.

Fowler, A. C., 1989, "Generation and creep of magma in the Earth," SIAM J. Appl. Math. 49(1), 231-245.

Friedman, P. D., and J. Katz, 2002, "Mean rise rate of droplets in isotropic turbulence," Phys. Fluids 14(9), 3059-3073.

Garcia, M. H., 2008, Sedimentation engineering: Processes, measurements, modeling, and practice (American Society of Civil Engineers).

Gerald, C. F., and P. O. Wheatley, 1999, Applied numerical analysis (Addison Wesley Publishing Company).

Ghoshal, K., and B. S. Mazumder, 2005, "Sediment-induced stratification in turbulent open-channel flow," Environmetrics 16, 673-685.

Godfrey, J. S., and A. C. M. Beljaars, 1991, “On the turbulent fluxes of buoyancy, heat and moisture at the air-sea interface at low wind speeds," J. Geophys. Res. 96(C12), 22043-22048.

Gosink, J. P., and T. E. Osterkamp, 1983, “Measurements and analyses of velocity profiles and frazil ice-crystal rise velocities during periods of frazil-ice formation in rivers," Ann. Glaciol. 4, 79-84.

Gow, A. J., S. F. Ackley, J. W. Govoni, and W. F. Weeks, 1998, “Physical and structural properties of land-fast sea ice in $\mathrm{M}^{c}$ Murdo Sound, Antarctica," Antarctic Research Series 74, 355-374. 
Gow, A. J., S. F. Ackley, W. F. Weeks, and J. W. Govoni, 1982, “Physical and structural characteristics of Antarctic sea ice," Ann. Glaciol. 3, 113-117.

Gow, A. J., and W. B. Tucker III, 1991, Physical and dynamic properties of sea ice in the polar oceans, Monograph 91-1, U.S. Army Cold Regions Research and Engineering Laboratory.

Grachev, A. A., C. W. Fairall, and S. E. Larsen, 1998, “On the determination of the neutral drag coefficient in the convective boundary layer," Bound.-Lay. Meteorol. 86, 257-78.

Heath, R. A., 1971, "Circulation and hydrology under the seasonal ice in $\mathrm{M}^{c}$ Murdo Sound, Antarctica," New Zeal. J. Mar. Fresh. 5, 497-515.

Hills, R. N., D. E. Loper, and P. H. Roberts, 1983, “A thermodynamically consistent model of a mushy zone," Q. J. Mech. Appl. Math. 36(Pt. 4), 505-540.

Hiscott, R. N., 1994, "Loss of capacity, not competence, as the fundamental process governing deposition from turbidity currents," J. Sediment. Res. A64(2), 209-214.

Holland, D. M., and A. Jenkins, 1999, "Modeling thermodynamic iceocean interactions at the base of an ice shelf," J. Phys. Oceanogr. 29, 1787-1800.

Holland, P. R., and D. L. Feltham, 2005, "Frazil dynamics and precipitation in a water column with depth-dependent supercooling," J. Fluid Mech. 530, 101-124.

Holland, P. R., D. L. Feltham, and S. F. Daly, 2007, “On the Nusselt number for frazil ice growth - A correction to "Frazil evolution in channels" by Lars Hammar and Hung-Tao Shen," J. Hydraul. Res. 45(3), 421-424.

Hort, M., 1997, "Cooling and crystallization in sheet-like magma bodies revisited," J. Volcanol. Geoth. Res. 76, 297-317. 
Hsu, T.-W., and C.-D. Jan, 1998, "Calibration of Businger-Arya type of eddy viscosity model's parameters," J. Waterw. Port C.-ASCE 124(5), 281-284.

Huppert, H. E., and M. G. Worster, 1985, “Dynamic solidification of a binary melt," Nature 314, 703-707.

van den Hurk, B. J. J. M., and A. A. M. Holtslag, 1997, “On the bulk parameterization of surface fluxes for various conditions and parameter ranges," Bound.-Lay. Meteorol. 82, 119-133.

Ingersoll, L. R., O. J. Zobel, and A. C. Ingersoll, 1948, Heat conduction with engineering and geological applications ( $\mathrm{M}^{c} \mathrm{Graw}-\mathrm{Hill}$ Book Company Inc.).

Ingham, M., D. Pringle, and H. Eicken, 2008, “Cross-borehole resistivity tomography of sea ice," Cold Reg. Sci. Technol. 52, 263-277.

Ippen, A. T., 1971, "A new look at sedimentation in turbulent streams," Journal of the Boston Society of Civil Engineers 58(3), 131-163.

Isla, E., D. Gerdes, A. Palanques, J.-M. Gili, and W. Arntz, 2006, “Particle fluxes and tides near the continental ice edge on the eastern Weddell Sea shelf," Deep-Sea Res. Pt. II 53, 866-874.

Jeffries, M. O., K. Schwartz, K. Morris, A. D. Veazey, H. R. Krouse, and S. Cushing, 1995, "Evidence for platelet ice accretion in Arctic sea ice development," J. Geophys. Res. 100(C6), 10905-10914.

Jeffries, M. O., and W. F. Weeks, 1992, "Structural characteristics and development of sea ice in the western Ross Sea," Antarct. Sci. 5(1), 63-75.

Jeffries, M. O., W. F. Weeks, R. Shaw, and K. Morris, 1993, “Structural characteristics of congelation and platelet ice and their role in the development of Antarctic land-fast sea ice," J. Glaciol. 39(132), 223-238. 
Jenkins, A., and A. Bombosch, 1995, "Modeling the effects of frazil ice crystals on the dynamics and thermodynamics of Ice Shelf Water plumes," J. Geophys. Res. 100(C4), 6967-6981.

Kay, J. M., 1963, An introduction to fluid mechanics and heat transfer (Cambridge University Press).

King, H. G. R., 1969, The Antarctic (Blandford Press Ltd.).

Koslowski, G., 1986, Landolt-Børnstein: Numerical data and functional relationships in science and technology - Group V Geophysics (Springer-Verlag), volume 3c, chapter 8, 167-190.

Kreplin, H. P., and H. Eckelmann, 1979, "Behavior of the three fluctuating velocity components in the wall region of a turbulent channel flow," Phys. Fluids 22(7), 1233-1239.

Lake, R. A., and E. L. Lewis, 1970, "Salt rejection by sea ice during growth," J. Geophys. Res. 75(3), 583-597.

Lamb, H., 1932, Hydrodynamics (Cambridge University Press), sixth edition.

Lange, M. A., 1988, “Basic properties of Antarctic sea ice as revealed by textural analysis of ice cores," Ann. Glaciol. 10, 95-101.

Lange, M. A., and H. Eicken, 1991, “Textural characteristics of sea ice and the major mechanisms of ice growth in the Weddell Sea," Ann. Glaciol. 15, 210-215.

Langhorne, P. J., C. R. Purdie, I. J. Smith, G. H. Leonard, E. W. Kempema, C. Petrich, M. A. Gribble, P. E. Bond, and T. G. Haskell, 2006, "Antarctic landfast sea ice: The role of platelet ice,", in the 18th IAHR International Symposium on Ice, 28 August-1 September, 2006, Sapporo, Japan, volume 1, 285-292. 
Langhorne, P. J., and W. H. Robinson, 1983, “Effect of acceleration on sea ice growth," Nature 305, 695-698.

Leeder, M. R., T. E. Gray, and J. Alexander, 2005, "Sediment suspension dynamics and a new criterion for the maintenance of turbulent suspensions," Sedimentology 52, 683-691.

Leonard, G. H., C. R. Purdie, P. J. Langhorne, T. G. Haskell, M. J. M. Williams, and R. D. Frew, 2006, "Observations of platelet ice growth and oceanographic conditions during the winter of 2003 in $\mathrm{M}^{c}$ Murdo Sound, Antarctica," J. Geophys. Res. 111(C04012).

Leppäranta, M., 1993, "A review of analytical models of sea-ice growth," Atmos. Ocean 31(1), 123-138.

Leppäranta, M., 2004, The drift of sea ice (Springer).

Li, M. Z., and G. Gust, 2000, "Boundary layer dynamics and drag reduction in flows of high cohesive sediment suspensions," Sedimentology $47,71-86$.

Liou, C. P., and M. G. Ferrick, 1992, "A model for vertical frazil distribution," Water Resour. Res. 28(5), 1329-1337.

Lock, G. S. H., 1990, The growth and decay of ice (Cambridge University Press).

Mahrt, L., D. Vickers, J. Edson, J. Sun, J. Højstrup, J. Hare, and J. M. Wilczak, 1998, "Heat flux in the coastal zone," Bound.-Lay. Meteorol. 86, 421-446.

van Maren, D. S., J. C. Winterwerp, H. J. de Vriend, Z. B. Wang, Z.-Y. Wang, J. J. Zhou, and B. S. Wu, 2005, "Sediment-induced density effects on channel patterns of silt-laden rivers,", in the Proceedings of the second international Yellow River forum on river basin management. 
Martin, S., 1981, “Frazil ice in rivers and oceans," Annu. Rev. Fluid. Mech. 13, 379-397.

Mathieu, J., and J. Scott, 2000, An introduction to turbulent flow (Cambridge University Press).

Maykut, G. A., 1978, "Energy exchange over young sea ice in the Central Arctic," J. Geophys. Res. 83(C7), 3646-3658.

Maykut, G. A., 1986, "The surface heat and mass balance," in The geophysics of sea ice, edited by N. Untersteiner (Plenum Press, New York), chapter 5, 395-463.

Maykut, G. A., and N. Untersteiner, 1971, "Some results from a timedependent thermodynamic model of sea ice," J. Geophys. Res. 76(6), 1550-1576.

Mazumder, B. S., and K. Ghoshal, 2006, "Velocity and concentration profiles in uniform sediment-laden flow," Appl. Math. Model. 30, 164-176.

$M^{c}$ Anally, W. H., and A. J. Mehta, 2001, “Collisional aggregation of fine estuarial sediment,", in Coastal and estuarine fine sediment processes (Elsevier Science), 19-39.

$\mathrm{M}^{c}$ Clung, D., and P. Schaerer, 2006, The avalanche handbook (The Mountaineers Books).

M $^{c}$ Dougall, T. J., R. Feistel, D. R. Jackett, D. G. Wright, B. A. King, G. M. Marion, C.-T. A. Chen, and P. Spitzer, 2009, "Calculation of thermophysical properties of seawater," Global ship-based repeat hydrography manual, IOCCP report no. 14 1-112.

McGuinness, M. J., 2009, “Modelling sea ice growth,” ANZIAM 51.

$\mathrm{M}^{c}$ Guinness, M. J., M. J. M. Williams, P. J. Langhorne, C. Purdie, and J. Crook, 2009, "Frazil deposition under growing sea ice," J. Geophys. Res. 114(C07014). 
M$^{c}$ Phee, M. G., 1987, "A time-dependent model for turbulent transfer in a stratified oceanic boundary layer," J. Geophys. Res. 92(C7), 6977-6986.

$M^{c}$ Phee, M. G., 1992, "Turbulent heat flux in the upper ocean under sea ice," J. Geophys. Res. 97(C4), 5365-5379.

$M^{c}$ Phee, M. G., 1994, "On the turbulent mixing length in the oceanic boundary layer," J. Phys. Oceanogr. 24, 2014-2031.

McPhee, M. G., C. Kottmeier, and J. H. Morison, 1999, “Ocean heat flux in the central Weddell Sea during winter," J. Phys. Oceanogr. 29, 11661179 .

M'Phee, M. G., G. A. Maykut, and J. H. Morison, 1987, “Dynamics and thermodynamics of the ice/upper ocean system in the marginal ice zone of the Greenland Sea," J. Geophys. Res. 92(C7), 7017-7031.

$M^{c}$ Phee, M. G., and J. H. Morison, 2001, "Under-ice boundary layer," in Encyclopedia of Ocean Sciences, edited by J. H. Steele, S. A. Thorpe, and K. K. Turekian (Academic, San Diego, Calif.), 3071-3078.

Mellor, G. L., M. G. M'Phee, and M. Steele, 1986, “Ice-seawater turbulent boundary layer interaction with melting or freezing," J. Phys. Oceanogr. 16, 1829-1846.

Miller, M. C., I. N. Mc Cave, and P. D. Komar, 1977, “Threshold of sediment motion under unidirectional currents," Sedimentology 24, 507-527.

Morse, B., and M. Richard, 2009, "A field study of suspended frazil ice particles," Cold Reg. Sci. Technol. 55, 86-102.

Nakawo, M., and N. K. Sinha, 1981, "Growth rate and salinity profile of first-year sea ice in the high Arctic," J. Glaciol. 27(96), 315-330.

Nielsen, P., 2007, "Mean and variance of the velocity of solid particles in turbulence," in Particle-laden flow: From geophysical to Kolmogorov scales (Springer), 385-391. 
Notz, D., 2005, Thermodynamic and fluid-dynamical processes in sea ice, Ph.D. thesis, Trinity College, University of Cambridge.

Notz, D., M. G. McPhee, M. G. Worster, G. A. Maykut, K. H. Schlünzen, and H. Eicken, 2003, "Impact of underwater-ice evolution on Arctic summer sea ice," J. Geophys. Res. 108(C7), 16-1 - 16-12.

Notz, D., J. S. Wettlaufer, and M. G. Worster, 2005, “A non-destructive method for measuring the salinity and solid fraction of growing sea ice in situ," J. Glaciol. 51(172), 159-166.

Omstedt, A., 1985, “On supercooling and ice formation in turbulent seawater," J. Glaciol. 31(109), 263-271.

Omstedt, A., and J. S. Wettlaufer, 1992, "Ice growth and oceanic heat flux: Models and measurements," J. Geophys. Res. 97(C6), 9383-9390.

Ongley, E., 1996, "Sediment measurements," in Water quality monitoring - A practical guide to the design and implementation of freshwater quality studies and monitoring programmes, edited by J. Bartram and R. Ballance (Taylor and Francis), chapter 13, 315-361.

Online, E. B., 2008, “Antarctica, online map/still,”, URL http: / /www . britannica.com/eb/art-93141.

Osterkamp, T. E., and J. P. Gosink, 1983, “Frazil ice formation and ice cover development in interior Alaska streams," Cold Reg. Sci. Technol. 8, 4356.

Owen, R., 2007, The Antarctic Ocean (Owen Press).

Parkinson, C. L., and W. M. Washington, 1979, "A large-scale numerical model of sea ice," J. Geophys. Res. 84(C1), 311-337.

Penner, E., 1962, “Ground freezing and frost heaving," Canadian Building Digest 26. 
Perey, F. G. J., and E. R. Pounder, 1958, “Crystal orientation in ice sheets," Can. J. Phys 36(4), 494-502.

Perham, R. E., 1980, "Harnessing frazil ice,", in the First workshop on the hydraulics of ice covered rivers (Committee on River Ice Processes and the Environment, Burlington, Ontario), 227-237.

Pettijohn, F. J., P. E. Potter, and R. Siever, 1987, Sand and sandstone (Springer).

Pringle, D. J., H. J. Trodahl, and T. G. Haskell, 2006, “Direct measurement of sea ice thermal conductivity: No surface reduction," J. Geophys. Res. 111(C05020).

Purdie, C. R., P. J. Langhorne, G. H. Leonard, and T. G. Haskell, 2006, "Growth of first-year landfast Antarctic sea ice determined from winter temperature measurements," Ann. Glaciol. 44, 170-176.

Redelsperger, J.-L., F. Guichard, and S. Mondon, 1999, "A parameterization of mesoscale enhancement of surface fluxes for large-scale models," J. Climate 13, 402-421.

Reid, I., and L. E. Frostick, 1994, "Fluvial sediment transport and deposition," in Sediment transport and depositional processes, edited by K. Pye (Blackwell Scientific Publications), chapter 4, 89-155.

van Rijn, L. C., 1983, "Sediment transportation in heavy sediment-laden flows,", in the Second international symposium on river sediment.

van Rijn, L. C., 1984, “Sediment transport, Part II: Suspended load transport," J. Hydraul. Eng.-ASCE 110(11), 1613-1641.

Robert, A., 2003, River processes: An introduction to fluvial dynamics (A Hodder Arnold Publication). 
Schmidt, G. A., C. M. Bitz, U. Mikolajewicz, and L.-B. Tremblay, 2004, “Iceocean boundary conditions for coupled models," Ocean Model. 7, 59-74.

Schnack-Schiel, S. B., 2003, "The macrobiology of sea ice," in Sea ice - An introduction to its physics, chemistry, biology and geology, edited by D. N. Thomas and G. S. Dieckmann (Blackwell Science Ltd), 211-239.

Schwerdtfeger, P., 1963, “Thermal properties of sea ice," J. Glaciol. 4, 789807.

Semtner, A. J., Jr., 1976, "A model for the thermodynamic growth of sea ice in numerical investigations of climate," J. Phys. Oceanogr. 6, 379-389.

Shcherbina, A. Y., L. D. Talley, and D. L. Rudnick, 2003, “Direct observations of North Pacific ventilation: Brine rejection in the Okhotsk Sea," Science 302(5652), 1952-1955.

Shirasawa, K., and R. G. Ingram, 1997, "Currents and turbulent fluxes under the first-year sea ice in Resolute Passage, Northwest Territories, Canada," J. Marine Syst. 11, 21-32.

Shirtcliffe, T. G. L., H. E. Huppert, and M. G. Worster, 1991, “Measurement of the solid fraction in the crystallization of a binary melt," J. Cryst. Growth 113, 566-574.

Shokr, M. E., and N. K. Sinha, 1994, "Arctic sea ice microstructure observations relevant to microwave scattering," Arctic 47(3), 265-279.

Shrestha, P. L., and A. F. Blumberg, 2005, "Cohesive sediment transport," in Encyclopedia of coastal science, edited by M. Schwartz (Springer), 327330 .

Skogseth, R., F. Nilsen, and L. H. Smedsrud, 2009, "Supercooled water in an Arctic polynya: observations and modeling," J. Glaciol. 55(189), 4352. 
Smedsrud, L. H., and A. Jenkins, 2004, "Frazil ice formation in an ice shelf water plume," J. Geophys. Res. 109(C03025).

Smith, I., 2001, Platelet ice in $M^{c}$ Murdo Sound, Ph.D. thesis, University of Otago, Dunedin.

Smith, I. J., P. J. Langhorne, T. G. Haskell, H. J. Trodahl, R. Frew, and M. R. Vennell, 2001, "Platelet ice and the land-fast sea ice of $\mathrm{M}^{c}$ Murdo Sound, Antarctica," Ann. Glaciol. 33, 21-27.

Smith, J. D., and S. R. McLean, 1977, "Spatially averaged flow over a wavy surface," J. Geophys. Res. 82(12), 1735-1746.

Soulsby, R., 1998, Dynamics of marine sands (Thomas Telford Ltd.).

Soulsby, R. L., and B. L. S. A. Wainwright, 1987, “A criterion for the effect of suspended sediment on near-bottom velocity profiles," J. Hydraul. Res. 25(3), 341-356.

Steele, M., G. L. Mellor, and M. G. M"Phee, 1989, "Role of the molecular sublayer in the melting or freezing of sea ice," J. Phys. Oceanogr. 19, 139-147.

Streeter, V. L., and E. B. Wylie, 1975, Fluid mechanics (Mㄷaw-Hill).

Stull, R. B., 1988, An introduction to boundary layer meteorology (Kluwer Academic Publishers).

Svensson, U., and A. Omstedt, 1994, "Simulation of supercooling and size distribution in frazil ice dynamics," Cold Reg. Sci. Technol. 22, 221-233.

Svensson, U., and A. Omstedt, 1998, "Numerical simulations of frazil ice dynamics in the upper layers of the ocean," Cold Reg. Sci. Technol. 28, $29-44$. 
Thomas, D. N., R. J. Lara, H. Eicken, G. Kattner, and A. Skoog, 1995, “Dissolved organic matter in Arctic multi-year sea ice during winter: Major components and relationship to sea ice characteristics," Polar Biol. 15, 477-483.

Tison, J.-L., R. D. Lorrain, A. Bouzette, M. Dini, A. Bondesan, and M. Stiévenard, 1998, "Linking landfast sea ice variability to marine ice accretion at Hells Gate ice shelf, Ross Sea," Antarctic Research Series 74, 375-407.

Toggweiler, J., and B. Samuels, 1995, "Effect of sea ice on the salinity of Antarctic bottom waters," J. Phys. Oceanogr. 25, 1980-1997.

Tropea, C., A. L. Yarin, and J. F. Foss, 2007, Springer Handbook of Experimental Fluid Mechanics (Springer).

Tsang, G., 1988, "Development of mathematical models for the prediction of river cooling and the formation of frazil ice and anchor ice,", in the Proceedings of the $5^{\text {th }}$ workshop on the hydraulics of ice covered rivers, Winnipeg, Manitoba, 393-416.

Turner, J. S., 1979, Buoyancy effects in fluids (Cambridge University Press).

UNESCO, 1978, "Background papers and supporting data on the practical salinity scale 1978," Unesco Technical Papers in Marine Science 37, 1145.

UNESCO, 1980, "Background papers and supporting data on the international equation of state of seawater 1980," Unesco Technical Papers in Marine Science 38, 1-192.

UNESCO, 1983, “Algorithms for computation of fundamental properties of seawater," Unesco Technical Papers in Marine Science 44, 1-30.

UNESCO, 1991, "Salinity and density of seawater: Tables for high salinities (42 to 50)," Unesco Technical Papers in Marine Science 62, 1-86. 
Untersteiner, N., 1967, “Natural desalination and equilibrium salinity profile of old sea ice," in Physics of snow and ice, edited by H. Oura (Institute of Low Temperature Science, Hokkaido University, Japan), volume 1, Part 1, 569-577.

Ushio, S., and M. Wakatsuchi, 1993, "A laboratory study on supercooling and frazil ice production processes in winter coastal polynyas," J. Geophys. Res. 98(C11), 20321-20328.

Vanoni, V. A., A. G. Anderson, J. F. Kennedy, N. P. Woodruff, W. S. Chepil, A. W. Zingg, H. W. Shen, S. Karaki, A. R. Chamberlain, M. L. Albertson, D. R. F. Harleman, and S. C. Happ, 2006, "Sediment transportation mechanics," in Sedimentation engineering, edited by V. A. Vanoni (American Society of Civil Engineers), chapter 2, 11-189.

Vernède, S., P. Jarry, and M. Rappaz, 2006, “A granular model of equiaxed mushy zones: Formation of a coherent solid and localization of feeding," Acta Mater. 5, 4023-4034.

Vrbka, L., and P. Jungwirth, 2005, “Brine rejection from freezing salt solutions: A molecular dynamics study,", Institute of Organic Chemistry and Biochemistry and Center for Biomolecules and Complex Molecular Systems, Academy of Sciences of the Czech Republic.

Wadhams, P., 2003, “How does Arctic ice form and decay?,", Scott Polar Institute, University of Cambridge, URL http://www arctic.noaa. gov/essay_wadhams.html.

Wadhams, P., J. C. Comiso, E. Prussen, S. Wells, M. Brandon, E. Aldworth, T. Viehoff, R. Allegrino, and D. R. Crane, 1996, "The development of the Odden ice tongue in the Greenland Sea during winter 1993 from remote sensing and field observations," J. Geophys. Res. 101(C8), 18213-18236.

Wang, N., S. Mokadem, M. Rappaz, and W. Kurz, 2004, "Solidification 
cracking of superalloy single- and bi- crystals," Acta Mater. 52, 31733182.

Washington, W. M., and C. L. Parkinson, 2005, Introduction to threedimensional climate modeling (University Science Books).

Weber, J. E., 1977, “Heat and salt transfer associated with formation of seaice," Tellus 29(2), 151-160.

Weeks, W. F., and S. F. Ackley, 1986, "The growth, structure, and properties of sea ice," in The geophysics of sea ice, edited by N. Untersteiner (Plenum Publishing Corporation), 9-164.

Weeks, W. F., and A. J. Gow, 1978, "Preferred crystal orientations in the fast ice along the margins of the Arctic Ocean," J. Geophys. Res. 83, 51055121.

Weeks, W. F., and A. J. Gow, 1980, "Crystal alignments in the fast ice of Arctic Alaska," J. Geophys. Res. 85(C2), 1137-1146.

Weeks, W. F., and G. Lofgren, 1967, “The effective solute distribution coefficient during the freezing of $\mathrm{NaCl}$ solutions," in Physics of snow and ice, edited by H. Oura (Institute of Low Temperature Science, Hokkaido University, Japan), volume 1, Part 1, 579-597.

Wettlaufer, J. S., M. G. Worster, and H. E. Huppert, 1997a, “Natural convection during solidification of an alloy from above with application to the evolution of sea ice," J. Fluid Mech. 344, 291-316.

Wettlaufer, J. S., M. G. Worster, and H. E. Huppert, 1997b, “The phase evolution of young sea ice," Geophys. Res. Lett. 24(10), 1251-1254.

Willmarth, W. W., N. E. Hawk, and R. L. Harvey, 1963, Investigations of the steady and unsteady motion of freely falling disks, Interim technical report, Department of Aeronautical and Astronautical Engineering, University of Michigan. 
Willmarth, W. W., N. E. Hawk, and R. L. Harvey, 1964, "Steady and unsteady motions and wakes of freely falling disks," Phys. Fluids $7(2)$, 197-208.

Winterton, R. H. S., 1997, Heat transfer (Oxford University Press).

Winterwerp, J. C., 2001, "Stratification effects by cohesive and noncohesive sediment," J. Geophys. Res. 106(C10), 22559-22574.

Winterwerp, J. C., and W. G. M. van Kesteren, 2004, Introduction to the physics of cohesive sediment in the marine environment (Elsevier B.V.).

Winterwerp, J. C., R. E. Uittenbogaard, and J. M. de Kok, 2001, “Rapid siltation from saturated mud suspensions," Proceed. Marine Sci. 125146.

Worster, M. G., 1986, "Solidification of an alloy from a cooled boundary," J. Fluid Mech. 167, 481-501.

Worster, M. G., 1991, “Natural convection in a mushy layer," J. Fluid Mech. 224, 335-359.

Worster, M. G., 1997, “Convection in mushy layers,” Ann. Rev. Fluid Mech. 29, 91-122.

Worster, M. G., and J. S. Wettlaufer, 1997, “Natural convection, solute trapping, and channel formation during solidification of saltwater," J. Phys. Chem. B 101, 6132-6136.

Wu, X., I. Simmonds, and W. F. Budd, 1997, “Modeling of Antarctic sea ice in a general circulation model," J. Climate 10, 593-609.

Wuebben, J. L., 1984, "The rise pattern and velocity of frazil ice,", in the Third workshop on the hydraulics of ice covered rivers (Committee on River Ice Processes and the Environment, Fredericton, New Brunswick), 297316. 
Yaglom, A. M., and B. A. Kader, 1974, "Heat and mass transfer between a rough wall and turbulent fluid flow at high Reynolds and Péclet numbers," J. Fluid Mech. 62(3), 601-623.

Ye, S. Q., and J. C. Doering, 2003, "A model for the vertical distribution of frazil ice,", in the $12^{\text {th }}$ workshop on the hydraulics of ice covered rivers.

Yen, Y.-C., 1981, Review of thermal properties of snow, ice and sea ice, Monograph 81-10, U.S. Army Cold Regions Research and Engineering Laboratory. 